\title{
North American Natural Gas Markets
}

\section{DISCLAIMER}

This report was prepared as an account of work sponsored by an agency of the United States Government. Neither the United States Government nor any agency thereof, nor any of their employees, makes any warranty, express or implied, or assumes any legal liability or responsibility for the accuracy, completeness, or usefulness of any information, apparatus, product, or process disclosed, or represents that its use would not infringe privately owned rights. Reference herein to any specific commercial product, process, or service by trade name, trademark, manufacturer; or otherwise does not necessarily constitute or imply its endorsement, recommendation, or favoring by the United States Government or any agency thereof. The views and opinions of authors expressed herein do not necessarily state or reflect those of the United States Government or any agency thereof.

\section{Energy Modeling Forum Stanford University Stanford, California 94305}




\section{Preface}

The Energy Modeling Forum (EMF) was established in 1976 at Stanford University to provide a structural framework within which energy experts, analysts, and policymakers could meet to improve their understanding of critical energy problems. The ninth EMF study, North American Natural Gas Markets, was conducted by a working group comprised of leading natural gas analysts and decisionmakers from government, private companies, universities, and research and consulting organizations. The EMF 9 working group met five times from October 1986 through June 1988 to discuss key issues and analyze natural gas markets.

This report discusses indepth the issues and results studied by the working group. It supplements the major conclusions appearing in the summary report released earlier. In addition, a third volume containing background technical papers prepared during the study is available through the Energy Modeling Forum, 406 Terman Center, Stanford University, Stanford, CA 94305 (Telephone: 415-723-0645). This volume contains the study design, individual modeler papers, a technical comparison of the model responses, and background studies on regulatory and supply issues.

Funding for this study was generously provided by the U.S. Department of Energy, the Electric Power Research Institute, and member organizations of the EMF Affiliates Program. Affiliate organizations include: Alberta Department of Energy, ARCO, Bonneville Power Administration, Conoco, Consolidated Edison, Gas Research Institute, General Motors, Interstate Natural Gas Association of America, Maxus, Pacific Gas and Electric, Shell U.S.A., Southem Califomia Edison, and Union Pacific Resources. Additional support for this study from Amoco, California Energy Commission, Southem Califomia Gas, and Benjamin Schlesinger and Associates is also gratefully acknowledged.

EMF's Senior Advisory Panel continues to offer valuable advice on topics as well as comments and suggestions for improving EMF reports. And finally, we would also like to acknowledge George Kohler, Edith Leni, Pamela McCroskey, Douglas Robinson, Dorothy Sheffield, and Susan Sweeney for their assistance in the production of this report.

This volume reports the findings of the EMF working group. It does not necessarily represent the views of Stanford University, members of the Senior Advisory Panel, or any organizations providing financial support. 


\section{Contents}

Preface $\ldots \ldots \ldots \ldots \ldots \ldots \ldots \ldots \ldots \ldots \ldots \ldots \ldots$

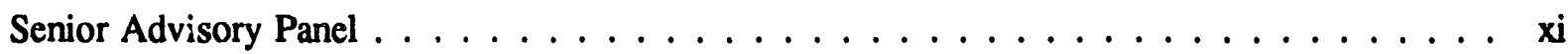

Working Group Participants $\ldots \ldots \ldots \ldots \ldots \ldots \ldots \ldots$ xii

Report Contributors .......................... xiv

Executive Summary $\quad$ xv

Summary Report 1

Scenarios .............................. 2

Major Findings and Issues $\ldots \ldots \ldots \ldots \ldots \ldots$

Natural Gas Pricing ........................ 2

Fuel Switching ........................ 6

Consumption (Demand) $\ldots \ldots \ldots \ldots \ldots \ldots \ldots$

Supply .............................. 9

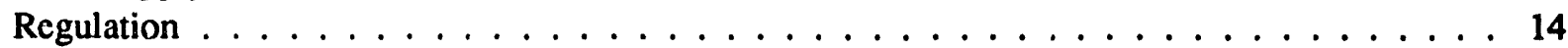

Key Issues in Completing the Process of Unbundling . . . . . . . . . . . . 15

Regulatory Policy Stability and Market Conditions . . . . . . . . . . . . . . . 17

Natural Gas Modeling . . . . . . . . . . . . . . . . . . . . . . . . . 17

Further Research . . . . . . . . . . . . . . . . . . . . . . . . . . 19

$\begin{array}{ll}\text { Working Group Report } & 21\end{array}$

1 Introduction $\quad 23$

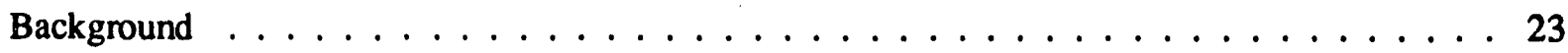

The Energy Modeling Forum Working Group . . . . . . . . . . . . . . . 23

The Use of Models . . . . . . . . . . . . . . . . . . . . . . . . . . 24

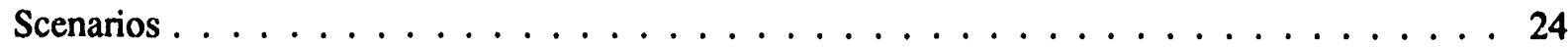

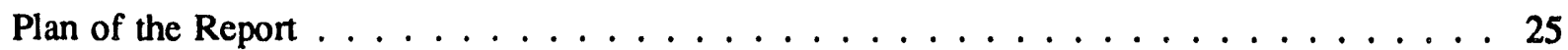

2 History of Natural Gas Markets and Regulation 27

Early Developments . . . . . . . . . . . . . . . . . . . . . . 27

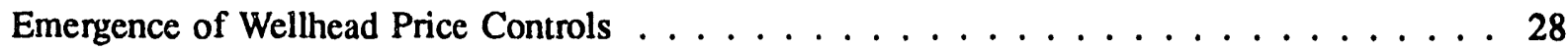

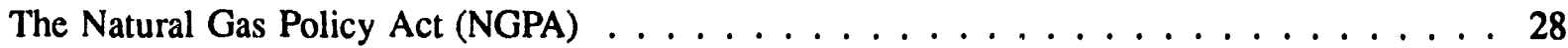

Declining Demand and the Gas Bubble . . . . . . . . . . . . . . . . . . . . 29

Industry Response to the Gas Bubble . . . . . . . . . . . . . . . . . . . . . . 30

Canadian Regulation . . . . . . . . . . . . . . . . . . . . 32 
Appendix to Chapter 2: U.S. Gas Reserves, Supply, and Demand, 1950-1987 . . . . . . . 33

3 Future Natural Gas Market Ir ssies $\quad 35$

Future Gas Supply Issues . . . . . . . . . . . . . . . . . . . . 35

The Natural Gas Resource Base . . . . . . . . . . . . . . . . . . . . 35

The Economics of Gas Recovery: Determining the Supply Curve . . . . . . . . . . 36

Imports . . . . . . . . . . . . . . . . . . . . . 37

Gas Demand Issues . . . . . . . . . . . . . . . . . . . . 38

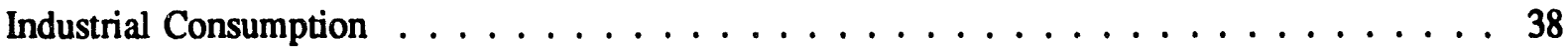

Electric Utility Consumption . . . . . . . . . . . . . . . . . . 39

Commercial Consumption . . . . . . . . . . . . . . . . . . 39

Residential Consumption ... . . . . . . . . . . . . . . . 40

Fuel Switching in the Industrial and Electric Utility Sectors . . . . . . . . . . . . 41

Natural Gas Pricing . . . . . . . . . . . . . . . . . . . . . . . 41

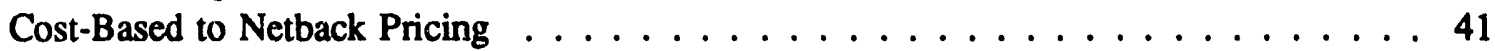

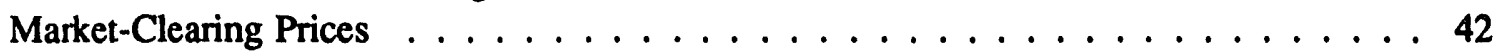

Oil and Gas Prices . . . . . . . . . . . . . . . . . . . . . . . 44

Transportation and Distribution Margins $\ldots \ldots \ldots \ldots \ldots$

Regulation . . . . . . . . . . . . . . . . . . . . . . 47

Key Issues in Completing the Process of Unbundling . . . . . . . . . . . . 48

Regulatory Policy Stability and Market Conditions . . . . . . . . . . . 50

4 Key Findings from the Model Results $\quad 51$

Models .............................. 51

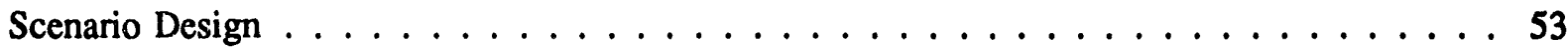

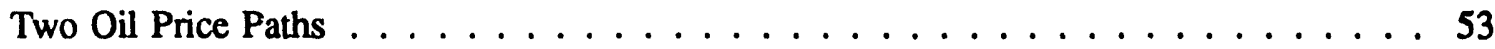

Low U.S. Resources . . . . . . . . . . . . . . . . . . . 55

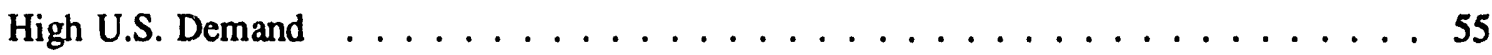

EMF Industry Survey $\ldots \ldots \ldots \ldots \ldots$

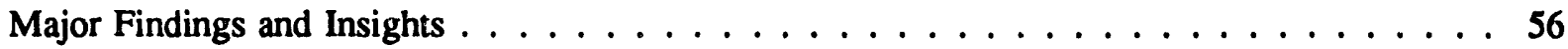

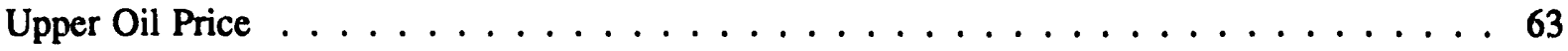

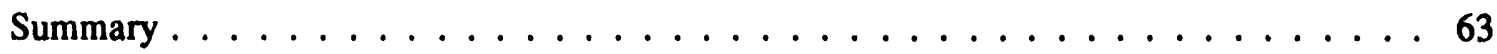

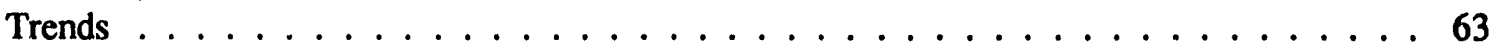

Representation of the Scenario .................... 63

Marketed Production . . . . . . . . . . . . . . . . . . 66

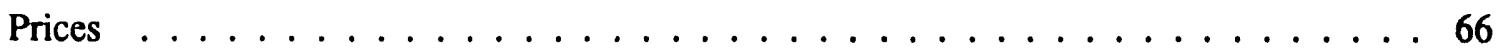

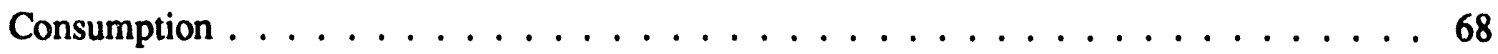

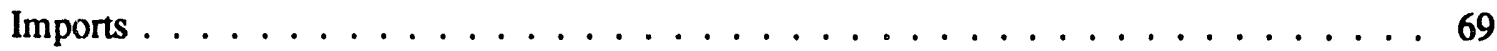

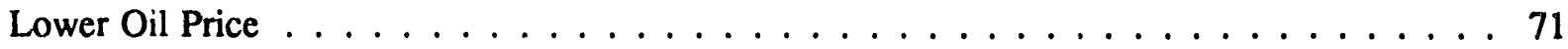

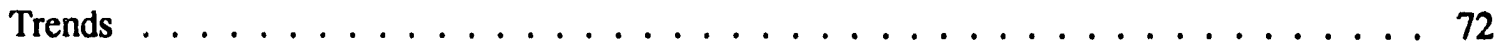

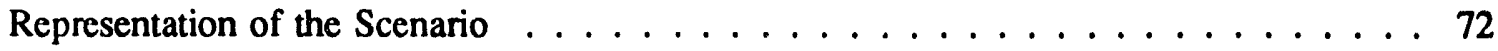

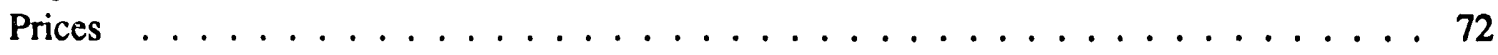

Production and Consumption $\ldots \ldots \ldots \ldots \ldots \ldots \ldots$

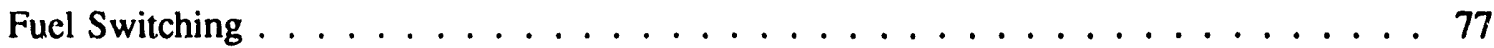

Imports ............................. 79 
Low U.S. Resource . . . . . . . . . . . . . . . . . . . . . . . 79

Summary . . . . . . . . . . . . . . . . . . . . 79

Trends . . . . . . . . . . . . . . . . . . . . . . 79

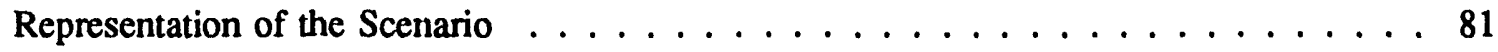

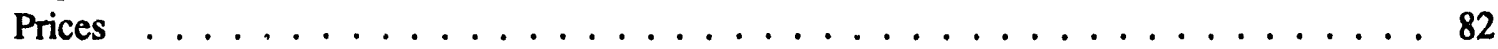

Consumption and Fuel Switching .................. 85

Production ............................ 85

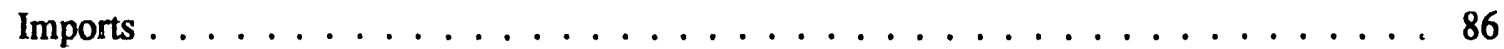

High U.S. Demand $\ldots \ldots \ldots \ldots$

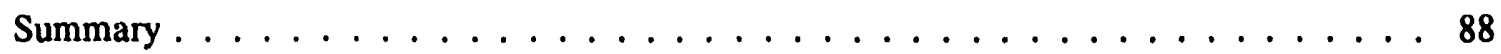

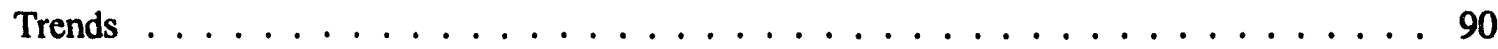

Representation of the Scenario . . . . . . . . . . . . . . . 90

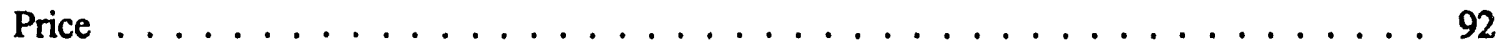

Marketed Production and Consumption . . . . . . . . . . . . . . . . . 94

Imports . . . . . . . . . . . . . . . . . . . . . . . 94

Comparison of Industry Survey and Model Results . . . . . . . . . . . . . . . . 96

5 The Structure and Regulation of the Natural Gas Industry 99

Introduction . . . . . . . . . . . . . . . . . . . . . . . 99

Economic Efficiency and Distributional Issues . . . . . . . . . . . . . . 100

Key Regulatory Policy Issues . . . . . . . . . . . . . . . . . . . . . . . 100

Pipeline Issues . . . . . . . . . . . . . . . . . . . 100

Local Distribution Company Issues . . . . . . . . . . . . . . . . 103

Canadian-U.S. Gas Trade Issues . . . . . . . . . . . . . . . . . . . . . . 107

Gas Industry Evolution in a More Competitive World . . . . . . . . . . . . . . . . . 107

The Benchmark Case: Characteristics of a Hypothetical Pro-Competitive Regulatory

Environment . . . . . . . . . . . . . . . . . . . . . . . . 108

The Moderately Competitive Case: What Limits to Competition Can Be Expected? . . . 108

Scenarios in Which the Industry May Not Evolve Into a Competitive World . . . . . . . . . 109

Political Pressures for Inefficient Regulatory Policies . . . . . . . . . . . . . . . . . . 109

Can the Competitive Genie Be Put Back in the Bottle? . . . . . . . . . . . . . 111

Effects of Policy Reversals on the Gas Market as a Whole . . . . . . . . . . . . . 111

Implications of Regulatory Issues for Future Modeling Efforts . . . . . . . . . . . . . 112

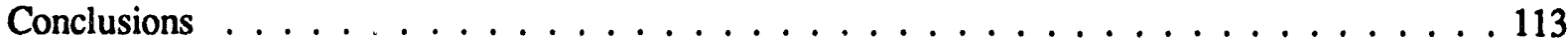

6 Key Results from Special Studies of Natural Gas Supply 115

New Departments of Interior and Energy Assessments of the Natural Gas Resource Base of the

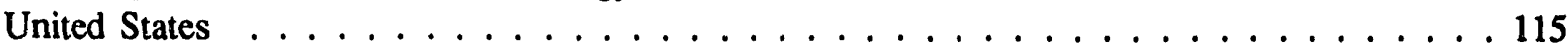

Gas Resources of Alaska and the Mackenzie Delta/Beaufort Sea Area of Canada . . . . . . 119

Natural Gas Supplies of Canada . . . . . . . . . . . . . . . . . . . . . . . . 119

Conventional Resource . . . . . . . . . . . . . . . . . . 120

Tight Gas Resource . . . . . . . . . . . . . . . . . . . . . . . 120

Production and Constraints . . . . . . . . . . . . . . . . . . 120

Summary of Key Resources Studies . . . . . . . . . . . . . . . . . . . . 121

Reserve Growth and Infill Drilling in Gas Reservoirs . . . . . . . . . . . . 123 
Other Reserve Growth Estimates . . . . . . . . . . . . . . . . . . . . . 124

Gas Reserve Growth in the EMF 9 Study Design . . . . . . . . . . . . . 125

Environmental Regulations . . . . . . . . . . . . . . . . . . 125

Appendix to Chapter 6: Key Results by Resource Category in the DOE Study . . . . . . . . 127

7 Suggestions for Future Research 131

Appendix: A Glossary of Economic and Industry Terms 135 


\section{List of Figures}

\section{Summary Report}

1 Model Means for Average U.S. Wellhead Price by Scenario . . . . . . . . . . . . 5

2 Industrial U.S. Gas-Oil Price Ratio by Model in the Upper Oil Price Scenario . . . . . 6

3 Industrial U.S. Gas-Oil Price Ratio by Model in the Lower Oil Price Scenario . . . . . 7

4 Model Means for Total U.S. Consumption by Scenario . . . . . . . . . . . . . . . . . 8

5 Model Means for U.S. Marketed Production (Dry Gas) by Scenario . . . . . . . . . . . . 12

6 U.S. Marketed Production in Industry Survey and EMF Results with Upper Oil Price Path 13

7 U.S. Marketed Production in Industry Survey and EMF Results with Lower Oil Price Path 13

8 Model Means for Total U.S. Imports by Scenario . . . . . . . . . . . . . . . . . . 14

9 Total Canadian Exports in Lower Oil Price Scenario for U.S. Models and for North American/Canadian Models . . . . . . . . . . . . . . . . . 15

\section{Working Group Report}

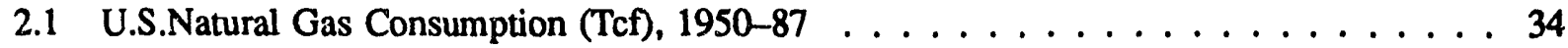

3.1 Supply-Demand Representation of a Market-Clearing Price . . . . . . . . . . . . . . 42

3.2 Energy Prices (\$ per million Btu) Delivered to Industrial Customers, 1975-1987 . . . . 45

3.3 Top 20 U.S. Interstate Pipelines Sales versus Transportation . . . . . . . . . . . . . . 45

3.4 Top 20 U.S. Interstate Pipelines Sales and Transportation Margins (1986\$/Mcf) . . . . . 46

3.5 Top 20 U.S. Interstate Pipelines Transportation Components . . . . . . . . . . . . . . . 47

3.6 Distribution Margins Based on National Average Gas Prices (1987\$/Mcf) . . . . . . . . 48

4.1 Model Means for Average U.S. Wellhead Fruje by Scenario . . . . . . . . . . . . . . . 57

4.2 Model Means for U.S. Marketed Prociuction (Dry Gas) by Scenario . . . . . . . . . . . . 59

4.3 Model Means for U.S. Imports by Scenario . . . . . . . . . . . . . . . . . . . . 60

4.4 Model Means for Total U.S. Consumption by Scenario . . . . . . . . . . . . . . . 61

4.5 Representation of Different Resource Cost Curves . . . . . . . . . . . . . . . 65

4.6 U.S. Marketed Production (Dry Gas) in the Upper Oil Price Case . . . . . . . . . . . . . 66

4.7 U.S. Average Wellhead Price by Model in the Upper Oil Price Case . . . . . . . . . . 67

4.8 Industrial U.S. Gas-Oil Price Ratio by Model in the Upper Oil Price Case . . . . . . . 68

4.9 Total U.S. Consumption by Model in the Upper Oil Price Case . . . . . . . . . . . . . 69

4.10 U.S. Imports by Model in the Upper Oil Price Scenario . . . . . . . . . . . . . . 70

4.11 Total Canadian Exports in the Uppe: Oil Price Scenario for U.S. and North American/Canadian Models . . . . . . . . . . . . . . . . . . . . 71

4.12 Supply-Demand Representation of the Lower Oil Price Scenario . . . . . . . . . . . . . 74 
4.13 Average U.S. Wellhead Price by Model in the Lower Oil Price Scenario . . . . . . . 74

4.14 Industrial U.S. Gas-Oil Price Ratio by Model in the Lower Oil Price Scenario . . . . . 75

4.15 Total U.S. Imports by Model in the Lower Oil Price Scenario . . . . . . . . . . . . 78

4.16 Total Canadian Exports in the Lower Oil Price Scenario by U.S. and North American/Canadian Models . . . . . . . . . . . . . . . . . . 78

4.17 Supply-Demand Representation of the Low Resource Scenario . . . . . . . . . . . . 82

4.18 Average U.S. Wellhead Price by Model in the Low Resource Scenario . . . . . . . . . 83

4.19 Industrial U.S. Gas-Oil Price Ratio by Model in the Low Resource Scenario . . . . . . 83

4.20 Change in U.S. Marketed Production (Dry Gas) by Model in the Low Resource Scenario (relative to the upper oil price case) $\ldots \ldots \ldots \ldots$. . . . . . . . 86

4.21 Total U.S. Imports by Model in the Low Resource Scenario . . . . . . . . . . . . . . . 87

4.22 Total Canadian Exports in the Low Resource Scenario by U.S. and North American/Canadian Models . . . . . . . . . . . . . . . . . . . . . . . . 87

4.23 Supply-Demand Representation of the High U.S. Demand Scenario . . . . . . . . . . 88

4.24 Average U.S. Wellhead Price by Model in the High U.S. Demand Scenario . . . . . . . 91

4.25 Industrial U.S. Gas-Oil Price Ratio by Model in the High U.S. Demand Scenario . . . . . 91

4.26 Change in the Average U.S. Wellhead Price by Model in the High U.S. Demand Scenario (relative to the upper oil price case) $\ldots \ldots \ldots \ldots$. . . . . . . . . . . . 92

4.27 Change in the Total U.S. Consumption by Model in the High U.S. Demand Scenario (relative to the upper oil price case) $\ldots \ldots \ldots \ldots \ldots \ldots$

4.28 Total U.S. Imports by Model in the High U.S. Demand Scenario . . . . . . . . . . . 95

4.29 Total Canadian Exports in the High U.S. Demand Scenario for U.S. and North American/Canadian Models . . . . . . . . . . . . . . . . . 96 


\section{List of Tables}

\section{Summary Report}

1 Key Scenario Inputs for EMF $9 \ldots \ldots \ldots \ldots \ldots \ldots$

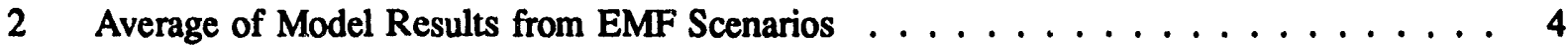

3 Estimates of the Recoverable Gas Resource $\ldots \ldots \ldots \ldots 10 \ldots \ldots$

4 Natural Gas Models Used in EMF $9 \ldots \ldots \ldots \ldots$

5 Issues Identified by the EMF 9 North American Natural Gas Working Group as Requiring More Analyses . . . . . . . . . . . . . . . . . . . . 20

\section{Working Group Report}

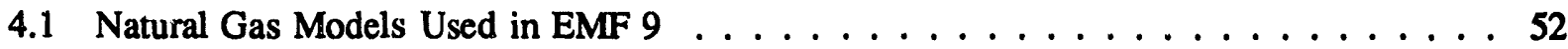

4.2 Key Scenario Inputs for EMF $9 \ldots \ldots \ldots$

4.3 Key U.S. Results from Upper Oil Price Scenario, 1985-2010 . . . . . . . . . . . . . 64

4.4 Key U.S. Results from Lower Oil Price Scenario, 1985-2010 . . . . . . . . . . . . 73

4.5 Average U.S. Delivered Price, Production, and Consumption Responses to Lower Oil Prices, 1990-2010 (with respect to the upper oil price case) . . . . . . . . . . . 76

4.6 Effect of Lower Oil Price on Total, Industrial, and Electric Utility Censumption by Model, 2000 and 2010 (with respect to upper oil price case) . . . . . . . . . . . . . 77

4.7 Key U.S. Results from Low U.S. Resource Scenario, 1985-2010 . . . . . . . . . . . 80

4.8 U.S. Production, Consumption, and Delivered Price Responses to Lower U.S. Resources, 1990-2010 (with respect to the upper oil price case) . . . . . . . . . . . . . 84

4.9 Effect of Low U.S. Resources on Total, Industrial, and Electric Utility Consumption by Model, 2000 and 2010 (with respect to the upper oil price case) . . . . . . . . . . 85

4.10 Key U.S. Results from High Demand Scenario, 1985-2010 . . . . . . . . . . . . 89

4.11 Demand Shifts in the Models to Represent High U.S. Demand Scenarios (Tcf) . . . . . 90

4.12 Averge U.S. Delivered Price, Production, and Consumption Responses to Higher U.S. Gas Demand, 1990-2010 (with respect to the upper oil price scenario) . . . . . . . 993

4.13 Mean U.S. Dry Gas Production (Tcf) In EMF Industry Survey and Model Results . . . . 97

4.14 Mean U.S. Consumption (Tcf) In EMF Industry Survey and Model Results . . . . . . . 97

4.15 Comparison of Mean U.S. Dry Gas Production (Tcf) with National Petroleum Council

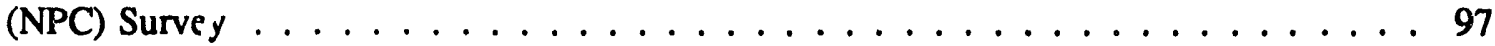

6.1 Estimates of the Recoverable Gas Resource . . . . . . . . . . . . . . . . . 117

6.2 Total U.S. Gas Reserves and Resources Assessed in the U.S. Department of Energy Study 118

6.3 Canadian Conventional Resource Estimates (Tcf) . . . . . . . . . . . . . 120 
6.4 Canadian Tight Gas Resource Estimates . . . . . . . . . . . . . . . . . 121

6.5 National Energy Boand Estimates of Conventional Resources of the Western Canada Sedimentary Basin (Tcf) . . . . . . . . . . . . . . . . . . . . 121

6.6 ICF-Lewin Energy's Estimate of Canada's Conventional and Tight Gas Resources of the Western Canada Sedimentary Basin (Tcf), $1986 \ldots$. . . . . . . . . . . . . . . 122

6.7 Canadian Hunter Estimates of Canadian Tight Gas Resources at Different Prices . . . . . 122

6.8 Westem Gas Marketing Resource Estimates (Tcf) for Westem Canada Sedimentary Basin 124 


\section{Senior Advisory Panel $\dagger$}

The Energy Modeling Forum (EMF) seeks to improve the usefulness of energy models by conducting tests of models in the study of key energy issues. The success of the Forum depends upon the selection of important study topics, the broad involvement of policymakers, and the persistent attention to the goal of improved communication. The EMF is assisted in these matters by a Senior Advisory Panel that recommends topics for investigations, critiques the studies, guides the operations of the project and helps communicate the results of the energy policymaking community. The Panel is not responsible for the results of the individual EMF working group studies.

Dr. Harvey Brooks, Chairman

Dr. Morris Adelman

Mr. Grady Baker

Dr. Richard Balzhiser

Mr. Glenn Bjorklund

The Honorable Danny J. Boggs

The Honorable William Bradley

Mr. Jarvis Cecil

Dr. Hollis Chenery

Mr. Stephen Chesebro'

Mr. Charles DiBona

The Honorable John Dingell

Dr. Daniel Dreyfus

Dr. John Gibbons

Dr. William Hogan

Mr. Myron Kanik

Dr. Rene Males

Mr. William Martin

Dr. Roger Naill

Dr. Jerrold M. Pachman

Mr. William Rusnack

The Honorable Philip Sharp

Dr. James Sweeney

Mr. Mason Willrich

Mr. Ronald Wishart
Prefessor, Harvard University

Professor, Massachusetts Institute of Technology

Executive Vice President, Georgia Power

President, Electric Power Research Institute

Vice President, Southern Califomia Edison

Judge, U.S. Sixth Circuit Court

Member, U.S. Senate

Executive Vice President, Consolidation Coal

Professor, Harvard University

President, Tenneco Gas Marketing

President, American Petroleum Inscitute

Member, U.S. House of Representatives

Vice President, Gas Research Institute

Director, Office of Technology Assessment

Professor, Harvard University

Deputy Minister, Department of Energy, Alberta

Senior Vice President, Wisconsin Electric Power

Deputy Secretary, Department of Energy

Vice President, Applied Energy Services

Vice President, Union Pacific Resources

Vice President, ARCO

Member, U.S. House of Representatives

Professor, Stanford University

Senior Vice President, Pacific Gas \& Electric

Vice President, Union Carbide

tAffiliation at the time of the study 


\section{Working Group Participants $\dagger$}

\begin{tabular}{|c|c|}
\hline Glen Schuler, Chairman & Tenneco \\
\hline Amold Baker & ARCO \\
\hline Michael Barron & Maxus \\
\hline David Beecy & U.S. Department of Energy \\
\hline Charles Blitzer & Massachusetts Institute of Technology \\
\hline Pieter Brakel & Department of Energy, Mines \& Resources, Canada \\
\hline Peter Carnavos & Consolidated Edison \\
\hline Robert Finley & University of Texas at Austin \\
\hline Edward Flom & Àmoco \\
\hline William Foster & Foster Associates, Inc. \\
\hline Nelson Hay & American Gas Association \\
\hline Alan Hiles & National Energy Board, Canada \\
\hline H. William Hochheiser & U.S. Department of Energy \\
\hline Paul Holtberg & G: : Research Institute \\
\hline R. Skip Horvath & Int retal: Natural Gas Association of America \\
\hline Hillard Huntington & Stanford University \\
\hline Richard Hyndman & Alberta Department of Energy \\
\hline Scott Jones & WEFA Econometrics \\
\hline Joseph Kalt & Harrard University \\
\hline Thomas Kennedy & Illinois Commerce Commission \\
\hline Harry Kent & Colorado School of Mines \\
\hline James Kimball & Pacific Gas and Electric \\
\hline Vello Kuuskraa & ICF-Lewin Energy \\
\hline Alan Manne & Stanford University \\
\hline Barbara Mariner-Volpe & U.S. Department of Energy \\
\hline Harold Milton & Exxon U.S.A. \\
\hline W. David Montgomery & U.S. Department of Energy \\
\hline Dale Nesbitt & Decision Focus Inc. \\
\hline Richard O'Neill & Federal Energy Regulatory Commission \\
\hline Stephen Plotkin & Office of Technology Assessment \\
\hline Donald Quon & Alberta Research Council \\
\hline Gopal Rana & Panhandle Eastem \\
\hline Kjell Roland & ECON, Norway \\
\hline John Rowse & University of Calgary \\
\hline Benjamin Schlesinger & Benjamin Schlesinger \& Associates \\
\hline Mark Segal & National Energy Board, Canada \\
\hline Richard Snyder & Tenneco \\
\hline William Stitt & ICF Incorporated \\
\hline
\end{tabular}


Mark Sweeney

Charles Teclaw

William Trapmann

Harry Vidas

Leonard Waverman

John Weyant

Alan Wiggins

Richard Wyman
Soutt: $\mathrm{m}$ Califomia Gas

U.S. Department of Energy

U.S. Department of Energy

Energy \& Environmental Analysis University of Toronto

Stanford University

Conoco, Inc.

Canadian Hunter Exploration Ltd

HAffiliation at the time of the study 


\section{Report Contributors $\dagger$}

During the study the Working Group drew upon the expentise of many analysts. We would like to particularly acknowledge the significant contribution of the following people:

\author{
Howard Ash \\ Brian Bowers \\ Stanley Brownell \\ Patrick Cheung \\ Joseph Coms \\ Christopher Duhon \\ John Fraser \\ Fred Gerber \\ Michael Godec \\ Donald Hanson \\ William Jarvis \\ David Kline \\ Thomas Lyon \\ William Pepper \\ Dennis Prince \\ James Shaw \\ Leon Tucker \\ John Underwood \\ Sam Wong \\ William Wood
}

\author{
Benjamin Schlesinger \& Associates \\ National Energy Board, Canada \\ Panhandle Eastem \\ ARCO Oil and Gas \\ Amoco \\ Tenneco \\ Tenneco \\ ARCO Oil and Gas \\ ICF-Lewin Energy \\ Argonne National Laboratory \\ Department of Energy, Mines \& Resources, Canada \\ California Energy Commission \\ Stanford University \\ ICF Incorporated \\ Alberta Department of Energy \\ Union Pacific Resources \\ American Gas Association \\ Tenneco \\ Alberta Research Council \\ Califomia Energy Commission
}

tAffiliation at the time of the study 


\section{Executive Summary}

This report summarizes the research by an Energy Modeling Forum working group on the evolution of the North American natural gas markets between now and 2010. The group's findings are based partly on the results of a set of economic models of the natural gas industry that were nun for four scenarios representing significantly different conditions: two oil price scenarios (upper and lower), a smaller total U.S. resource base (low U.S. resource case), and increased potential gas demand for electric generation (high U.S. demand case). Several issues, such as the direction of regulatory policy and the size of the gas resource base, were analyzed separately without the use of models.

\section{Pricing}

- By 1990 , gas prices in the United States and Canada begin to reverse their decline of the 1980 s in the scenarios analyzed, reflecting the elimination of the current excess deliverability condition.

- After 1990, gas prices in the United States and Canada rise continuously, reflecting higher oil prices and smaller field size and higher exploration and development costs of future reserve additions. By 2000 , inflation-adjusted gas prices reach their peaks of the early 1980 s, even in the lower oil price case.

- In the long run, bumertip natural gas and residual fuel oil prices need not necessarily equate on a per Btu (i.e., heat content) basis. Depending upon the model, gas prices are at or below parity with residual fuel oil in the upper oil price case; are generally at parity in the high demand case; and are at or above parity in the low resource and lower oil price cases.

- There currently exists considerable capability for switching between natural gas and residual oil in equipment that can bum either fuel (the dual-fuel market). When gas supplies are plentiful enough to saturate this dual-fuel market, gas prices may fall below the price of residual fuel oil; conversely, when supplies are limited enough to cause this dualfuel market to be lost, the gas price will rise above the residual fuel oil price. As long as a large amount of gas continues to be used by these dual-fired industrial and powerplant customers, gas prices will tend to be capped by residual fuel oil prices.

\section{Supply}

- Resource base estimates are highly uncertain. The cost of proving and producing resources is as important as the extent of resources in place for detcrmining gas supply and price. Despite standardizing on oil price and the physical magnitude of the resource base, substantial variations in incremental resource costs exist among the models.

- Poorly drained reservoirs or uncontacted compartments in existing reservoirs may contain significant gas reserves that can be produced through infill drilling and recompletions. This phenomenon, reserve growth, represents a potentially significant source of ad- 
ditional gas, although confirmation of preliminary estimates is needed.

- Changes in oil prices, undiscovered resources, and gas demands can lead to a wide variation in production across the four scenarios-from 14 to $18 \mathrm{Tcf}$ by 2000 and from 12 to $19 \mathrm{Tcf}$ by 2010 (according to the average of all model results).

- Total U.S. gas imports rise substantially in all scenarios, reaching 1.5 icf by 2010 in the lower oil price case and 2 Tcf or more in the other scenarios compared to $1 \mathrm{Tcf}$ in 1987. Although Canada remains the principal source of U.S. imports, liquefied natural gas (LNG) and, in some instances, Mexican gas, also contribute to U.S. imports.

- To sustain annual Canadian gas export levels at 2 Tcf in the upper oil price case, Canadian frontier and unconventional supplies need to be developed in a timely manner for delivery after the turn of the century. In this study, Canadian gas exports are generally less in the Canadian and North American models than in the U.S. models in all scenarios.

\section{Consumption (Demand)}

- Variations in the projections of industrial demand are quite large by 2010, ranging from a total of $4 \mathrm{Tcf}$ to approximately $8 \mathrm{Tcf}$ in different models in the upper oil price scenario, constituting 22 to 41 percent of total demand. Much of this variation stems from fuelswitching and different assumptions about the penetration of new industrial gas-fired technologies. The range in the demand by electric utilities is also large-from 2.9 to $5.7 \mathrm{Tcf}$ by 2010 - depending upon assumptions about environmental regulations, fuel prices, and load growth.

- In the lower oil price and low resource cases, gas consumption declines relative to the upper oil price case as industrial and electric utility users switch to oil, primarily in dualfired boilers. Since U.S. oil production is expected to decline in the future, some of the lost gas consumption will be met by rising oil imports. The average gas consumption decline across a'l models was $2.9 \mathrm{Tcf}$ in 2010 in the lower oil price case and $3.5 \mathrm{Tcf}$ in the low U.S. resource case, or in oil-equivalent terms, 1.4 million barrels per day (MMBD) and 1.7 MMBD, respectively.

- Satisfying the higher electric utility gas demands of the high U.S. demand case requires higher gas prices than in the upper oil price case. The higher gas price brings forth additional gas supplies, primarily domestic, by encouraging exploration and development, and reduces consumption in other gas demand sectors. While potential gas demand is increased by $2.8 \mathrm{Tcf}$, actual total gas consumption rises by only 1.5 to 2.0 Tcf by 2010 as a result of the higher gas price.

\section{Regulatory Policy}

- The U.S. gas industry has been highly regulated and regulatory decisions have often interfered with market forces. With increased competition, the focus of regulation is changing from price and volume controls to the conditions of access to and participation in the gas market. In the future, regulatorsstate, provincial, and federal in the U.S. and Canada-will continue to have a major impact on the gas market.

- The distribution of gains and risks among producers, pipelines, local distribution companies (LDCs), and end-users will be an important element in many regulatory issues, such as rate design, the allocation of pipeline capacity, and bypass of LDCs by their customers. Nevertheless, market forces will constrain the ability of regulators to reallocate economic benefits and risks among market participants. 
- A streamlined approval process for the construction of new interstate pipeline facilities into new markets will be important to improve the allocation of resources.

- Under sonıe scenarios-especially a lower resource base-regulators may face political pressures to overturn, or not adopt, some procompetitive policies. To the extent industry participants anticipate that pro-competitive policies will be reversed by regulators, some participants may respond to this uncertainty by reducing investment.

\section{Natural Gas Modeling}

- Several methodologies exist to model natural gas markets. Methodology, however, accounts for only a portion of the variation among model results. Different perspectives about fundamental gas supply, demand, and pricing relationships are also important explanations for variations between model results.
- The models used in this study were originally developed to project long-term trends in gas prices, production, and consumption. They have been useful for understanding some key long-run relationships and developing insights about the industry's development. Most models, however, did not directly incorporate regulatory behavior in their structures, nor did they allow transmission and distribution margins to be determined by gas market forces.

- As the gas market develops, it will be important to better reflect within the model frameworks the increasing integration of the U.S. and Canadian gas markets, interregional competition within each country, impacts of regulatory policy, technological changes in gas supply and dennand, alternative natural gas resource base estimates, the setting of transmission and distribution margins, price volatility, environmental regulations, and short-run dynamics. Developing better analyses of these factors will improve decisionmaking and represents an important challenge. 


\section{Summary Report}

A dozen years ago, the United States was in the throes of a severe natural gas shortage. Moratoria on new customers were instituted and large existing customers had their gas service curtailed. Prices were set under long-term contracts, which were subject to regulation from the field to the burnertip. ${ }^{1}$ In this environment, frequent reference was made to natural gas being a "premium" fuel that in an unregulated market could attract a price above that of distillate fuel oil, reflecting its cleaner-burning properties.

Gas market conditions are dramatically different today. The gas-producing industry has been mired in excess deliverability for several years. Both U.S. and Canadian producers are aggressively searching for new markets for their surplus gas, while consumers are enjoying the benefits of lower prices. Many long-term contracts with fixed prices have been renegotiated to incorporate market-responsive pricing and many have been replaced by shorter-term contracts and spot market sales. More than half of today's annual gas sales are spot-market transactions. The regulatory policy debate has shifted from an emphasis on the security of supply to the deregulation of field prices and then to the issues of access to and the allocation of pipeline capacity. Gas prices are being set by "gas-to-gas" competition, which has lead to bumertip gas prices falling below residual fuel oil prices.

This shift in market conditions from one constrained by regulations to one relying more upon market forces emphasizes the uncertainty about this industry's future evolution. What will this

\footnotetext{
Italics indicate the first use in the summary report of words or phrases listed and defined in the Appendix.
}

market look like through the 1990 s and beyond? Will excess deliverability continue? Will the pricing of natural gas revolve around the switchable end-use market comprised of large industrial and electric utility users with dual fuel-buming capacity? Or will natural gas and residual fuel oil prices diverge under certain conditions? How will the regulatory environment resolve such issues as "open access" to the nation's gas transmission system?

In short, growing competition in the North American natural gas market has increased the uncertainty about the industry's development. In addition, industry experts hold divergent opinions on such critical issues as resource availability, enduse demands, the proper regulatory climate, and pricing.

The Energy Modeling Forum working group (EMF 9) analyzed the development of the North American natural gas industry under different conditions with respect to oil prices, the natural gas resource base, and gas demand. In addition, regulatory policy issues were addressed. This group comprised leading natural gas analysts, listed at the beginning of this report, from government, industry, universities, and research and consulting organizations. In conducting the analyses, the group pursued two broad goals. First, it sought to develop insights about the gas market's development under a range of different environments by using economic models and additional analyses. Second, it sought to evaluate the existing analytical approaches available for understanding this industry and discuss their strengths and limitations.

The models of the natural gas industry guided the group's thinking about many important market relationships and helped identify important differ- 
ences of opinion about future outcomes. While many of the conclusions depend on the model results, several issues, such as regulatory policy and the size of the resource base, could not be analyzed using the models. These latter issues were studied separately by group members to determine how they might affect the industry's evolution.

\section{Scenarios}

Models are often used to develop projections about the "most likely" market conditions. The working group, however, did not define such a case in this study. Given the uncertainty about the future development of the North American natural gas market, the group found it more valuable to develop insights about key gas market relationships under very different environments. In this study, the working group evaluated four standardized scenarios that included the effects of different gas resource bases, oil price paths, and potential sources of gas demand on the natural gas market.

The key scenario inputs are listed in Table 1. The two oil price scenarios are extensions of price paths analyzed in a National Petroleum Council (NPC) study. ${ }^{2}$ In the upper oil price scenario, the oil price rises from $\$ 15$ per barrel in 1986 to $\$ 36$ in 2000 and $\$ 44$ in 2010 (1986 dollars). In the lower oil price scenario, it ics is $\$ 21$ in 2000 and $\$ 26$ in 2010 . The two oil price scenarios incorporate a lower-48 natural gas resource base of 933 trillion cubic feet of undiscovered and inferred resources plus proved reserves. ${ }^{3}$ Using the upper oil price assumptions, the group also investigated two other scenarios. In one scenario, the effects of a lower U.S. resource base of 591 trillion cubic feet of undiscovered resources plus proved reserves

\footnotetext{
${ }^{2}$ National Petroleum Council, Factors Affecting U.S. Oil and Gas Outlook, Washington, D.C., 1987.

${ }^{3}$ For comparison, a recent DOE lower-48 estimate is 1059 trillion cubic feet. See U.S. Department of Energy, An Assessment of the Natural Gas Resource Base of the Uniled States. Washington, D.C., May 1988.
}

(low U.S. resource case) were examined. ${ }^{4}$ Another scenario assumes a higher level of potential gas demand for electric generation resulting from an acid rain policy and from increased penetration of combined-cycle gas turbine technologies (high U.S. demand case). In all four scenarios, Canadian gas exports to the United States are capped at 2 trillion cubic feet per year, reflecting the working group's assessment of the maximum economically sustainable export levels between the two countries.

Eleven models of the U.S. and Canadian gas markets were run for each scenario by standardizing on the key inputs contained in Table 1. In some cases, e.g., the resource base, the EMF inputs differed substantially from those often used by the proprietors of a model.

The EMF 9 working group also surveyed a group of oil companies and other organizations to determine their natural gas supply and demand outlooks for comparison to the model results. A similar survey was conducted by the National Petroleum Council in 1986. The results from the EMF 9 survey were in close agreement with the NPC survey results.

\section{Major Findings and Issues}

Based upon discussions and analysis, the group reached conclusions on gas pricing, consumption, supply, regulatory policy, and the use of models. Table 2 contains averages of the model results for selected variables for the $1985-2010$ period across the four scenarios.

\section{Natural Gas Pricing}

Surplus deliverability - the gas bubble-has existed in the U.S. gas industry since the beginning of the 1980s and has contributed to declining gas prices in recent years. The model results show this price trend reversing by 1990 in all scenar-

\footnotetext{
${ }^{4}$ For comparison, a preliminary 1988 Department of Interior estimate is 517 trillion cubic feet.
} 
Table 1: Key Scenario Inputs for EMF 9

\begin{tabular}{|c|c|c|c|c|}
\hline Key Assumptions & $\begin{array}{l}\text { Upper Oil } \\
\text { Price }\end{array}$ & $\begin{array}{l}\text { Lower Oil } \\
\text { Price } \\
\end{array}$ & $\begin{array}{l}\text { Low U.S. } \\
\text { Resource }\end{array}$ & $\begin{array}{l}\text { High U.S. } \\
\text { Demand }\end{array}$ \\
\hline \multicolumn{5}{|l|}{$\begin{array}{l}\text { World crude oil price } \\
\text { (1986\$/barrel) }\end{array}$} \\
\hline 1986 & $\$ 15$ & $\$ 15$ & $\$ 15$ & $\$ 15$ \\
\hline 1990 & $\$ 22$ & $\$ 14$ & $\$ 22$ & $\$ 22$ \\
\hline 2000 & $\$ 36$ & $\$ 21$ & $\$ 36$ & $\$ 36$ \\
\hline 2010 & $\$ 44$ & $\$ 26$ & $\$ 44$ & $\$ 44$ \\
\hline \multicolumn{5}{|l|}{ US economic growth rate, } \\
\hline \multicolumn{5}{|l|}{$\begin{array}{l}\text { US Lower- } 48 \text { inferred and } \\
\text { undiscovered resources (Tcf) }\end{array}$} \\
\hline Conventional & $627^{a}$ & $627^{a}$ & $388^{b}$ & $627^{a}$ \\
\hline Unconventional at $\$ 5 / \mathrm{Mcf}$ & 97 & 97 & 0 & 97 \\
\hline Infill Drilling at $\$ 5 / \mathrm{Mcf}$ & 50 & 50 & 44 & 50 \\
\hline TOTAL & 774 & 774 & 432 & 774 \\
\hline Proven Reserves Lower-48 $\left(\right.$ Tcf, 1986) ${ }^{c}$ & 159 & 159 & 159 & 159 \\
\hline Total Undiscovered Plus Proven & 933 & 933 & 591 & 933 \\
\hline Canadian Export Cap (Tcf/yr) & 2 & 2 & 2 & 2 \\
\hline \multicolumn{5}{|l|}{$\begin{array}{l}\text { Extra potential U.S. } \\
\text { utility gas demand (Bcf/yr) }\end{array}$} \\
\hline 1990 & 0 & 0 & 0 & 296 \\
\hline 2000 & 0 & 0 & 0 & 1431 \\
\hline 2010 & 0 & 0 & 0 & 2807 \\
\hline \multicolumn{5}{|c|}{$\begin{array}{l}\text { Tcf-Trillion cubic feet. } \\
\text { Bcf-Billion cubic feet. } \\
\text { Mcf-Thousand cubic feet. } \\
\text { a } 1986 \text { Potential Gas Committee (PGC) Most Likely Estimate, plus } 7 \text { Tcf for offshore gas deeper than } 1000 \text { meters. Estimate } \\
\text { is not based upon any explicit price assumptions. } \\
\text { bBased upon } 1986 \text { PGC Low Estimate, which assumes "that there is approximately a } 90 \text { percent or greater probability that at } \\
\text { least this much natural gas resources is present." Also includes } 4 \text { Tcf of offshore gas in water deeper than } 1000 \text { meters. Estimate } \\
\text { is not based upon any explicit price assumptions. See "EMF } 9 \text { Study Design" in Volume } 3 \text {. } \\
\text { cDiscovered gas that is excluded from estimates of undiscovered resources. }\end{array}$} \\
\hline
\end{tabular}


Table 2: Average of Model Results from EMF Scenarios

\begin{tabular}{|c|c|c|c|c|c|c|}
\hline & \multicolumn{6}{|c|}{$\begin{array}{l}\text { Gas Volumes in Trillion Cubic Feet (Tcf) } \\
\text { Oil and Gas Prices in 1986\$/Thousand Cubic Feet (Mcf) }\end{array}$} \\
\hline & 1985 & 1990 & 1995 & 2000 & 2005 & 2010 \\
\hline \multicolumn{7}{|l|}{ Upper Oil Price: } \\
\hline Marketed Production & 16.38 & 16.47 & 16.69 & 17.25 & 17.14 & 17.11 \\
\hline Total Imports & 0.95 & 1.12 & 1.58 & 1.58 & 1.84 & 2.17 \\
\hline Total Consumption ${ }^{a}$ & 17.28 & 17.41 & 18.03 & 18.87 & 19.04 & 19.35 \\
\hline Average Wellhead Price & $\$ 2.57$ & $\$ 2.25$ & $\$ 3.10$ & $\$ 3.86$ & $\$ 4.50$ & $\$ 4.96$ \\
\hline Average Delivered Price & $\$ 4.84$ & $\$ 4.07$ & $\$ 4.86$ & $\$ 5.72$ & $\$ 6.36$ & $\$ 6.75$ \\
\hline Crude Oil Price & $\$ 4.83$ & $\$ 3.79$ & $\$ 4.83$ & $\$ 6.21$ & $\$ 6.90$ & $\$ 7.59$ \\
\hline \multicolumn{7}{|l|}{ Lower Oil Price: } \\
\hline Marketed Production & 16.38 & 15.19 & 14.45 & 14.92 & 14.07 & 14.79 \\
\hline Total Imports & 0.95 & 0.93 & 1.43 & 1.39 & 1.56 & 1.69 \\
\hline Total Consumption ${ }^{a}$ & 17.28 & 15.94 & 15.67 & 16.14 & 15.47 & 16.43 \\
\hline Average Wellhead Price & $\$ 2.57$ & $\$ 1.86$ & $\$ 2.54$ & $\$ 3.10$ & $\$ 3.71$ & $\$ 4.17$ \\
\hline Average Delivered Price & $\$ 4.84$ & $\$ 3.59$ & $\$ 4.22$ & $\$ 4.84$ & $\$ 5.50$ & $\$ 6.03$ \\
\hline Crude Oil Price & $\$ 4.83$ & $\$ 2.41$ & $\$ 2.93$ & $\$ 3.62$ & $\$ 3.97$ & $\$ 4.48$ \\
\hline \multicolumn{7}{|l|}{ Lower Resources: } \\
\hline Marketed Production & 16.38 & 16.07 & 15.41 & 14.84 & 14.07 & 12.92 \\
\hline Total Imports & 0.95 & 1.17 & 1.70 & 2.23 & 2.74 & 2.88 \\
\hline Total Consumption ${ }^{a}$ & 17.28 & 17.07 & 16.88 & 16.88 & 16.63 & 15.77 \\
\hline Average Wellhead Price & $\$ 2.57$ & $\$ 2.40$ & $\$ 3.38$ & $\$ 4.93$ & $\$ 5.59$ & $\$ 7.28$ \\
\hline Average Delivered Price & $\$ 4.84$ & $\$ 4.22$ & $\$ 5.19$ & $\$ 6.82$ & $\$ 7.56$ & $\$ 9.36$ \\
\hline Crude Oil Price & $\$ 4.83$ & $\$ 3.79$ & $\$ 4.83$ & $\$ 6.21$ & $\$ 6.90$ & $\$ 7.59$ \\
\hline \multicolumn{7}{|l|}{ High Demand: } \\
\hline Marketed Production & 16.38 & 16.73 & 17.31 & 18.12 & 18.13 & 18.76 \\
\hline Total Imports & 0.95 & 1.12 & 1.65 & 1.95 & 2.26 & 2.52 \\
\hline Total Consumption $^{a}$ & 17.28 & 17.66 & 18.69 & 19.84 & 20.12 & 21.21 \\
\hline Average Wellhead Price & $\$ 2.57$ & $\$ 2.34$ & $\$ 3.26$ & $\$ 4.28$ & $\$ 4.95$ & $\$ 5.77$ \\
\hline Average Delivered Price & $\$ 4.84$ & $\$ 4.14$ & $\$ 4.99$ & $\$ 6.09$ & $\$ 6.84$ & $\$ 7.57$ \\
\hline Crude Oil Price & $\$ 4.83$ & $\$ 3.79$ & $\$ 4.83$ & $\$ 6.21$ & $\$ 6.90$ & $\$ 7.59$ \\
\hline
\end{tabular}

Averages for seven U.S. models; excludes GRI Hydrocarbon for which io consumptien or imports were reported. ${ }^{a}$ Consumption excludes changes in inventories ano unaccounted for. 


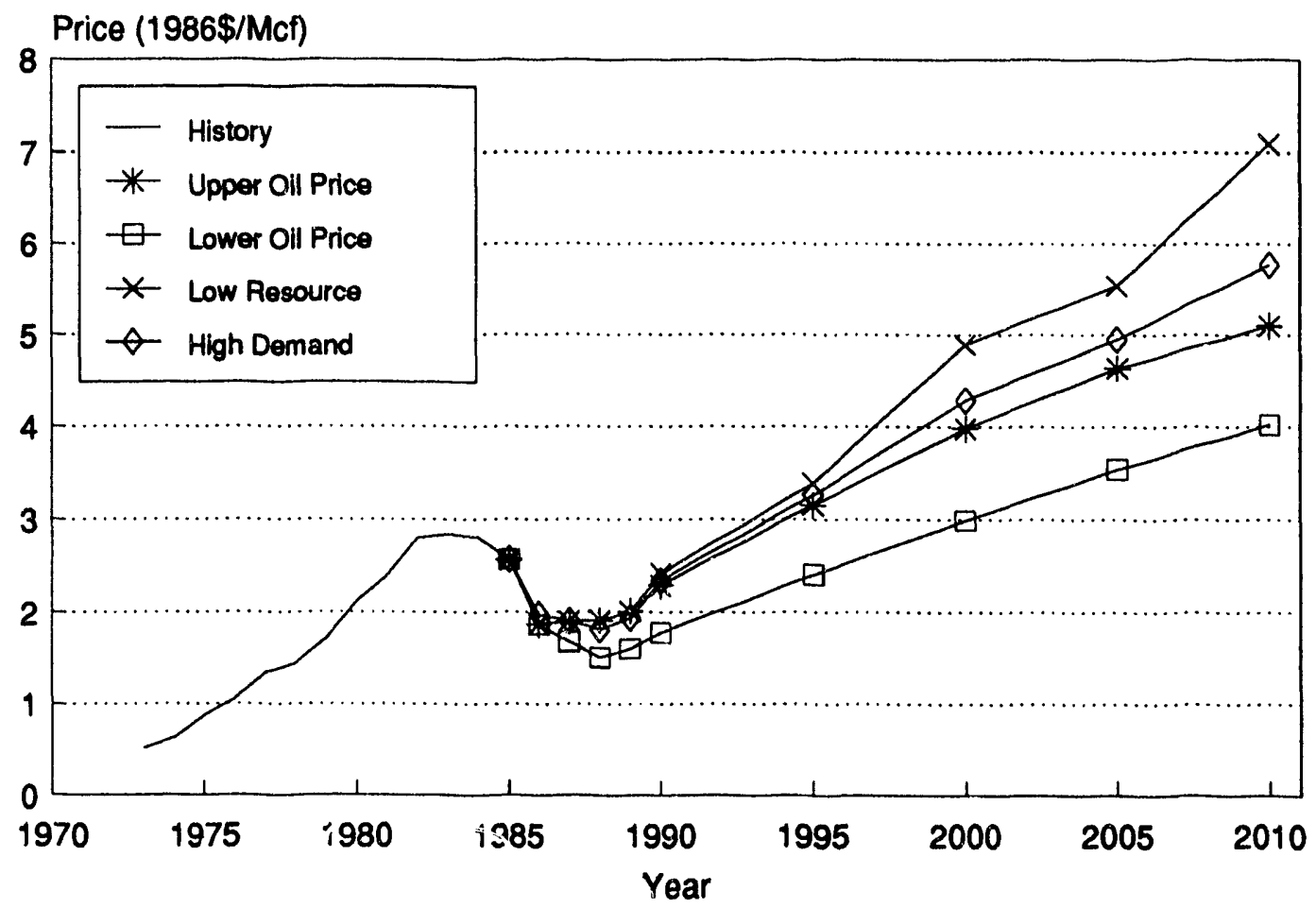

Figure 1: Model Means for Average U.S. Wellhead Price by Scenario

ios (Figure 1), suggesting that the period of excess deliverability is nearing an end.

Once the current excess deliverability of natural gas is eliminated and gas supply and demand are more in balance, gas prices in the United States and Canada rise continuously in the scenarios analyzed. Prices increase most rapidly in the low resource case and least rapidly in the low oil price scenario. By 2000 , the inflation-adjusted gas price exceeds its early 1980s peak of almost $\$ 3$ per thousand cubic feet $(M c f)$ in $1986 \$$, even in the low oil price case.

Through the early 1990s, higher gas prices reflect increases in oil prices and the elimination of today's excess deliverability condition. Over the long run, wellhead gas prices reflect the higher cost of finding and developing gas reserves. Over the next 25 years, the results show that the U.S. gas industry will need to find and develop another 350 to 400 trillion cubic feet ( $T c f$ ) of reserves. Increased drilling productivity, above that represented in the model runs, could reduce the rate of cost increase but is unlikely to reverse the upward trend in costs and prices. In addition, price volatility around these long-run trends can be expected as the industry adopts more flexible-pricing mechanisms. Seasonal conditions will contribute to swings in price as well.

As the North American natural gas industry becomes more competitive, rapid and accurate gas price signals from the wellhead through the burnertip will maintain a better balance between gas supply and demand. Moreover, in the long run, natural gas and residual fur. oil prices need not necessarily track each other on a Btu (i.e., heat content) basis. Simple "rules-of-thumb" relating the two fuels, e.g., oil netback prices, may lead to incorrect forecasts and decisions.

There currently exists considerable capability for switching between natural gas and residual fuel oil in equipment that can burn either fuel (the dual-fuel market). When gas supplies are plentiful enough to saturate this dual-fuel market, gas prices may fall below the price of residual oil; conversely, when 


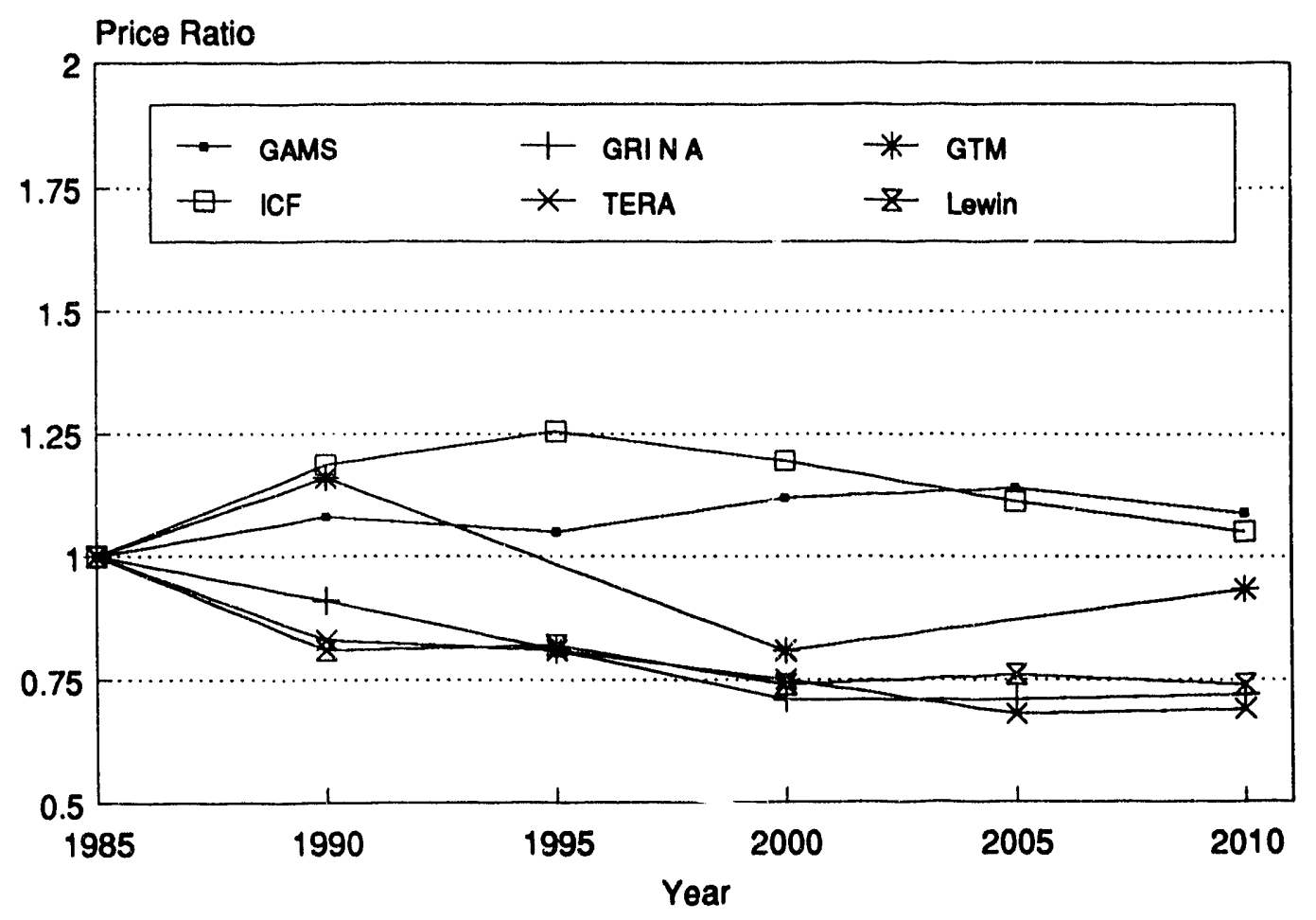

Figure 2: Industrial U.S. Gas-Oil Price Ratio by Model in the Upper Oil Price Scenario

supplies are limited enough to cause this dual-fuel market to be lost, the gas price will rise above the residual fuel oil price. As long as a large amount of gas continues to be used by these dual-fired industrial and power-plant customers, gas prices will tend to be capped by residual fuel oil prices.

In the upper price path, sufficient gas supply is forthcoming to meet a growing gas market at industrial bumertip prices competitive with or less than residual oil prices. Half of the models show national residual fuel oil and natural gas prices in rough equivalence on a Btu basis (Figure 2). ${ }^{5}$ In the other models, the gas price falls below the residual fuel oil price at the industrial bumertip.

Under the lower oil price conditions, industrial bumertip gas prices rise relative to residual fuel oil prices. Gas loses market share to oil as it becomes less price competitive. With oil prices only mod-

\footnotetext{
${ }^{5}$ Model abbreviations in Figure 2 are identified in Table 4. Burnertip parity pricing for large industrial customers is maintained in the ICF results by the assumption that transportation costs are heavily discounted for these customers.
}

estly higher than today's levels by 2000 ( $\$ 21$ per barrel in 1986\$), gas prices rise above the average residual fuel oil price in those models that indi-. cated residual oil-gas parity in the upper oil price case (Figure 3). Meanwhile, gas compeles directly with residual fuel oil in those models that had indicated a gas price below the oil price in the higher oil price scenario.

\section{Fuel Switching}

Fuel switching between oil and gas, especially in dual-fired boilers, has important implications for how gas markets will adjust to changes in marke ! conditions. As gas supply and demand conditions change, gas price change, restoring the supplydemand balance. If gas becomes more or less expensive to use than oil, the larger the amount of demand that can readily switch between gas and oil, the smaller the price change needed to rebalance demand and supply at any one time. Estimates of the amount of fuel switching capability with dual- 


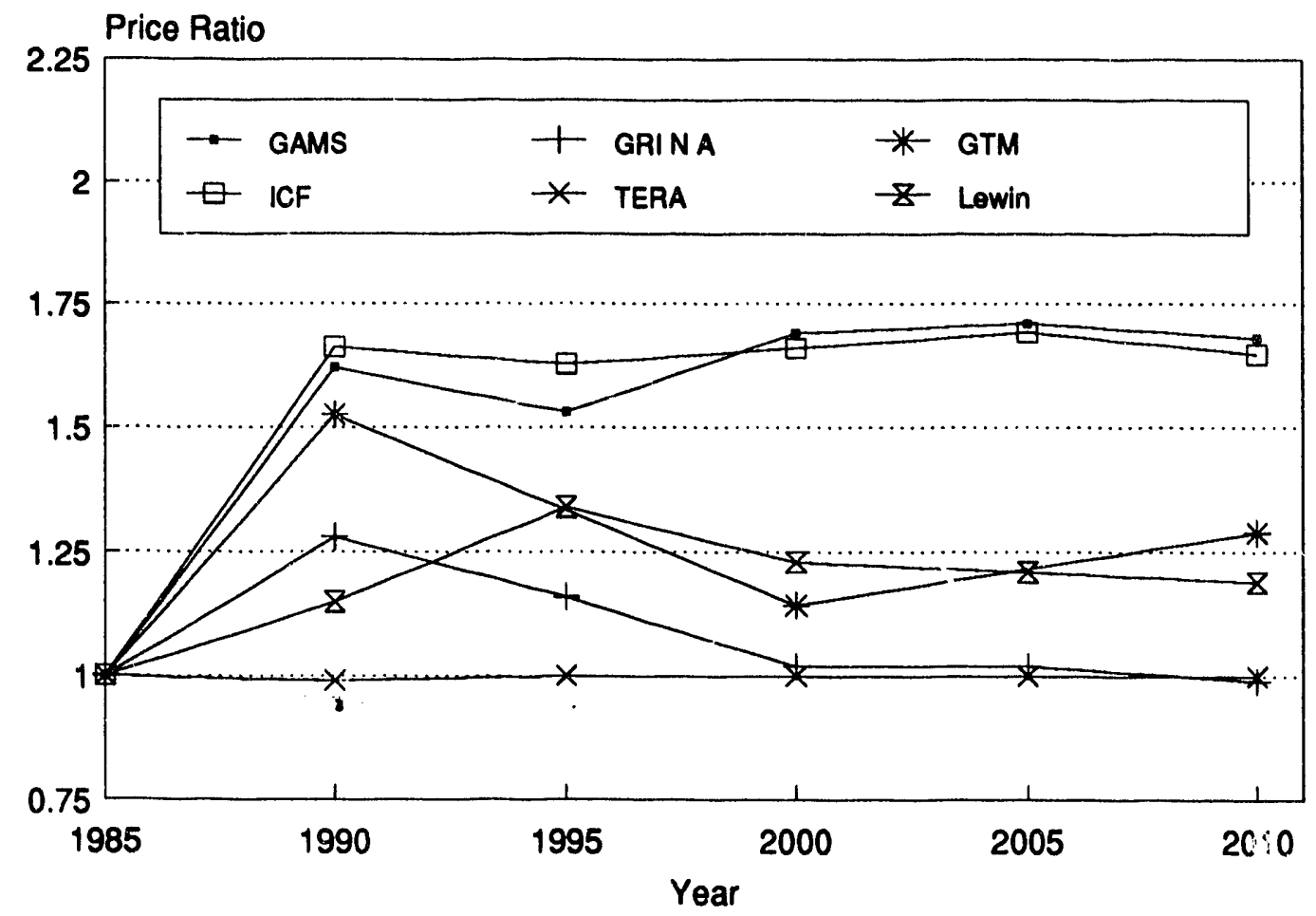

Figure 3: Industrial U.S. Gas-Oil Price Ratio by Model in the Lower Oil Price Scenario

fuel boilers vary considerably. As much as 30 percent of U.S. gas consumption may be switchable to other fuels with the lion's share being to oilprimarily residual fuel oil-in the electric utility and industrial sectors.

This potential fuel-switching response will be critical in determining gas prices under altemative conditions. When fuel choices are very sensitive to relative fuel price changes, gas prices will not change appreciably in response to shifts in supply or demand conditions because large swings in gas usage will be experienced. Under these conditions, oil prices will essentially be determining gas prices. On the other hand, if fuel switching is less extensive, shifts in supply or demand conditions could cause gas prices to rise or fall sharply, with oil and gas prices diverging from each other.

\section{Consumption (Demand)}

The future level of gas demand will depend on gas and other energy prices, economic and de- mographic growth, technological change, regulatory and environmental policy, and the adequacy of the gas transmission and distribution infrastructure. Variations in the projections of industrial demand are quite large by 2010 , ranging from a total of 4 Tcf to approximately $8 \mathrm{Tcf}$ in different models in the upper oil price scenario. Much of this variation stems from fuel switching and different assumptions about the penetration of new industrial gas-fired technologies. The range in the demand by electric utilities is also large-from 2.9 to $5.7 \mathrm{Tcf}$ by 2010 -depending upon assumptions about environmental regulations, fuel prices, and load growth.

Based on the averages of the model results, total gas use (Figure 4) ranges from 16 to 20 Tcf by 2000 and 15.5 to $21.5 \mathrm{Tcf}$ by 2010 . Total consumption averages $19.4 \mathrm{Tcf}$ in the upper oil price case by 2010 , ranging from 18.4 to $21.4 \mathrm{Tcf}$, depending upon the model.

In the low oil price scenario, total gas consumption in the various results falls by between 1 and 5 


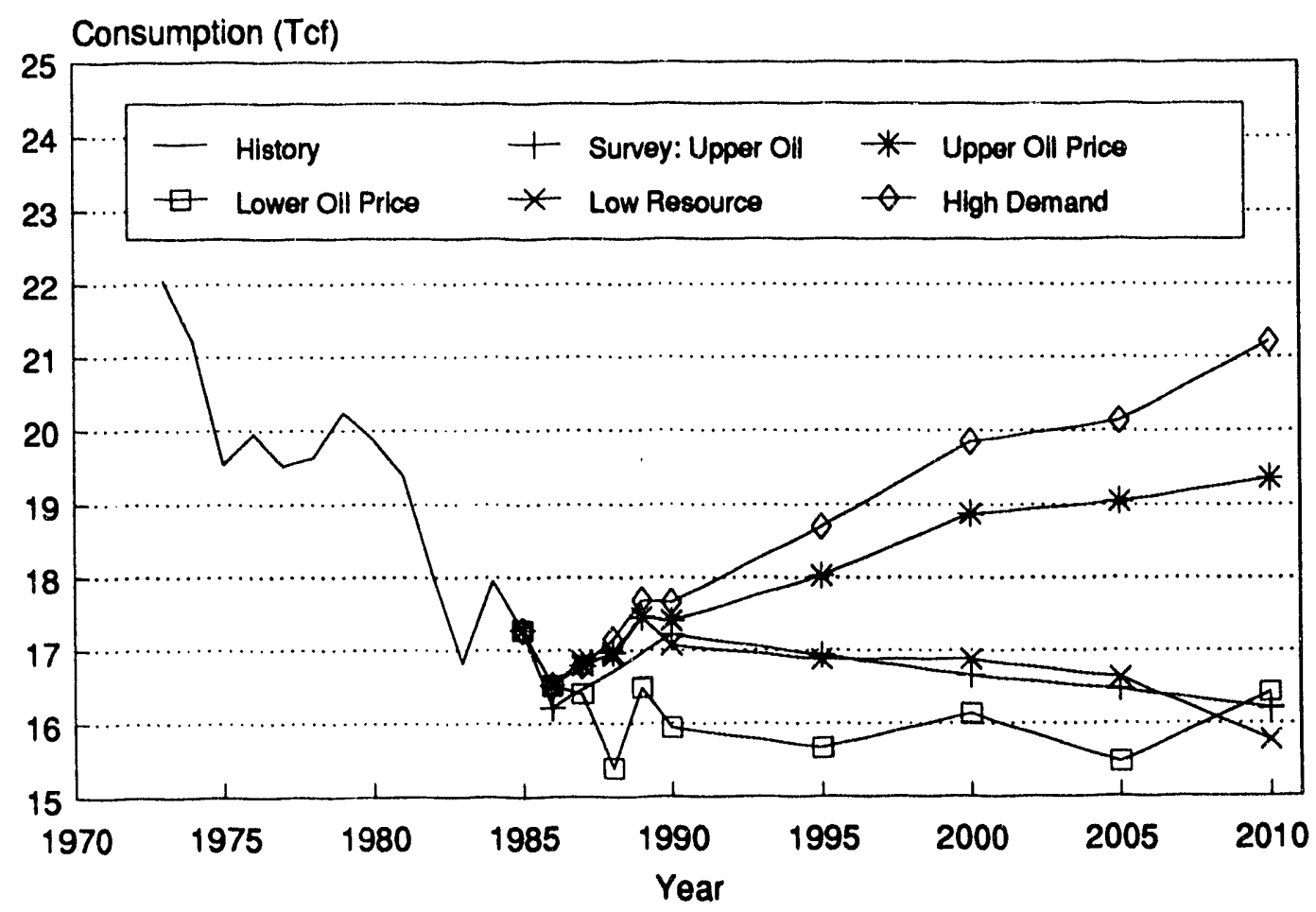

Figure 4: Model Means for Total U.S. Consumption by Scenario

Tcf by the year 2010 relative to the high oil price scenario, with an average decline of $2.9 \mathrm{Tcf}$. In the low resource case, total gas consumption falls by between 1 and 7 Tcf by the year 2010, with an average decline of $3.5 \mathrm{Tcf}$.

Natural gas consumption declines in both the lower oil price and low U.S. resource cases because gas becomes more expensive relative to residual fuel oil. Initially, a lower oil price causes gas users to switch to oil. Gas prices fall but not by as much as residual fuel oil prices, however, because lower gas prices reduce the incentives for gas production, making gas a scarcer, more valued fuel (relative to residual fuel oil) than before the decline in oil prices. In the low U.S. resource case, the available gas supplies are less than in the upper oil price at any given price level. In order to allocate the scarcer gas supply to higher valued uses, gas prices must rise even though oil prices remain unchanged in this scenario.

Much of the reduction in gas consumption in these two cases is due to industrial and electric utility users switching to oil. While not all lost gas consumption will be replaced by oil imports, the average declines are equivalent to 1.4 to 1.7 million barrels per day of oil use. These trends indicate increasing reliance on oil imports to replace gas. However, other indigenous fuels, e.g., coal, may also be substituted for gas.

The effect of an increase in gas demand in the electric utility sector is analyzed in the high demand scenario. Additional combined-cycle gas turbine capacity and an acid rain policy favoring gas use are assumed to augment potential gas demand in this scenario by $2.8 \mathrm{Tcf}$ by 2010 .

The model results indicate that higher demand levels by electric utilities can be sustained under these conditions, but gas prices must increase to bring forth the required gas supplies. The higher price encourages additional exploration and development of gas resources. It also reduces electric utility and industrial gas usage that competes with lower valued fuels (such as residual fuel oil) as well as gas consumption in other sectors. As a re- 
sult, the net increase in total consumption is considerably smaller than $2.8 \mathrm{Tcf}$-between 1.5 and $2.0 \mathrm{Tcf}$ by the year 2010. Increased U.S. domestic production in response to the higher gas prices accounts for most of the additional gas sold. Imports rise by less than 0.2 Tcf from their upper oil price case levels in most models, due partially to the upper bound of $2 \mathrm{Tcf}$ per year imposed on Canadian gas trade.

While gas prices in the high demand scenario are higher than those in the upper oil price scenario, gas continues to be competitive in the dual fuelburning boiler maiket in most models. In several models, where there is already price parity between natural gas and residual fuel oil, fuel switching by industrial customers prevents prices from rising much more with the higher demand.

\section{Supply}

The level and location of U.S. and Canadian gas production will depend on oil and gas prices, the two countries' resource bases, advances in exploration and production technology, the producer decisionmaking process, and pipeline availability to move domestic and imported supplies.

\section{Resource Base}

Future gas production depends on future reserve additions, which are influenced by future wellhead gas prices as well as by the size of the resource base. Recently, the Department of Energy (DOE) ${ }^{6}$ and the United States Geological Survey (USGS) and Minerals Management Service (MMS) of the

\footnotetext{
${ }^{6}$ Fisher, W.L., Finley, R.J., Seni, S.J., Ruppel, S.C., White, W.G., Ayers, W.B., Jr., Dutton, S.P., Kuuskraa, V.A., Mcfall, K.S., Godec, Michael, and Jcnnings, T.V., An Assessment of the Natural Gas Resource Base of the United States, The University of Texas at Austin (Bureau of Economic Geology), ICF-Lewin Energy Division (ICF, Inc.), and Argonne National Laboratory, report prepared for Office of Policy Planning and Analysis, U.S. Department of Energy, under contract no. 80622401,77 p., plus appendices (bound separately), 126 pp., May 1988.
}

Department of Interior (DOI) ${ }^{7}$ developed new U.S. gas resource estimates, which have generated some controversy.

Table 3 places the EMF scenario inputs in the context of the recent DOI and DOE estimates. The 1988 DOI estimate of unproven recoverable gas is 34 percent lower than its 1981 estimate-358 Tcf versus $670 \mathrm{Tcf}$-because (1) new discoveries since 1979 have caused some undiscovered resources to move into the proved reserves category, (2) drilling since 1979 has produced new geologic information that has reduced the estimated undiscovered resource in some basins, (3) DOI now uses a play methodology, as opposed to a volumetric approach, which reduces the amount of estimated undiscovered gas in some basins, (4) DOI is using a more explicit economic criterion in its current report for assessing how much gas may become recoverable, and (5) tight gas formations are explicitly excluded from the 1988 gas estimate.

The assessment of natural gas resources conducted for the U.S. Department of Energy also analyzed the major components of the natural gas supply, based upon existing resource estimates derived using established methodologies. This study found a technically recoverable resource base of 1059 trillion cubic feet of natural gas in the lower48 states, including proven reserves (Table 3).

In addition to the traditionally defined elements of the natural gas resource base, a new component-reserve growth from heterogeneous reservoirs-is quantified in the DOE study. Disaggregation of oil reserve addition figures ${ }^{8}$ has shown that most recent additions have been through reserve growth rather than new field discoveries. Despite the greater mobility of gas in the reservoir, the same factors of reservoir heterogeneity are believed to apply to gas. In the DOE study, a geological assessment of the gas reserve growth capacity

\footnotetext{
${ }^{7}$ U.S. Department of Interior, U.S. Geological Survey and Minerals Management Service, National Assessment of Undiscovered Conventional Oil and Gas Resources, USGS-MMS Working Paper, Open-File Report 88-373, May 1988.

${ }^{8}$ W.L. Fisher, "Can the U.S. Oil and Gas Resource Base Support Sustained Production?" Science, Vol. 236, pp. 16311636, 1987.
} 
Table 3: Estimates of the Recoverable Gas Resource

Trillion Cubic Feet

\begin{tabular}{|c|c|c|c|c|c|}
\hline PGC 1986 & & & & & \\
\hline $\begin{array}{l}\text { Most } \\
\text { Likely }\end{array}$ & $\begin{array}{c}\text { EMF } \\
\text { Contmol }\end{array}$ & EMF & $\begin{array}{c}\text { DOE } \\
1988\end{array}$ & $\begin{array}{l}1981 \\
\text { Mean }\end{array}$ & $\begin{array}{l}1988 \\
\text { Mean }\end{array}$ \\
\hline
\end{tabular}

\section{Undiscovered $^{b}$ \\ Lower-48 \\ Onshore \\ Off-shore \\ Total Lower-48 \\ Alaska, Total \\ Total Undiscovered}

\begin{tabular}{rrrrrr}
356.1 & 356.2 & 212.4 & 219.0 & 390.2 & 187.7 \\
109.9 & 116.9 & 61.4 & 134.0 & 102.4 & 74.0 \\
\hline 466.0 & 473.1 & 273.8 & 353.0 & 492.6 & 261.7 \\
109.8 & n. e. & n. e. & 93.0 & 101.2 & 2.4 \\
\hline 531.6 & & & 446.0 & 593.8 & 264.1
\end{tabular}

\section{Lower-48}

Undiscovered Conventional (From Above) Inferred/Probable

Unconventional at $\$ 5.00 / \mathrm{Mcf}$

Infill Drilling

Lower-48 Unproven

Proven Reserves

(end of 1986)

Unconventional above $\$ 5.00 / \mathrm{Mcf}$

\section{Total Resource}

\begin{tabular}{rrrrrr}
466.0 & 473.1 & 273.8 & 353.0 & 442.5 & 261.7 \\
153.6 & 153.6 & 113.8 & 108.0 & 171.9 & 95.8 \\
n. e. & 97.0 & 0.0 & 146.0 & n. e. & n. e. \\
n. e. & 50.0 & 44.0 & 180.0 & n. e. & n. e. \\
\hline 619.6 & 773.7 & 431.6 & 787.0 & 664.5 & 357.5 \\
158.9 & 158.9 & 158.9 & 158.9 & 158.9 & 158.9 \\
& & & & & \\
n. e. & 37.0 & 0.0 & 113.0 & n. e. & n. e. \\
\hline 778.5 & 969.6 & 590.5 & 1058.9 & 823.4 & 516.4
\end{tabular}

Table places EMF scenario inputs in the context of other resource estimates; it is not meant to be a rigorous comparison of estimates because: (1) economic assumptions are not the same across studies, and (2) some studies did not estimate all categories, resulting in their totais not being directly comparable.

n. e.-not estimatec. PGC and 1981 DOI estimates include some unconventional gas in undiscovered category; 1988 DOI estimates include little or no unconventional in this category.

'The 1988 Department of Interior (DOI) estimate was developed by the United States Geological Survey (USGS) and Minerals Management Service (MMS) using different methodologies, while the 1981 DOI estimate was developed by USGS.

'Potential Gas Committee (PGC) and Energy Modeling Forum (EMF) undiscovered includes possible and speculative resource only. PGC estimate includes some gas in tight formations. 
was made on a play-by-play analysis. The result is a reserve growth potential of $180 \mathrm{Tcf}$ through infill drilling when extrapolated across the full lower-48 onshore associated and nonassociated gas reserve base, including probable resources.

Estimates of gas volume from reserve growth are less sensitive to price because this gas exists in reservoirs already discovered. In addition, since most existing fields are already attached to existing pipeline systems, this gas will be fairly low cost to bring to market, if the cost estimates for reserve growth are correct.

As shown in Table 3, the EMF low resource scenario for the lower-48 gas resource base falls close to the new DOI estimate. Moreover, the EMF estimate of $774 \mathrm{Tcf}$ of unproven natural gas resources (plus $159 \mathrm{Tcf}$ of proved reserves, totaling $933 \mathrm{Tcf}$ ) for the other scenarios is close to the DOE estimate of $946 \mathrm{Tcf}$ of technically recoverable natural gas resources available in the lower-48 states. $^{9}$ Thus, the EMF cases provide a reasonable range of estimates for those who want to analyze the impacts of variations in the resource base.

\section{Gas Costs}

The costs of proving and producing reserves are as important as the extent of resources in place for determining gas supply and price. There is wide disagreement, however, over what these costs will be in different producing regions.

Costs to find, develop, and produce the gas resource are critically affected by field size, location, geologic setting, and depth of occurrence. Assumptions about these factors and the way these assumptions are implemented affect the relationships between future gas supplies and wellhead gas prices (the supply curves) represented in a model. The model results emphasize that these costs are at least as important as geologic estimates of the extent of the resource base in physical terms in de-

\footnotetext{
${ }^{9}$ This number does not include unconventional gas economic above $\$ 5.00$ per thousand cubic feet (Mcf). The addition of this category would bring the DOE total to the 1059 Tcf shown in Table 3.
}

termining gas supply. However, since most published resource estimates are given in terms of the ultimate resources yet to be discovered, market analysts must translate the published estimates into a form usable for their analyses.

As a result, despite standardizing on oil price and the physical magnitude of the resource base in this study, there were substantial differences in incremental resource costs among the models. Modclers using the same aggregate resource base are generally not using the same supply curve relating future production to prices. More optimism about supply costs leads to lower market-clearing prices and higher consumption; less optimism about these costs results in higher market-clearing prices and lower consumption. In addition, important differences in interpretation of the low resource scena io were discovered. One expert may believe that a more pessimistic resource outlook means less highcost gas but little change in the amount of low-cost gas. To another, a lower resource base may mean less gas for all cost categories. Gas production and prices generally change more between the two resource scenari os when the gas resources for all cost categories are reduced proportionately than when only the high-cost gas resource is reduced.

\section{Gas Production}

Based on the average model results, changes in oil prices, the level of the resource base, and gas demand cause marketed U.S. gas production to range from 14 to 18 trillion cubic feet (Tcf) by 2000 and from 12 to $19 \mathrm{Tcf}$ by 2010 across the four scenarios. Despite this wide range, gas production remains below $19 \mathrm{Tcf}$ in all scenarios through 2010 (Figure 5), or several Tcf below its historical peak of 21.7 Tcf in 1973. Substantially higher wellhead gas prices are required to keep gas production at the upper end of this range. Generally, the models indicate that while gas supplies are definitely responsive to price, the percentage increase in marketed production is less than the percentage increase in the wellhead gas price. 


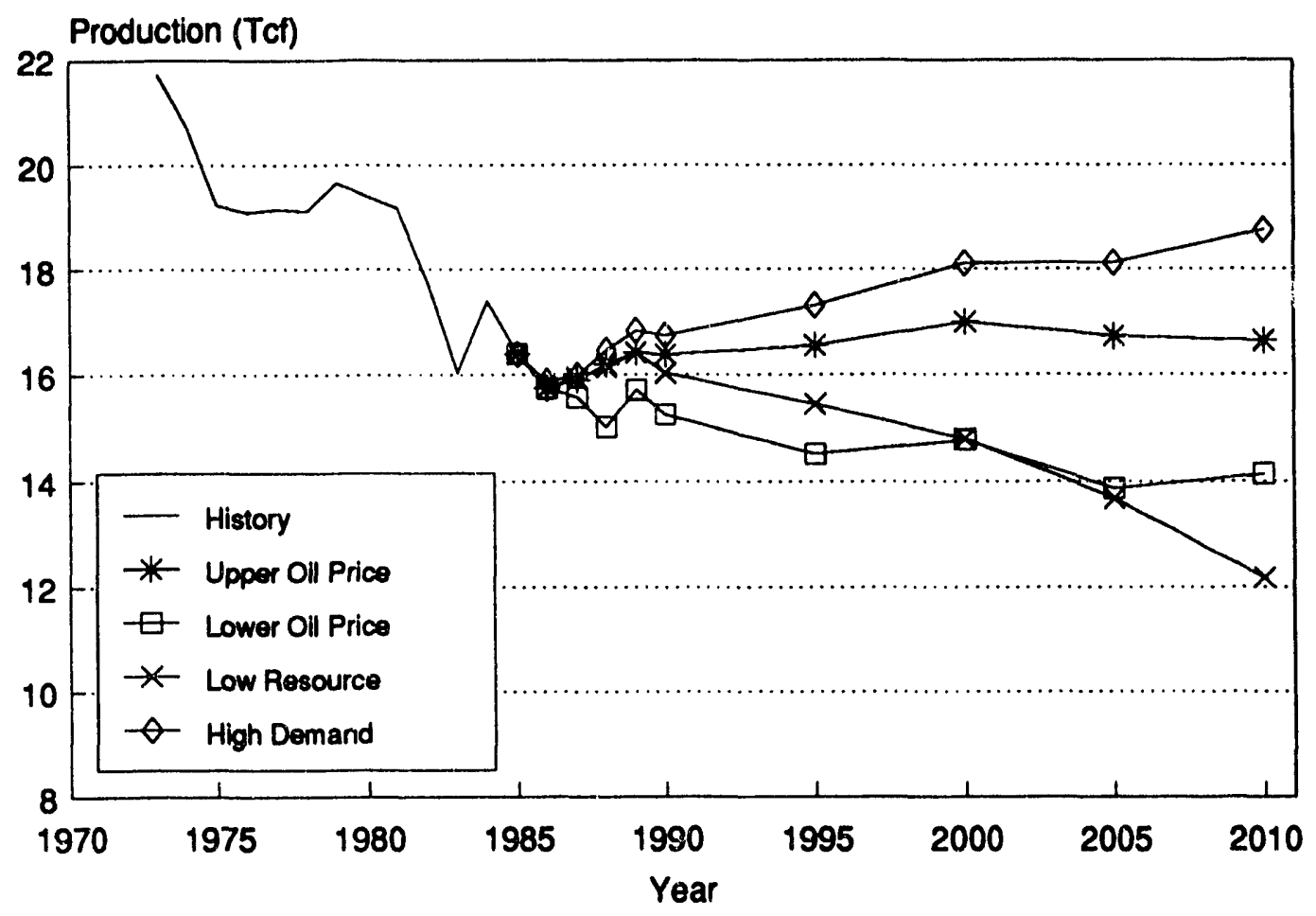

Figure 5: Model Means for U.S. Marketed Production (Dry Gas) by Scenario

Marketed production in the United States remains relatively stable at about 16 to $17 \mathrm{Tcf}$ in the upper price scenario, as shown in Figure 5. Both the lower oil price and the low resource conditions result in declines in U.S. gas production relative to the upper oil price scenario. Production, on average, is $2.5 \mathrm{Tcf}$ lower in 2010 in the lower oil price case and 4.5 Tcf lower in 2010 in the low resource case.

Production declines in the lower oil price case because falling gas prices reduce drilling and exploration incentives. It falls in the lower U.S. resource case because it becomes more costly to find and develop the same volume of gas as in the upper oil price case. As gas prices rise in this scenario, consumers demand less than before, resulting in lower levels of production and consumption.

A survey of industry forecasts was also compiled and averaged. Figure 6 shows that the EMF industry survey's average estimate for U.S. dry gas production with the upper oil price assumptions lies much more in line with the EMF model results for the low U.S. resource scenario through 2000. By 2010, the average survey estimate lies between the average EMF results from the upper oil price and low U.S. resource cases, but closer to the latter. The lower estimates from the survey respondents can be attributed to one or more of the following factors: a lower resource base estimate than in the EMF control resource inputs, less future spending for oil and gas drilling, and higher costs for finding and developing natural gas. For the lower price case (Figure 7), the survey respondents show less production than the modelers, the average being 15 percent lower in 2000 and about 30 percent lower in 2010.

\section{Gas Imports}

U.S. gas imports rise in all scenarios (Figure 8), reflecting the need to supplement stable or declining domestic production in meeting U.S. demand at the projected prices. In most scenarios, total U.S. gas imports reach an average of 2 Tcf or more by 2010 


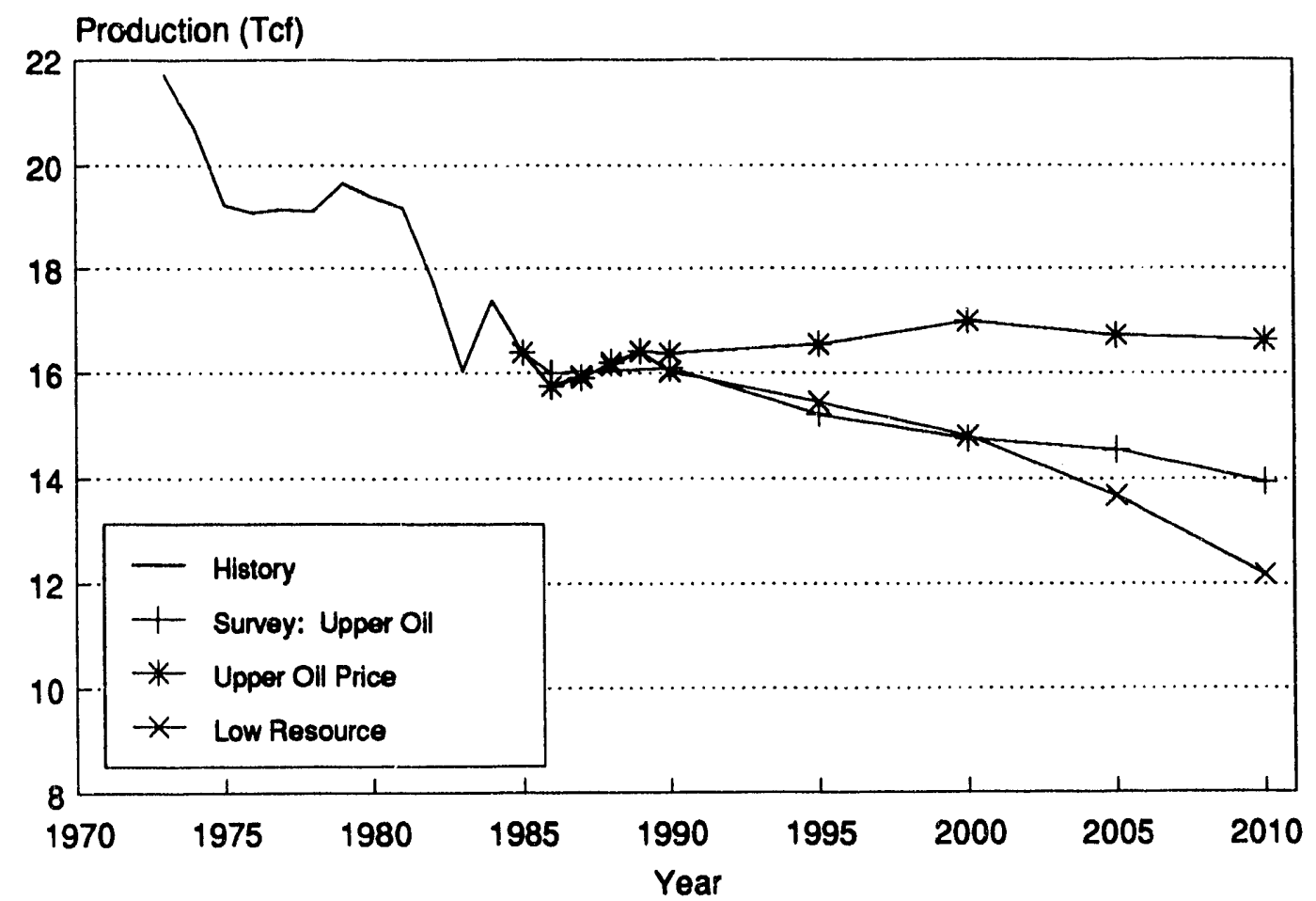

Figure 6: U.S. Marketed Production in Industry Survey and EMF Results with Upper Oil Price Path

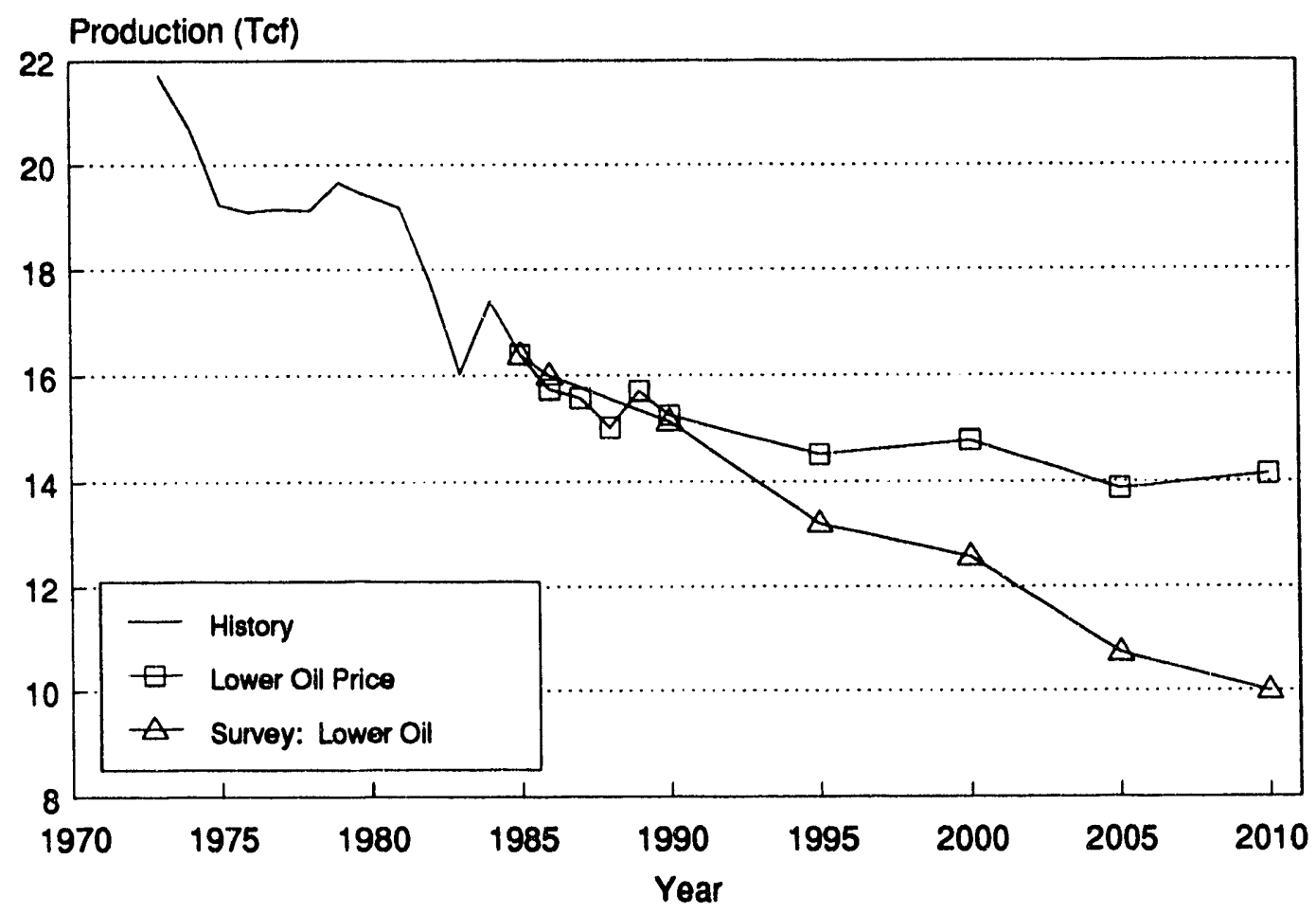

Figure 7: U.S. Marketed Production in Industry Survey and EMF Results with Lower Oil Price Path 


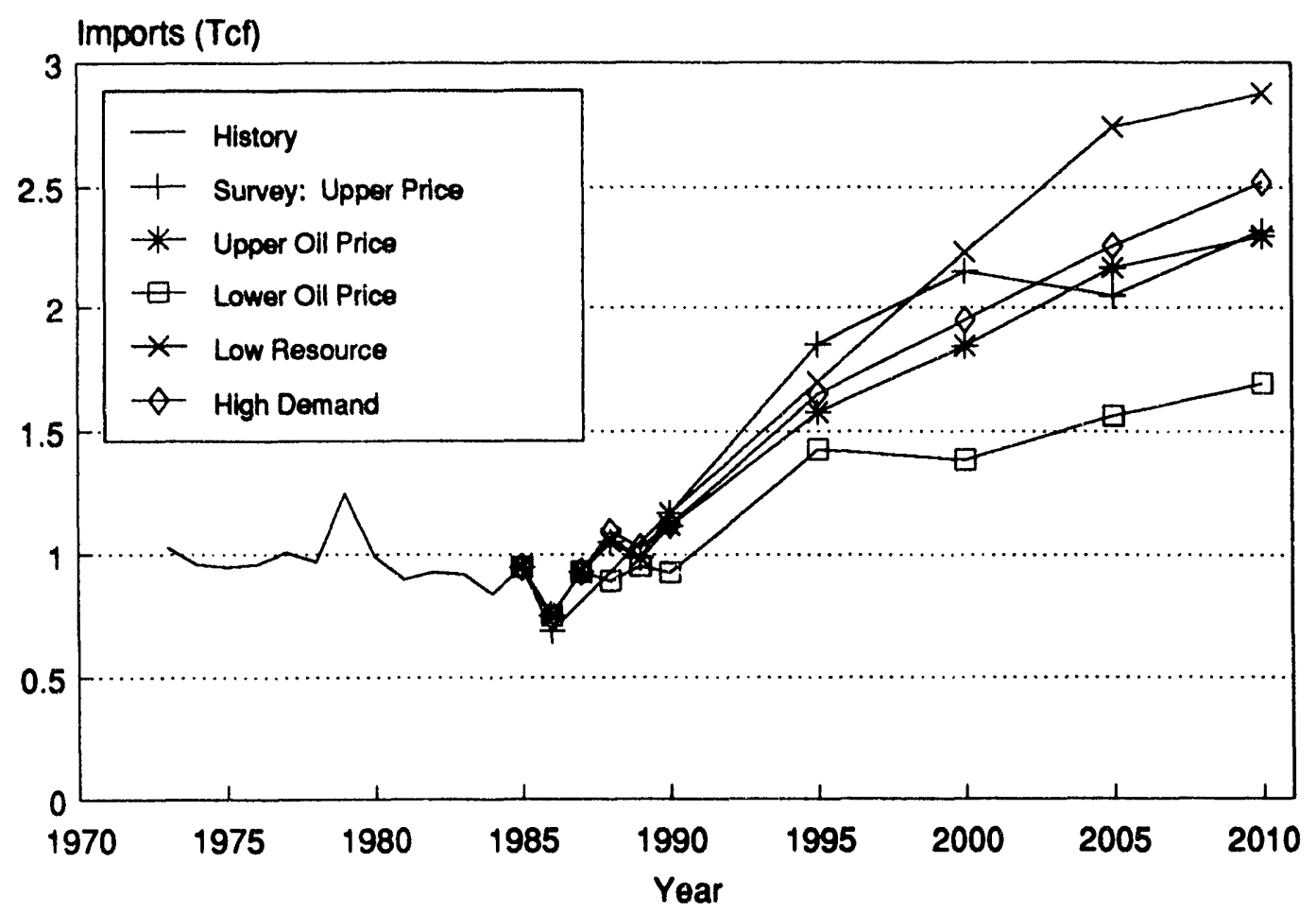

Figure 8: Model Means for Total U.S. Imports by Scenario

compared to about 1 Tcf in 1987. The import share of total consumption is higher under the low U.S. resource and high U.S. demand cases. Most of the imports are from Canada, but some of the models also include large amounts of liquefied natural gas (LNG) or Mexican gas.

Imports become more important in the low resource case. They rise to $2.5 \mathrm{Tcf}$ by 2000 and 3.0 Tcf by 2010 , increasing the import share from about 5 percent to 15-20 percent of total U.S. consumption. In the other cases, the import share rises steadily to about 10 to 15 percent of the U.S. market in this case.

To sustain Canadian gas export levels at 2 trillion cubic feet in the upper oil price case, Canadian frontier and unconventional supplies need to be developed in a timely manner for delivery after the turn of the century. Under the low oil price conditions, Canadian gas exports to the United States are likely to remain below 2 trillion cubic feet since inadequate incentives exist to maintain Canadian production and develop new transmission facilities to the United States.

The response of Canadian gas exports to different U.S. market conditions underscores the value of considering the North American gas industry as an integrated market. Many U.S. projections do not incorporate the feedbacks between Canadian and U.S. markets. In this study, Canadian gas exports are generally less in the Canadian and North American models, which incorporate these interactions, than in the U.S. models for most scenarios. These differences are particularly pronounced for the low oil price case (Figure 9).

\section{Regulation}

The U.S. gas industry has been highly regulated and the regulators' decisions have often interfered with market forces. Virtually unregulated at its beginning, the gas industry became increasingly regulated from the 1930s through the 1970s with regard to supply, demand, price, and entry. Since the 


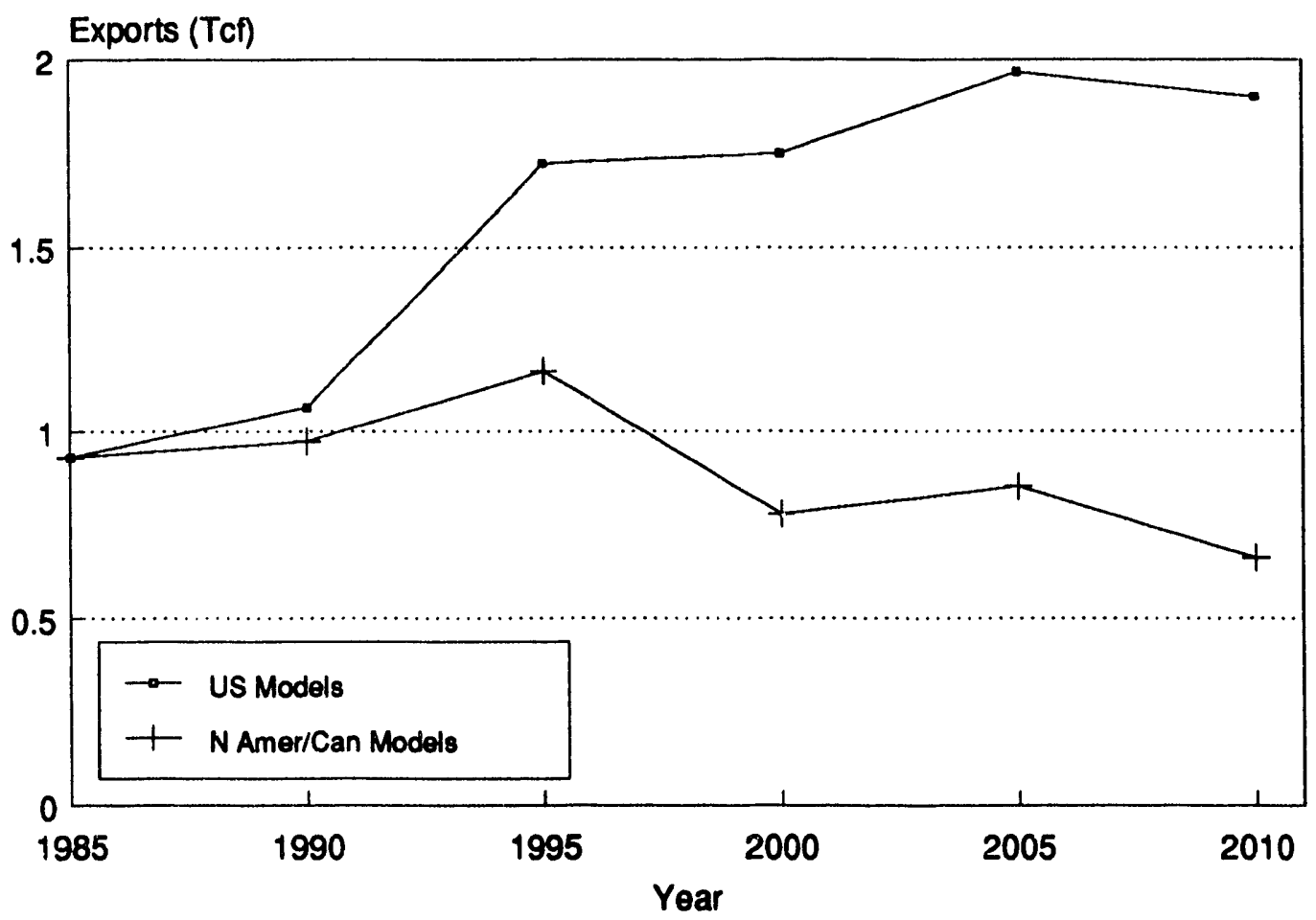

Figure 9: Total Canadian Exports in Lower Oil Price Scenario for U.S. Models and for North American/Canadian Models

late 1970 s, the trend has been toward deregulation in the more competitive aspects of the industry, primarily wellhead gas sales, pipeline transportation, and end-user/local distribution company (LDC) gas supply.

A key to this pro-competitive shift is the unbundling of pipeline and LDC services, allowing market forces to guide the allocation of goods and services. Most important is the separation of gas sales from transportation, encouraged by partial wellhead decontrol and increasingly open access to interstate pipeline transportation. The two major regulatory issues facing the gas industry are:

1. how best to complete the process of unbundling gas sales and transportation service, assuming political support for pro-competitive policies continues to prevail, and

2. under what conditions to place a higher priority on regulatory objectives other than economic efficiency.

\section{Key Issues in Completing the Process of Un- bundling}

While much progress has been made, a number of regulatory issues must be addressed in order to complete the unbundling of pipeline and LDC services:

\section{Pipeline-FERC Issues}

1. Implementation of pipeline open accessThe Federal Energy Regulatory Commission $(F E R C)$, in Orders 436 and 500, facilitated the unbundling of services in the interstate gas market, but difficulties in resolving takeor-pay concerns have slowed the transition to a more competitive market.

2. Pipeline rate structure-Even though many pipeline services will be unbundled, they will remain regulated. The rate structures used by regulators to price those services will have a significant impact on the efficiency of the 
evolving market, on the allocation of different types of service, and on the interplay of regulated and unregulated services.

3. Pipeline service obligation-Part of the tradition of public utility regulation in the pipeline industry has been that pipelines, in exchange for monopoly privileges in a particular market, are not allowed to unilaterally reduce the level of service provided once they are officially certificated. FERC Orders 380 and 500 have reduced the obligation of local distribution companies (LDCs) to purchase gas from pipelines, but have left pipelines with the obligation to remain ready to meet the original contract demand levels of their LDC customers. A method of compensating pipelines for this responsibility must be found if pipelines are to remain reliable gas suppliers.

4. Economic allocation of pipeline capacity-A key aspect of pipeline rates is how they allocate pipeline capacity, especially during peak periods. On an annual basis, there is considerable excess capacity in the U.S. pipeline system as a whole, but in some segments bottlenecks exist during peak pcriods. Allocat ing capacity on these segments on an economic basis, e.g. through the usc of a secondary market in capacity rights, will increase the likelihood that gas is used by those who value the space most and may provide a clearer indication of where additional pipeline capacity is needed.

5. New pipeline entry-Proposals to build new pipelines must currently move through a lengthy regulatory process. Improvements to the approval process are needed to enhance the responsiveness of the pipeline network to changes in supply and demand, while reconciling gas needs with environmental concems and property rights.

\section{Local Gas Distribution Company (LDC)- Public Utility Commission (PUC) Issues}

6. LDC open access with unbundling-In response to the unbundling of pipeline service initiated by the FERC, many state public utility commissions (PUCs) are requiring utilities to offer transportation through their system on an unbundled basis. As at the pipeline level, open access at the LDC level must be reconciled with the LDC's obligation to serve, particularly in the case of large industrial customers, for whom an obligation to provide gas sales service may no longer be appropriate.

7. LDC bypass-Under current utility rate structures, some industrial customers find it desirable to build their own direct link to the pipeline system rather than go through their local utility. More competitive utility rate structures or legal restrictions on bypass will reduce the tendency of industrial customers to connect directly to pipelines. PUC decisions in this area are likely to be important as the gas industry evolves.

8. LDC marketing/growth policy-Historically, many PUCs, concerned about possible gas shortages resulting from wellhead price controls, have impeded the attempts of utilities to market gas service to new customers. With a largely deregulated wellhead market allowed to balance supply and demand, such policies need rethinking.

9. PUC oversight of LDC contracts-As the spot market has grown, PUCs and state legislatures have imposed a plethora of new regulations affecting gas purchasing decisions of local gas utilities. These policies are designed to encourage their gas utilities to choose a mix of long-term contracts and spot-market purchases that will ensure supply reliability and price stability at the lowest possible cost to consumers. 


\section{Regulations Affecting Canadian Natural Gas Exports}

10. Canadian export policy-In 1987 the National Energy Board replaced its surplus determination formula for natural gas exports with a "Market-Based Procedure." This procedure has two main objectives. First, Canadians should have access to Canadian gas on terms and conditions similar to those of the proposed export (for comparable service). Second, the proposed exports should not cause Canadians difficulty in meeting their energy needs at fair-market prices. The operation of this new framework will unfold in forthcoming export applications. In addition to Canadian policies, U.S. pipeline regulations and tariffs will continue to influence the amount of Canadian gas exported to the United States.

\section{Regulatory Policy Stability and Market Conditions}

Under some scenarios, regulators may face strong political pressure to overturn some pro-competitive policies. Some of the factors which may prompt regulators to place greater priority on objectives other than economic efficiency are described below.

If delivered gas prices fall and stay below parity with delivered oil product prices, policymakers might face political pressures to raise bumertip gas prices to industrial customers with dual-fuel capability, and use the additional revenue to subsidize residential customers. Such cross-subsidization, however, will be possible only if industrial gas customers are restricted from buying their own gas and transporting it through the utility, or from bypassing the utility altogether.

If gas prices increase sharply, regulators may face pressure to ensure that high-priority customers (e.g., residential customers, hospitals, schools, etc.) receive the supplies they nced at "just and reasonable" prices. In essence, such a strategy implies price controls for high-priority customers and cross-subsidization by lower-priority customers. In addition, a PUC my choose to disallow the recovery of some gas costs if the utility's average cost of gas rises too high. The frequent price renegotiation required under most new long-term contracts may protect LDCs from some retroactive disallowances, but there is nothing to prevent PUCs from later arguing that LDCs should have locked in low prices when the market bottomed out.

Lastly, with additional gas demand, capacity bottlenecks might become increasingly tight, leading to price increases on these segments. Regulators, seeking to protect high-priority customers, mighi abandon an economic system for allocating capacity and adopt fixed priorities for particular customer classes.

If industry participants believe that regulatory policies are unpredictable and may be reversed, they may respond to this uncertainty by reducing investment in gas-using capital equipment, new pipeline capacity, new gas wells, and computerized systems to cut costs in gas trading and transportation.

\section{Natural Gas Modeling}

The models used in the study were particularly helpful in organizing information about various segments of the industry into a coherent and consistent picture of the natural gas market. For example, in a competitive environment, the underlying U.S. resource base and supply conditions will affect the oil-gas pricing relationship, which will, in turn, alter overall gas demand levels and the incentives for Canadian producers to export gas. Such relationships are often difficult to follow and analyze fully without the use of a formal framework. Such use of models helped to focus the working group's discussion on the critical issues and quantify their relative importance (e.g., the relationship between oil and gas prices, the interaction between Canadian and U.S. markets, the implications of a lower resource base, and the effects of increased gas demand).

In general, the models assume competitive behavior; producers and consumers respond to price, 
Table 4: Natural Gas Models Used in EMF 9

Model

Group A:

AGAS

GRI North American (GRI N A)

Gas Trade Model (GTM)

MIT North American (MIT)

Rowse

\section{Group B:}

Gas Analysis Modeling System (GAMS)

GRI Hydrocarbon (GRI Hydro)

ICF Gas Market Evaluation System (ICF)

Lewin Natural Gas Model (LEWIN)

NEB Energy Demand/Gas Supply Models (NEB)

A.G.A.-TERA (TERA)
Alberta Research Council

Decision Focus, Inc.

Stanford University

Massachusetts Institute of Technology

University of Calgary
North America

North America

North America

Canada

Canada

Abbreviation of model name used in this report is shown in parentheses.

and prices adjust with shifts in supply and demand conditions. Many of the models used in the study, however, did not incorporate the regulatory environment explicitly in their frameworks.

While the models used in this study have a similar focus, they form a heterogeneous group. Those listed under Group A in Table 4 were developed primarily to study the interdependence of supply-demand balances in many different regional markets. Rather than using detailed submodels to describe drilling activities and finding rates by resource category, these models represent supply conditions as reduced-form relationships linking gas production to gas prices. These relationships are often based upon more detailed studies of the resource base and production activities. Similar reduced-form relationships are used to describe consumption as a function of price. The models focus their analyses on how gas produced in a sup- ply region is allocated to demand regions on the basis of competitive economic conditions. These models are particularly well suited for nalyzing future regional gas flows if the industry is workably competitive at all levels.

The models in Group B devote considerably more attention to studying the specific relationships governing supply and demand decisions in the market. They generally employ engincering-economic relationships to describe these interactions. The demand submodels usually represent residential and commercial consumption decisions with statistical equations, while using detailed submodels representing different technologies and processes to simulate industrial and electric utility decisions. These models were generally constructed for detailed studies of the economic and technical factors influencing supply and demand decisions. They were not developed primarily to an- 
alyze how regional gas flows would be allocated based upon competitive economic conditions, even though all but one were used in this study to determine market-clearing prices equating the quantity supplied to that demanded.

Methodology accounts for only a portion of the variation among model results. Different perspectives about fundamental gas supply, demand, and pricing relationships are also important explanations for why model results vary.

Both groups of modelers potentially can learn much from each other. Additional physical realities, such as leasing, exploration, development, and the production cycle, could be usefully incorporated in economic models focusing on regional supply-demand interactions. Additional economic realities of regional competition for gas flows could be usefully incorporated in engineering-economic models that represent supply and demand decisions in considerable detail.

Many of the models used in this study were originally developed to reflect a long-term, workably competitive natural gas market. Most of the models did not directly incorporate regulatory behavior in their structures, nor did they explicitly link transmission and distribution margins to changes in market forces. As the gas market develops, it will be important to better reflect within the model frameworks the increasing integration of the U.S. and Canadian gas markets, interregional competition within each country, impacts of regulatory behavior, technological changes in gas supply and demand, altemative natural gas resource base estimates, transmission and distribution margin development, price volatility, environmental regulations, and short-run dynamics. Devcloping better analyses of these factors will improve decisionmaking and represents an important challenge.

\section{Further Research}

During the study, the group identified several natural gas industry issues, listed in Table 5, that required additional research. Some of the topics require theoretical analyses (e.g., effects of regulatory decisionmaking on the gas industry's structure and behavior, and gas price volatility) before they can be modeled. Other issues that are understood theoretically require more accurate data (shape of the gas demand curve and fucl switching) to improve the analysis. Several analysts have already begun work on some of these issues. Nevertheless, further resolution of these uncertainties is needed. A better understanding of these issues, both theoretical and quantitative, will improve analyses and decisionmaking within the gas industry at all levels-regulatory, producer, distributor, pipeline, and end-user. 
Table 5: Issues Identified by the EMF 9 North American Natural Gas Working Group as Requiring More Analyses

1. Modeling of Regulations

2. Transportation and Distribution Rates

3. Regional Wellhead Price Differentials

4. Interaction of Canadian and U.S. Gas Markets

5. Price Volatility and Seasonality

6. Shapes of Gas Supply and Demand Curves

7. Potential Fuel Switching

8. Gas Conservation

9. Effect of Electric Utility Deregulation on Natural Gas Use

10. Impact on Natural Gas Use of Advanced Gas/Non-Gas Technologies

11. Potential for Natural Gas as a Transportation Fuel

12. Supplemental Gas Supplies (e.g., LNG, Alaska, Canadian, Frontier, etc.)

13. U.S. and Canadian Resource Bases

14. Effects of Advanced Gas Drilling and Production Techniques

15. Effect of Environmental Regulations on Gas/Oil Drilling and Production

16. Pipeline and Storage Capacities 


\section{Working Group Report}




\section{Chapter 1}

\section{Introduction}

\section{Background}

A dozen years ago, the United States was in the throes of a severe natural gas shortage. Moratoria on new customers were instituted and large customers had their gas service curtailed. Prices were set under long-term contracts, which were subject to regulation from the field to the burnertip. ${ }^{1}$ In this environment, frequent reference was made to natural gas being a "premium" fuel that in an unregulated market could attract a price above that of distillate fucl oil, reflecting its cleaner-burning properties.

Gas market conditions are dramatically different today. The gas-producing industry has been mired in excess deliverability for several years. Both U.S. and Canadian producers are aggressively searching for new markets for their surplus gas, while consumers are enjoying the benefits of lower prices. Many long-term contracts with fixed prices have been renegotiated to incorporate market-responsive pricing and many have been replaced by shorter-term contracts and spotmarket sales. More than half of today's annual gas sales are spot-market transactions. The regulatory policy debate has shifted from an emphasis on the security of supply to the deregulation of field prices and then to the issues of access to and the allocation of pipeline capacity. Gas prices are being set by gas-to-gas competition, which has lead to burnertip gas prices falling below residual fuel oil prices.

\footnotetext{
${ }^{1}$ Italics indicate the first use of words or phrases listed and defined in the Appendix.
}

This shift in market conditions from one constrained by regulations to one relying more upon market forces emphasizes the uncertainty about this industry's future evolution. What will this market look like through the 1990s and beyond? Will excess deliverability continue? Will the pricing of natural gas revolve around the switchable end-use market comprised of large industrial and electric utility users with dual fuel-buming capacity? Or will natural gas and residual fuel oil prices diverge under certain conditions? How will the regulatory environment resolve such issues as open access to the nation's gas transmission system?

The last dozen years underscore the uncertainty about how the North American natural gas market will evolve through the end of this century and beyond. In addition, divergent opinions exist among experts on such critical issues as resource availability, end-use demands, the proper regulatory climate, and pricing. The range of possible outcomes in this market motivated the current $E_{n}$ ergy Modeling Forum study focusing on the future of the North American natural gas market.

\section{The Energy Modeling Forum Work- ing Group}

This report summarizes the research of an Energy Modeling Forum working group that analyzed how the North American natural gas market will evolve over the next 25 years. This working group comprised leading natural gas analysts in govemment, industry, universities, and research and consulting 
organizations. Members of the group are listed at the beginning of this report. In conducting this analysis, the group pursued two broad goals. First, it sought to develop insights about the industry's performance under a range of different environments by using computer models and additional analyses. And second, it sought to evaluate the existing analytical approaches available for understanding this industry and discuss their strengths and limitations.

The findings depend partially upon a set of computer models that have been used previously to analyze natural gas markets. The results from these models were used to guids the group's thinking about key market relationships and to identify important differences of opinion about future outcomes. While many of these conclusions result from the use of these models, they do not represent an uncritical acceptance of numerical outputs. In many instances, the conclusions of the study were developed by comparing and contrasting model results with perspectives of participating experts who were not modelers.

The group also relied upon other research that was not tied to any explicit modeling of the natural gas industry. Although certain gas supply and many regulatory policy and market structure issues were not amenable to analysis by the existing models, they were considered important enough to warrant further probing. In these cases, a member or group of members conducted special analysis of the issue, emphasizing how it might affect the industry's evolution.

\section{The Use of Models}

The models used in the study were particularly helpful in organizing information about various segments of the industry into a coherent and consistent picture of a total market for natural gas. For example, in the current competitive environment, the underlying U.S. resource base and supply conditions will affect the oil-gas pricing relationship and will alter the incentives for Canadian producers to export gas. Such relationships are often difficult to follow and analyze fully without the use of some formal framework. The use of these models also helped to focus the working group's discussion of several critical relationships: the relationship between oil and gas prices, the interaction between Canadian and U.S. markets, and the implications of a lower resource base and increased gas demand on the market. By using them in this study, the group was able to focus its discussions on these issues and to quantify their relative importance.

The models used in the study focus on the supply and demand response to changes in prices and other economic, technological, and geologic conditions. Most of the models assume competitive market conditions and do not explicitly incorporate the regulatory environment that exists in the industry. As already noted, a separate study group was formed to analyze how changes in the regulatory environment might evolve and affect gas markets.

The group emphasized conclusions based upon all or most of the models. In the course of the analysis, interesting differences were discovered that often reflected alternative views of important gas market relationships and altemative ways of modeling these relationships. The group probed these differences and their implications for the gas market.

\section{Scenarios}

Although models are often used to develop projections to represent the "most likely" market conditions, the working group has not attempted to define such a case in this study. Given the uncertainty about the future development of the North American natural gas market, the group found it most valuable to use the models to develop insights about very different conditions. In this study, the working group considered four standardized cases that examined the effects of different resource bases, oil price paths, and new potenuial sources of gas demand on the natural gas market.

The working group designed four scenarios: upper and lower oil prices, a low U.S. natural gas 
resource base, and a high U.S. demand case. The two oil price scenarios are based upon price paths analyzed in a National Petroleum Council (NPC) study ${ }^{2}$ on the oil and gas markets. The upper oil price path range: from $\$ 15$ per barrel in 1986 to $\$ 36$ in 2000 and $\$ 44$ in 2010 , while the lower oil price path rises to $\$ 21$ in 2000 and $\$ 26$ in 2010. (All prices in this report are in 1986 dollars unless noted otherwise.) The two oil price cases incorporate the same U.S. natural gas resource base assumptions, using the 1986 Potential Gas Committee's most likely estimate for conventional undiscovered resources, with supplemental estimates provided by the EMF working group for additional discoveries through infill drilling and unconventional gas resources. Gas exports from Canada to the United States are capped at 2 trillion cubic feet ( $T c f)$, reflecting the working group's assessment of maximum economic export capacity between the two countries. Using the upper oil price path, the group also investigated the effects of a lower U.S. resource base (low U.S. resource case) and increased potential gas demand for electric generation (high U.S. demand case).

\section{Plan of the Report}

After a brief chapter on the history of natural gas markets, this report discusses critical future issues in supply, demand, prices, and regulation. This discussion provides a conceptual framework for reviewing the quantitative results from the models. Chapter 4 analyzes extensively the findings based on the model results. Particular attention is devoted to developing key conclusions common to all models and drawing the implications of differences among models on key issues. Chapter 5 reviews the key regulatory and market structure issues that need to be resolved if the gas industry is to continue becoming more competitive. Chapter 6 discusses the principal findings from the re-

\footnotetext{
${ }^{2}$ National Petroleum Council, Factors Affecting US. Oil and Gas Oullook. Washington, D.C.. 1987. The EMF working group extended the NPC trends, which ended : 12000 , through 2010.
}

search conducted on supply issues that were not amenable to formal modeling. The last chapter suggests additional issues that should be addressed either through modeling or detailed analysis. ${ }^{3}$

\footnotetext{
${ }^{3}$ Supporting technical papers will appear in a forthcoming Volume 3.
} 


\section{Chapter 2}

\section{History of Natural Gas Markets and Regulation}

Although the study rocuses on the dynamics of the North American natural gas markets, a historical perspective to the transition in U.S. natural gas markets and regulatory policy is useful. This chapter begins with a review of the effects of regulation on the U.S. gas market, mentioning some changes in Cunadicn regulation as well. ${ }^{1}$ The appendix to tius chapter reviews the overall U.S. gas supply and demand conditions since 1950.

The U.S. natural gas industry has followed a course from being unregulated to almost fully regulated to partially deregulated at the wellhead. Virtually unregulated at first, the gas industry became increasingly $r$ gulated from the 1930 s through the 1970 s with segard to supply, demand, price, and entry. In this decarie. the trend has been toward deregulation in the more competitive aspects of the industry, primarily wellhead gas sales, pipeline transportation, and end-users/distributor gas supply.

\section{Early Developments}

From its beginning in the 1850 s until the 1930 s, the natural gas industry was generally confined to the gas-producing regions of the U.S. Southwest since no reliable or inexpensive means to transport gas over great distances existed. Advances in high-

\footnotetext{
${ }^{1}$ Readers familiar with this background information may want to proceed directly to the next chapter.
}

pressure pipeline technology in the 1930s allowed the development of a national pipeline grid system.

Until the 1930s, the gas industry was vertically integrated; large holding companies controlled production, transmission, and local distribution thmughout the country. State regnlatory commissions were set up in the early part of the century to monitor the activities of the local distribution companies (LDCs) and other public utilities. They had only limited regulatory powers over the services and rates offered by these interstate holding companies.

In response to a Federal Trade Commission report contending that a small number of companies dominated the transportation of natural gas, Congress passed the Natural Gas Act of 1938 (NGA). Specifically, the NGA gave the Federal Power Commission (FPC) authority to regulate the sales for resale and interstate transportation of natural gas. (The FPC was succeeded by the Federal Energy Regulatory Commission (FERC) in 1977.) FPC approval was also necessary for the extension and abandonment of service and facilities. The FPC was further empowered to grant certificates of "public convenience and necessity" for all new jurisdictional pipeline construction. The NGA specifically excluded from federal regulation gas production and gathering, intrastate activities, 10cal gas distribution, and pipelines' direct sales to end-users. Initially, the Act was not interpreted to cover wellhead prices. 
The Public Utility Holding Company Act of 1935 forced holding companies to sell their pipelines. These pipelines became private carriers, or gas merchants, generally buying gas at the wellhead from producers and selling it to LDCs. The merchant function of the pipelines was to aggregate long-term gas supplies for their customers. The FPC required that pipelines have long-term gas supply contracts and it reviewed and approved long-term contracts with their gas utility customers. Both kinds of contracts contained minimum purchase provisions, called take-or-pay, in producerpipeline contracts and minimum bills in pipelineLDC contracts. These developments created the traditional natural gas supply chain of offsetting obligations from producer to pipeline to LDC, with the pipelines and LDCs owning the gas flowing through their systems.

\section{Emergence of Wellhead Price Con- trols}

In 1954, the U.S. Supreme Court, in Phillips Petroleuin Company vs. Wisconsin, held that interstate sales taking place after the gathering or production function constituted a sale for resale requiring FPC regulation. This ruling initiated a long series of decisions that set wellhead gas prices for interstate sales. The decision also set up two markets for natural gas at the wellhead: the regulated interstate market (between states) and the unregulated intrastate market (within a producing state).

Due to the Phillips decision, the FPC set ceiling prices for wellhead gas. Initially, the FPC tried to develop wellhead prices by producer on a cost-ofservice basis. However, given the large number of producers in the United States, this proved unmanageable. In 1960, the FPC moved to an "area rate" methodology in which uniform ceiling prices were set for all gas produced in a geographic area. The methodology was based on average production costs and other costs incurred by local producers. A two-tier pricing system developed: old (existing) gas and new gas. The higher new-gas price was designed to offer producers incentives to continue exploration.

As already noted, the FPC had no control over wellhead prices in the intrastate gas market (e.g., within Texas, Louisiana, and other producing states). Under the dual market system, gas prices in the intrastate market rose well above gas prices in interstate markets during the 1970 s. Consequently, producers increasingly dedicated their supplies to the intrastate market, where they commanded higher prices. This caused interstate supplies to dwindle.

During the mid-1950s to early 1970s, low regulated wellhead prices fostered significant gas consumption growth. By 1960, gas consumption had doubled from the 1950 level to $12 \mathrm{Tcf}$ and reached its peak of 22 Tcf in 1972.

Though U.S. gas consumption peaked in 1972, domestic gas reserves began to decline precipitously after 1967. In 1973, domestic gas production started a decline that continued until the late 1970s. Wellhead price controls, the lack of supply development incentives, regional pipeline capacity problems, and the abundance of gas dedicated to the intrastate market all served to decrease available interstate gas supplies. With shrinking supplies, pipelines began limited curtailments of industrial customers in 1970 to ensure that residential and commercial customers had adequate supplies. In 1974, widespread curtailments occurred. The curtailments led regulators to recognize the need for higher gas prices to increase exploration and development activity. By 1976, the FPC raised its highest allowable wellhead price to $\$ 1.42$ per million Btu (MMBtu), approximately 700 percent higher than the average price in 1972. Even so, the unusually cold winters of 1976-1977 caused curtailments to reach $3.7 \mathrm{Tcf}$ in 1977 and forced the closings of businesses, factories, and schools throughout the country.

\section{The Natural Gas Policy Act (NGPA)}

In response to the curtailment problems and after 18 months of debate, Congress in 1978 passed 
the Natural Gas Policy Act (NGPA) and the Powerplant and Industrial Fuel Use.Act (PIFUA or FUA) as part of the National Energy Plan.

The NGPA set price ceilings for dozens of categories of gas according to vintage, location, and type, including previously unregulated intrastate gas. It decontrolled the prices for certain categories of natural gas in January 1985, and for other selected categories in July 1987. Ceiling prices for new and "high-cost" gas escalated, based on the change in economy-wide prices plus other factors. Most "old" gas was to remain regulated at escalating price ceilings until it was depleted. Finally, the incremental pricing mechanism of the NGPA was designed to shift the burden of increased gas prices onto industrial users up to a competitive fuel price level, thus limiting increases in residential rates. The ceiling prices contained in the Act were based on a price forecast through 1985 . This price forecast proved inaccurate but the FERC could not easily modify the ceiling prices to meet actual price levels.

Section 311 of the NGPA provided temporary relief from interstate gas shortages by allowing limited interstate pipeline transportation of intrastate supplies on a contract carriage basis. This provision became the basis of the pipelines' transition a decade later from gas merchants to transporters of gas owned by others.

The Powerplant and Industrial Fuel Use Act prohibited the use of oil and natural gas in new large industrial and electric utility boilers and it limited usage in existing industrial boilers to the average level consumed from 1974 to 1976 . Exemptions to these rules, however, could be granted by the Department of Energy. The prohibition on the use of gas and oil in existing boilers was removed in 1983. In 1987, the remaining portion of the Act conceming new gas-fired construction was repealed.

In the late 1970s, the pipeline industry's perceptions were that lower-priced controlled gas could be averaged with higher-priced gas to keep delivered prices competitive. In addition, gas demand and gas and oil prices were projected to rise. Since pipelines were unable to offer prices above the ceilings, they competed for available supplies in the late 1970 s by offering increasingly high take-orpay levels and inflexible price escalators.

In the late 1970s and early 1980s, in response to the relaxation of regulatory constraints at the wellhead (NGPA 1978), prices rose significantly as pipelines bid aggressively to lock in supplies to avoid additional curtailments. In most instances, pipelines signed long-term contracts at the maximum lawful price. When the FPC's successor, the FERC, subsequently removed or raised the maximum lawful price on certain gas categories, prices on those categories shot to record levels (e.g., over $\$ 10$ per thousand cubic feet $(M c f)$ for certain contracts for gas found below 15,000 feet in 1979).

Basically, high gas prices did exactly what they were designed to do; additional supplies were developed and lower-valued uses were discouraged. By 1980, deliverability had increased to the point where curtailments were no longer necessary.

\section{Declining Demand and the Gas Bubble}

The industry's expectations of increasing gas demand, however, were not met. Price-induced conservation, long-term fuel switching, industrial restructuring away from gas-consuming industries, and energy efficiency improvements reduced gas demand from about 20 Tcf in 1980 to approximately $16.8 \mathrm{Tcf}$ in 1983 . Commercial and residential gas usage declined due to more efficient equipment and other conservation measures which caused per-customer and total usage to decline. In the industrial sector, demand declined due to energy conservation and the industrial restructuring of the U.S. economy away from many gasintensive industries. Finally, powerplant consumption decreased mostly due to the replacement of gas-fired base load capacity by new coal and nuclear powerplants.

Therefore, while deliverability had increased as a result of the energy price increases of the late 
1970s and the resulting exploration boom, gas consumption declined, creating the gas bubble or excess deliverability of natural gas. Although it has dwindled somewhat, the gas bubble still remained in 1988.

The gas bubble has continued much longer than expected for several reasons. First, there has been an unwarranted optimism about the recovery in gas demand. Many respected forecasters expected demand to rise to the 19-20 Tcf range. Second, oil production was higher than many expected, increasing the amount of associated gas produced. Third, the large anticipated declines in Gulf of Mexico production did not occur. In fact, reserve additions and production potential in the Gulf were maintained. Fourth, the decline in gas drilling costs allowed producers to drill profitably even with lower wellhead prices. Moreover, the growth in high deliverability wells in relation to productive reserve capacity, especially in the Gulf of Mexico, has maintained supply above most expectations throughout the 1980s. Fifth, many producers needed cash flow to service debt so they opted for drilling programs that maximized deliverability. Finally, Canadian gas export policy became more market responsive. ${ }^{2}$

As a result of the excess deliverability which developed in the early 1980s, the gas industry began to experience gas-on-gas and pipeline-on-pipeline competition. Gas-on-gas competition was caused by the gas bubble as gas suppliers competed for markets. This caused wellhead gas prices to soften. Pipeline-on-pipeline competition was caused by excess pipeline capacity as customers with more than one supplier sought to choose the cheapest option. Inflexibilities in gas industry contracts from the wellhead to the bumertip did not initially permit gas markets to clear. What was needed was a spot market and more flexible transportation arrangements to move gas to market. However, in the early 1980s, the spot gas market and flexible transportation were inhibited by regulations.

\footnotetext{
${ }^{2}$ Shuttlesworth, G., "North American Natural Gas Markets," New York: Petroleum Industry Research Associates, presentation, November 1985.
}

For the first time, in early 1983, increasing gas prices collided with decreasing residual fuel oil prices. When this occurred, gas load was lost to residual fuel oil as industrial and powerplant customers with dual-fuel capabilities switched. At this point, pipelines were required to charge all customers the same weighted average cost of gas for their merchant sales, and widespread access to gas transportation services did not exist. In short, changes in the gas industry's structure were needed to make gas prices more flexible and increase access to transportation services.

\section{Industry Response to the Gas Bubble}

During this period, pipelines instituted various mechanisms to regain gas competitiveness. Many pipelines reduced their prices by invoking the market-out clauses in their contracts with producers. Where possible, pipelines also varied their purchase pattems within contract constraintsthey bought cheaper gas supplies in preference to higher-priced supplies. The lack of marketout clauses and high take-or-pay levels in many contracts left pipelines with long-term obligations which did not permit them to achieve gas supply costs low enough to compete effectively. Pipelines started to renegotiate their producer contracts to include market-sensitive pricing and reduced take-orpay provisions. Finally, an increased emphasis on marketing started to develop as the industry sought ways to stop the erosion of its sales. Initially, these actions were limited in their effectiveness.

The regulators also began to put programs into effect that were designed to provide more flexibility and encourage the development of a gas spot market. In 1983, the FERC began to approve pipeline Special Marketing Programs (SMPs), which allowed pipelines to release gas under contract with producers and transport it at reduced prices to large industrial customers. These policies made gas prices more competitive with oil prices. The SMPs were designed to prevent 
industrial customers from switching from gas to alternative fucls.

As noted above, after passage of the NGPA, the FERC began to promulgate rules to implement and expand the emergency Section 311 transportation of gas in minor ways. Through a series of orders from 1979 through 1983, the FERC allowed both interstate and intrastate pipelines to transport gas for each other, other LDCs, and for both highpriority and low-priority end-users. In 1983, however, the FERC made basic changes by streamlining the application process for these transportation authorizations by issuing blanket certificates for this transportation to pipelines that met certain criteria, rather than individual certificates for each transaction.

As a means of giving interstate pipeline customers greater flexibility in choosing between competing suppliers, in August 1984, the FERC instituted Order 380, which eliminated the variable portion of minimum bills that pipelines charged their LDC customers. These minimum bills with pipeline customers had provided an offsetting obligation to pipelines' take-or-pay requirements from producers. When a pipeline customer bought less than the minimum bill amount of gas, he had to pay for the cost of the gas not purchased. Order 380 eliminated this obligation. With Order 380 , the LDCs no longer had a financial incentive to buy gas from their traditional pipeline suppliers, for it eliminated the economic penalty imposed on LDCs for buying less than their minimum contract quantities from pipelines. This freed LDCs to seek cheaper alternative gas suppliers. However, the corresponding take-or-pay provisions in pipeline and producer contracts remained in place. As the LDCs reduced their purchase of more expensive pipeline gas, pipelines accumulated takeor-pay liabilities with producers for gas not taken below the take-or-pay contract level.

FERC Order 380 spurred the development of the spot market in natural gas by allowing and encouraging LDCs to turn away from their traditional pipeline suppliers to new sources of lower-priced gas supply. As a result, the spot market grew rapidly from 5 percent of the market in 1983 to 33 percent of the market in 1985.

The wide availability of large supplies of gas from a myriad of producers, and the emerging segment of gas marketers (buying and selling thirdparty gas), made the wellhead gas market increasingly competitive. Additionally, the existence of at least two pipelines serving most major distribution companies caused transportation of spotmarket gas to end-use markets to be competitive as well. Finally, gas still had to compete with residual fuel oil in industrial markets at a time when crude oil and petroleum product prices were falling.

By the fall of 1985, many of the FERC's pipeline transportation programs were due to expire, and the U.S. Court of Appeals had declared SMPs illegal because not all con.umers had equal access to the cheaper gas supplies. In respoise, the FERC issued new rules for transportation service in Order 436. This voluntary sper-access plan required a pipeline that accepted the Order to transport gas for all customers (including end-users) on a nondiscriminatory, first-come, first-serve basis. The FERC continued to regulate carriage service and maximum transportation rates, but now pipelines could also discount their carriage fees to a minimum variable cost rate. Thus, a greatly increased number of gas consumers had the opportunity to shop for gas supplies from any source, producers gained direct access to end-use markets, and both entities could obtain transportation service.

The spot market continued to grow under Order 436 and the interim Section 311 transportation to over 50 percent of the market in 1986. As the merchant function continued to diminish with the growth of the spot market, pipelines began to unbundle their services, offering a menu of separate gas commodity, transportation, storage, and other auxiliary services to their customers.

One area that Order 436 did not address was the take-or-pay problems of pipelines. As already noted, shrinking gas demand and the tremendous growth of pipeline transportation had caused most pipelines to incur significant take-or-pay liabilities. 
This overhanging liability caused many pipelines to not accept the open transportation system designed by Order 436.

In June 1987, the U.S. Court of Appeals largely affirmed Order 436 , but remanded the Order to the FERC primarily because it did not address the growing take-or-pay problem. In response, the FERC issued Interim Order 500, which retained the open-access transportation program and sought to satisfy the court's objections on the take-orpay issue. The Order included a procedure for pipelines to share take-or-pay costs with their customers. It also required a producer to give a pipeline take-or-pay credit for gas transported by the pipeline.

In response to competition in gas markets, FERC has also streamlined the procedures for abandonment of wellhead sales and certification of new pipeline construction. For example, Order 451 sets a single ceiling price, equal to that for NGPA 102 gas, for old gas dedicated to interstate commerce prior to enactment of the NGPA. It provides the producer the ability to terminate a contract and move old gas on the spot market, with the pipeline required to provide transportation, if satisfactory prices below the ceiling cannot be renegotiated with the pipeline. It does, however, allow the pipeline to retain the gas if it is willing to raise old gas prices to the ceiling.

Gas transportation has increased as a result of the new regulatory initiatives. Since 1985, it has grown from 33 percent to over 60 percent of total deliveries in 1987.

The changes in federal regulation have shifted more responsibility to state and local regulators. Most PUCs recognize the new gas purchasing opportunities available to their state's LDCs and many have focused their attention on the prudence of the LDCs' gas purchasing practices. Where once the PUCs had merely to look at FPC- and FERC-approved pipeline rates to determine prudence, they must now assess the price and reliability aspects of a myriad of supply options. The PUCs are also beginning to address the effects of greater competition in the market and the unbundling of LDC services, which follows the trend of pipelines unbundling their gas commodity, transportation, and other services in the wake of their transition from gas merchants to gas transporters.

\section{Canadian Regulation}

Canada has also implemented major changes in its regulation of the natural gas trade, to provide for market-determined pricing and reserve allocation. Unlike the United States, Canada had no gas price regulation until 1974, never had wellhead price controls, and eliminated minimum bills between TransCanada Pipeline (TCPL) and LDCs in the mid-1970s. LDCs pay demand charges for pipeline capacity, and they have contracts in place with TCPL for annual quantities and maximum day takes. From the mid-1970s to November 1985, a regulated Toronto citygate natural gas price existed, and border prices for exports were regulated. Until 1985, as in the United States, pipelines offered a bundled merchant-transporter function and limited access was available to other shippers. In Canada, TCPL is the only pipeline connecting Western producers with markets east of Alberta.

Since November 1985, policies have been implemented to increase competition in Canadian gas markets. Open access to transportation now exists. This has caused the direct sales market to grow substantially-particularly in the industrial and large commercial/institutional markets. The National Energy Board (NEB) has not made provisions for gas utilities to displace volumes under contract with TCPL; however, this matter is now under review in the current TCPL rate hearing.

Since 1987, Canada has used a market-based procedure for evaluating the public interest in licensing export applications. In essence, it rests on the premise that normally markets should allocate gas efficiently. There may be circumstances, however, in which this will not occur. Hence, the NEB considers gas proposed for export to be surplus within the context of Canadian needs, pro- 
vided that the export arrangement meets certain market and public interest criteria. ${ }^{3}$

\section{Appendix to Chapter 2}

\section{U.S. Gas Reserves, Supply, and De- mand, 1950-1987}

\section{Reserves}

Proved U.S. gas reserves grew from $180 \mathrm{Tcf}$ in 1950 to a peak of $290 \mathrm{Tcf}$ in 1967 before declining to about $190 \mathrm{Tcf}$ in 1986. From the mid-1950s through the 1970s, the Gulf of Mexico became an increasingly important source of U.S. natural gas reserves. As a percent of total U.S. proved gas reserves, the Gulf of Mexico peaked at 20 percent in 1979 before declining to 17 percent in 1986. Currently, the Gulf of Mexico accounts for one-fourth of lower-48 natural gas production. Gas reserves increased in 1970 due to the addition of $26 \mathrm{Tcf}$ from Prudhoe Bay in Alaska. Currently, Alaska accounts for about 17 percent of proved reserves. These reserves, however, are not economic at today's prices.

\section{Marketed Production}

Total marketed production grew from 6.2 Tcf in 1950 to a peak of almost 22 Tcf in the early 1970s. Due to insufficient incentives under wellhead price controls, production declined in the mid-1970s. Although deliverability has remained relatively stable since 1980, gas production has fallen as gas demand has declined.

Including both onshore and offshore production, Texas and Louisiana remain the two most important sources of domestic gas pmduction. They have accounted for 65 to 75 percent of U.S. marketed natural gas production since 1950 . Including Oklahoma, the three states account for between 70 percent and 80 percent of U.S. production.

\footnotetext{
${ }^{3}$ As described in the National Energy Board's Reasons for Decision in the Malter of Review of Natural Gas Surplus Determination Procedures, July 1987.
}

\section{Reserves-to-Production Ratio}

The U.S. natural gas reserves-to-production ratio fell from almost 30 in 1950 to about 10 in the late 1970 s. Since 1980 , the ratio has risen somewhat because of the effect of declining demand on production.

\section{Total U.S. Gas Supply}

In addition to lower-48 and Alaskan production, total U.S. gas supplies also include net imports by pipeline and liquefied natural gas and other categories such as propane air and coal gasification. The primary source of U.S. gas supplies has been lower-48 production, accounting for at least 94 percent of total supplies. It was not until 1958 that imports exceeded exports. Net imports peaked at about 1 Tcf in the 1970s, primarily from Canada, as domestic supplies were curtailed. Imports were cut back in the early 1980s due to their high cost. In 1987, imports rose to almost $1 \mathrm{Tcf}$ again as they became increasingly price competitive.

The curtailments of the late 1970s stimulated the development of several liquefied natural gas (LNG) projects to augment conventional gas supplies. In general, price and supply reliability problems have hindered the development of these projects. Thus, while peak LNG imports were 253 Bcf in 1979 and $131 \mathrm{Bcf}$ in 1983, imports in other years averaged 40 Bcf.

\section{U.S. Gas Demand}

The low regulated wellhead gas prices of the mid1950s to mid-1970s caused U.S. gas consumption to rise from $5.8 \mathrm{Tcf}$ in 1950 (18 percent of U.S. energy) to a peak of $22.1 \mathrm{Tcf}$ in 1972 (30 percent of U.S. energy). Consumption remained in the 19 20 Tcf range in the late 1970 s, but declined in the 1980 s due to gas price increases, energy conservation efforts, industrial restructuring, energy efficiency improvements, and a recession.

While residential gas demand has been extremely stable since 1970, industrial and electric 


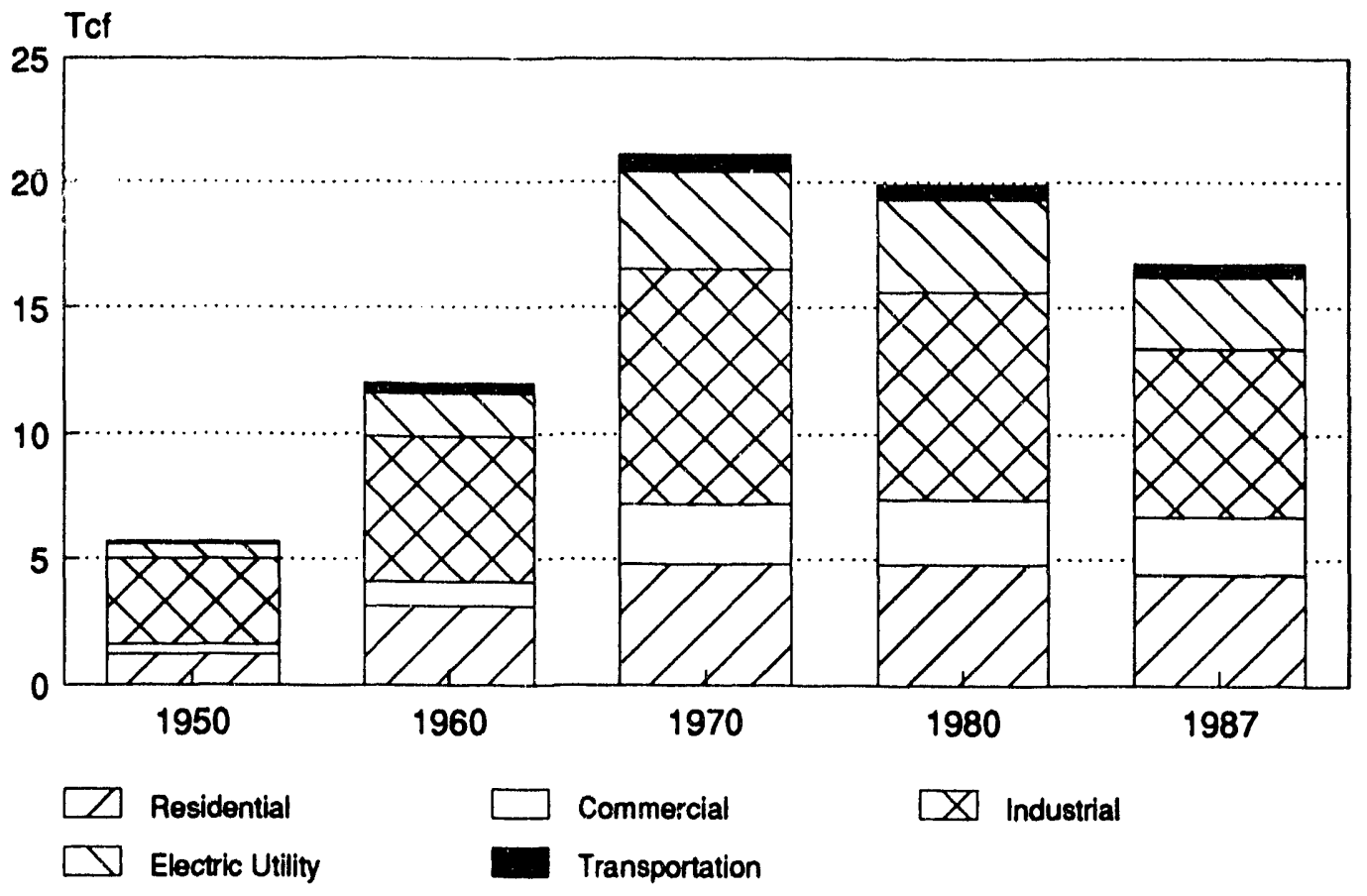

Figure 2.1: U.S.Natural Gas Consumption (Tcf), 1950-87. Source: Annual Energy Review 1987, Energy Information Administration, Washington, D.C., May 1988.

utility or powerplant gas use has declined (Figure 2.1), exhibiting wide swings from year to year. The proportional usages by sector were 21 percent residential, 7 percent commercial, 59 percent industrial, 10 percent powerplant, and 3 percent other in 1950. By 1987, U.S. gas consumption was 26 percent residential, 14 percent commercial, 34 percent industrial, 17 percent powerplant, and 9 percent other. 


\section{Chapter 3}

\section{Future Natural Gas Market Issues}

This chapter focuses on the major supply, demand, and pricing issues that will shape the North American market. It provides a conceptual framework for discussing the model results presented in the next chapter as well as the major findings reported in Chapter 6 that are derived from supplementary analysis not directly tied to the computer models.

\section{Future Gas Supply Issues}

The supply of natural gas for U.S. markets depends on several important physical, economic, technical, and institutional factors: the characteristics of the gas resource base, the economics of gas recovery (e.g., prices and production costs), prices, advances in gas exploration and production technology, producer exploration and production decisions, and imports from Canada and other countries. Careful evaluation of these issues is required in projecting how much gas will be available in a particular year at different prices.

\section{The Natural Gas Resource Base}

The physical size of the resource base is a major constraint on the future supply of natural gas. There exists substantial uncertainty about the size of the gas resource base because techniques do not exist to determine it definitely. Several organizations, including government agencies, trade associations, and individual companies, make assessments of the gas resource base. These estimates can differ significantly from one another, both nationally and regionally. Moreover, the same organization may change its estimates considerably between assessments on the basis of new information. Compounding the problem is the use of different terminology, different definitions for the same terms, different methodology, and different accounting conventions. Once these differences are reconciled, the remaining disparity often reduces to the professional judgment of geologists.

The proper use of any resource estimate requires a good understanding of the methodology and assumptions underlying it. Some of the issues involved include:

- What is included in the resource base? Is it only undiscovered resources, or is the traditional expansion of known fields (variously called inferred reserves or probable resources) included? Are unconventional resources such as tight gas formations incorporated? Which ones? Did the evaluators consider deep gas or formations under deep water?

- What economics are embodied in the resource estimate? Was an economic criterion used in considering what resources to include, either explicitly or implicitly, e.g., by the use of minimum field sizes?

- What assumptions were made about exploration and production rechnology to be used when estimating recoverable gas? What well spacing was assumed? These considerations 
can be important factors in determining recovery efficiency.

Even when these definitions are standardized, there reinains considerable uncertainty about the resource base. This situation requires that the prudent analyst consider the implications for gas markets of a range of resource estimates. Some organizations estimate a range for the res urce base as well as presenting a most likely estir.ate. Estimates of recoverable gas in different resource categories have varying levels of uncertainty associated with them, ranging from proved to speculative. It must be emphasized that all elements of the natural gas resource base, except proved reserves, must be converted to reserves before they can be produced and become part of the supply stream. This rrquires discovery and development and in some cases further research to improve understanding of reservoir characteristics and extraction technology. The volume of gas that is ultimately produced depends on the amount of drilling, which is in turn sensitive to price, transportation, and technology development.

\section{The Economics of Gas Recovery: Determin- ing the Supply Curve}

Analysts forecasting gas supply need to know more than just the total amount of gas in the resource base. They must distribute that resource along a supply curve by determining the cost to recover successive increments of gas. Since most resource estimates do not include explicit economic criteria, analyst must derive this supply curve. There are several ways to do this, ranging from simple functional forms to detailed analysis of field sizes in individual basins.

How the supply curve is developed can significantly affect the results of a forecast. For example, the way analysts implement a lower resource base assumption can strongly influence the results from their models. One analyst might shift the whole supply curve proportionately, thus increasing or decreasing resources at all cost levels. This approach would be appropriate if uncertainty about the resource base applied equally to low-cost and high-cost gas. Another analyst might change mainly the high-cost portion of the resource represented at the upper part of the supply curve. The rationale behind the latter approach would be that less is known about the high-cost gas, which will be produced later and which is likely to be in frontier areas, hostile environments, very small fields, or at greater drilling depths.

\section{Geologic Issues}

Some of the geologic issues that should be considered when constructing a supply curve from resource estimates include:

- The amount of the resource in high-cost areas, such as deep water, the Arctic, or deep formations;

- The number of small fields still to be found onshore;

- The amount of recoverable gas existing in unconventional resources, such as tight sandstone formations, Devonian shale, and coal beds;

- The amount of incremental gas to be added by strategic infill drilling.

\section{Costs}

Attention must also be paid to the cost estimates that are used in constructing the supply curve. If cost data from a single year are used, this constitutes an assumption that year is representative of future years. Yet, costs for exploration and development have swung widely in recent years, and studies show that costs depend upon energy prices, market conditions, and technology. These factors should be taken into account when choosing the costs to be used in an analysis of future supply.

\section{Technology}

Assumptions about technology and the rate of technology advancement are embedded in resource and 
cost estimates. Usually, estimates that are historically based assume a future rate of technological progress that is the same as that which has occurred in the past. More detailed analyses may make explicit assumptions about technological achievements. This is especially important when estimating the potential of unconventional resources, gas from frontier areas, or infill drilling. Advances in both exploration and production technology will significantly influence the size of the recoverable resource and recovery economics.

\section{Producer Decisionmaking}

A supply analysis must represent producers' decisions to explore for and produce gas resources. Some general economic factors include: exploration and production costs, wellhead prices, cost to transport the gas to market, gas market characteristics, and for the resource owner, the value of selling the gas this year rather than waiting for a future period. Other factors include willingness to explore for new gas fields versus developing reserves within existing fields, willingness to use advanced technology, the cost of capital, taxes, and regulations such as well-spacing limitations.

These factors will affect the timing of investment and production decisions with regard to each category of the natural gas resource, e.g., onshore, offshore, frontier, infill drilling, or unconventional resources. The results of any gas supply forecast must be understood in the context of how the industry is represented in the model and how decisions to explore and produce are made.

\section{Imports}

In a competitive North American natural gas market, U.S. demand for imported gas should depend upon the extent to which this gas is competitive with U.S. supply in each regional market. Competitiveness depends upon relative direct supply costs and transportation costs from source to market. Each cost has a number of contributing factors.
Issues that should be considered in assessing the availability of Canadian gas imports to the United States include:

- The geologic characteristics of the Canadian gas resource base, including conventional sources, unconventional gas (primarily tightformation gas from the Deep Basin area of Alberta and British Columbia), and gas from frontier areas, such as the Mackenzie Delta and the Arctic Islands;

- Canadian exploration and production costs;

- The availability and cost of transportation for Canadian gas, including pipelines from frontier areas and pipelines for carrying gas across the U.S. border and to the appropriate demand regions;

- Canadian demand for gas, which will compete for supply with U.S. demand;

- U.S. and Canadian trade and pipeline regulation and tax structures.

Ideally, an analysis that include U.S.-Canadian gas trade would have an integratevi representation of the North American gas market, including supply, transportation networks, and demand in both the United States and Canada, on a regional basis.

While Canadian gas is seen as the largest source of future U.S. imports in the time frame of this analysis, it is not the only source. LNG from overseas (e.g., Norway, Nigeria, Algeria) may also be a significant source of supply. The major issues concerning LNG are the price at which it will become available and the capacity of regasification facilities. While existing facilities on the East and Gulf Coasts will accommodate about 800 billion cubic feet per year, additional capacity may be constrained by barriers to siting such facilities. Gas may also be imported by pipeline from Mexico. The availability of this gas has been largely determined by Mexican internal energy and oil export policies, making analysis of this supply source by traditional methods very difficult. 


\section{Gas Demand Issues}

Future gas demand will be determined by a variety of factors, ranging from the rate of economic growth in each of the end-use sectors to the pace of technological advance. Although the basic economic factors affecting gas demand in aggregate are fairly well understont, no one can say with certainty what the level a gas demand will be. However, it is possible to review current trends and issues and develop projections about the future.

There are at least six general factors which contribute to the variation in future gas demand: the rate of economic and demographic growth, gas price, price competition from altemative fuels, advances in gas and nongas technologies, regulatory and environmental policies, and pipeline availability. A better understanding of these factors can be gained from examining the factors affecting the individual demand sectors. ${ }^{1}$

\section{Industrial Consumption}

In 1987, the industrial sector consumed over 40 percent of the gas in the United States. Gas consumption in this sector includes gas use for petrochemical feedstocks as well as heat and power in manufacturing, agriculture, and construction and mining. Factors affecting future industrial gas demand include the continuing restructuring of the industrial sector, the penetration of cogeneration, fuel switching due to price competition and technological change, and conservation.

Historically, growth in industrial energy consumption has been driven by strong growth in energy-intensive industries, such as chcmicals, primary metals, and pulp and paper. However, future growth in industrial energy consumption will be similarly affected by the restructuring of the indus-

\footnotetext{
${ }^{1}$ This discussion focuses on developments that are more likely to be important in the near term. A number of other developments may be important in the future, including the potential for gas use in the transportation sector, waste disposal, and conversion to gasoline.
}

trial sector. Recent history demonstrates the new trends. Total U.S. industrial production grew at an annual rate of 2.2 percent between 1973 and 1986. Among the most energy-intensive industries, only the food and chemical industries grew faster than the average. The pulp and paper industry grew at the average, while stone, clay, and glass grew slower than the average. The petroleum refining industry showed no growth over this period, and production in the primary metals industry actually declined by over 30 percent.

The dominant growth industries over the period from 1973 to 1986 were furniture and fixtures, printing, rubber and plastics, and electric machinery. All of these industries grew from 50 to over 100 percent faster than the industrial sector as a whole, but most of these industries are not very energy intensive. A number of factors have contributed to this shift in economic activity, including higher energy prices and changes in the value of the dollar. This growth pattern, combined with differences in the energy intensity of production by different industries, has significantly affected the energy requirements of the industrial sector.

The industrial sector is the largest producer of cogenerated electricity among end-use sectors. In 1987 , it had roughly 20,000 megawatts of cogeneration capacity. Much of this capacity is gas-fired. The potential for gas consumption in the industrial sector will be affected by the continued growth in industrial cogeneration, which will depend upon the level of buyback rates and the attitude about, or changes to, the Public Utility Regulatory Policy Act (PURPA).

Fuel switching is important in determining future gas demand in the industrial sector. Fuel switching traditionally refers to the switching between oil and gas and other fuels based on relative price competition.

Gas also faces fuel switching due to technological change. For example, today gas dominates fuel use in direct process heat applications (industrial processes where the flame impinges on the product); however, as new technologies enter the market (e.g., infrared drying, lasers), gas could lose 
part of its share of this market, mostly to electricity. Unlike the price-based fuel switching in boilers, technological change could result in a permanent loss of market.

Industrial sector gas demand also will be influenced by the goals of industrial decisionmakers. With more moderate energy price increases, the incentives that govern the design and selection of production methods are changing. Industrial costcutting attention now emphasizes reductions in labor costs, raw materials, and other factors of production, as well as energy costs. The most significant example of these trends is increased use of automation. (Gas may not be as conveniently adapted to automated production processes as is electricity.)

\section{Electric Utility Consumption}

In 1987, electric utilities accounted for over 15 percent of U.S. gas consumption. The utility sector, however, has the potential for a large increase in gas demand. Factors which will affect this growth include the level of electricity demand growth, the penetration of cogeneration in end-use sectors, the impact of deregulation on utility industry capacity issues, the penetration of clean coal technologies, changes in nuclear or environmental issues, and relative energy prices.

Electricity demand depends upon the demand by other sectors for lighting and electrically driven equipment and is highly uncertain. During the period from the mid-1970s to 1983 , electricity demand growth was slow due to low economic growth and rapidly increasing electricity prices, but recently it has been growing more vigorously, reflecting stronger economic growth.

The penetration of cogeneration in end-use sectors will be another important factor in determining the demand for electricity from utilities. To the extent cogeneration grows, correspondingly less utility-generated electricity will be required. This may depress electric utilities' use of natural gas, although gas use for cogeneration will be higher.
Recently, the federal government has begun a process to deregulate, to some degree, the electric utility industry. As part of deregulation, independent power producers (IPP) may play a bigger role in providing electricity. IPPs will tend to have shorter investment horizons and will tend to build smaller capacity generating systems. These criteria fave $r$ natural gas.

The reliability of electric utility capacity to meet future generation requirements is receiving increased attention today. Little new capacity is formally included in currently published electric utility plans. By the mid-199(s, however, new electric utility plants will be required. Given the long lead times required to coristruct coal-generating capacity, there is some concern that capacity will be inadequate to meet the generating requirements in the mid-1990s. If short lead times are required in the mid-1990s, more new gas-fired units, which can be more quickly constructed than new coalfired plants, will be placed in service, increasing utility gas demands. Moreover, the lifting of the Powerplant and Industrial Fuel Use Act (PIFUA) restrictions creates potential opportunities for increased use of combined-cycle, gas-fired units.

Environmental concems may also significantly alter electric utility gas demands, as reflected in changes in nuclear or environmental issues and the penetration of clean coal-burning technologies. If no new nuclear powerplants are constructed beyond those currently announced or if acid rain legislation is passed that allows gas to be used, the potential for increased gas demand by electric utilities will be enhanced. By contrast, if electric utilities adopt clean coal-burning technologies, the demand for gas could be reduced.

\section{Commercial Consumption}

Energy consumption in the commercial sector is dominated by requirements for ventilation, space cooling, space heating, and lighting. In the past, these four loads have generally been captured by electricity. Newly introduced gas technologiescogeneration, engine-driven chillers, and desiccant 
systems-now provide gas with the opportunity to capture the space cooling services directly and the ventilation and lighting services indirectly. The possible market penetration of these three technologies accounts for much of the potential variation in the level of future gas demand in the commercial sector.

The rate and type of growth in commercial square footage also help to shape future levels of gas demand. A shift in the economy toward a larger service sector suggests a larger commercial sector with greater energy demana levels. The relative growth by building type is also important. Commercial buildings historically have tended to use different fuels depending on their service requirements. For example, hotels, health facilities, and restaurants have tended to use more gas per square foot than education or office buildings.

The location of the growth is also particularly important. A higher level of growth in warmer regions implies a greater emphasis on space cooling. A greater level of growth in cooler regions implies a greater space heating demand.

\section{Residential Consumption}

Through the early 1970s, natural gas was the fuel of choice in the residential sector. Gas traditionally captured over 60 percent of the new residential space heating market in the United States. As a result of rising prices in the 1970s and early 1980 s and moratoria on new pipeline hookups in the 1970s, the gas market share sagged through the early 1980s, although it has recently recovered.

The level of gas demand in the future will depend to some degree on the influence of a number of issues which are identifiable today-the rate and location of population growth, the type of housing constructed, average fucl use efficiency trends, and the extent of the transmission and distribution infrastructure.

U.S. population today is growing at roughly one percent per year. Variations in population growth and its regional distribution will influence energy demand. Increased growth in warmer regions im- plies a greater emphasis on space cooling; a greater growth in cooler regions implies a greater space heating demand. Competitively, gas is favored in regions with large space heating loads because of lower overall costs relative to competing fuels.

Also important to determining the level of future gas demand is the mix of housing types. Historically, electricity has captured a much larger share of space heating in multifamily homes than gas because the investment cost for electric heating equipment is lower than for gas or oil. By contrast, gas tends to capture a larger share of space heating in single-family homes.

The average fuel use efficiencies of gas-burning equipment (AFUE) have been increasing as newer more efficient units have been substituted for older lesser efficient ones. Trends in the AFUE of both gas equipment and equipment using alternative fiels will help to determine future levels of gas demand through their effect on both the type of direct energy input required and the relative equipment. efficiencies.

A potential major impact on the AFUE trends is the recently passed "National Appliance Energy Conservation Act" of 1987. The Act establishes appliance efficiency standards for gas, electric, and heating oil appliances. In particular, the Act requires that by 1992 fumaces with an output of greater that 45,000 Btu per hour must have an AFUE of 78 percent. By comparison, approximately 50 percent of the gas-fired furnaces sold in 1987 could not meet this standard. The Act may also have a major impact on the fuel shares of new appliances sold in the United States after 1992 for competitive as well as safety reasons.

A final issue which will affect future residential gas demand is the extent of the transmission and distribution pipeline infrastructure. Due to pipeline moratoria in the 1970 s, some areas do not have gas service available to meet growth outside of major metropolitan areas. This is particularly true in the growing Southern and Northeastern markets of the United States. Residential gas demand could be significantly increased at existing prices if gas dis- 
tribution companies could extend gas distribution lines into areas that do not now have service.

\section{Fuel Switching in the Industrial and Electric Utility Sectors}

Fuel switching between gas and other fuels will be an important determinant of future natural gas demand. If gas prices rise relative to alternative fuel prices, the responses of those gas users who can switch fuels, especially in the dual-fired industrial and electric utility boiler markets, will strongly influence gas demand. Different estimates of the size and switching capability exist, contributing to the uncertainty about gas demand.

The number and type of fuel-switching customers vary depending on the period of adjustment. Fuel switching can be separated by the rate at which it can occur:

- Very short-term switching (within a few months) of gas to an alternate fuel in dualfired boilers, primarily to residual or distillate oil;

- Intermediate-term switching (within a year) through retrofits to make gas boilers that can only burn gas, dual fired with other fuels; and

- Longer-term switching (within several years) of gas equipment to use nongas fuels.

The determinants of the amount of short-term fuel switching are the relative prices of gas and alternative fuels, relative equipment and operating costs, the capacity of dual-fuel capability equipment currently installed, and environmental controls restricting the emissions of air pollutants. Electric utilities can also accomplish fuel switching by generating power from different plants using different fuels. This short-term fuel switching on the basis of small unexpected changes in fuel prices, sometimes referred to as a penny-switch situation, is the response frequently discussed in energy trade journals.
If higher gas prices occurred and persisted for an extended period of time, additional fuel-switching capability in the intermediate term could be created by minor modifications in fuel-using equipment. With an additional several months, much of the industrial gas equipment can be retrofitted to use altemative fuels.

A key factor affecting the amount of switching in the intermediate term is the price differential between the alternative fuel and gas. The price differential must be great enough and expected to persist long enough to justify the capital expenditure. In the current regulatory environment, electric utilities are constrained in retrofitting existing equipment.

The long term involves a more complex combination of factors affecting gas markets. Capital substitution becomes increasingly possible. The longer time frame allows additional displacement of gas by alternative fuels and conservation measures.

\section{Natural Gas Pricing}

The pricing of natural gas has been radically transformed over the last decade. Regulated cost-based pricing was the norm until the early 1980 s with prices since then increasingly determined by market conditions. This section discusses pricing concepts, competition between oil and gas, and developments in transmission and distribution margins.

\section{Cost-Based to Netback Pricing}

As discussed in Chapter 2, until passage of the Natural Gas Policy Act of 1978, wellhead gas prices paid by interstate pipelines to producers were regulated on a cost-justified basis. Transmission and distribution charges were regulated on a cost-ofservice basis and added to the field or wellhead price to determine delivered or burnertip prices. The resulting delivered prices, based upon incurred costs, generally remained below the prices of competitive fuels until the early 1980 s. 


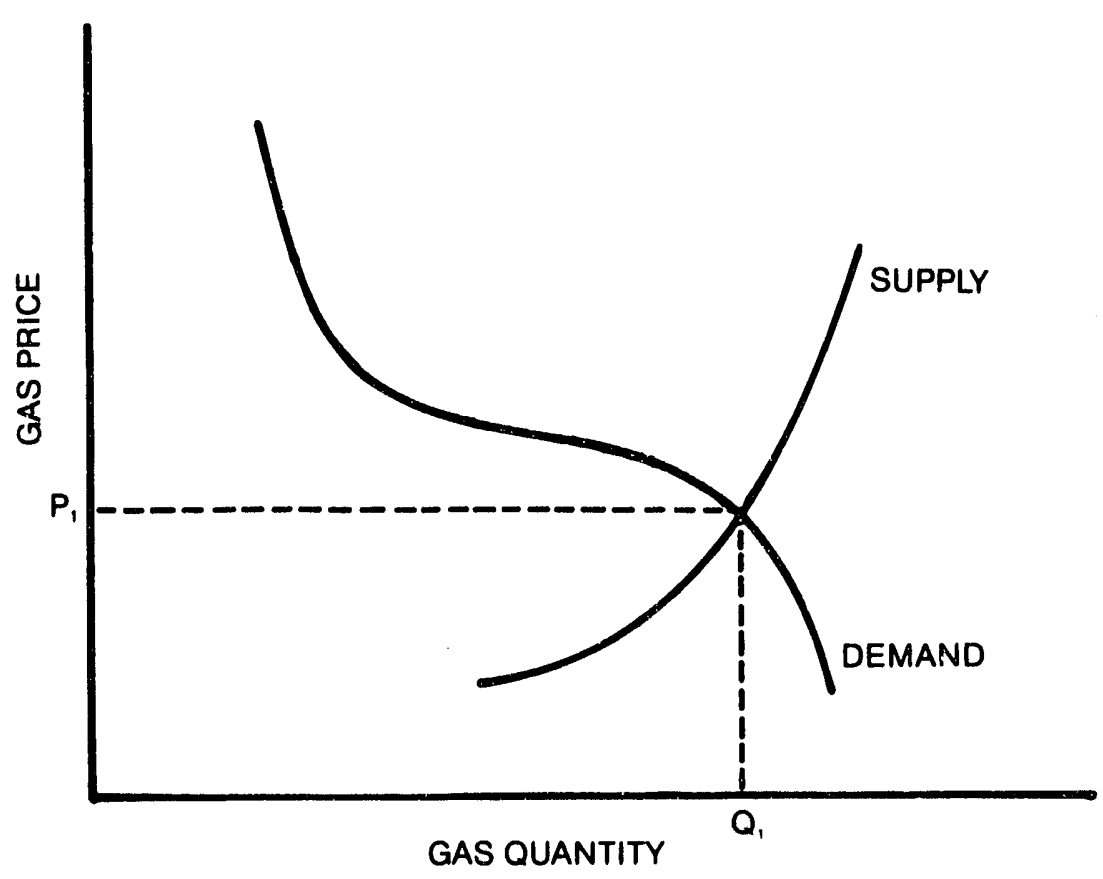

Figure 3.1: Supply-Demand Representation of a Market-Clearing Price

Over the last decade, less gas has been held under wellhead price controls. As gas and oil prices in end-use markets moved closer together, netback wellhead pricing was used in many contracts. In this approach, wellhead gas prices could be determined by subtracting or netting out transmission and distribution costs from the delivered Btu industrial residual fuel oil price.

Netback pricing rules, however, will not reflect the relative abundance or scarcity of gas resources to meet potential demand. If producers have abundant gas, prices will tend to move lower, competing with lower quality residual fuel oil, other gas supplies, and perhaps even with coal. Due to the gas bubble, gas prices have been largely determined by competition among gas suppliers, with gas prices falling below residual fuel oil. On the other hand, if gas becomes relatively scarce and expensive, gas might compete in industrial markets with higher quality residual oil and even with distillate oil under certain conditions. By contrast, world oil prices are not strongly influenced by domestic supply and demand conditions because crude oil and petroleum products are more readily traded in an international market. As a result, the market prices for gas and oil, while related, need not move in tandem.

\section{Market-Clearing Prices}

The relationship between oil and natural gas prices can be shown most clearly through the use of a simple analytical framework. Figure 3.1 presents the basic approach emphasizing market prices being determined jointly by supply and demand conditions in the short term.

The demand curve in Figure 3.1 shows that lower prices encourage more consumption. ${ }^{2}$ At higher prices, only gas demand by the residential

\footnotetext{
${ }^{2}$ The position of this curve is determined by factors other than the gas price, including alternative energy prices, the level and composition of economic output, and some advances in energy-using technology. Over time, changes in these factors will shift the position of this curve. In addition, as discussed later in this section, the shape of the curve may be altered by
} 
and commercial sectors is observed. This market consists primarily of small users whose altemative energy choice is electricity or distillate oil and who require new equipment to substitute between fuels. While consumption is responsive to price, the cost of new energy-using capital limits this response. Hence, the curve at these higher prices is steeper than at lower prices, where gas demand by the switchable industrial and electric utility sectors enters the market and is added to the demand by the premium sector. This new source of demand represents users whose dual fuel-burning equipment allows them to switch easily between residual oil and natural gas. Hence, the demand curve becomes relatively flat in this portion because a small change in gas price can lead to a large change in demand levels. At still lower prices, the demand curve turns steeper again as gas saturates the switchable market and begins to compete with coal. The cost of new coal equipment makes users at these lower prices less responsive to the gas price than in the switchable market.

The demand curve for gas in the fuel oil competitive segment is not completely flat because endusers have differing fuel oil requirements: some can bum a relatively inexpensive high-sulfur residual fuel oil, while others can bum lower-sulfur residual fuel oils, and still others only high-cost distillate oil as an alternative. Another source of variation is the degree of fuel-switching capability: some end-users who can technically bum fuel oil don't have the fuel oil handling equipment installed to do so. For them, the price of gas must exceed that of the competing fuel oil by a margin sufficient to justify the capital costs of installing the fuel oil equipment before fuel switching will occur. The third source of variation in the demand curve in the fuel oil competitive market (when viewed against changes in gas wellhead prices) is transportation and distribution costs. An end-user facing high gas transportation and distribution costs will tend to switch sooner than one whose T\&D costs are low. The low end of the demand curve, therefore,

the introduction of new energy-using equipment that changes the responsiveness of gas demand to gas prices. tends to represent end-users with installed dual-fuel capability who can burn a dirty, relatively cheap oil. The upper end of the fuel-competitive portion of the demand curve (the last to switch to oil) represents those who must install equipment to bum high-cost distillate oil.

The supply curve in Figure 3.1, which represents production and not deliverability, shows that lower prices reduce the amount produced by lowering the incentives to find more costly resources. ${ }^{3}$ The intersection of the demand and supply curves determines the market-clearing price $\left(P_{1}\right.$ on the vertical axis) and the amount sold ( $Q_{1}$ on the horizontal axis) in a particular year when the market is in equilibrium.

Note that Figure 3.1 shows the supply curve intersecting the demand curve to the right of its very flat portion; gas is being priced below residual oil under these conditions. At gas prices above this level, e.g., at $P_{2}$, surplus gas would remain, even after meeting the gas demand in the competitive or switchable end-use market. Under these conditions, there would be incentives to find new end-use markets for gas, which might be priced to compete with coal. Prices would tend to fall until increased consumption and decreased quantity supplied restored the market to its competitive equilibrium at price $P_{1}$ and quantity $Q_{1}$.

The adjustment described above does not happen instantaneously. Temporary surpluses or shortages may appear but over time would be eliminated by market forces, particularly if pro-competitive regulatory policies prevailed. Other regulatory policies, however, could inhibit the adjustment process. In addition, the position and shape of the supply and demand curves will change over time as new investment is realized. As institutional and capital constraints are relaxed, the steeper portions of the demand curve would tend to flatten. However, as long as the end-use markets can be characterized

\footnotetext{
${ }^{3}$ The position of the supply curve is determined by factors other than the gas price, such as the cost of capital. Conceptually, the curve could also exhibit different price sensitivities at different price levels. However, there is less consensus on whether the response varies, and if so, at what prices.
} 
by two sectors, one with dual fuel-buming capacity and one without, the generic representation of Figure 3.1 remains a useful framework for explaining how gas prices are formed in this market.

In the North American natural gas market, many different supply regions are linked through a pipeline system to particular demand regions. Thus, in reality, there are many different regional wellhead prices rather than one single national price. In general, wellhead prices over the long run should be lower in supply regions that are farther away from the major demand service areas because transportation costs must be included in the delivered gas price. While the regional issue adds complexity to the discussion of price formation, the same basic supply-demand framework operates at a regional level as wcll.

\section{Oil and Gas Prices}

This conceptual framework emphasizes that oil and gas prices will not necessarily be tied to each other. If plentiful and relatively inexpensive, gas would capture (in the short-run sense in which installed dual-firing capability or gas transportation capacity are fixed) the entire fuel-competitive market. In this case, gas-to-gas competition is setting gas prices so that changes in oil prices will have little effect on gas prices. This circumstance, for example, was evident in the early part of 1987 as gas prices fell even while oil prices were rebounding from their 1986 lows. Alternatively, gas could become relatively scarce and very expensive, thereby losing the industrial and utility fuel oil competitive market. In this second case, oil price changes will have little effect on gas. Between these two cases, gas is competing with some type of fuel oil in some marginal market and thus wellhead gas prices are set as a "netback" from that marginal market. The degree to which a given change in oil price affects wellhead gas prices depends upon the shape and position of the supply and demand curves for gas.

The trends in residual fuel oil and gas prices to industrial users since 1978, displayed in Figure 3.2, provide three historical examples of fuel switching in the United States This experience emphasizes that oil and gas prices reflect conditions in the two fuel markets and that the oil-to-gas price relationship is volatile in the short run as well. ${ }^{4}$

After the passage of the Natural Gas Policy Act (NGPA) in 1978, industrial gas prices rose from $\$ 1.86 / \mathrm{MMBtu}$ in January 1979 to $\$ 4.25 / \mathrm{MMBtu}$ in January 1983 (21 percent per annum). Residual oil prices fell from the peak levels of 1981 and stabilized in late 1982 at around $\$ 4.20 / \mathrm{MMBtu}$. As a result, in early 1983, gas prices collided with residual fuel oil prices. When this occurred, gas load was lost to residual fuel oil as industrial and powerplant customers switched.

Gas prices regained competitiveness from mid1983 through 1985 as oil prices firmed and the emerging spot market allowed for lower average gas prices. Fuel switching again occurred as residual oil prices fell in the first quarter of 1985 due to the settlement of the British coal strike. Residual oil prices decreased from $\$ 4.50 / \mathrm{MMBtu}$ in January 1985 to $\$ 3.57 / \mathrm{MMBtu}$ in June 1985 . Gas prices decreased slowly and regained parity with residual oil briefly in the third quarter, 1985. Following this, gas prices drifted upward due to seasonal factors in the fourth quarter, 1985.

Then the dramatic plunge in oil prices in early $1986(\$ 28 / \mathrm{Bbl}$ in December 1985 to $\$ 10 / \mathrm{Bbl}$ in April 1986) created a wide disparity in residual oil and gas prices, and caused additional fuel switching. By the summer of 1986, average gas prices were in the vicinity of $\$ 3.00 / \mathrm{MMB}$ tu while residual fuel oil prices were below $\$ 2.00 / \mathrm{MMBtu}$. Since then through the fall of 1988 , natural gas has regained competitiveness with residual fuel oil.

\section{Transportation and Distribution Margins}

Many natural gas analyses assume that transportation and distribution (T\&D) margins don't change

\footnotetext{
"The source for the energy prices in Figure 3.2 is the Energy Information Administration: industrial gas prices are from Table 13, Natural Gas Monthly; high-8ulfur residual fuel oil prices to end-users are from Table 9.5. Monthly Energy Review.
} 


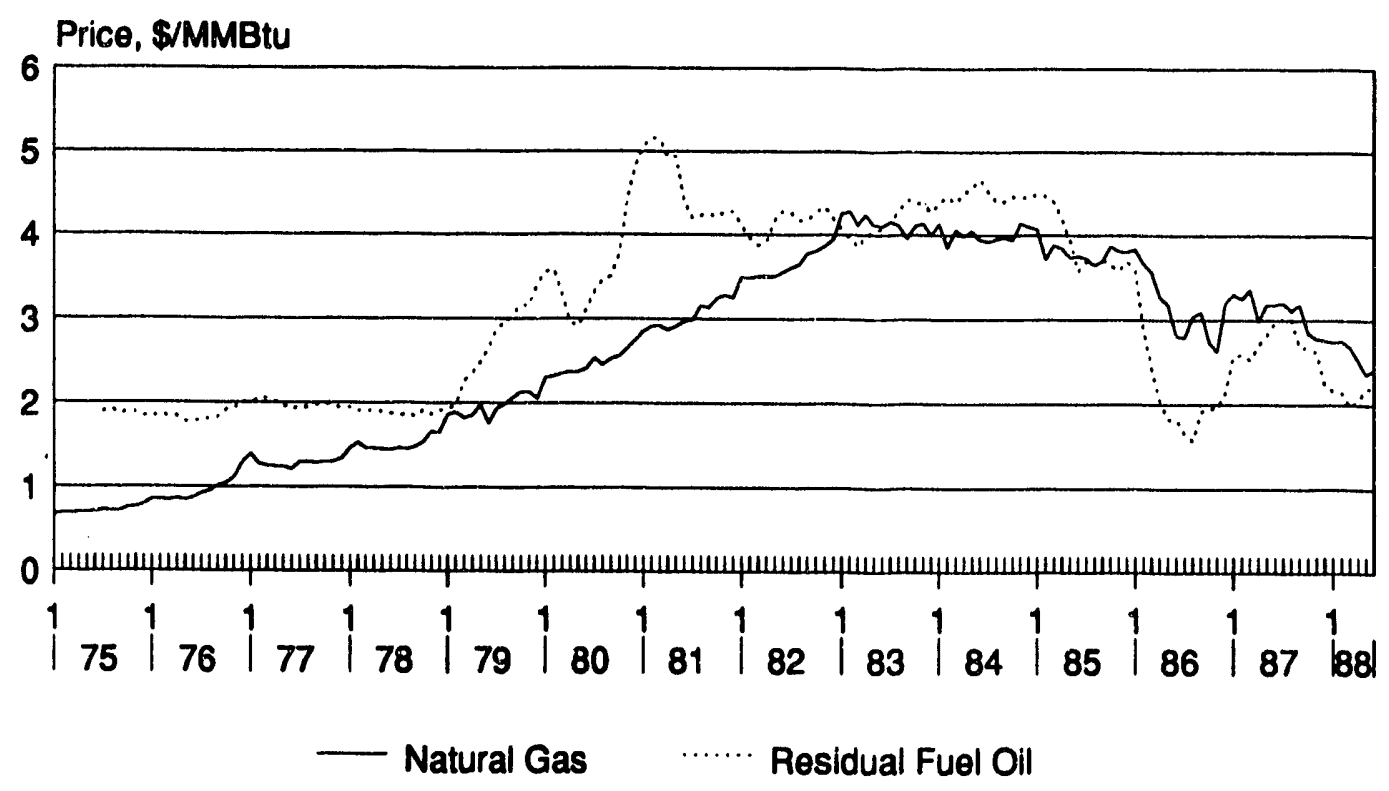

Figure 3.2: Energy Prices (\$ per million Btu) Delivered to Industrial Customers, 1975-1987. Source: Energy Information Administration.

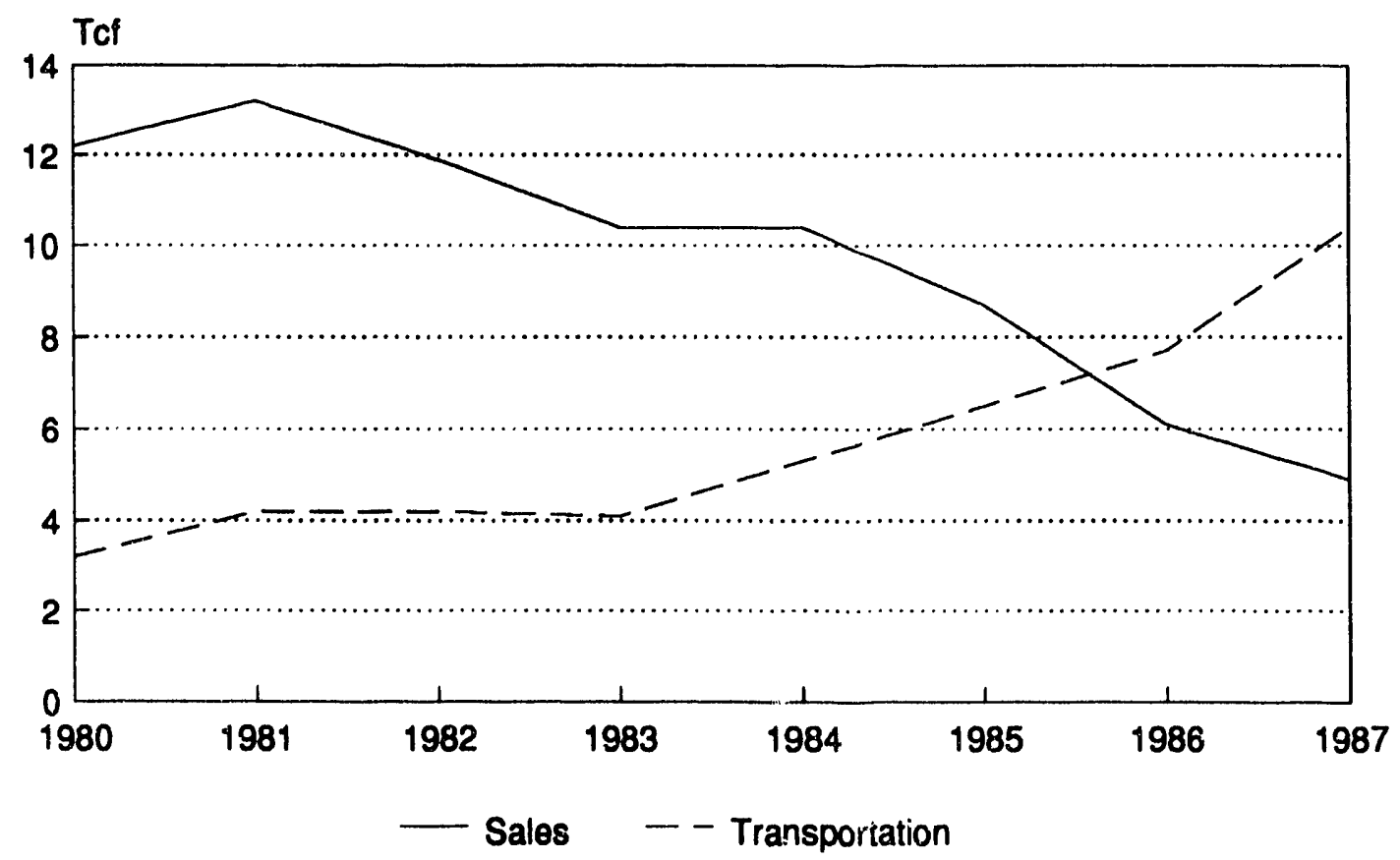

Figure 3.3: Top 20 U.S. Interstate Pipelines Sales versus Transportation. Source: FERC Form 2; Tenneco. 


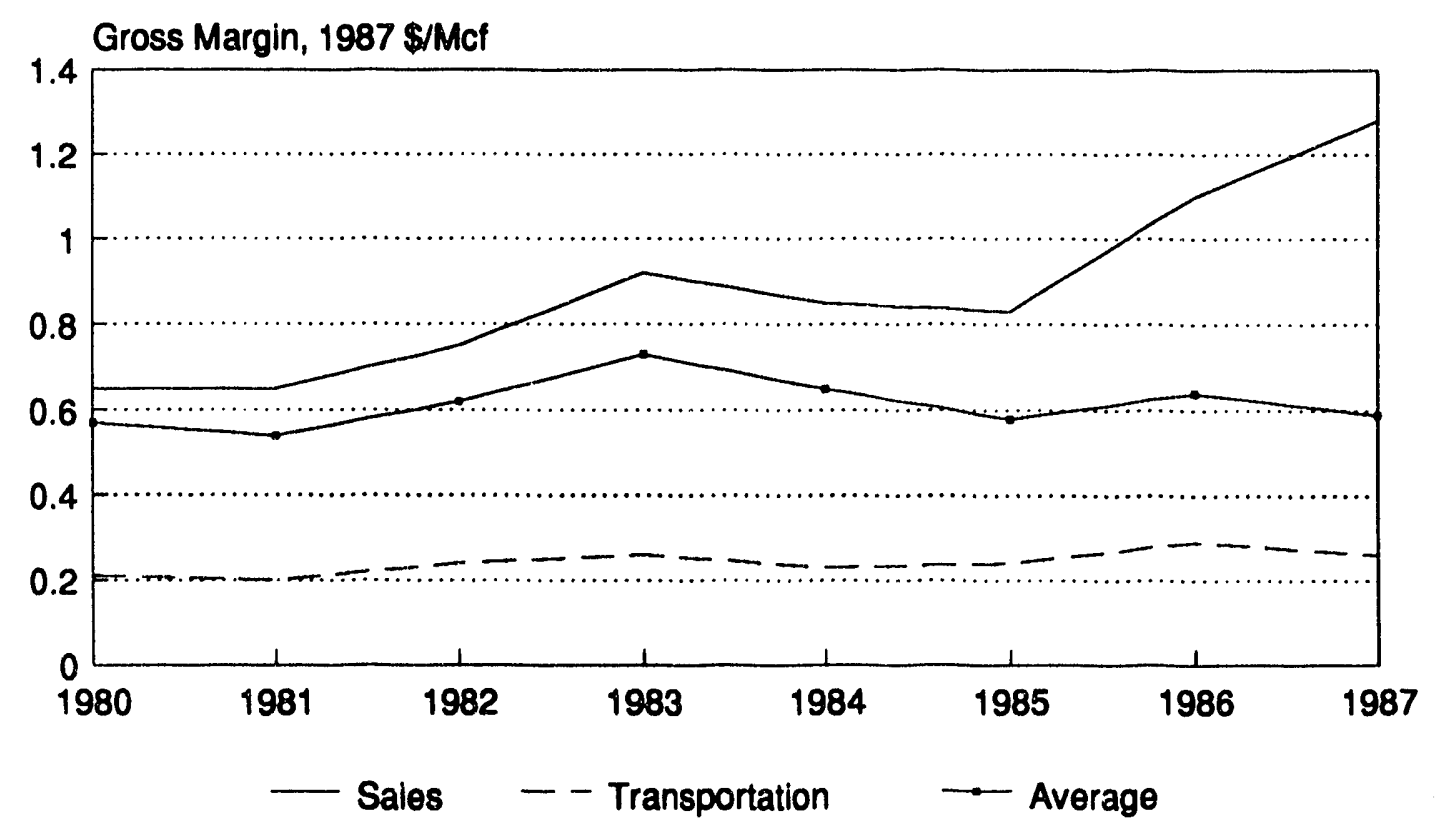

Figure 3.4: Top 20 U.S. Interstate Pipelines Sales and Transportation Margins (1986\$/Mcf). Source: FERC Form 2; Tenneco.

over time. In reality, T\&D margins will almost certainly not be constant.

Prior to 1983, pipeline-owned gas (sales volumes) comprised 75 percent of the gas delivered by interstate pipeline (Figure 3.3). Transportation on interstate pipelines was largely performed for other interstates ( 75 percent of total transportation), and total transportation volumes were fairly constant at $4 \mathrm{Tcf} / \mathrm{yr}$. Since 1983, however, as noted in Chapter 2, regulatory change has led to a dramatic increase in the transportation of gas that was not owned by pipelines. These deliveries, or transportation volumes, now comprise over 60 percent of total gas sales. Meanwhile, sales volumes have decreased as end-users have gained more direct supply access, producer direct gas marketing has increased, and the spot market has expanded.

The shift in the role of pipelines, from predominantly merchant to predominantly transporter, has affected most gross margins (Figure 3.4). Sales margins have increased as fixed costs have been spread over smaller sales volumes. Transportation margins increased slightly through 1983, but generally declined after 1983 due to competitive market forces and open access, which allowed transportation margin discounting. The rise in 1986 was due partly to longer transportation hauls. Although final data are not available, it is expected that both sales and transportation margins fell in 1987 after the reduction in tax rates and the discounting mechanisms provided by Orders 436 and 500 .

Uncertainty surrounds the future trend in transportation margins, which may vary by region. If the industry continues to become more competitive and transportation service continues to increase, transportation margins could decrease. The dramatic rise in transportation for others on interstate pipelines since 1983 (Figure 3.5) has been a reflection of producer, end-user, and broker activity. Several components may lead to increased competition and decreased margins. For example, as the gas bubble ends, competition for gas supply 


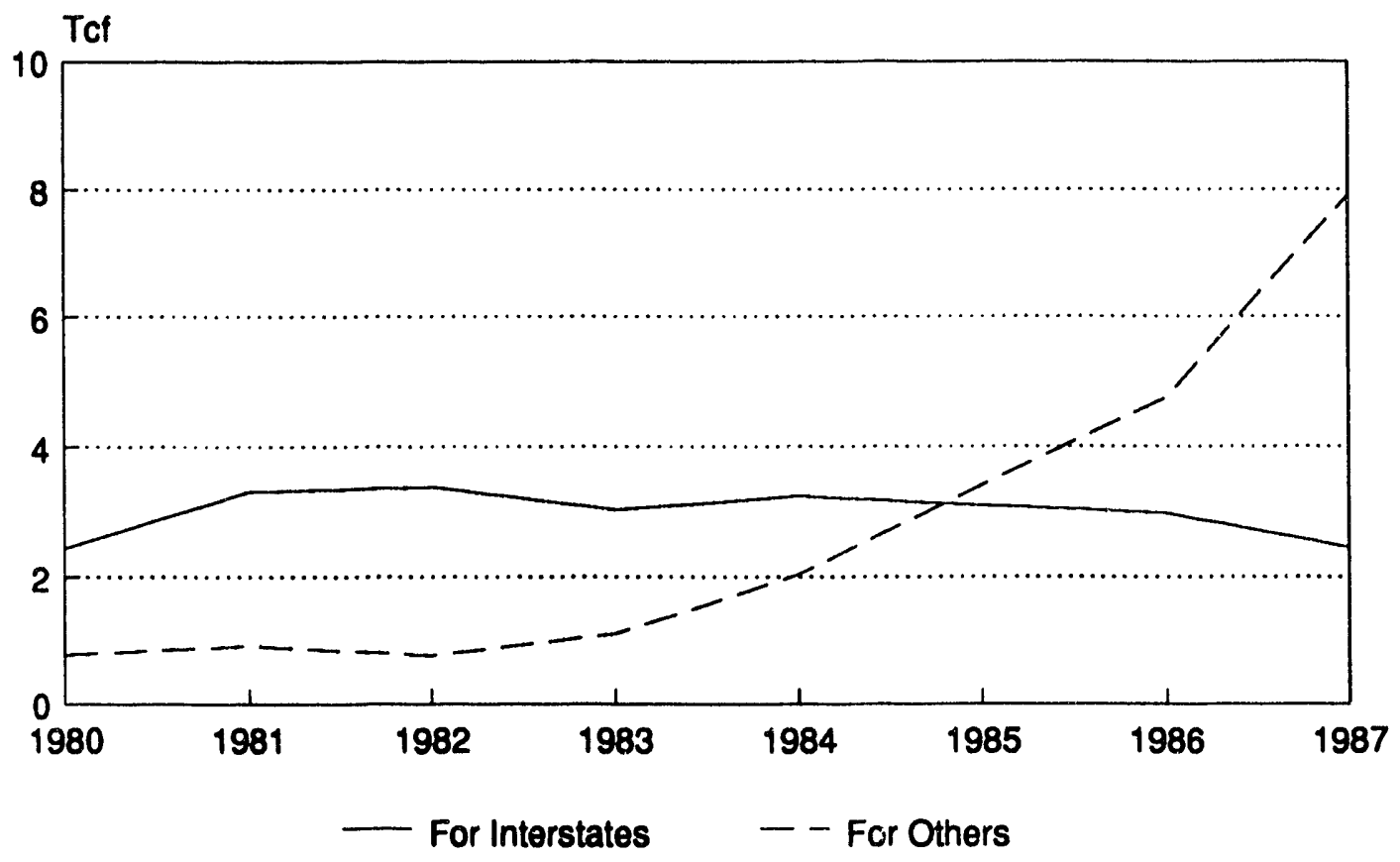

Figure 3.5: Top 20 U.S. Interstate Pipelines Transportation Components. Source: FERC Form 2; Tenneco.

will cause wellhead gas prices to rise. Therefore, competition for supplies may force pipelines to bid down margins to remain competitive.

Furthermore, continued excess pipeline capacity in many areas will serve to put downward pressure on margins. Peak-year consumption is not expected to reach historical levels of 22 Tcf under any EMF scenario. Meanwhile, pipeline capacity remains at about 25 Tcf. Especially in an era of decreasing supplies, competition for end-use markets may reduce transportation margins. Less discounting may occur in those regions with tighter pipeline capacity.

The distribution margins of LDCs have decreased slightly in recent years as gas prices have fallen (Figure 3.6). The average calculated distribution margin has fallen 6 percent from 1985 to $1987 .^{5}$ However, distribution margins have remained above the average interstate pipeline margins of \$.70/MMBtu (See Figure 3.4). The threat

\footnotetext{
${ }^{5}$ Average calculated margins equal the average delivered price minus the average citygate price.
}

of LDC bypass could lower distribution margins through increased competition. If bypass occurs, however, the margins to remaining customers could increase.

The loss of industrial load has increased the contribution of residential and commercial revenue, mainly in the winter, for the distribution company. This has tended to make the average calculated distribution margin appear more seasonal. Increased fuel switching may tend to further increase the seasonality of margins. If LDC bypass occurs, seasonality of the margins would increase mildly. On the other hand, if new gas-fired electric generation markets develop, seasonality could be reduced.

\section{Regulation}

As discussed in Chapter 2, the history of regulation in the natural gas industry reveals ongoing tensions between alternative regulatory objectives. Regulators must balance concems about allocating 


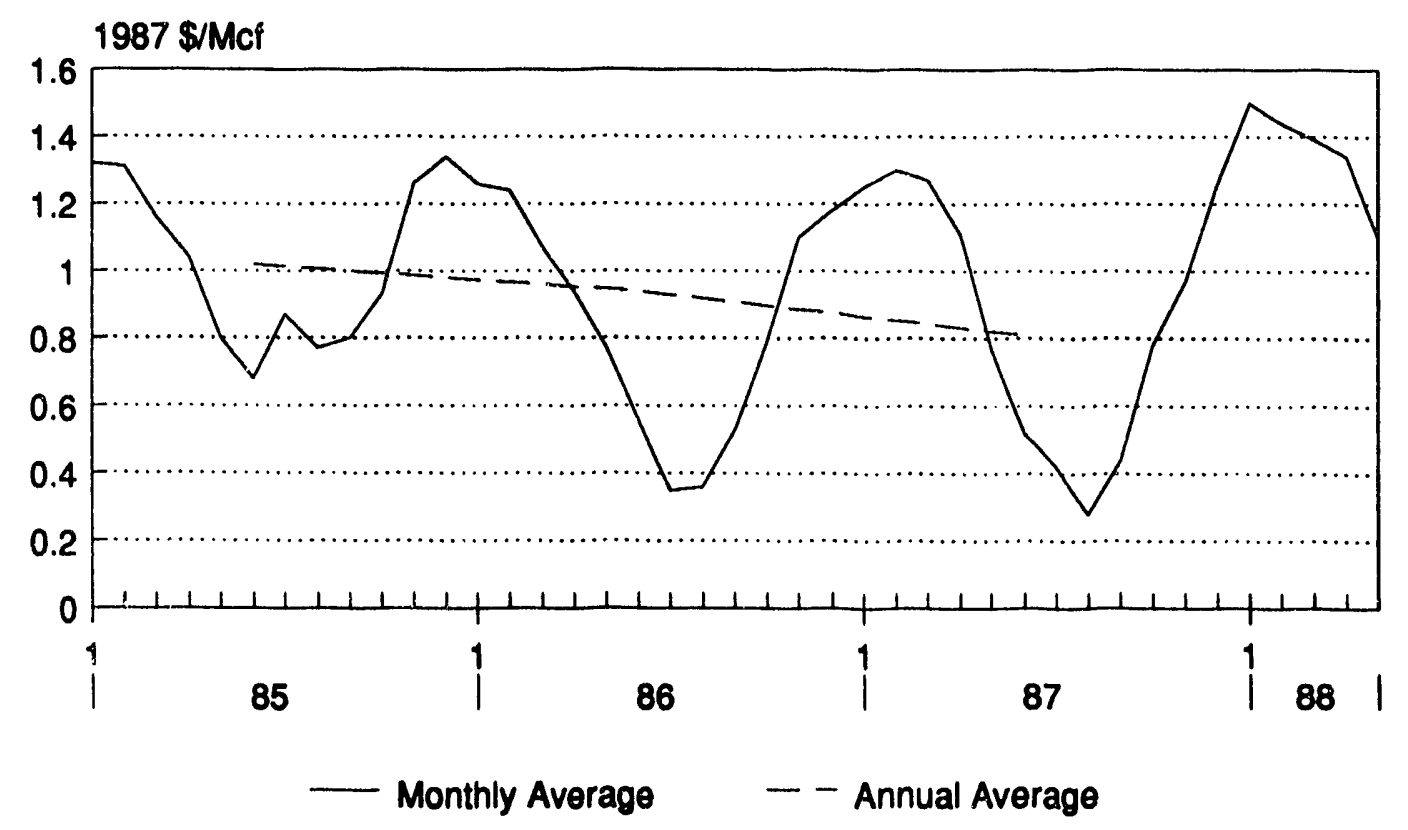

Figure 3.6: Distribution Margins Based on National Average Gas Prices (1987\$/Mcf). Source: Energy Information Administration, Natural Gas Monthly; Tenneco.

gas efficiently with those about the distribution of benefits and costs among market participarits.

Since the enactment of the Natural Gas Policy Act in 1978, regulatory policy in the gas industry has been moving steadily in a more competitive direction. The key to this pro-competitive shift has been the move toward unbundling of pipeline and some local distribution company (LDC) services, allowing market forces to guide the allocation of goods and services. Most important has been the separation of gas sales from transportation, encouraged by partial wellhead decontrol and increasing access to interstate pipeline transportation. Given the recent changes in gas regulation, the two key regulatory issues facing the gas industry today are:

1. How best to complete the process of unbundling gas sales and transportation, assuming political support for pro-competitive policies continues to prevail, and;
2. Under what conditions to place higher priority on regulatory objectives other than economic efficiency.

\section{Key Issues in Completing the Process of Un- bundling}

A number of regulatory issues must be addressed in order to complete the unbundling of pipeline and LDC services:

\section{Pipeline-FERC Issues}

1. Implementation of pipeline open accessThe Federal Energy Regulatory Commission (FERC), in Orders 436 and 500, has facilitated the unbundling of services in the interstate gas market, but difficulties in resolving take-or-pay concems have slowed the transition to a inore competitive market.

2. Pipeline rate structure-As pipeline services are unbundled, many will remain regulated. 
The rate structures regulators use to price those services will have a significant impact on the efficiency of the evolving market, on the allocation of different types of service, and on the interplay of regulated and unregulated services.

3. Pipeline service obligation-Part of the tradition of public utility regulation in the pipeline industry has been that pipelines, in exchange for monopoly privileges in a particular market, are not allowed to unilaterally reduce the level of service provided once they are officially certificated. FERC Orders 380 and 500 have reduced the obligation of local distribution companies (LDCs) to purchase gas from pipelines, but have left pipelines with the obligation to remain ready to meet the original contract demand levels of their LDC customers. A method of compensating pipelines for this responsibility must be found if pipelines are to remain reliable gas suppliers.

4. Economic allocation of pipeline capacity-A key aspect of pipeline rates is how they allocate pipeline capacity, especially during peak periods. On an annual basis, there is considerable excess capacity in the U.S. pipeline system as a whole, but in some segments bottlenecks exist during peak periods. Allocating capacity on these segments on an economic basis, e.g., through the use of a secondary market in capacity rights, could ensure that they are used by those who value the space most and provide a clearer indication of where additional pipeline capacity is needed.

5. New pipeline entry-Proposals to build new pipelines must currently move through a lengthy regulatory process. Improvements to the approval process are needed to enhance the responsiveness of the pipeline network to changes in supply and demand, while reconciling gas needs with environmental concerns and property rights.
Local Gas Distribution Company (LDC)-Public Utility Commission (PUC) Issues

6. LDC open access with unbundling-In response to the unbundling of pipeline services initiated by the FERC, many state public utility commissions (PUCs) are requiring utilities to offer transportation through their system on an unbundled basis. As at the pipeline level, open access at the LDC level must be reconciled with the LDC's obligation to serve. This need arises particularly in the case of large customers with alternative gas and nongas fuel sources, for whom an obligation to provide gas sales service may no longer be appropriate.

7. LDC bypass-Some industrial customers find it desirable to build their own direct link to the pipeline system rather than to go through their local utility. The extent to which PUCs constrain the ability of LDCs to be bypassed is likely to be an important issue as the gas industry evolves.

8. LDC marketing/growth policy-Historically, many PUCs, concerned about possible gas shortages resulting from wellhead price controls, have prevented utilities from marketing gas service to new customers. With a largely deregulated wellhead market allowed to balance supply and demand, such policies need rethinking.

9. PUC oversight of LDC contracts-As the spot market has grown, PUCs and state legislatures have imposed a plethora of new regulations designed to encourage their gas utilities to choose a mix of long-term contracts and spot-market purchases that will ensure supply reliability and price stability at the lowest possible cost to consumers. These policies may have a significant effect on how gas utilities operate in the gas supply market. 


\section{Regulations Affecting Canadian Natural Gas Exports}

10. Canadian export policy-Canada has been moving towards a market-oriented regime for natural gas since 1985. In 1987, the National Energy Board abandoned reserve/production $(\mathrm{R} / \mathrm{P})$ ratio requirements for determining the exportable surplus; instead the board adopted a "Market-Based Procedure" for considering the licensing of export applications. Within this proccdure the Board will use public hearings and ongoing monitoring to ensure that the market operates in an efficient manner, and correspondingly, that Canadian customers are not placed at a disadvantage relative to export customers.

\section{Regulatory Policy Stability and Market Conditions}

Under some scenarios, regulators may face strong political pressure to overturn some pro-competitive policies. Some of the factors which may prompt regulators to place greater priority on objectives other than economic efficiency are described below.

\section{Oil-Gas Competition}

If delivered gas prices fall below parity with delivered oil product prices, policymakers might face political pressures to raise prices to industrial customers with dual-fuel capability, and use the additional revenue to subsidize residential customers. (The incremental pricing provisions of the NGPA prescribed such a policy of cross-subsidization.) Many industrial customers have or could develop options other than buying from their local utility, however, such as buying their own gas and transporting through the utility, or bypassing the utility altogether. Thus, cross-subsidization will only be possible to the extent industrial users' options are restricted.

On the other hand, if delivered gas prices are above parity with oil product prices, dual-fuel cus- tomers can switch from gas to oil, and regulators will have little opportunity for cross-subsidization.

\section{Sharply Rising Gas Prices}

If gas prices increase sharply, regulators may face pressure to ensure that high-priority customers (e.g., residential customers, hospitals, schools, etc.) receive the supplies they need at "fair" prices. In essence, such a strategy implies price controls for high-priority customers and cross-subsidization by lower-priority customers. In extreme cases, a congressional move toward wellhead price recontrol and restrictions on the access of low-priority customers to gas supplies could occur.

Sharply rising gas prices may affect PUC oversight of gas contracting practices as well. Even if the PUC grants prior approval to a utility's gas supply plans, it may later choose to disallow the recovery of some gas costs if the utility's average cost of gas rises too high. The frequent price renegotiation required under most new long-term contracts may protect LDCs from some retroactive disallowances, but in theory there is nothing to prevent PUCs from later arguing that LDCs should have locked in low prices when the market bottomed out.

\section{Sharply Rising Rates for Transportation Capacity}

With additional gas demand, capacity bottlenecks might become increasingly tight, leading to price increases on these segments. Regulators, seeking to protect high-priority customers, might abandon an economic system for transportation capacity allocation for one with fixed priorities for particular customer classes. By restricting the access of low-priority customers to the transportation network, demand would be reduced, and prices could be held down for those customers allowed access; such a policy creates cross-subsidies similar to those generated by wellhead price controls and attempts to allocate available supplies to highpriority users. 


\section{Chapter 4}

\section{Key Findings from the Model Results}

Most decisionmakers are familiar with forecasts from computer models. Given the considerable uncertainty about the development of the North American natural gas markets, the EMF working group decided not to make forecasts but to explore the range of possible market outcomes based on a set of scenarios about the industry's development. The scenarios have been selected to challenge both the modelers and nonmodelers in the working group to think broadly about how the industry might evolve under very different sets of conditions. Thus, no one scenario or one model output is considered to be most likely.

This chapter describes the scenarios chosen by the working group, reviews the general conclusions drawn from the model results, and presents more detailed comparisons of the individual model results by scenario. ${ }^{1}$

\section{Models}

Eleven models were simulated using standardized assumptions describing four scenarios. These models, listed in Table 4.1, focus on the U.S. and Canadian markets.

The models use multiple relationships to describe the production and consumption decisions of the market participants. Although the working group focused on aggregate indicators of the North American market, the models generally rep-

\footnotetext{
${ }^{1} A$ forthcoming Volume 3 contains several technical papers covering the scenario design in depth, the results for individual models, and a detailed comparison of model responses.
}

resent regional markets and the interregional flow of gas. The models chosen for this study were originally developed to examine long-run trends based upon market-clearing prices rather than short-run dynamics of markets under conditions of excess or limited capacity.

While the models have a similar focus, they form a heterogeneous group. Those listed under Group A in Table 4.1 were developed primarily to study the simultaneous equilibria in many different regional markets. Rather than using detailed submodels to describe drilling activities and finding rates by resource category, these models represent supply conditions as simple, reduced-form relationships linking gas production to gas prices. These relationships are often based upon more detailed studies of the resource base and production activities. Similar reduced-form relationships are used to describe consumption as a function of price. The models focus their analyses on how gas produced in a supply region is allocated to demand regions on the basis of competitive economic conditions. The industry is assumed to be workably competitive at all levels. These models are particularly well suited for analyzing the regional flow of gas.

Three of the models in this group are either operated at Canadian institutions or focus primarily upon Canada (AGAS, MIT North American, and Rowse). The Gas Trade Model was developed at Stanford to study the potential gains from gas trade between countries, while GRI North American is used by the Chicago office of the Gas Research In- 
Table 4.1: Natural Gas Models Used in EMF 9

\begin{tabular}{|c|c|c|}
\hline Model $^{a}$ & Organization $^{b}$ & Country Focus \\
\hline \multicolumn{3}{|l|}{ Group A: } \\
\hline AGAS & $\begin{array}{l}\text { Alberta Research Council } \\
\text { (Don Quon) }\end{array}$ & North America \\
\hline GRI North American (GRI N A) & $\begin{array}{l}\text { Decision Focus, Inc. } \\
\text { (Dale Nesbitt) }\end{array}$ & North America \\
\hline Gas Trade Model (GTM) & $\begin{array}{l}\text { Stanford University } \\
\text { (Alan Manne) }\end{array}$ & North America \\
\hline MIT North American (MIT) & $\begin{array}{l}\text { Massachusetts Institute } \\
\text { of Technology } \\
\text { (Charles Blitzer) }\end{array}$ & Canada \\
\hline Rowse & $\begin{array}{l}\text { University of Calgary } \\
\text { (John Rowse) }\end{array}$ & Canada \\
\hline \multicolumn{3}{|l|}{ Group B: } \\
\hline Gas Analysis Modeling System (GAMS) & $\begin{array}{l}\text { Energy Information } \\
\text { Administration } \\
\text { (Barbara Mariner-Volpe) }\end{array}$ & United States \\
\hline GRI Hydrocarbon (GRI Hydro) & $\begin{array}{l}\text { Energy \& Envir. Analysis } \\
\text { (Harry Vidas) }\end{array}$ & United States \\
\hline ICF Gas Market Evaluation System (ICF) & $\begin{array}{l}\text { ICF, Inc. } \\
\text { (William Stitt) }\end{array}$ & United States \\
\hline Lewin Natural Gas Model (LEWIN) & $\begin{array}{l}\text { ICF-Lewin Energy } \\
\text { (Vello Kuuskraa) }\end{array}$ & United States \\
\hline NEB Energy Demand/Gas Supply Models (NEB) & $\begin{array}{l}\text { National Energy Board } \\
\text { (Mark Segal) }\end{array}$ & Canada \\
\hline A.G.A.-TERA (TERA) & $\begin{array}{l}\text { American Gas Association } \\
\text { (Leon Tucker) }\end{array}$ & United States \\
\hline
\end{tabular}

stitute to evaluate the potential benefits from additional gas research and development expenditures. The GRI Baseline Projection issued by the GRI Washington office is based upon a different set of models: the GRI Hydrocarbon model, which is listed in the second group of models, and the Data
Resources, Inc. Energy and Macroeconomic models, which were not used in this study.

The models in Group B devote considerably more attention to studying the specific relationships governing the supply and demand decisions in the market. They generally employ engineeringeconomic relationships to describe these interac- 
tions. Some models (ICF, Levin, and GRI Hydrocarton) include a detailed assessment of the resource base by depth and field size, while others (the American Gas Association's TERA model) project supply from equations based upon statistical fits to historical data. The demand submodels usually represent residential and commercial consumption decisions with statistical equations, while using detailed submodels representing different technologies and processes to simulate industrial and electric utility decisions.

The models in this second group were generally constructed for detailed studies of the economic and technical factors influencing supply and demand decisions. They were not developed primarily to analyze how regional gas flows are allocated based upon competitive economic conditions, even though all but two (GRI Hydrocarbon and National Energy Board) were used in this study to determine market-clearing prices equating the quantity supplied with that demanded. Several of the models in Group B adjust exploration and development costs to changes in market conditions.

These models were run for each scenario by standardizing on certain key inputs agreed upon by the EMF working group. ${ }^{2}$ In some cases, the EMF inputs, e.g., the resource base, differ substantially from those often used by the proprietors of a model. Since they may be strongly influenced by these EMF scenario specifications, the reported model results should not be interpreted as a forecast of a particular model's proprietor or organization.

\section{Scenario Design}

The working group designed four scenarios: an upper and lower oil price, a low U.S. resource, and a high U.S. demand. The critical input assumptions are summarized in Table 4.2.

\footnotetext{
${ }^{2}$ These scenarios were analyzed in the fall of 1987 . Some historical data have bcen revised since the model results wore finalized.
}

\section{Two Oil Price Paths}

The two oil price scenarios were based upon price paths analyzed in a recent National Petroleum Council (NPC) study on the oil and gas markets. In the upper path, the U.S. average refinery acquisition crude oil price rises from $\$ 15$ per barrel (all prices are in $1986 \$$ ) in 1986 to $\$ 22$ by 1990 , increases 5 percent faster than inflation to $\$ 36$ per barrel by 2000 , and grows 2 percent faster than inflation after 2000. The oil price in the lower path decreases to $\$ 14$ per barrel by 1990 , rises 4 percent faster than inflation to $\$ 21$ per barrel by 2000 , and grows 2 percent faster than inflation after 2000 .

The lower oil price path is assumed to result from a higher level of world oil supplies being available rather than from lower world economic growth. The growth rate in U.S. GNP (adjusted for inflation) is mildly stimulated by the lower oil price trend, consistent with recent research that changes in oil prices have a very modest effect on economic growth rates. ${ }^{3}$

The two oil price scenarios assume the same U.S. natural gas resource base. This resource base assumes the 1986 Potential Gas Committee's ${ }^{4}$ (PGC) "most likely" estimate for conventional, undiscovered natural gas resources. This represented the most recently available, national-level estimate of natural gas resources at the time the modeling scenarios were specified and run for this study.

The PGC estimates are supplemented with separate estimates developed by the EMF supply study group to include resources not incorporated

\footnotetext{
${ }^{3}$ While oil price shocks cause severe economic dislocations and temporary reduction in real GNP, they do not appreciably alter the underlying economic growth rate, in the absence of discretionary economic policies for controlling inflation. See Energy Modeling Forum, Macroeconomic Impacts of Energy Shocks, EMF Report 7, Stanford University, Stanford, CA (also published in Bert G. Hickman, Hillard G. Huntington, and James L. Sweeney, Macroeconomic Impacts of Energy Shocks, Amsterdam: North Holland, 1987), and National Petroleum Council, op.cis.

4Potential Gas Committee, Potential Supply of Natural Gas in the United States, December 31, 1986, Potential Gas Agency, April 1987.
} 
North American Natural Gas Markets

Table 4.2: Key Scenario Inputs for EMF 9

\begin{tabular}{|c|c|c|c|c|}
\hline Key Assumptions & $\begin{array}{l}\text { Upper Oil } \\
\text { Price } \\
\end{array}$ & $\begin{array}{l}\text { Lower Oil } \\
\text { Price }\end{array}$ & $\begin{array}{l}\text { Low U.S. } \\
\text { Resource }\end{array}$ & $\begin{array}{l}\text { High U.S. } \\
\text { Demand }\end{array}$ \\
\hline \multicolumn{5}{|l|}{$\begin{array}{l}\text { World Crude Oil Price } \\
\text { (1986\$/barrel) }\end{array}$} \\
\hline 1986 & $\$ 15$ & $\$ 15$ & $\$ 15$ & $\$ 15$ \\
\hline 1990 & $\$ 22$ & $\$ 14$ & $\$ 22$ & $\$ 22$ \\
\hline 2000 & $\$ 36$ & $\$ 21$ & $\$ 36$ & $\$ 36$ \\
\hline 2010 & $\$ 44$ & $\$ 26$ & $\$ 44$ & $\$ 44$ \\
\hline \multicolumn{5}{|l|}{ U.S. Economic Growth Rate, } \\
\hline \multicolumn{5}{|l|}{$\begin{array}{l}\text { U.S. Lower-48 Inferred and } \\
\text { Undiscovered Resources (Tcf) }\end{array}$} \\
\hline Conventional & $627^{a}$ & $627^{a}$ & $388^{b}$ & $627^{a}$ \\
\hline Unconventional at $\$ 5 / \mathrm{Mcf}$ & 97 & 97 & 0 & 97 \\
\hline Infill Drilling at $\$ 5 / \mathrm{Mcf}$ & 50 & 50 & 44 & 50 \\
\hline TOTAL & 774 & 774 & 432 & 774 \\
\hline Proved Reserves Lower-48 (Tcf, 1986) ${ }^{c}$ & 159 & 159 & 159 & 159 \\
\hline Total Undiscovered Plus Proved & 933 & 933 & 591 & 933 \\
\hline Canadian Export Cap (Tcf/yr) & 2 & 2 & 2 & 2 \\
\hline \multicolumn{5}{|l|}{$\begin{array}{l}\text { Extra Potential U.S. } \\
\text { Utility Gas Demand (Bcf/yr) }\end{array}$} \\
\hline 1990 & 0 & 0 & 0 & 296 \\
\hline 2000 & 0 & 0 & 0 & 1431 \\
\hline :010 & 0 & 0 & 0 & 2807 \\
\hline \multicolumn{5}{|c|}{$\begin{array}{l}\text { Tcf-Trillion cubic feet. } \\
\text { Bcf--Billion cubic feet. } \\
\text { Mcf-Thousand cubic feet. } \\
\text { a } 1986 \text { Potential Gas Committee (PGC) Most Likely Estimate, plus } 7 \text { Tcf for offshore gas deeper than } 1000 \text { meters. Estimate } \\
\text { is not based upon any explicit price assumptions. } \\
\text { bBased upon } 1986 \text { PGC Low Estimate, which assumes "that there is approximately a } 90 \text { percent or greater probability that at } \\
\text { least this much natural gas resource is present." Also includes } 4 \text { Tcf of offshore gas in water deeper than } 1000 \text { meters. Estimate } \\
\text { is not based upon any explicit price assumptions. See "EMF } 9 \text { Study Design" in Volume } 3 \text {. } \\
\text { 'Discovered gas that is excluded from estimates of undiscovered resources. }\end{array}$} \\
\hline
\end{tabular}


in the PGC estimates. These resources include those from extended infill drilling, unconventional sources (tight sand formations, Devonian shale, and coal beds), and offshore areas in water depths greater than 1,000 meters. The total lower-48 natural gas resource base equals $933 \mathrm{Tcf}$ of undiscovered gas plus proved reserves. ${ }^{5}$

Gas exports from Canada to the United States are capped at $2 \mathrm{Tcf}$ each year. In the near term, this upper limit represents the existing pipeline capacity (1.75 Tcf/year) for Canadian exports, with minor modifications such as repressuring. In the longer term, the 2 Tcf cap reflects the group's assessment of the maximum economic export capacity from Canada to the United States. No standardized assumptions are adopted for the Canadian resource base, leaving specific inputs to the discretion of each analyst.

\section{Low U.S. Resources}

The low resource scenario is designed to study the effect of a lower U.S. resource base on the North American gas market. The Canadian resource base, constraints on Canadian-U.S. gas trade, oil prices, and economic growth assumptions remain unchanged from the upper oil price scenario, which serves as a control case for comparing the low U.S. resource and high U.S. demand as well as lower oil price scenarios.

The resource base in the low resource scenario is derived from the minimum potential resource estimate published in the 1986 PGC report. ${ }^{6}$ This resource estimate assumes a 90 percent probability that there is at least this much conventional gas remaining to be discovered. Separate estimates for the resource from infill drilling and deepwater areas are also included in this scenario, but at lower levels than those specified in the control resource

\footnotetext{
${ }^{5}$ This scenario approximates the recent DOE lower- 48 gas resource estimate of $1059 \mathrm{Tcf}$, after adjusting for minor differences in definitions. See Chapter 6 for details.

${ }^{6} \mathrm{~A}$ rule-of-thumb algorithm was used to approximate the probabilistic methodology that would be required to correctly add regional estimates. See "EMF 9 Study Design" in Volurne 3 for the methodology used to derive these estimates.
}

base. Total undiscovered resources (including the additional sources) available at $\$ 5.00$ per Mcf are reduced from $774 \mathrm{Tcf}$ in the control resource base to $432 \mathrm{Tcf}$ in the low resource base. Including proved reserves, the low resource base incorporates 591 Tcf. $^{7}$

The PGC also publishes a high or maximum resource estimate, which assumes a 10 percent probability of at least that amount of conventional gas remaining to be discovered. For purposes of this study, however, the EMF working group decided not to consider a high resource base because the range of resource estimates from the first two resource estimates in this study bracketed the range of resource estimates from other studies.

\section{High U.S. Demand}

Gas use in electric generation has attracted considerable interest within both the natural gas and electric utility industries. Electric generation represents a potential growth sector for natural gas use, which has been stagnant or declining for almost two decades. At the same time, producers of electric power find gas-based technologies attractive for many reasons.

The high dernand scenario is specified so that the effects of increased gas use for electric generation on the natural gas market can be examined. This analysis is not intended to predict the level or potential for increased gas consumption for electric generation. There is a number of available studies which examine this potential and predict future consumption levels. Instead, the high demand results provide an opportunity to systematically examine the impact of increased gas use in generating electricity on delivered and weilhead gas prices, total and sectoral consumption, marketed production, and imports.

Most modelers have already incorporated significant gas use for cogeneration and some gas use

\footnotetext{
${ }^{7}$ The EMF estimate in the low U.S. resource case is about 60 Tcf higher than the recent Department of Interior estimate of 527 Tcf of undiscovered plus proved gas reserves. See Chapter 6 for details.
} 
for combined-cycle gas turbines in the other three scenarios. Thus, the high U.S. demand case represents extra gas demand by electric utilities for combined-cycle gas turbines and an acid rain policy that encourages natural gas use. All other assumptions remain unchanged from the upper oil price scenario.

\section{EMF Industry Survey}

The EMF 9 Study Group also surveyed a group of oil companies and other organizations to determine their natural gas supply and demand outlooks for comparison to the model results. A similar survey was conducted by the National Petroleum Council (NPC) in 1986. The results from the EMF 9 survey were in close agreement with the NPC survey results.

\section{Major Findings and Insights}

Although there are some important differences among models, the averages of the model results from the four scenarios reveal some key trends and relationships:

1. Gas prices in the United States and Canada begin to reverse their decline by 1990 , thereafter rising continuously in all scenarios. By 2000 , inflation-adjusted gas prices reach their peak of the early 1980s, even in the lower oil price case.

Surplus deliverability - the gas bubble-has existed in the U.S. gas industry since the beginning of the 1980s and has contributed to declining gas prices in recent years. The model results show this price trend reversing by 1990 in all scenarios (Figure 4.1), suggesting that the period of excess deliverability is nearing an end.

Starting from 1990, all scenarios show wellhead prices increasing over time, but by varying rates depending on the scenario. Through the early 1990s, higher gas prices reflect increases in oil prices and the elimination of today's excess deliverability condition. Over the long run, wellhead gas prices reflect the higher cost of finding and developing gas reserves. Prices increase most rapidly in the low resource case and least rapidly in the low oil price scenario.

Over the next 25 years, the projections show that the U.S. gas industry will need to find and develop another 350 to 400 trillion cubic feet (Tcf) of reserves. Increased drilling productivity, above that represented in the model runs, could reduce the rate of cost increase but is unlikely to reverse the upward trend in costs and prices. In addition, price volatility around these long-run trends can be expected as the industry adopts more flexible-pricing mechanisms. Seasonal conditions will contribute to wide swings in price as well.

2. Natural gas and residual fuel oil prices need not necessarily track each other on a Btu basis. Future market conditions could cause oil and gas prices to diverge. Simple rules relating the two fuel prices, e.g., oil-netback prices, could lead to incorrect forecasts and decisions.

Bumertip parity between gas and residual fuel oil prices may not hold throughout the next several decades. Across a reasonable range of uncertainty in oil price, resource base size, and demand assumptions, no "ironclad" rule relating gas to residual oil prices was observed in the model results.

Models such as those used here can help to identify precisely which fuel sets the price of gas. The upper oil price path encourages sufficient gas supply to meet a growing gas market at prices competitive with or less than residual oil prices. Half of the models show average U.S. residual fuel oil and industrial natural gas prices in rough equivalence on a Btu basis. In the other models, gas and oil prices decouple since gas supplies are more than adequate to meet market demand at competitive residual fuel oil prices.

Under the lower oil price conditions, gas production and consumption generally decrease through the period while gas prices rise relative to residual fuel oil prices. Gas loses market share to oil as it becomes less price competitive. With oil prices only slightly higher than today's levels by 2000 


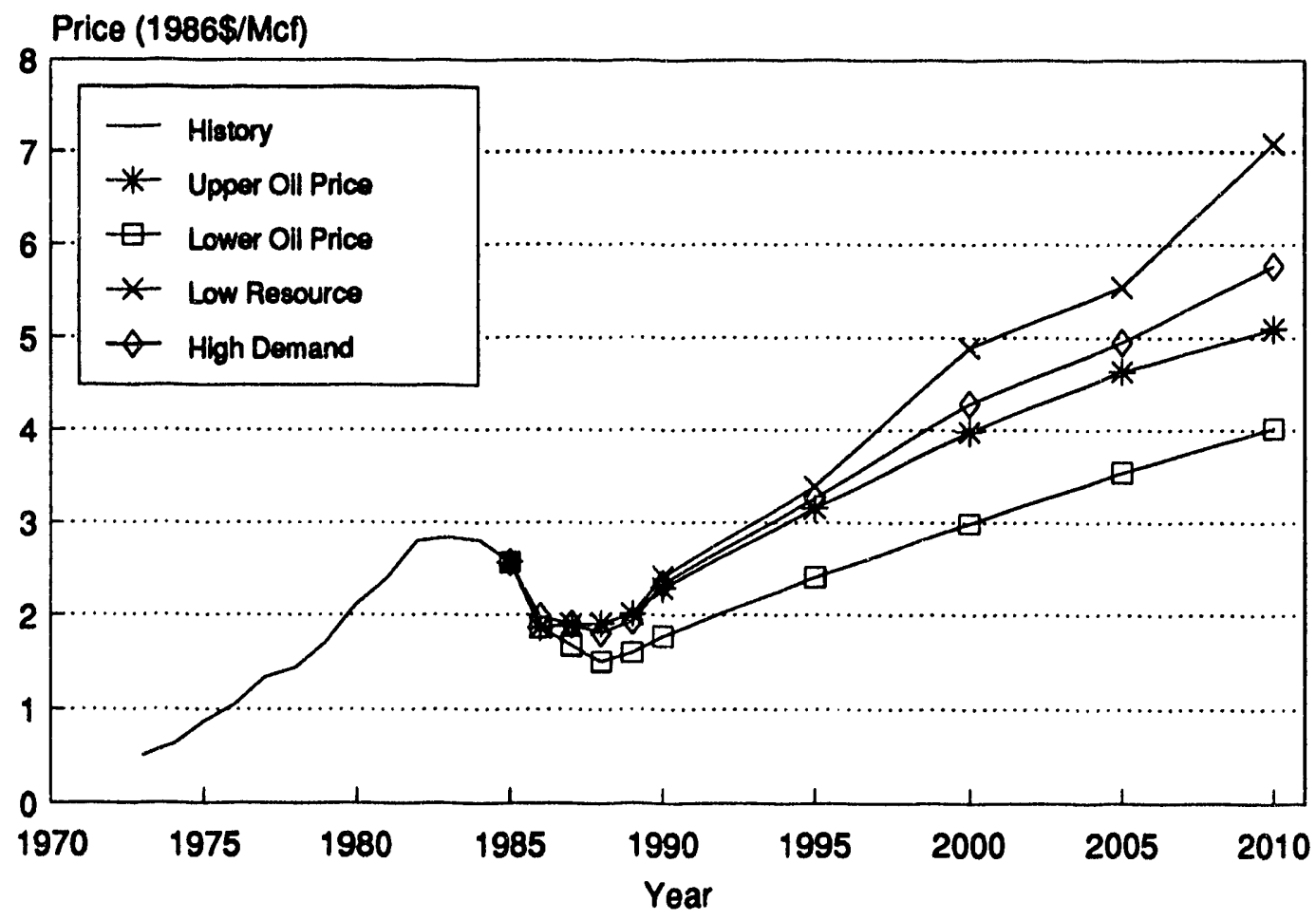

Figure 4.1: Model Means for Average U.S. Wellhead Price by Scenario

( $\$ 21$ per barrel in 1986\$), gas prices rise above the average residual oil price in those models that had indicated residual oil-gas parity in the upper oil price case, as gas competes against low-sulfur residual oil and distillate oil. Meanwhile, gas competes directly with residual fuel oil in those models that had indicated oil-gas price decoupling with the higher oil price.

3. The cost of proving and producing reserves is as important as the extent of resources in place for determining gas supply and price. There is wide disagreement over what these costs will be in different producing regions. Despite standardizing on the oil price and physical magnitude of the resource base, these differences lead to substantial variations in marginal resource costs among the models.

Costs to find, develop, and produce the gas resource are critically affected by field size, location, geologic setting, and depth of occurrence. Assumptions about these factors will affect the shapes of the supply curves represented in a model. The model results emphasize that these costs are at least as important as geologic estimates of the extent of the resource base in physical terms in determining gas supply. However, since most published resource estimates are given in terms of the ultimate resources yet to be discovered, market analysts must translate the published estimates into a form usable for their analyses.

As a result, despite standardizing on oil price and the physical magnitude of the resource base in this study, there were substantial differences in marginal resource costs among the models. Modelers using the same aggregate resource base are generally not using the same supply curve relating future production to prices. These differences explain much of the variation in consumption in the upper oil price scenario among those models with a detailed set of supply and demand balancesICF, GAMS, and TERA. More optimism about supply costs leads to lower market-clearing prices and higher consumption; less optimism about these 
costs results in higher market-clearing prices and lower consumption. In addition, important differences in interpretation of the low resource scenario were discovered. One expert may believe that a more pessimistic resource outlook means less highcost gas but little change in the amount of low-cost gas. To another, a lower resource base may mean less gas for all cost categories. The impact of these two views on the gas market can be dramatically different.

4. The level of future U.S. production will depend upon oil prices, the costs of undiscovered resources, and gas demands. These factors alone can result in a wide range of production across the four scenarios-from 14 to 18 trillion cubic feet (Tcf) by 2000 and from 12 to $19 \mathrm{Tcf}$ by 2010 (according to the model means).

A combination of changing market conditions, structural shifts in the U.S. economy, and resource considerations may cause a wide variation in the amount of gas produced. Future conditions keep gas production below $19 \mathrm{Tcf}$ in all scenarios through 2010 (Figure 4.2), or several Tcf below its historical pcak (21.7 Tcf in 1973). While this would seem to indicate a surplus of pipeline capacity throughout that period, regional shifts in both supply and demand centers could mean that the existing capacity is not located where it will be needed in the future.

The working group also polled industry analysts on their projections for the gas market under the two predetermined oil price paths. These alternative projections represent a combination of company-specific modeling and informal analysis. Figure 4.2 shows that the EMF industry survey's average estimate for U.S. dry gas production with the upper oil price assumptions lies much more in line with the EMF model results for the low U.S. resource scenario through 2000. By 2010, the average survey estimate lies between the average EMF results from the upper oil price and low U.S. resource cascs, but closer to the latter. The lower survey cstimates can be attributed to one or more of the following factors: a lower resource base estimate than in the EMF control resource inputs, less future spending for oil and gas drilling, and higher costs for finding and developing natural gas.

5. Marketed production in the United States remains relatively stable at about $16 \mathrm{Tcf}$ in the upper oil price scenario. Both the lower oil price and the low resource conditions result in declines in U.S. gas production relative to the upper oil price scenario. Production, on average, is $2.5 \mathrm{Tcf}$ lower in 2010 in the lower oil price case and 4.5 Tcf lower in 2010 in the low resource case.

In the lower oil price case, reduced production is caused by lower drilling and exploration incentives due to lower gas prices and to fuel switching, since burnertip gas prices do not fall as much as residual fuel oil prices. In the low resource case, insufficient gas production exists to meet the demand, causing gas prices to rise relative to fuel oil prices. The higher relative gas prices induce fuel switching from gas to oil to rebalance the gas market.

6. The demand for U.S. gas imports grows significantly, reaching 2 Tcf or more by 2010 in most scenarios compared to about $1 \mathrm{Tcf}$ in 1987. The import share of total consumption is higher under the low U.S. resource or high U.S. demand cases.

U.S. gas imports rise in all scenarios (Figure 4.3), reflecting the need for large amounts of foreign gas to supplement domestic production to meet U.S. demand at the projected prices. Most of the imports are from Canada, but some of the models also call on significant amounts of LNG imports and some Mexican gas to satisfy demand. Imports become very important in the low resource case. They rise to $2.5 \mathrm{Tcf}$ by 2000 and $3.0 \mathrm{Tcf}$ by $20^{\prime} 0$, which raises the import share from about 5 percent to 15-20 percent of total U.S. consumption. In the other cases, the import share rises steadily to about 10 to 15 percent of the U.S. market. 


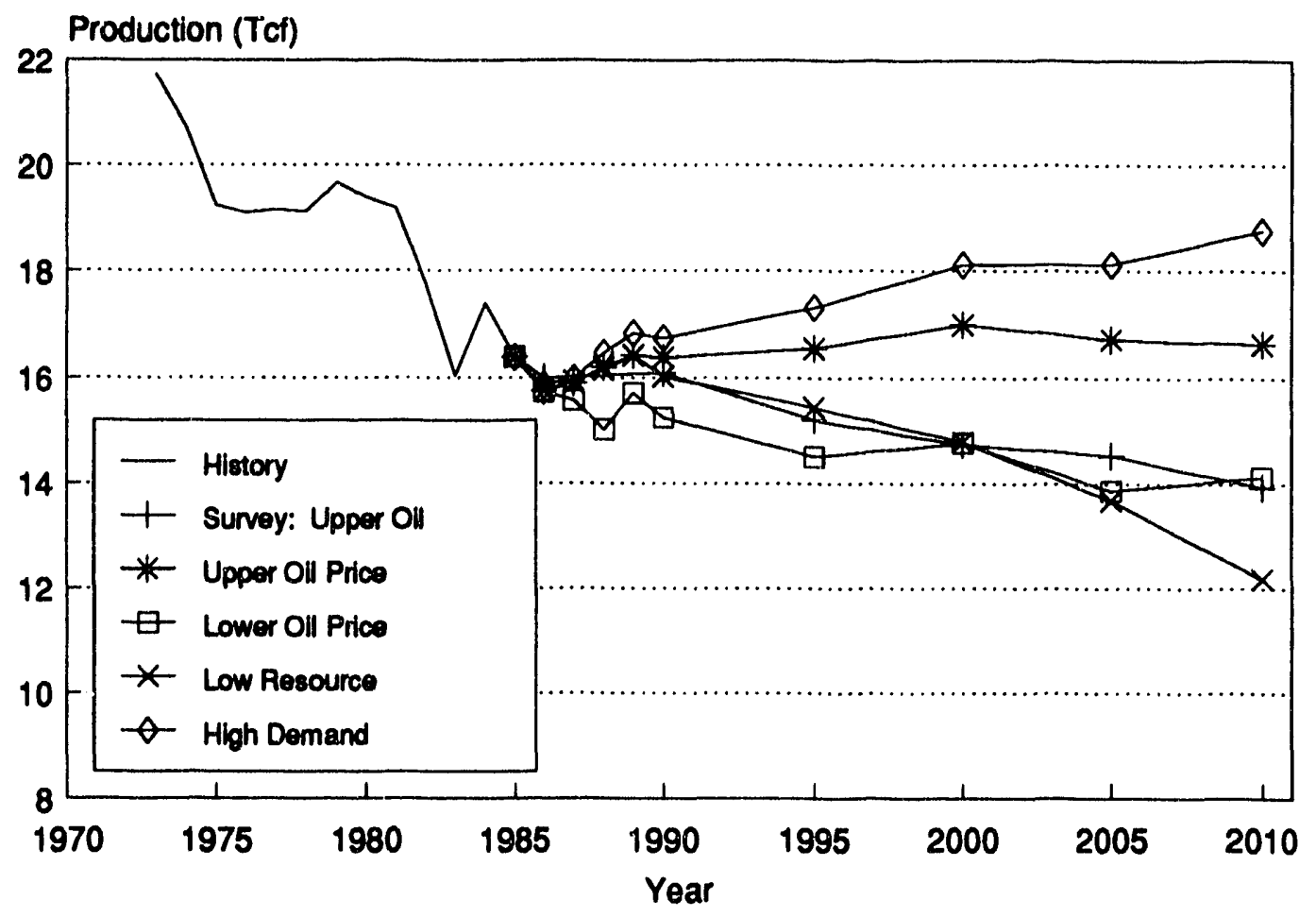

Figure 4.2: Model Means for U.S. Marketed Production (Dry Gas) by Scenario

Note: Figure is not based at zero in order to show clearly the differences in trends. Hence, relative differences are exaggerated.

In the low oil price case, switchable load substitutes oil for gas, shrinking the size of the U.S. gas market. Initially, gas prices fall to meet this competition, but the marginal cost of gas increases over time, causing gas prices to rise relative to oil prices. In this kind of world, low prices and a constricted gas market limit opportunities for Canadian exports.

7. Canadian export levels of 2 Tcf can be sustained with the upper oil price path if frontier and unconventional supplies are developed in a timely manner. Under lower oil price conditions, however, gas trade between the two countries is likely to decline below this level. Additional analyses need to be undertaken to reconcile U.S. import requirements and Cana. dian export potential.

While most industry observers do not expect significant U.S. gas trade with Mexico, they do an- ticipate growth in Canadian imports. The recent shift towards more competitive policies in Canada and in the United States and regulatory changes in energy trade between the U.S. and Canada mean that pipeline imports into the United States will be increasingly driven by market conditions.

Models that contain explicit representation of Canadian gas production and the Canadian gas market cast doubt on whether the exports (American imports) assumed by the other models will be forthcoming at the projected prices. In the low oil price case, gas prices are low and result in enough Canadian production to supply only about $1.5 \mathrm{Tcf}$ of exports by 2010 . However, half of the U.S. models forecast a need for 2 Tcf or more by 2010 in this scenario. Higher prices in the other scenarios result in more Canadian exports, although much of that Canadian gas may have to come from the Canadian frontier (e.g., the Mackenzie Delta and the Arctic Islands) and from tight formations in the 


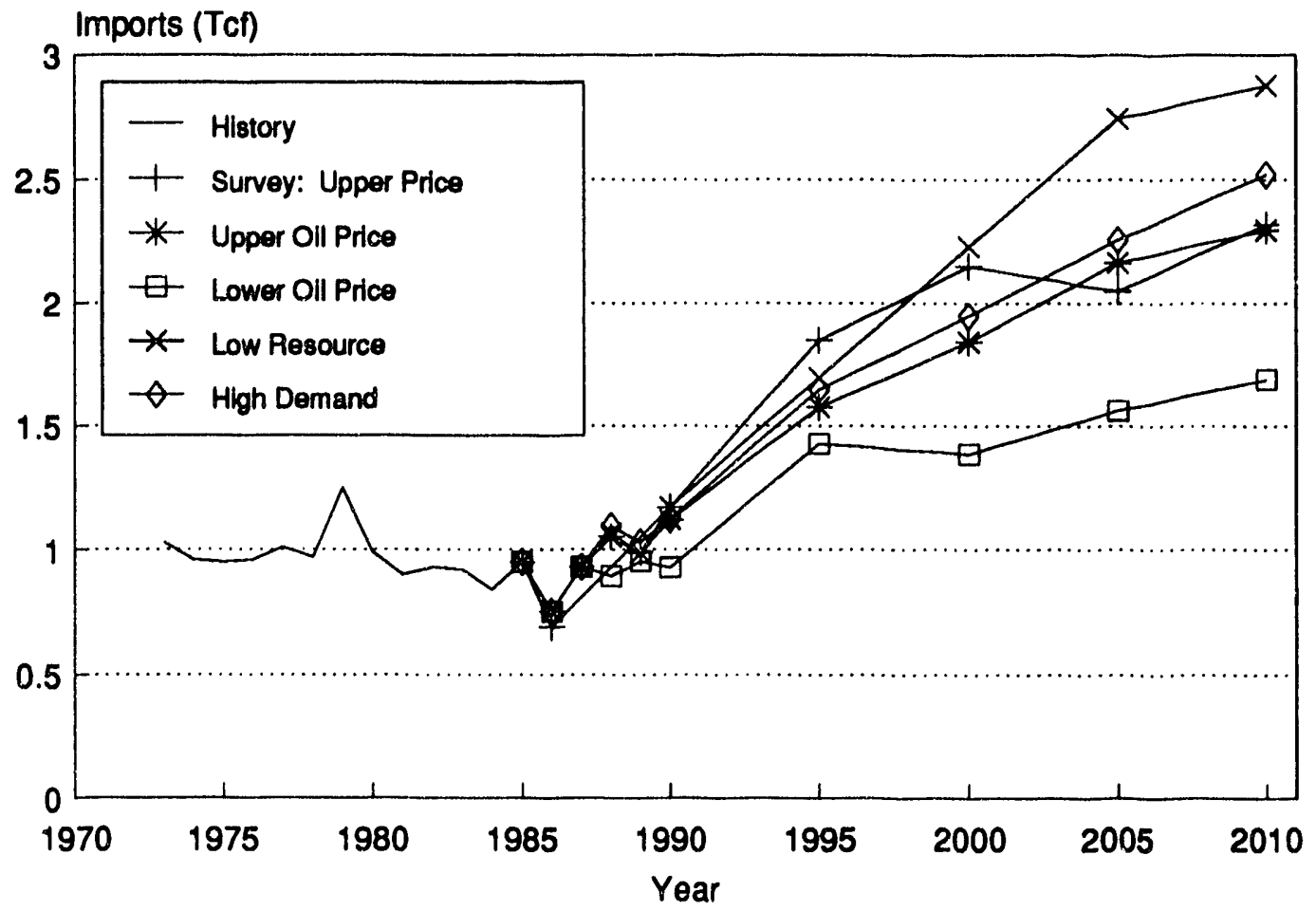

Figure 4.3: Model Means for U.S. Imports by Scenario

Deep Basin areas of Alberta and British Columbia. The needed transportation facilities for frontier gas and production technology for tight gas must be put in place in time for production to occur in the projected time frame.

The response of gas imports to different U.S. market conditions underscores the value of considering the North American gas industry as an integrated market. Many U.S. projections, and a few of the models in this study, do not incorporate the feedbacks between Canadian and U.S. markets. This approach may lead to projections of imports that are too high under lower oil prices or too low when U.S. supplies are more expensive.

8. Variations in the results of industrial demand are quite large by 2010 , ranging from a total of $4 \mathrm{Tcf}$ to approximately $8 \mathrm{Tcf}$ in different models in the upper oil price scenario. Much of this variation stems from fuel switching and different assumptions about the penctration of new industrial gas-fired technologies. The range in the demand by electric utilities is also large-from 2.9 to $5.7 \mathrm{Tcf}$ by 2010 - depending upon assumptions about environmental regulations, fuel prices, and load growth. Furthermore, commercial demands will vary substantially, depending on the peneiration of gas-fired cooling and cogeneration.

9. Gas consumption falls in the low oil price and low resource cases as many industrial and electric utility users switch to oil. These trends indicate increasing reliance on oil imports to replace gas. However, other indigenous fuels, e.g., coal, may also be substituted for gas.

Total U.S. gas use (Figure 4.4) ranges from 16 to $20 \mathrm{Tcf}$ by 2000 and from 15.5 to $21.5 \mathrm{Tcf}$ by 2010 , according to the mean of individual model results by scenario. In the low oil price scenario, total gas consumption in the various projections falls by between 1 and 5 Tcf by the year 2010 when compared to the high oil price scenario, with an average decline of $2.9 \mathrm{Tcf}$. In the low resource 


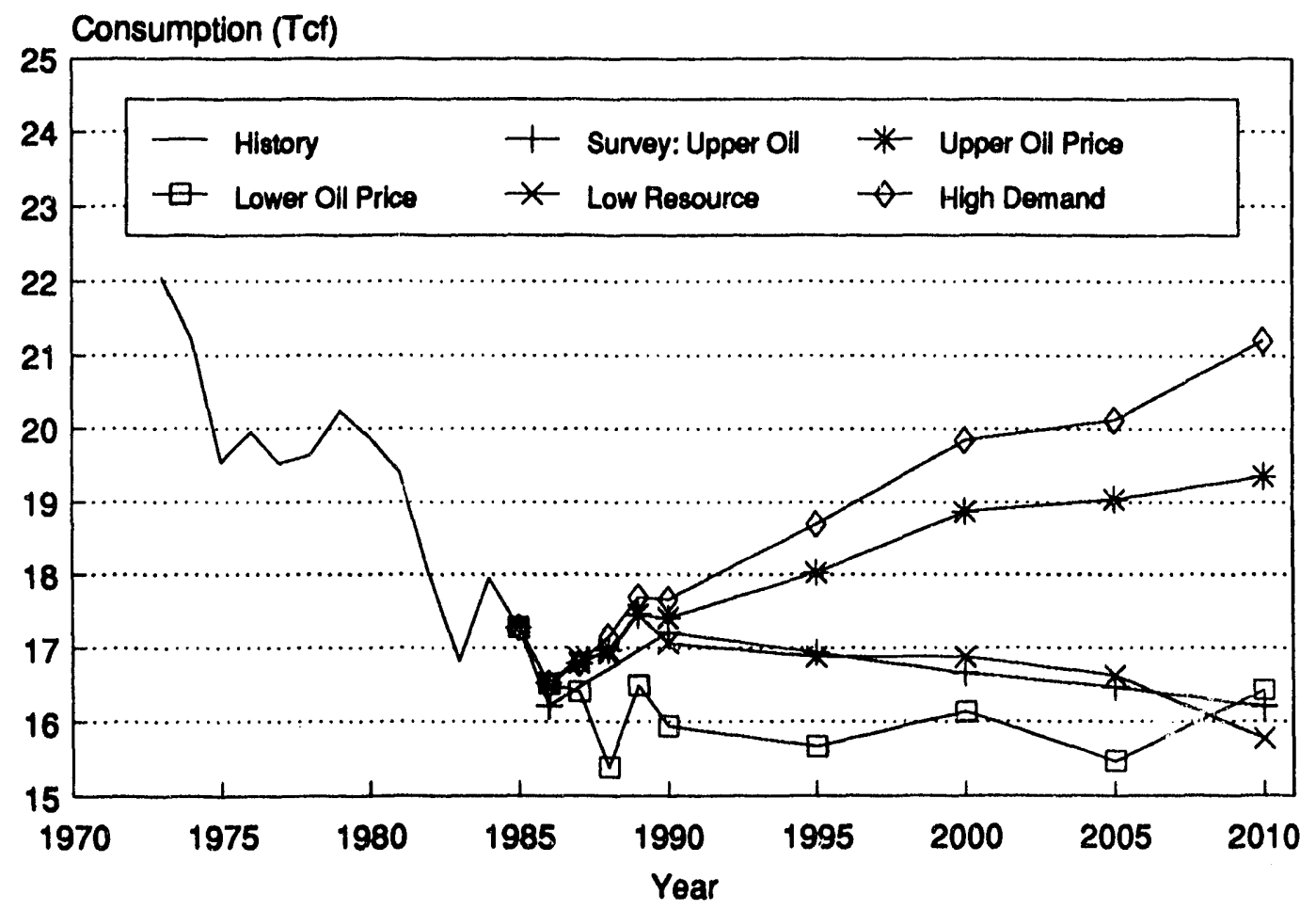

Figure 4.4: Model Means for Total U.S. Consumption by Scenario

Note: Figure is not based at zero in order to show clearly the differences in trends. Hence, relative differences are exaggerated.

case, total gas consumption falls by between 1 and $7 \mathrm{Tcf}$ by the year 2010, with an average decline of 3.5 Tcf. While not all lost gas consumption is replaced by oil imports, these average declines are equivalent to 1.4 to 1.7 million barrels per day of oil use.

10. The high demand scenario suggests that higher demand levels by electric utilities can be sustained, but gas prices must increase to bring forth the required gas supplies. The higher gas prices reduce gas consumption in other gas demand sectors and encourage additional exploration and development of gas resources.

The effect of an increase in gas demand in the electric utility sector was analyzed in the high demand scenario. Additional combined-cycle gas turbine capacity and an acid rain policy favoring gas use are assumed to augment potential gas demand in this scenario by $2.8 \mathrm{Tcf}$ by 2010 .

The model results indicate that higher demand levels by electric utilities can be sustained under these conditions, but gas prices must increase to bring forth the required gas supplies. The higher price encourages additional exploration and development of gas resources. It also reduces electric utility and industrial gas usage that competes with lower-valued fuels (such as residual fuel oil) as well as gas consumption in other sectors. As a result, the net increase in total consumption by 2010 is considerably smaller than $2.8 \mathrm{Tcf}$-between 1.5 and $2.0 \mathrm{Tcf}$. Increased U.S. domestic production in response to the higher gas prices accounts for most of the additional gas sold. Imports rise by less than 0.2 Tcf from their upper oil price case levels in most models, due partially to the upper bound of 2 Tcf per year imposed on Canadian gas trade. 
While prices are higher than those in the upper oil price scenario, gas continues to be competitive in the dual fuel-burning, switchable market in this scenario for most models. In several models where price parity between natural gas and residual oil already exists in the upper oil price (control) case, fuel switching by industrial customers prevents prices from rising much more with the higher demand.

11. Fuel switching between oil and gas in dualfired boilers has important implications for how gas markets adjust to changes in market conditions. The larger the potential fuelswitching response to changes in the oil-togas price ratio, the smaller the price adjustment required to restore the balance between gas supplies and demands as industry conditions change.

Estimates of the amount of fuel switching in dual-fired boilers vary. This response can be critical in determining gas prices under alternative conditions. When potential fuel switching is extensive, gas prices will not change appreciably in response to shifts in supply or demand conditions because large losses in loads are experienced. Under these conditions, oil prices essentially determine gas prices. On the other hand, if fucl switching is less extensive once gas and oil prices are decoupled, shifts in resource or demand conditions could cause prices to rise or fall sharply.

12. The response of gas supply to price changes will be importarit for determining how gas markets adjust to changes in market conditions. The more responsive gas supply is to price, the smaller will be price adjustments for balancing supply and demand when resource or demand conditions change.

Prices in the North American gas markets are increasingly being set by the interaction of supply and demand conditions. When demand or supply conditions change, prices must change to restore a balance. The response of gas supplies to price will have a significant effect on how high prices will have to increase to encourage more supply to meet higher levels of demand. The more responsive gas supplies (including imports) are to higher prices, the less gas prices will need to increase. Generally, the models indicate that while gas supplies are definitely responsive to price, the percentage increase in marketed production is less than the percentage increase in the wellhead gas price.

13. Several methodologies exist for modeling natural gas markets, with the appropriate approach depending upon the objectives of the analysis. However, methodology appears to account for only a portion of the variation in model results. More important are different perspectives on and uncertainty about fundamental supply, demand, and pricing relationships in the market.

The models used in this study represent two distinct approaches to determining natural gas prices and quantities. One group of models represents supply and demand decisions in considerable detail, using a combination of detailed resource estimates, engineering process description, and econometric relationships. Another group of models focuses on the allocation of gas to satisfy competitive equilibria in many regional markets, using relatively simple relationships between supply (and demand) and prices.

Key differences in model results did not appear to be directly attributable to the methodologies adopted. The responses in prices, production, consumption, and imports are more dependent on key parameters, such as the response of supply and demand to price, reflecting fundamental uncertainties about gas market dynamics.

Both groups of modelers potentially can leam much from each other. Additional physical realities, such as leasing, exploration, development, and production cycle, could be usefully incorporated in economic models focusing on regional supplydemand equilibria. Additional economic realities of regional competition for gas flows could be usefully incorporated in engineering-economic models 
that represent supply and demand decisions in considerable detail.

14. Models of the natural gas markets have been very useful in this study for understanding some key long-run relationships goveming the gas markets under workably competitive conditions in the industry. As the market develops, it will become important to use these frameworks for representing the increasing integration between supply and demand decisions in different regions and countries. At the same time, the models used in EMF 9 do not completely represent either short-run market dynamics or regulatory behavior changes. Developing analyses that incorporate shortrun market and regulatory behavior represents an important challenge for modelers and other analysts.

The use of these models has helped to focus the working group's discussion of several critical relationships: the relationship between oil and gas prices, the interaction between Canadian and U.S. markets, the implications of a lower resource base, and increased gas demand on the market. By using the models in this study, the group was able to focus its discussions on these issues and to quantify their relative importance. While the model results stimulated discussionss of many important issues, gas price volatility, for axample, could not be probed with the models. Additionally, regulatory issues, such as the pricing of pipeline access, could not be examined. Future natural gas modeling should include efforts to incorporate these critical issues.

\section{Upper Oil Price}

\section{Summary}

The upper oil price scenario is based on oil prices escalating from $\$ 18$ in 1986 to $\$ 22$ in 1990 and $\$ 36$ in 2000 (1986\$). The undiscovered resource base of $774 \mathrm{Tcf}$ used in this scenario was the PGC "most likely" estimate, adjusted to include unconventional, infill, and deepwater Gulf of Mexico reserves. Under these conditions, several key conclusions emerge:

- There are important differences among models in the costs of U.S. resources, even though all models used the same volumetric estimate of physical gas resources. In this scenario, models using a detailed resource base description generally have lower production than those using a more aggregated description of the resource base.

- Gas prices rise in all models. However, gas competes favorably in the switchable market with prices equal to or less than residual fuel oil prices.

- Total consumption is expected to be at least 16 Tcf through 2010. While model consumption results vary by as much as 4 Tcf, historical peak consumption levels of $22 \mathrm{Tcf}$ are not reached.

- U.S. imports are projected to be 1 to $2 \mathrm{Tcf}$ from now to 2000 , and 2 Tcf or greater in the post-2000 period.

\section{Trends}

As represented by the average projection in Table 4.3, this scenario calls for a market in which marketed production (dry gas) remains remarkably stable, with much of the growth in consumption being satisfied by rising imports. Although gas prices rise throughout the period, the industrial gas price remains well below the residual fuel oil price on a Btu basis. There exists some variation around the average in these results (as shown in Table 4.3). Relative to the averages reported at the top of the table, this variation is particularly large for imports and small for production and consumption.

\section{Representation of the Scenario}

Differences in supply conditions explain much of the variation in the projected prices and quantities 
Table 4.3: Key U.S. Results from Upper Oil Price Scenario, 1985-2010

\begin{tabular}{|c|c|c|c|c|c|c|}
\hline & 1985 & 1990 & 1995 & 2000 & 2005 & 2010 \\
\hline \multicolumn{7}{|l|}{ Average } \\
\hline \multicolumn{7}{|l|}{ Tcf/yr: } \\
\hline Marketed Production & 16.38 & 16.47 & 16.69 & 17.25 & 17.14 & 17.11 \\
\hline Total Imports & 0.95 & 1.12 & 1.58 & 1.84 & 2.17 & 2.30 \\
\hline Total Consumption ${ }^{a}$ & 17.28 & 17.41 & 18.03 & 18.87 & 19.04 & 19.35 \\
\hline Import Share (\%) & $5.5 \%$ & $6.4 \%$ & $8.7 \%$ & $9.8 \%$ & $11.4 \%$ & $11.9 \%$ \\
\hline \multicolumn{7}{|l|}{ Price (1986\$/Mcf): } \\
\hline Average Wellhead & 2.57 & 2.25 & 3.10 & 3.86 & 4.50 & 4.96 \\
\hline Average Delivered & 4.84 & 4.07 & 4.86 & 5.72 & 6.36 & 6.75 \\
\hline Crude Oil Parity ${ }^{b}$ & 4.83 & 3.79 & 4.83 & 6.21 & 6.90 & 7.59 \\
\hline \multicolumn{7}{|l|}{ Pct of Crude Oil } \\
\hline Average Wellhead Price & $53.2 \%$ & $59.4 \%$ & $64.2 \%$ & $62.2 \%$ & $65.3 \%$ & $65.4 \%$ \\
\hline Average Delivered Price & $100.3 \%$ & $107.3 \%$ & $100.6 \%$ & $92.2 \%$ & $92.2 \%$ & $89.0 \%$ \\
\hline \multicolumn{7}{|l|}{ Pct of Residual Fuel } \\
\hline Industrial Gas Price & $100.0 \%$ & $99.6 \%$ & $94.9 \%$ & $88.7 \%$ & $88.1 \%$ & $87.1 \%$ \\
\hline \multicolumn{7}{|l|}{ Relative Deviation } \\
\hline \multicolumn{7}{|l|}{ From Average ${ }^{\mathcal{C}}(\%)$ : } \\
\hline Marketed Production & & $4.9 \%$ & $6.9 \%$ & $7.1 \%$ & $6.8 \%$ & $6.0 \%$ \\
\hline Total Imports & & $31.0 \%$ & $28.4 \%$ & $36.1 \%$ & $48.0 \%$ & $42.1 \%$ \\
\hline Total Consumption & & $4.2 \%$ & $5.5 \%$ & $5.6 \%$ & $5.1 \%$ & $5.2 \%$ \\
\hline Average Wellhead Price & & $14.6 \%$ & $21.1 \%$ & $22.4 \%$ & $18.0 \%$ & $14.3 \%$ \\
\hline Average Delivered Price & & $8.4 \%$ & $13.7 \%$ & $15.2 \%$ & $14.0 \%$ & $11.8 \%$ \\
\hline
\end{tabular}

\footnotetext{
Averages for seven U.S. models; excludes GRI Hydrocarbon for which no consumption or imports were reported. ${ }^{a}$ Excludes changes in inventories and unaccounted for.

${ }^{b}$ Crude oil parity is the crude oil price in $1986 \$$ Mcf.

${ }^{c}$ Measures how much each model result deviates from the average on a percentage basis. In actuality, calculated as the standard deviation divided by the mean (in percentage terms).
} 


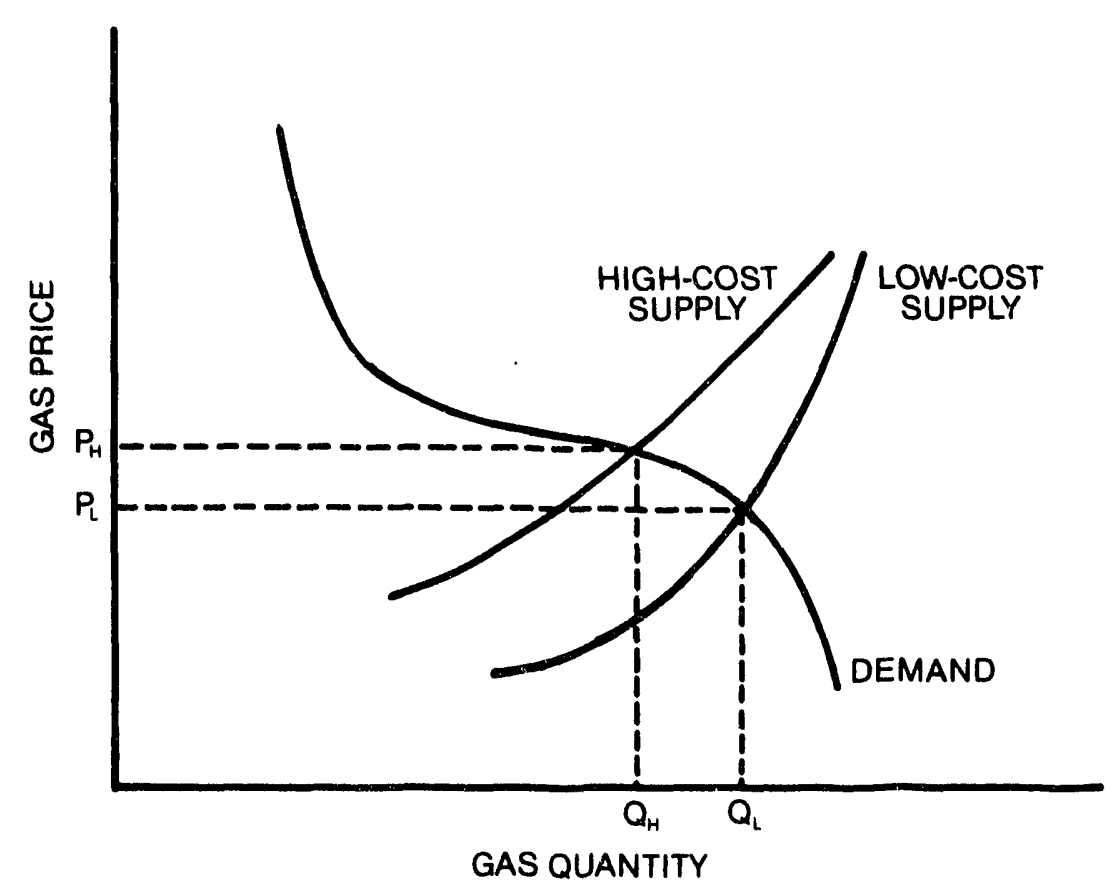

Figure 4.5: Representation of Different Resource Cost Curves

among the various models. This important result can be demonstrated by referring to the rudimentary framework from Chapter 3 to explain the interaction between supply and demand conditions in determining prices and the amount sold. Figure 4.5 extends that framework by showing the effect of two different supply curves on prices and consumption, holding the demand curve fixed. The price required to bring forth any given production level is consistently higher for the curve labeled "high-cost supply" than for the one marked "lowcost supply" (the first curve lies consistently above the second one). With the low-cost supplies, gas markets clear at price $P_{L}$ and quantity $Q_{L}$ for the reasons discussed in Chapter 3. Under high-cost supply conditions, however, prices cannot remain at $P_{L}$ because there is insufficient gas supply to meet demand at that price. As a result, prices must rise to reduce consumption and increase production and imports, until gas markets clear-at a higher price $P_{H}$ and lower consumption level $Q_{H}$ than with the low-cost supply conditions.
This inverse relationship between price and consumption should be observed consistently among models in the EMF results if resource cost conditions vary more across models than do demand conditions. $^{8}$

Models with higher-cost supply should exhibit higher prices and less consumption than models with lower-cost supply. The technical difficulties in translating resource base estimates into projections of marketed production suggest that this will be the case, particularly for models projecting demand by sector, where the EMF scenario inputs could be implemented more precisely. To emphasize these relationships, the discussion of this scenario begins with a comparison of marketed production, proceeds to the issue of market-clearing gas prices and consumption, and ends with a section on gas imports.

\footnotetext{
${ }^{8}$ If demand conditions are more variable than are supply conditions among the models, prices and consumption will move together. Models showing higher (lower) consumption will show higher (lower) prices.
} 


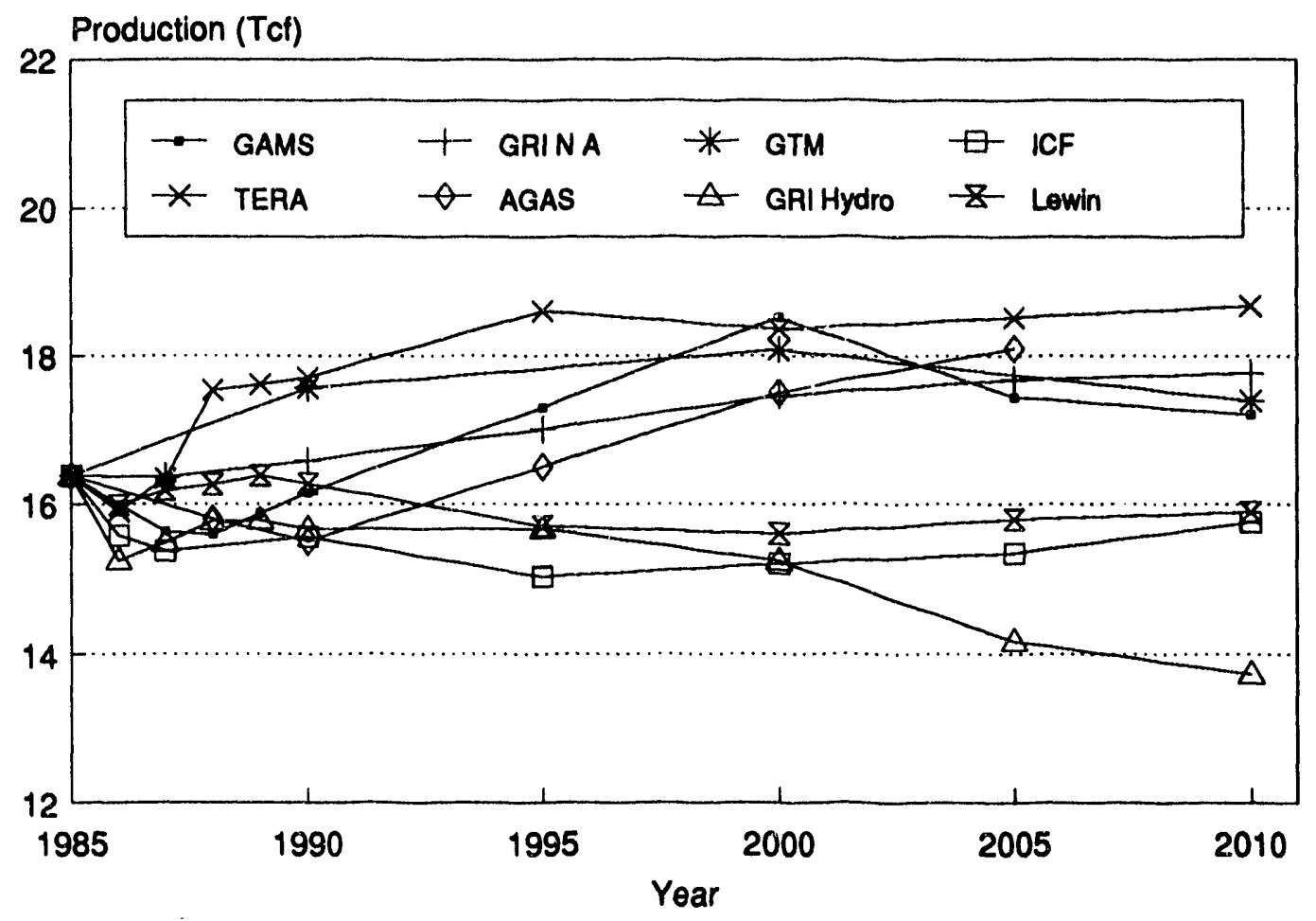

Figure 4.6: U.S. Marketed Production (Dry Gas) in the Upper Oil Price Case

\section{Marketed Production}

Two very different sets of results for production are displayed in Figure 4.6. After 1990, one set declines slowly while the other group rises slowly over time. Differences in the underlying supply conditions, rather than differences in the projected wellhead prices, appear to explain these different production paths.

The production estimates for Lewin, ICF, and GRI Hydrocarbon after 1990 remain consistently lower than those for the other models, despite the fact that wellhead prices in these models are generally higher, as will be discussed in the next section. These three models employ detailed information on the costs and type of resources. In this study, their approach appears to lead to higher costs of finding new gas supplies.

In contrast, marketed production estimated by the other models rises slightly over the horizon. Among these models, only the Energy Information Administration's GAMS projections are based upon detailed resource base inputs, and this model's higher production path is due partially to higher wellhead prices than are projected by the other models in this group. The TERA supply estimates are based upon supply equations fitted statistically to historical data with no explicit representation of the resource base. GTNi and GRI North American use reduced-form supply curves that relate gas production to prices. While these curves are implicitly linked to aggregate resource base inputs, they do not categorize resources by depth and field size. ${ }^{9}$

\section{Prices}

Gas prices rise in all models. However, gas competes favorably in the switchable market with prices equal to or less than residual oil. Although the models agree that the clear trend is up, they disagree on the actual price path.

\footnotetext{
${ }^{9} \mathrm{GRI}$ North American disaggregates the gas resource curve by type of technology.
} 


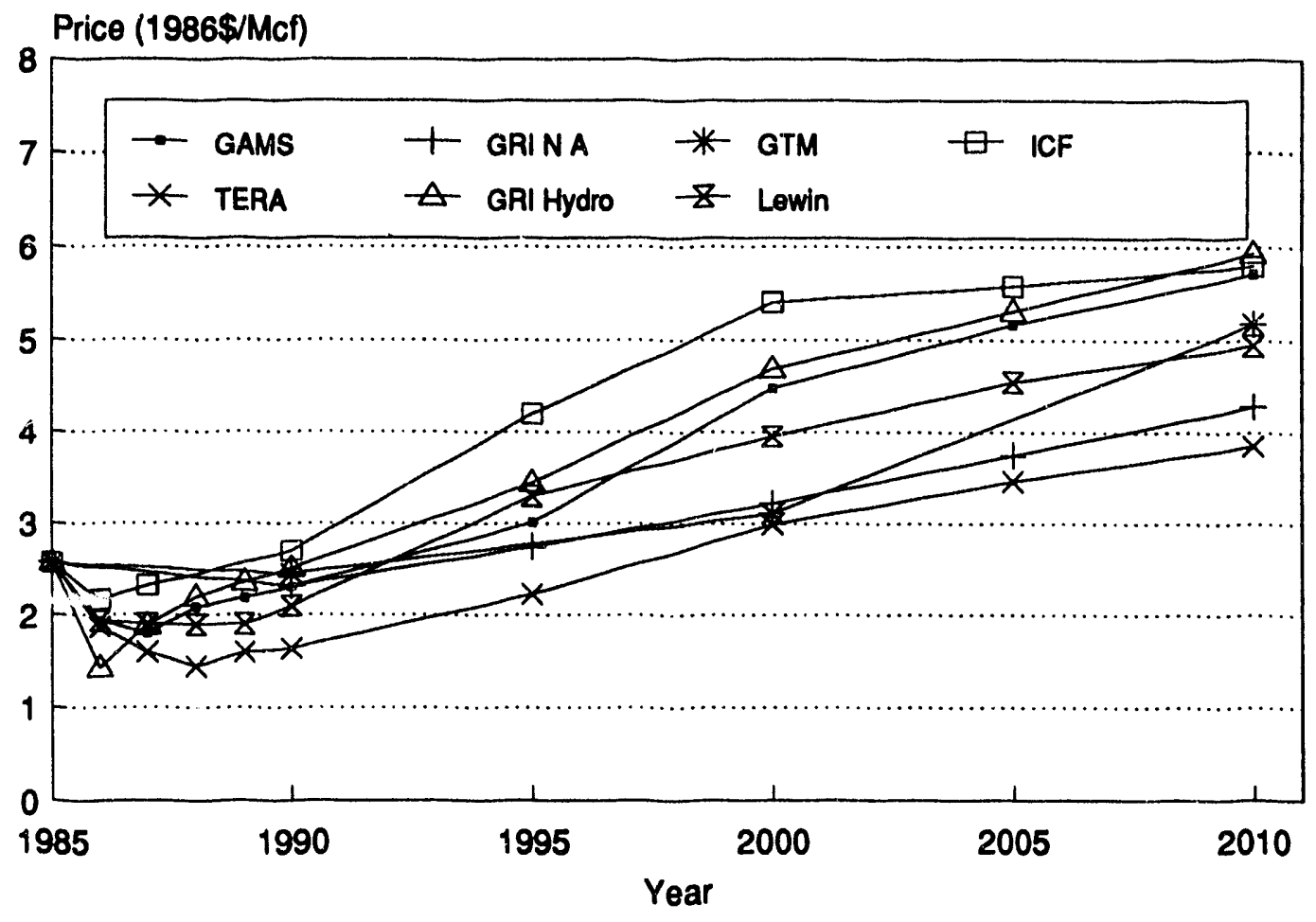

Figure 4.7: U.S. Average Wellhead Price by Model in the Upper Oil Price Case

In Figure 4.7, wellhead prices in the upper oil price case ari geneially higher for models with lower production paths. Thus, the lower production estimates among these models in Figure 4.6 are not due to lower wellhead prices. This general result applies to GRI Hydrocarbon, ICF, and Lewin. The price projections for TERA, GRI North American, and GTM-models with higher production levels-generally remain at the lower end of the range for most of the 1990-2010 period. The GAMS results do not follow this pattern; they show a higher path for both price and production.

All but one model detcrmined a market-clearing price that satisfied both supply and demand conditions. GRI Hydrocarbon was simulated as a standalone supply model, using nethack wellhead prices calculated by EMF. Hence, the price path shown in Figure 4.7 for this model is an assumption developed by the working group rather than a marketclearing price as in the other models' price paths. It is constructed by equating natural gas and residual oil Btu prices at the industrial bumertip and then subtracting a fixed transportation and distribution charge from the delivered gas price. ${ }^{10}$

The average delivered natural gas price for the industrial sector usually equals or falls below the residual fuel oil price on a Btu basis in this scenario (Figure 4.8). Among the models showing fuel price parity during the period, ICF's average industrial gas price initially exceeds the average residual fuel oil price through 2000 . In the model, however, competition between the fuels is maintained by the assumption that large industrial and powerplant customers pay a lower transmission charge than other industrial customers. GAMS and AGAS $^{11}$ also indicate Btu parity between natural gas and residual fuel oil prices. The GTM results altemate between Btu-parity pricing and price decoupling over the period. The remaining models-

\footnotetext{
${ }^{10}$ Chapter 3 contains a discussion of the limitations of netback price calculations and assumed fixed transportation and distribution (T\&D) margins.

"Although AGAS did not report industrial gas prices, the proprietors of this model have confirmed that gas prices are set by residual fuel oil prices in this scenario.
} 


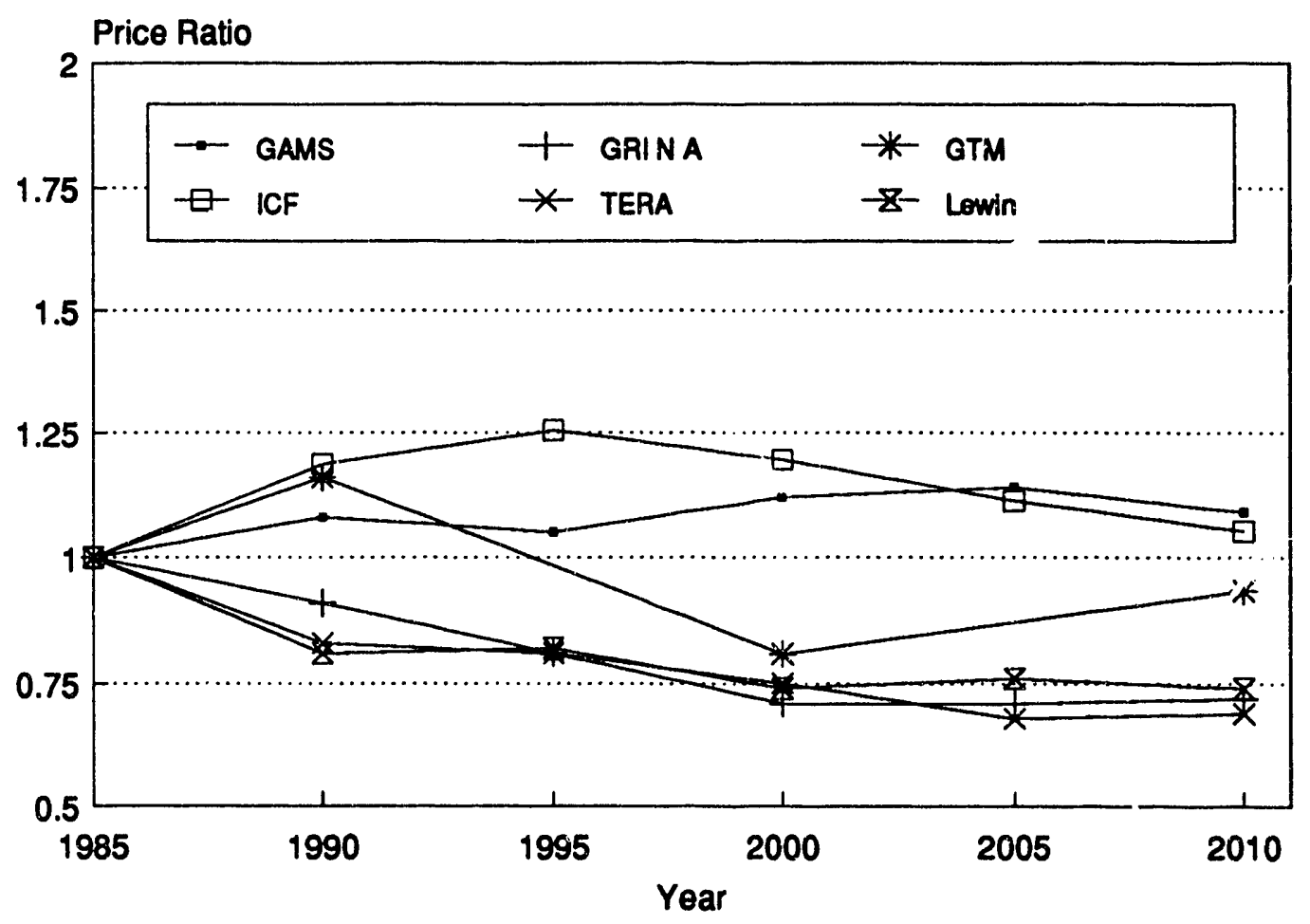

Figure 4.8: Industrial U.S. Gas-Oil Price Ratio by Model in the Upper Oil Price Case

GRI North American, Lewin, and TERA-show gas prices falling below oil prices, reflecting the relative abundance of gas supplies.

\section{Consumption}

Total consumption is expected to be at least 16 Tcf through 2010. While model consumption results vary by as much as $4 \mathrm{Tcf}$, historical peak consumption levels of 22 Tcf are not reached.

GTM, GAMS, ICF, and TERA disaggregate gas use by the four major end-use sectors, while GRI North risucrican, Lewin, and AGAS do not. TERA's projected consumption levels are exceeded by GTM in the residential sector and by GAMS in the electric utility sector. The variation of consumption levels within any one sectc $r$ across models appears to be greater than within total consumption as a whole.

It should be expected that the four models that disaggregate demand by major end-use sectors were able to standardize more precisely their de- mand conditions to the EMF specifications for energy prices, economic activity, and demographics for this scenario. Under these conditions, gas consumption should be highest for those models projecting the lowest gas prices, shown in Figure 4.7 above. This trend is observed in the upper oil price results for these four models.

The TERA consumption path remains consistently higher than the other results in Figure 4.9. Higher supply keeps the gas price lower and more competitive with the oil price, thus stimulating gas use, particularly in commercial and industrial sectors (except for ICF in 2010), than in the other models. Except for the year 2000, GTM's consumption shown in Figure 4.9 lies above the levels projected by GAMS. This result is attributable to the lower gas prices in GTM. The ICF consumption levels are the lowest of the four modelsconsistent with its higher price path-until after 2000. In later years, industrial gas use in ICF grows sharply spurred by rapid penetration of gas- 


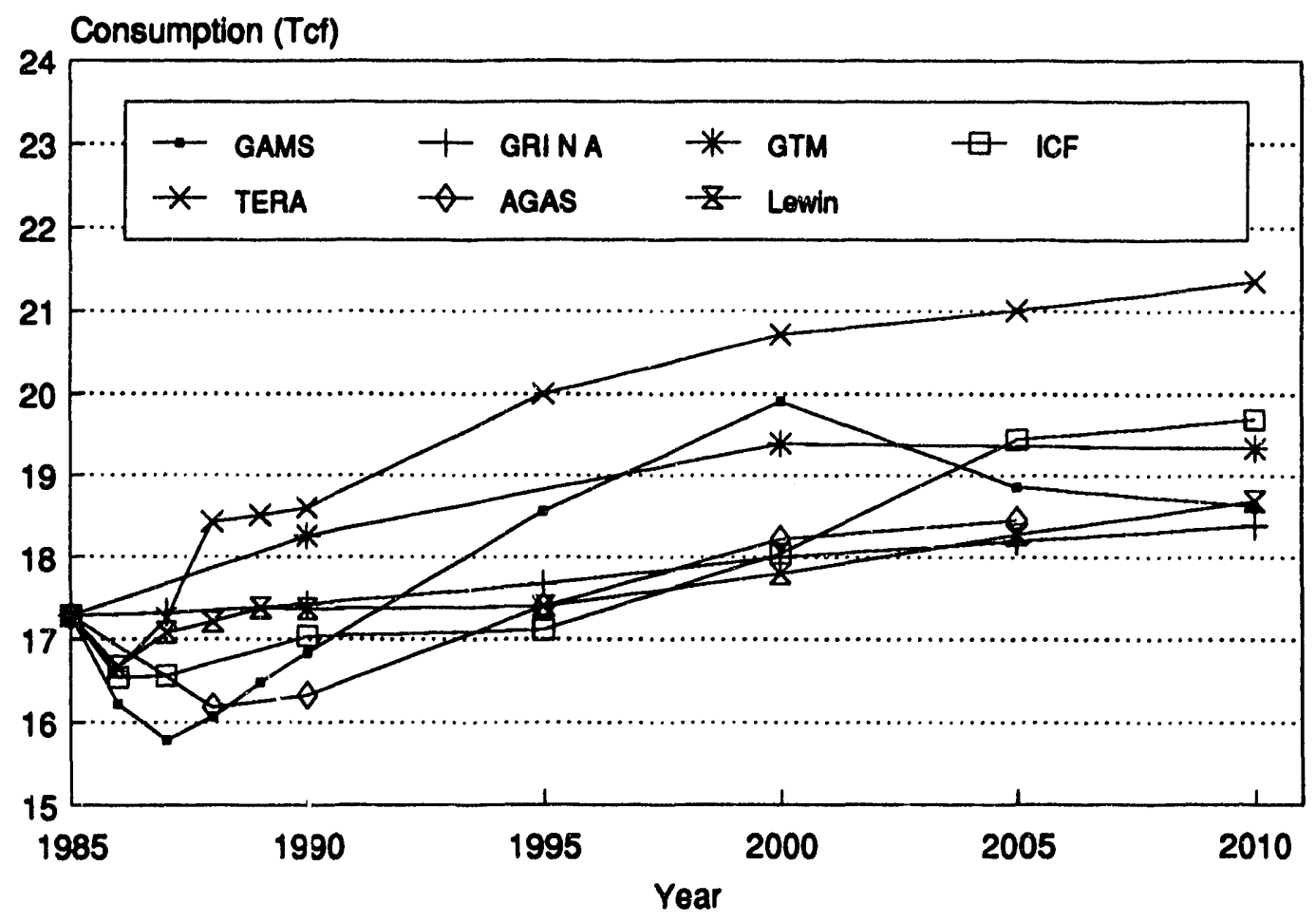

Figure 4.9: Tota! U.S. Consumption by Model in the Upper Oil Price Case

fired cogeneration and smaller incresses in gas prices.

\section{Imports}

U.S. imports are projected to be 1 to 2 Tcf from now to 2000 , and $2 \mathrm{Tcf}$ or greater in the post2000 period. In the model results, Canada is the primary source of U.S. gas imports, with Mexico and foreign suppliers of LNG being secondary. All modelers adopted the EMF guideline that imports from Canada not exceed 2 Tcf/year.

Imports grow between 1990 and 2010, at a rate averaging approximately 2 percent per year. However, imports remain low relative to domestic consumption, growing from 6.4 percent in 1990 to 11.9 percent in 2010.

The import projections reveal a considerable range among models (Figure 4.10). U.S. imports from all sources exceed 2 Tcf by 2000 in three models: ICF, Lewin, and TERA. By the end of the time pericid, ICF and Lewin include about 0.8
Tcf of liquefied natural gas (LNG), while TERA reports about 0.7 Tcf from Mexico. (Urfortunately, the import estimates reported by ICF are not directly comparable to others because they also include some Alaskan gas as imports.) GRI North American, GTM, GAMS, and AGAS do not foresee any gas imports from sources other than Canada throughout the period under the upper oil price conditions.

The higher import levels in ICF and Lewin occur in a market in which U.S. demand grows modestly while domestic production remains essentially stable. Along with GRI Hydrocarbon, which did not project imports, both ICF and Lewin are characterized by relatively low U.S. domestic gas production, relative to other models. This result implies that domestic gas is relatively more expensive than imported gas in these models. The higher import levels in TERA result from considerably stronger U.S. gas demand than in other models in all years; gas production, too, is substantial and the highest of all models after 2005. 


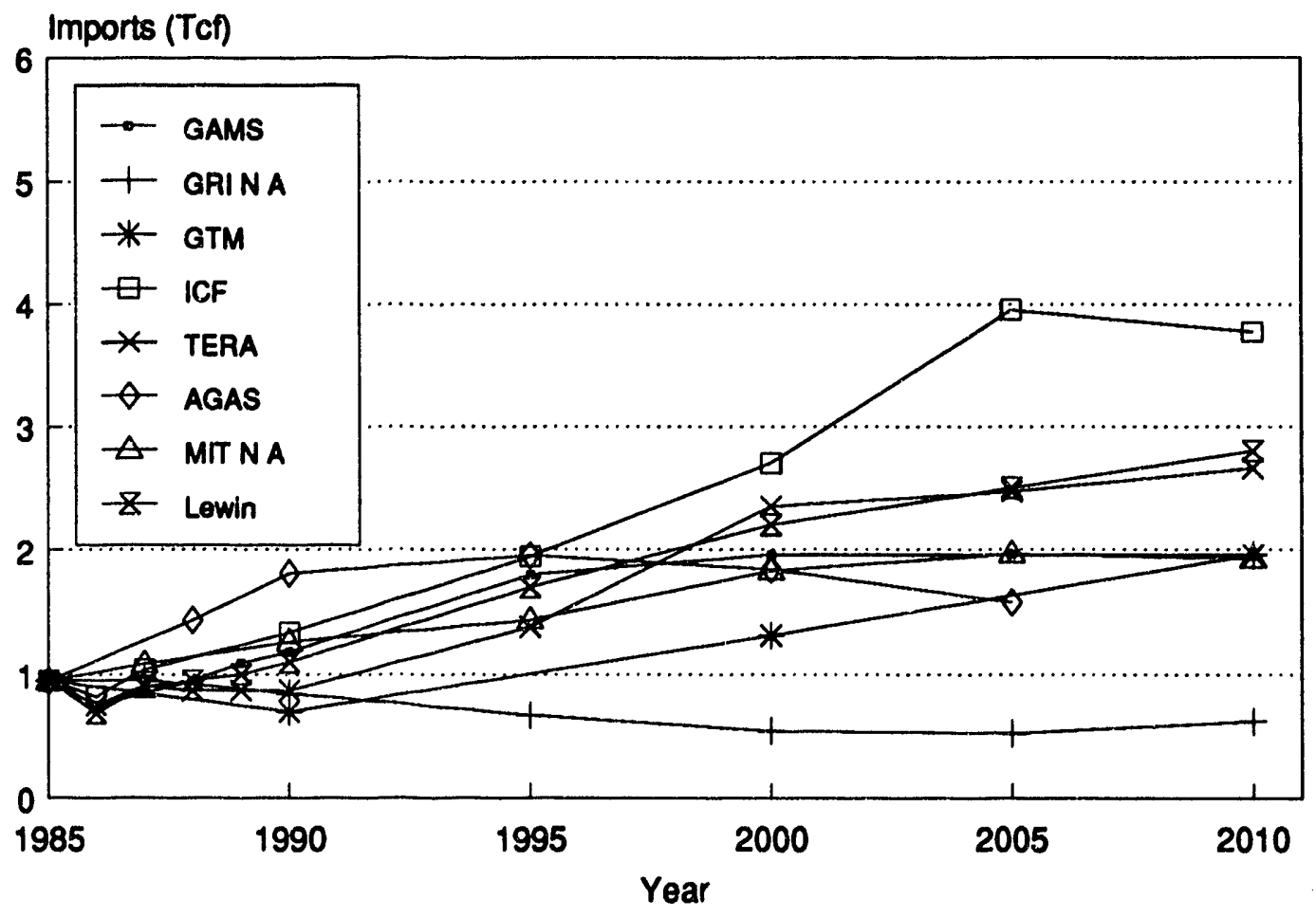

Figure 4.10: U.S. Imports by Model in the Upper Oil Price Scenario

GRI North American depicts a situation opposite to that described above for the ICF and Lewin results. It projects the lowest import levels of all the models because U.S. gas resources are viewed as being relatively irexpensive compared to Canadian gas resources, under the resource base conditions specified for this scenario.

Differences in import projections also depend upon modeling approach. As a group, modelers focusing primarily upon the U.S. market foresee higher import levels in this and other scenarios than do modelers focusing on the Canadian or both U.S. and Canadian markets. Imports from Canada will depend upon the relative costs of Canadian and U.S. gas, Canadian gas consumption levels, and the location of incremental Canadian gas resources, substantial volumes of which are long distances from some major end-use markets. These factors, which tend to limit the economic feasibility of Canadian gas imports, are incorporated less well, if at all, in many models of the U.S. gas markets.
This point is clearly demonstrated in the projections of Canadian gas exports shown in Figure 4.11. The models have been grouped into two classes: (1) those focusing on the U.S. market, and (2) those focusing on an integrated North American market or on Canada alone. The first group includes GAMS, ICF, Lewin, and TERA, while the second group includes AGAS, GRI North American, GTM, MIT North American, and Rowse. (The NEB results are discussed below.) The average Canadian export levels for the two groups are comparable through 1995, but depart noticeably from each other after that year. The average Canadian exports projected in the U.S. models exceed those in the North American/Canadian models by about $0.5 \mathrm{Tcf}$ from 2000 to 2010 .

The third trend shown in Figure 4.11-the National Energy Board (NEB) result-illustrates the importance of allowing the Canadian gas price to be determined by the supply and demand for gas rather than by a rule imposing oil-gas pricing parity. Using EMF oil-related netback prices for nat- 


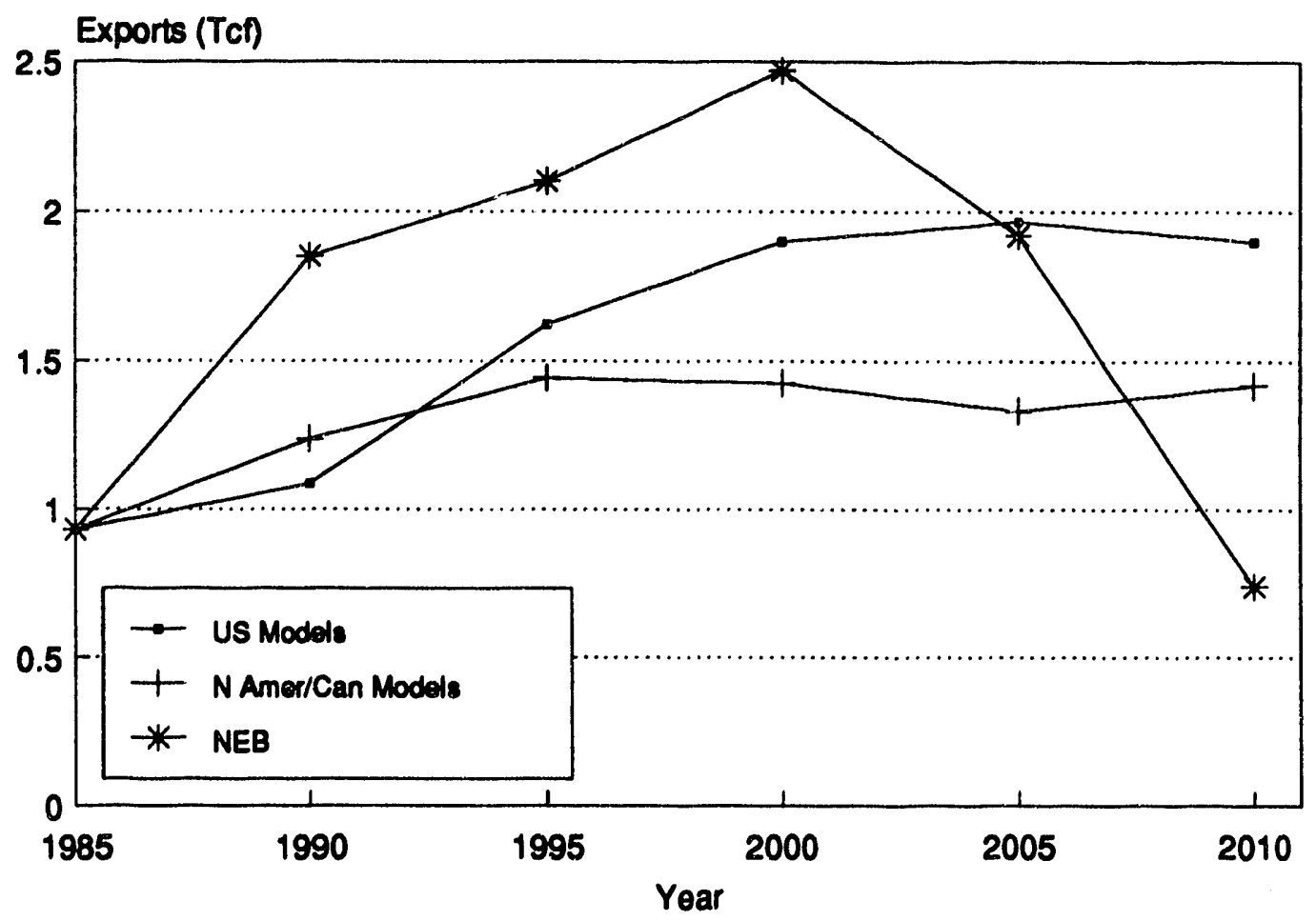

Figure 4.11: Total Canadian Exports in the Upper Oil Price Scenario for U.S. and North American/Canadian Models

ural gas, NEB calculated excess supply potential from Canada. The NEB result is a simulation of the export potential at oil-related netback prices rather than of exports per se. ${ }^{12}$ These estimates are based upon NEB's view of Canadian supply and demand at these prices. A growing surplus occurs as long as price exceeds marginal cost, and a declining surplus occurs as Canadian demand grows and the netback price becomes less attractive relative to the cost of incremental Canadian supplies.

With market-clearing prices, the path of actual exports would become more stable than the NEB's projection of export capacity. Exports would be less than NEB's estimates prior to 2000 and greater after that year. Figure 4.11 implies that prior to 2000, NEB's estimate of the export potential for Canadian gas would exceed the U.S. gas demand import projected by the models us-

\footnotetext{
${ }^{12}$ After the completion of this work, NEB has developed a modeling procedure which finds equilibrium gas prices by interacting between its domestic demand and supply models.
}

ing market-clearing prices. Under this condition, market forces would drive the gas price below the oil-price parity level, gradually sliminating some of this surplus capacity. After 2000 , the reverse situation would prevail. Since Canadian production would be too small to meet domestic and export gas demands, gas prices would rise above the oil-parity price in order to bring forth additional Canadian gas production and reduce the demand for Canadian gas.

\section{Lower Oil Price}

In the lower oil price scenario world crude oil prices rise from about $\$ 15$ in 1986 to $\$ 21$ per barrel in 2000 (1986\$). A comparison of this scenario with the upper oil price case underscores several points about the outlook for natural gas markets under low oil prices: 
- Gas prices fall but by less than oil prices. As a result, gas is often priced at the bumertip at or above the average residual fuel oil price.

- Gas consumption declines and to some extent is replaced by oil imports.

- Gas consumption falls in the switchable market, where industrial and utility users have dual fuel-burning equipment.

- Gas imports and U.S. gas production decline.

- Gas prices and consumption tend to fall most in those models where residual fuel oil and gas prices are most closely linked in the upper price scenario.

\section{Trends}

The size of the U.S. gas market, as measured by the average projection of domestic consumption, declines somewhat over time under the lower oil price conditions (Table 4.4). Falling gas consumption to some extent is replaced by oil. Since domestic oil production is expected to decline in the future, this implies rising oil imports. Gas prices rise more rapidly than oil prices, resulting in gas becoming less competitive in the switchable market than under higher oil prices. The average Btu industrial gas price is some 30 percent greater than the residual fuel oil price, in contrast to being 10 to 15 percent below that price in the upper oil price case. As in the other oil price scenario, the widest range of results occurs with the projections for gas prices and imports.

\section{Representation of the Scenario}

The analysis shown in Figure 3.1 of Chapter 3 can be extended to a world of lower oil prices. The simple netback pricing rule would hold that, on a Btu basis, gas prices would fall a dollar for every dollar decrease in the residual oil price. The analysis based upon market-clearing prices shows that gas prices are likely to fall by less than a dollar, thus causing the average gas price to rise relative to the average residual oil price.

Suppose that the market clears under the upper oil price conditions at a price $P_{1}$ in Figure 4.12, where the last unit of gas has been sold to an industrial user in the Mid-Atlantic region who can switch easily to high-sulfur residual oil, a lower quality fuel oil. If the price of this residual oil falls by a dollar, gas prices would have to fall accordingly to maintain that customer. The demand curve shifts downward by that amount to the curve labeled "lower oil price demand", where $P_{2}^{*}$ represents the new oil-equivalent price for that customer. As gas prices fall, however, gas production will be discouraged, as shown by the supply curve depicted in Figure 4.12. Suppliers will allocate their relatively more scarce gas to highervalued uses, causing gas prices to rise to $P_{2}$, above the oil parity price for that industrial user in the Mid-Atlantic region. The user will switch to fuel oil, and his fuel oil altemative no longer sets the market-clearing price for gas. The last unit of gas sold may now occur in a region closer to the wellhead or may be competing with a higher quality fuel oil. In this case, the ratio of the average wellhead gas price to residual oil price will rise. In the process, some switchable load is lost to the oil market.

\section{Prices}

Wellhead prices in Figure 4.13 rise but at a slower rate than in the upper oil price scenario. They are usually equal to or above the EMF average netback price that assumes price parity at the industrial burnertip bc.ween residual fuel oil and natural gas (the GRI Hydrocarbon trend in Figure 4.13).

Delivered industrial gas prices equal or are above the residual fuel oil prices on a Btu basis in this scenario. Figure 4.14 highlights these trends, where the legend orders the models according to the oil-gas price ratio in $\mathbf{2 0 1 0}$ in the upper oil price scenario, from highest to lowest. This result contrasts with the upper oil price scenario, where gas is generally priced at or below residual fuel oil. 
Table 4.4: Key U.S. Results from Lower Oil Price Scenario, 1985-2010

\begin{tabular}{|c|c|c|c|c|c|c|}
\hline & 1985 & 1990 & 1995 & 2000 & 2005 & 2010 \\
\hline \multicolumn{7}{|l|}{ Average } \\
\hline \multicolumn{7}{|l|}{ Tcf/Yr: } \\
\hline Marketed Production & 16.38 & 15.19 & 14.45 & 14.92 & 14.07 & 14.79 \\
\hline Total Imports & 0.95 & 0.93 & 1.43 & 1.39 & 1.56 & 1.69 \\
\hline Total Consumption ${ }^{a}$ & 17.28 & 15.94 & 15.67 & 16.14 & 15.47 & 16.43 \\
\hline Import Share (\%) & $5.5 \%$ & $5.8 \%$ & $9.1 \%$ & $8.6 \%$ & $10.1 \%$ & $10.3 \%$ \\
\hline \multicolumn{7}{|l|}{ Price (1986\$/Mcf): } \\
\hline Average Wellhead & 2.57 & 1.86 & 2.54 & 3.10 & 3.71 & 4.17 \\
\hline Average Delivered & 4.84 & 3.59 & 4.22 & 4.84 & 5.50 & 6.03 \\
\hline Crude Oil Parity ${ }^{b}$ & 4.83 & 2.41 & 2.93 & 3.62 & 3.97 & 4.48 \\
\hline \multicolumn{7}{|l|}{ Pct of Crude Oil } \\
\hline Average Wellhead Price & $53.2 \%$ & $77.1 \%$ & $86.6 \%$ & $85.5 \%$ & $93.6 \%$ & $93.0 \%$ \\
\hline Average Delivered Price & $100.3 \%$ & $148.5 \%$ & $143.8 \%$ & $133.7 \%$ & $138.7 \%$ & $134.6 \%$ \\
\hline \multicolumn{7}{|l|}{ Pct of Residual Fuel } \\
\hline Industrial Gas Price & $100.0 \%$ & $137.1 \%$ & $133.1 \%$ & $129.0 \%$ & $132.6 \%$ & $129.9 \%$ \\
\hline \multicolumn{7}{|l|}{ Relative Deviation } \\
\hline \multicolumn{7}{|l|}{ From Average $^{c}(\%)$ : } \\
\hline Marketed Production & & $6.7 \%$ & $9.7 \%$ & $9.8 \%$ & $8.7 \%$ & $4.0 \%$ \\
\hline Total Imports & & $33.7 \%$ & $32.3 \%$ & $49.9 \%$ & $48.5 \%$ & $49.5 \%$ \\
\hline Total Consumption & & $6.6 \%$ & $8.9 \%$ & $9.6 \%$ & $11.3 \%$ & $7.3 \%$ \\
\hline Average Wellhead Price & & $14.1 \%$ & $19.3 \%$ & $21.1 \%$ & $18.3 \%$ & $16.8 \%$ \\
\hline Average Delivered Price & & $9.8 \%$ & $13.3 \%$ & $15.4 \%$ & $14.3 \%$ & $14.0 \%$ \\
\hline
\end{tabular}

Averages for seven U.S. models; excludes GRI Hydrocarbon for which no consumption nr imports were reported.

${ }^{a}$ Excludes changes in inventories and unaccounted for.

${ }^{6}$ Crude oil parity is the crude oil price in $1986 \$$ Mcf.

"Measures how much each model result deviates from the average on a percentage basis. In actuality, calculated as the standard deviation divided by the mean (in percentage terms.. 


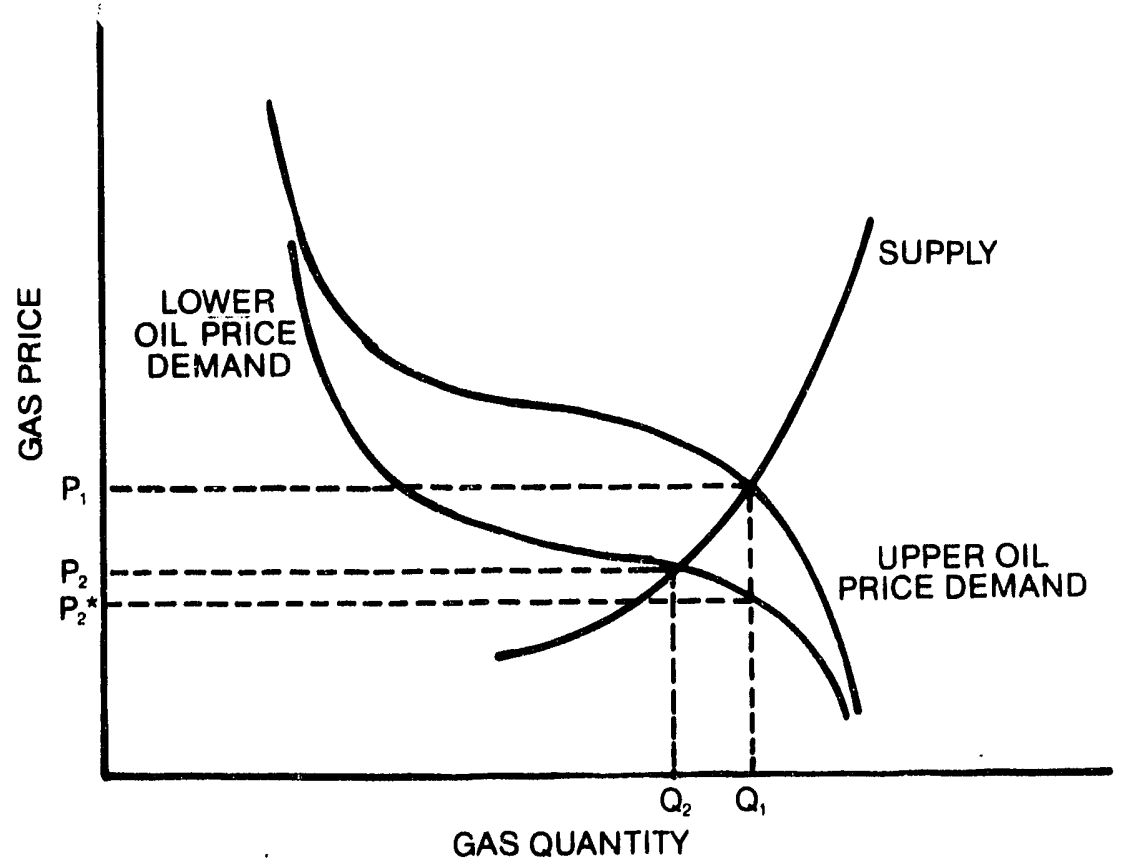

Figure 4.12: Supply-Demand Representation of the Lower Oil Price Scenario

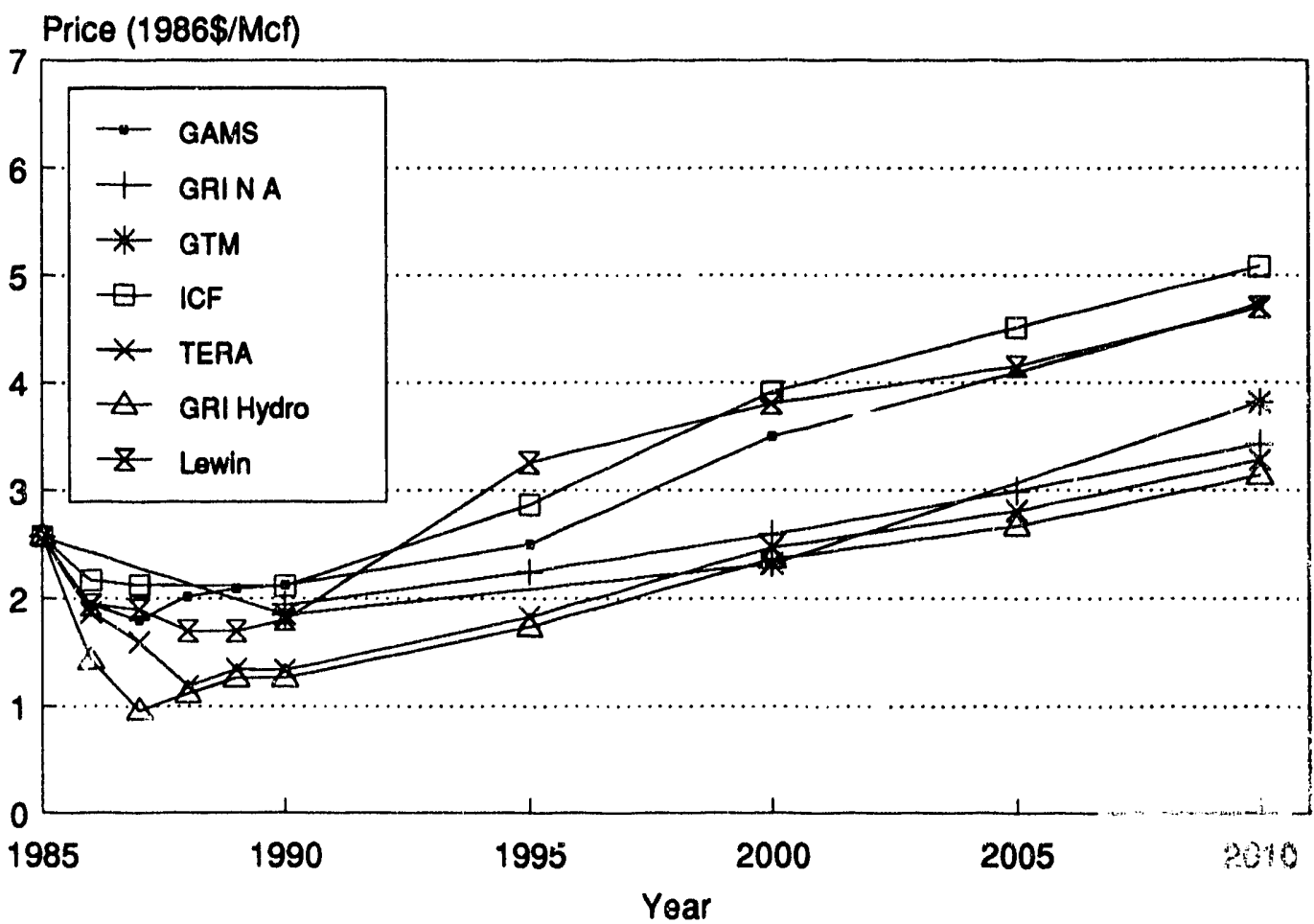

Figure 4.13: Average U.S. Wellhead Price by Model in the Lower Oil Price Scenario 


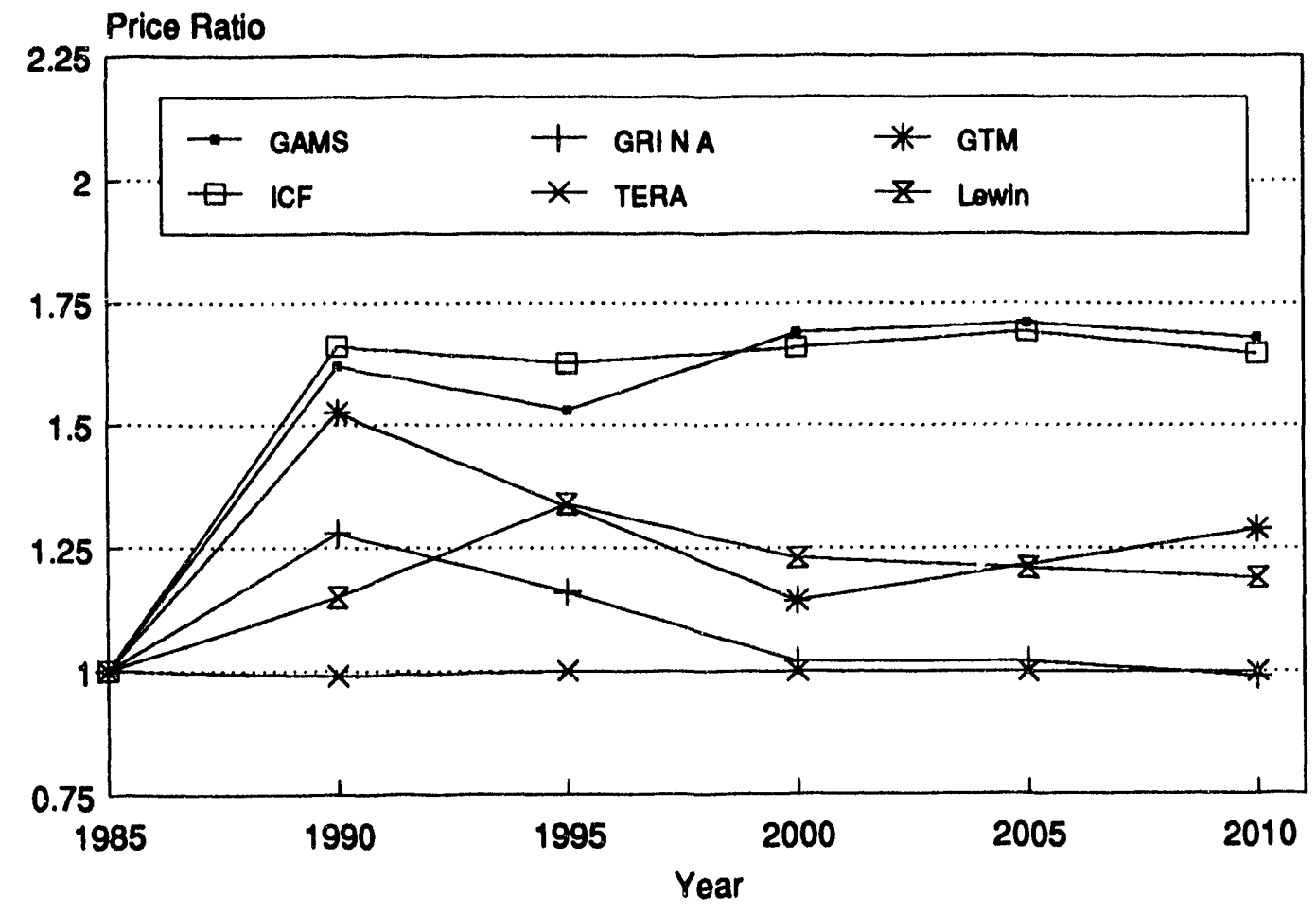

Figure 4.14: Industrial U.S. 9s-Oil Price Ratio by Model in the Lower Oil Price Scenario

In the face of this competition with oil, gas loses some of the market share, particularly in the dualfuel industrial and utility markets.

The top half of Table 4.5 shows that relative to the upper oil price scenario, the increased competition from oil occurs because gas prices fall by less than oil prices. The average delivered gas price for all sectors falls by $\$ 0.30$ per Mcf for each $\$ 1.00$ per Mcf decline in the crude oil equivalent price (approximately $\$ 5.60$ per barrel). Gas prices fall very little with the lower oil price in the Lewin results, shown in Table 4.5 as the minimum change. This rigidity in gas prices occurs because investment in gas exploration and production is reduced sharply by both the lower oil prices and the reduction in gas demand levels. In the Liwin model, gas becomes a scarcer fuel that is allocated primarily to the residential and commercial markets, where consumers are willing to pay gas prices substantially higher than residual fuel oil prices. The Lewin analysts think that the lower oil price scenario is essentially untenable, given the severe problems it cre- ates for oil and gas investment. Other analysts do not project such a sharp drop in ges investment, although they see gas production still falling with lower prices.

The maximum decline in gas prices due to the lower oil price path shown in Table 4.5 is accounted for by either the AGAS or ICF results. Both show intense oil-gas price competition in the upper oil price case. As oil prices fall, gas prices must follow if the switchable market is to be maintained. Gas prices, however, do not need to fall as much as oil prices because in a smaller gas market, supplies will be allocated to higher-valued uses.

\section{Production and Consumption}

Gas consumption declines relative to the upper oil price case levels and, to some extent, is replaced by oil imports. Gas consumption falls in the switchable market, where industrial and utility users have dual fuel-burning equipment. The bottom half of Table 4.5 reveals the substantial decline in U.S. gas 
Table 4.5: Average U.S. Delivered Price, Production, and Consumption Responses to Lower Oil Prices, 1990-2010 (with respect to the upper oil price case)

\begin{tabular}{|c|c|c|c|c|c|}
\hline & 1990 & 1995 & 2000 & 2005 & 2010 \\
\hline \multicolumn{6}{|l|}{ Average Delivered Price } \\
\hline Upper Oil Price (Mean) & 4.07 & 4.86 & 5.72 & 6.36 & 6.75 \\
\hline \multicolumn{6}{|l|}{ Change $(1986 \$ / \mathrm{Mcf})^{a}$} \\
\hline Maximum & -0.72 & -1.17 & -1.78 & -1.65 & -1.31 \\
\hline Mean & -0.40 & -0.64 & -0.88 & -0.86 & -0.72 \\
\hline Minimum & -0.20 & -0.05 & -0.15 & -0.40 & -0.25 \\
\hline \multicolumn{6}{|l|}{ Change in Crude Oil } \\
\hline Parity Price (1986 \$/Mcf) & -1.42 & -1.96 & -2.67 & -3.03 & -3.21 \\
\hline \multicolumn{6}{|l|}{ Change in Delivered Gas } \\
\hline \multicolumn{6}{|l|}{ Price for each $\$ 1 / \mathrm{Mcf}$} \\
\hline \multicolumn{6}{|l|}{ Change in Crude Oil } \\
\hline \multicolumn{6}{|l|}{ Parity Price } \\
\hline Maximum & 0.51 & 0.60 & 0.67 & 0.54 & 0.41 \\
\hline Mean & 0.28 & 0.33 & 0.33 & 0.28 & 0.22 \\
\hline Minimum & 0.14 & 0.03 & 0.06 & 0.13 & 0.08 \\
\hline \multicolumn{6}{|l|}{ Marketed Production } \\
\hline Upper Oil Price (Mean) & 16.3 & 16.5 & 17.0 & 16.7 & 16.6 \\
\hline \multicolumn{6}{|l|}{ Change (Tcf) } \\
\hline Maximum & -2.61 & -3.80 & -3.72 & -6.40 & -3.55 \\
\hline Mean & -1.13 & -2.03 & -2.22 & -2.85 & -2.48 \\
\hline Minimum & 0.00 & -0.76 & -0.33 & -1.33 & -1.13 \\
\hline \multicolumn{6}{|l|}{ Total Consumption } \\
\hline Upper Oil Price (Mean) & 17.1 & 17.5 & 18.7 & 18.8 & 19.2 \\
\hline \multicolumn{6}{|l|}{ Change (Tcf) } \\
\hline Maximum & -3.04 & -4.00 & -3.82 & -6.08 & -4.83 \\
\hline Mean & -1.30 & -1.97 & -2.71 & -3.54 & -2.89 \\
\hline Minimum & 0.00 & 0.00 & -0.82 & -1.52 & -1.33 \\
\hline
\end{tabular}

\footnotetext{
${ }^{a}$ Change in each variable equals the value in lower oil price scenario minus that in upper oil price scenario.
} 
production and consumption due to the lower oil prices. The average decline in domestic marketed gas production ranges from 2.0 to $2.8 \mathrm{Tcf}$ per year after 1990, while the average decline in total consumption varies between 2.0 and 3.5 Tcf per year during the same period. Oil import demand will likely be higher in this scenario, as oil replaces gas in many applications. Although not all lost gas consumption will be replaced by oil imports, the lower oil price reduces gas use by an average of 2.7 Tcf by 2000 , or 1.4 million barrels per day oil equivalent.

The decline in total gas consumption from the upper oil price case varies by model from almost no effect to $3 \mathrm{Tcf}$ as early as 1990 . After 1995 . ICF and AGAS report the largest reductions in consumption due to the lower oil price. As indicated previously, these models reported the largest declines in gas prices. In addition, gas supply in these models is more responsive to price declines than in many other models, resulting in large reductions in consumption after the gas market has equilibrated under the lower oil price conditions. Thus, the effects of a lower oil price on gas consumption appear to be most pronounced when: (1) oil and gas prices are closely linked to begin with (see previous section), and (2) gas supply is more responsive to price. ${ }^{13}$

\section{Fuel Switching}

Much of the adjustment in the gas market occurs in the switchable market, where large industrial and electric utility users operate equipment that can burn either natural gas or residual oil. As shown in Table 4.6, the fall in total consumption is overwhelmingly concentrated in these two sectors in ICF and TERA and in the electric utility sector alone in GAMS. The responses are noticeably smaller in the GAMS results for industry and in the G'M results for both sectors. The other models-

\footnotetext{
${ }^{13}$ This point can be seen by referring to Figure 4.12. A downward shift in the gas demand curve produces larger changes in quantity when both the demand and supply curves are flatter.
}

GRI North American, AGAS, and Lewin-did not report demand disaggregated by the four major end-use sectors.

More fuel switching is observed when gas prices compete directly with oil prices in the upper oil price case (e.g., the ICF results) than when gas is priced below residual oil (e.g.. the TERA results).

Table 4.6: Effect of Lower Oil Price on Total, Industrial, and Electric Utility Consumption by Model, 2000 and 2010 (with respect to upper oil price case)

\begin{tabular}{lll}
\hline Change in: & 2000 & 2010 \\
\hline Total Consumption (Tcf) & & \\
GAMS & -2.19 & -2.30 \\
ICF & -3.82 & -4.83 \\
TERA & -3.70 & -3.42 \\
GTM & -0.82 & -2.12 \\
& & \\
Industrial Consumption (Tcf) & & \\
GAMS & -0.53 & -0.09 \\
ICF & -1.20 & -2.55 \\
TERA & -1.46 & -1.38 \\
GTM & -0.03 & -0.36 \\
& & \\
Utility Consumption (Tcf) & & \\
GAMS & -1.79 & -2.50 \\
ICF & -2.86 & -2.25 \\
TERA & -1.41 & -1.21 \\
GTM & -0.10 & -0.55 \\
Industrial Gas-Oil Price & & \\
Differential (1986 \$/Mcf) & \\
GAMS & & \\
ICF & 1.58 & 2.03 \\
TERA & 1.20 & 2.48 \\
GTM & 1.72 & 2.45 \\
\hline
\end{tabular}

\footnotetext{
andustrial gas price change (negative) minus oil price change (negative). Change in the average delivered gas price was used for GTM because industrial gas price was not reported.
} 


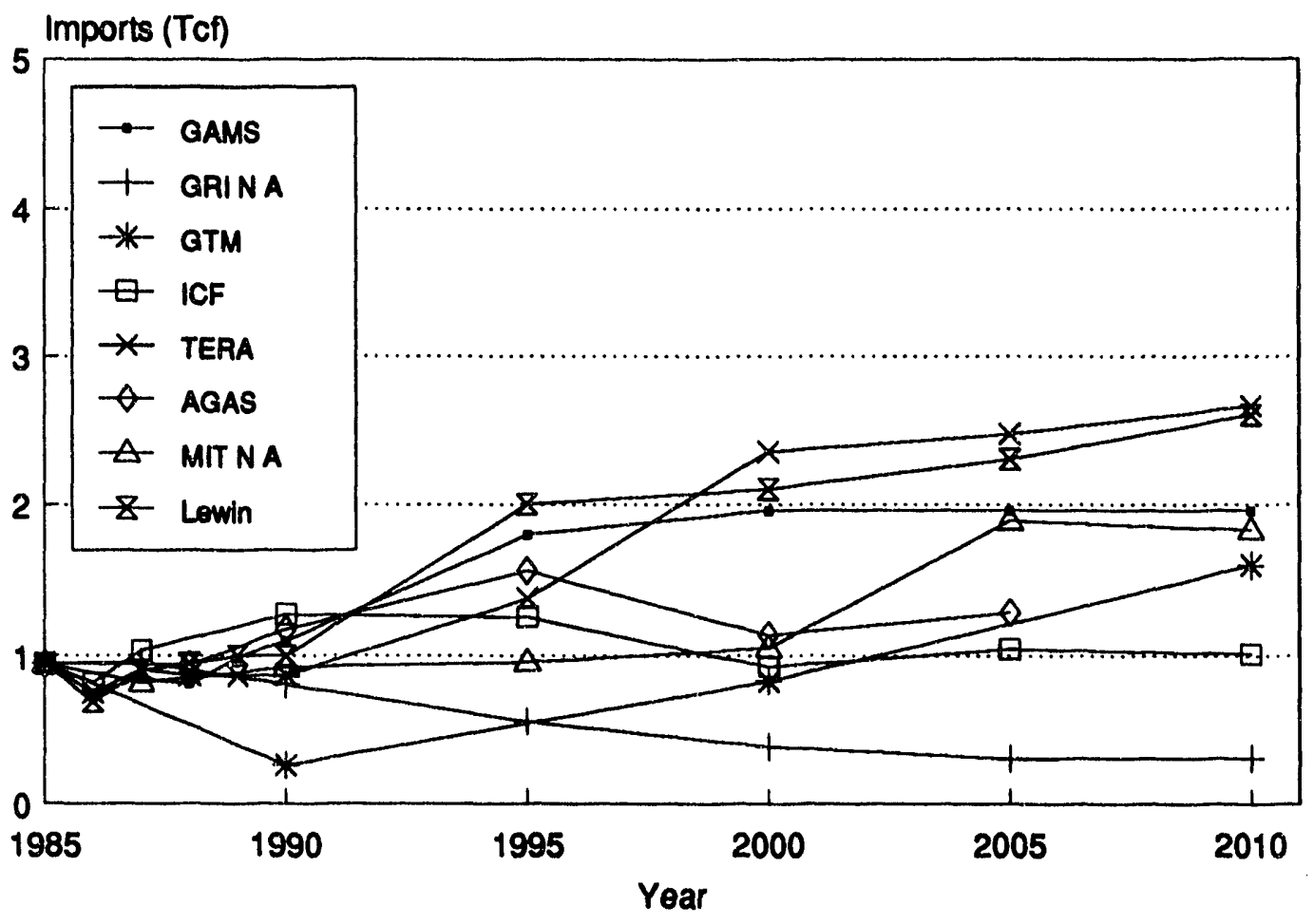

Figure 4.15: Total U.S. Imports by Model in the Lower Oil Price Scenario

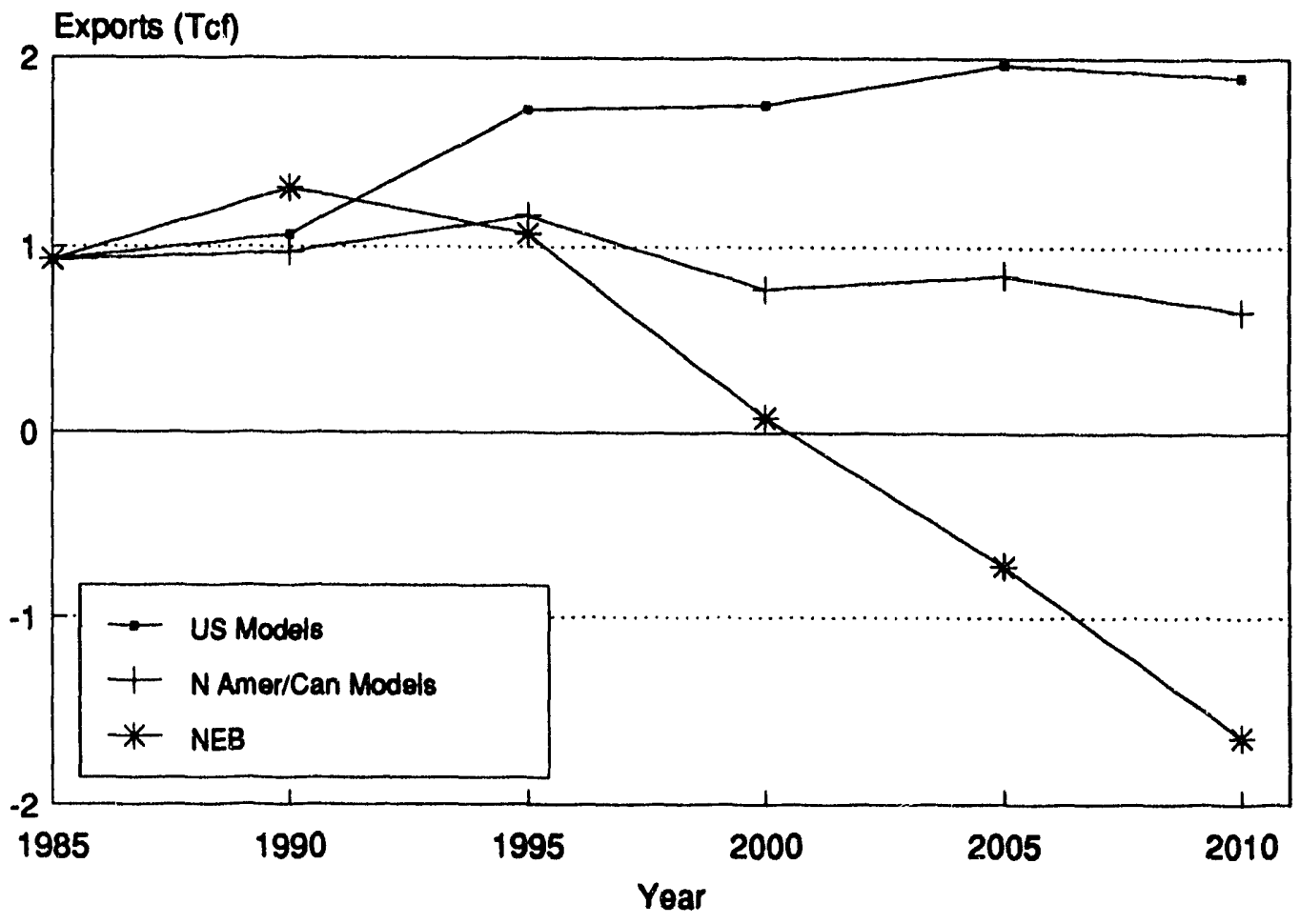

Figure 4.16: Total Canadian Exports in the Lower Oil Price Scenario by U.S. and North American/Canadian Models 


\section{Imports}

Gas imports are well below their levels of the upper oil price scenario, accounting for a smaller share of the U.S. gas market. Lower imports result because the decline in oil prices causes U.S. gas consumption to fall more rapidly than U.S. gas production. Nevertheless, gas imports still grow at 1.8 percent per year from 1990 to 2010.

Projections of U.S. imports from all sources (Figure 4.15) differ considerably among models, following the pattems established in the upper oil price case. Lewin's U.S. gas resources are relatively more expensive than Canadian resources; hence, imports represent a higher proportion of total gas supply. GRI North American, on the other hand, portrays the Canadian gas resources as being relatively more expensive; hence, Canadian exports decline to $0.3 \mathrm{Tcf}$ by 2010 . The major difference between the two scenarios occurs with ICF, which shows Canadian frontier supplies becoming uneconomic with the lower oil and gas prices. (ICF's imports also fall sharply because it includes Alaskan gas, which is uneconomic as well with the lower oil prices.)

Under the upper oil price conditions, Canadian exports were consistently higher after 1995 in the U.S. models than in the North American/Canadian models. This result applies even more forcefully in the lower oil price case. The export levels projected in the U.S. models cannot be sustained in the other models, as revealed by the average trends for the two groups in Figure 4.16. The Canadian export volumes projected by the U.S. models (except ICF) remain unchanged with the lower oil prices. Meanwhile, exports decline strongly from their upper oil price levels in the North American/Canadian models.

In the NEB results in Figure 4.16, the oilrelated netback price is too low to provide an exportable supply from Canada after 2000. Without oil-related netback pricing, however, the wellhead price fo 6 Canadian gas would increase to a level that $b$ lances domestic and export gas demand and Canacian gas supply. At these prices, there would be some level of exports from Canada that is competitive in U.S. regional markets.

\section{Low U.S. Resource}

\section{Summary}

The low resource scenario depicts a lower level of the U.S. gas resource base. A comparison with the upper oil price case emphasizes the market adjustment needed to balance the gas quantities supplied and demanded under these conditions:

- Gas prices rise even though oil prices are unchanged. In general, burnertip industrial gas prices by 2000 are at or above residual fuel oil prices in this scenario, as opposed to being at or below in the upper oil price scenario.

- By the year 2010, marketed production is 4 Tcf lower in this case relative to the upper oil price case.

- There are wide differences in the model results for the price and production impacts, depending upon how the changes in resource conditions are implemented. Gas production tends to fall more and price tends to rise more when the lower resource condition is applied by changing low-cost as well as high-cost resources.

- Gas consumption falls in the switchable market, where industrial and utility users have dual fuel-buming equipment, and to some extent is replaced by oil imports.

- Relative to the upper oil price case, gas imports are about 1 Tcf per year higher, reaching almost 3 Tcf per year.

\section{Trends}

As a result of the lower U.S. resource base, the average result (Table 4.7) shows domestic production declining throughout the period to $13 \mathrm{Tcf}$ by 
Table 4.7: Key U.S. Results from Low U.S. Resource Scenario, 1985-2010

\begin{tabular}{|c|c|c|c|c|c|c|}
\hline & 1985 & 1990 & 1995 & 2000 & 2005 & 2010 \\
\hline \multicolumn{7}{|l|}{ Average } \\
\hline \multicolumn{7}{|l|}{ Tcf/Yr: } \\
\hline Marketed Production & 16.38 & 16.07 & 15.41 & 14.84 & 14.07 & 12.92 \\
\hline Total Imports & 0.95 & 1.17 & 1.70 & 2.23 & 2.74 & 2.88 \\
\hline Total Consumption ${ }^{a}$ & 17.28 & 17.07 & 16.88 & 16.63 & 16.63 & 15.77 \\
\hline Import Share (\%) & $5.5 \%$ & $6.9 \%$ & $10.1 \%$ & $13.2 \%$ & $16.5 \%$ & $18.2 \%$ \\
\hline \multicolumn{7}{|l|}{ Price (1986\$/Mcf): } \\
\hline Average Wellhead & 2.57 & 2.40 & 3.38 & 4.93 & 5.59 & 7.28 \\
\hline Average Delivered & 4.84 & 4.22 & 5.19 & 6.82 & 7.56 & 9.36 \\
\hline Crude Oil Parity ${ }^{b}$ & 4.83 & 3.79 & 4.83 & 6.21 & 6.90 & 7.59 \\
\hline \multicolumn{7}{|l|}{ Pct of Crude Oil } \\
\hline Average Wellhead Price & $53.2 \%$ & $63.2 \%$ & $69.9 \%$ & $79.4 \%$ & $81.04 \%$ & $96.0 \%$ \\
\hline Average Delivered Price & $100.3 \%$ & $111.2 \%$ & $107.4 \%$ & $109.8 \%$ & $109.4 \%$ & $123.4 \%$ \\
\hline \multicolumn{7}{|l|}{ Pct of Residual Fuel } \\
\hline Industrial Gas Price & $100.0 \%$ & $103.6 \%$ & $101.4 \%$ & $107.8 \%$ & $107.8 \%$ & $122.7 \%$ \\
\hline \multicolumn{7}{|l|}{ Relative Deviation } \\
\hline \multicolumn{7}{|l|}{ From Average ${ }^{\mathcal{c}}(\%)$ : } \\
\hline Marketed Production & & $7.2 \%$ & $11.1 \%$ & $10.3 \%$ & $11.3 \%$ & $15.5 \%$ \\
\hline Total Imports & & $28.6 \%$ & $16.1 \%$ & $19.0 \%$ & $25.2 \%$ & $19.5 \%$ \\
\hline Total Consumption & & $6.3 \%$ & $10.0 \%$ & $10.0 \%$ & $13.1 \%$ & $15.5 \%$ \\
\hline Average Wellhead Price & & $18.9 \%$ & $17.8 \%$ & $21.0 \%$ & $19.9 \%$ & $27.5 \%$ \\
\hline Average Delivered Price & & $8.9 \%$ & $11.7 \%$ & $16.1 \%$ & $16.4 \%$ & $25.0 \%$ \\
\hline
\end{tabular}

\footnotetext{
Averages for seven U.S. models; excludes GRI Hydrocarbon for which no consumption or imports were reported.

${ }^{a}$ Excludes changes in inventories and unaccounted for.

${ }^{b}$ Crude oil parity is the crude oil price in $1986 \$$ /Mcf.

${ }^{c}$ Measures how much each model result deviates from the average on a percentage basis. In actuality, calculated as the standard deviation divided by the mean (in percentage terms).
} 
2010. Declining U.S. production is partially replaced by rising imports. As with the lower oil price path, an increase in gas prices causes a loss in competitiveness in switchable markets. In general, the average delivered industrial gas price is at or above the average Btu residual fuel oil price. Variations in the model results are substantial for all variables and are greater than those observed for the other scenarios.

The results of this scenario require careful interpretation. The enormous pressures due to the lower gas resource base will create major incentives for developing new gas sources and for utilizing gas more efficiently. While some of these responses are incorporated in the models included in the study, other developments, perhaps tied to R\&D activity, may be represented less well. If the low resource case materialized, and decisionmakers began to expect significantly tighter gas markets, these efforts will presumably be accelerated, thus easing some of the pressures in ways not incorporated in these model results.

\section{Representation of the Scenario}

There are strong parallels between the impacts of fewer resources and lower oil prices on the natural gas markets, even though gas nrices in this scenario are rising rather than falling from their upper oil price case levels. Both conditions make domestic gas scarcer relative to oil. In both cases, gas prices must rise relative to oil, reducing gas use in the switchable market, thereby releasing gas for higher-valued uses. At the same time, changes in the wellhead gas price will alter the levels of domestic gas production and Canadian exports. For these reasons, the same adjustments that were important in the lower oil price case need to be examined here as well, e.g., oil imrorts replacing gas in the dual-fired market.

This adjustment process can be represented in terms of the analytical framework described in Chapter 3. The supply and demand curves in the upper oil price case intersect at a market-clearing price $P_{1}$ and quantity $Q_{1}$ in Figure 4.17. A lower resource base is represented as a leftward shift in that supply curve to a new schedule labeled "lower resource supply"-fewer resources can be found at all prices. If gas prices were to remain fixed at the prevailing oil-parity price, there would be too much demand for the available gas supply. Prices would begin to drift upward, some gas users would start 0 reduce their gas consumption (as shown by the demand curve in Figure 4.17), and Canadian and domestic producers would supply additional gas (as shown by the low resource supply curve). This adjustment would continue until the quantity that producers are willing to sell matches the quantity demanded at a price $P_{2}$.

Costs to find, develop, and produce the gas resource are critically affected by field size, location, geologic setting, and depth of occurrence. Assumptions about these factors and the way these assumptions are implemented in a model will affect the interpretation of the low resource scenario. One expert may believe that a pessimistic resource outlook means less high-cost gas but little change in the amount of low-cost gas. To another, a lower resource base may mean less gas for all cost categories. The impact of these two views on the gas market can be dramatically different. However, most published data on gas resources refer only to physical volumes of gas (Tcf) without explicit reference to cost. ${ }^{14}$ Consistent with thi practice, EMF provided estimates of physical volumes only, leaving the interpretations of cost/volume relationships to the analysts.

GTM and GRI North American consistently show larger reductions in marketed production than the other models as a result of a lower resource

\footnotetext{
${ }^{14}$ Recently published research conducted by the Colorado School of Mines for the Gas Research Institute and Electric Power Research Institute does address the cost issue: Institute for Energy Resource Studies, Golden, Colorado, "Projections of Cost of Development of U.S. Natural Gas Potential", Electric Power Research Institute, EPRI P-5284, June 1987. New work currently in progress by Geological Exploration Associates, sponsored by Gas Research Institute and American Gas Association, will also present cost analyses: Geological Exploration Associates, Ltd., "Natural Gas Resource Data Base for the United States (1987)", Gas Research Institute and American Gas Association, February 1988.
} 


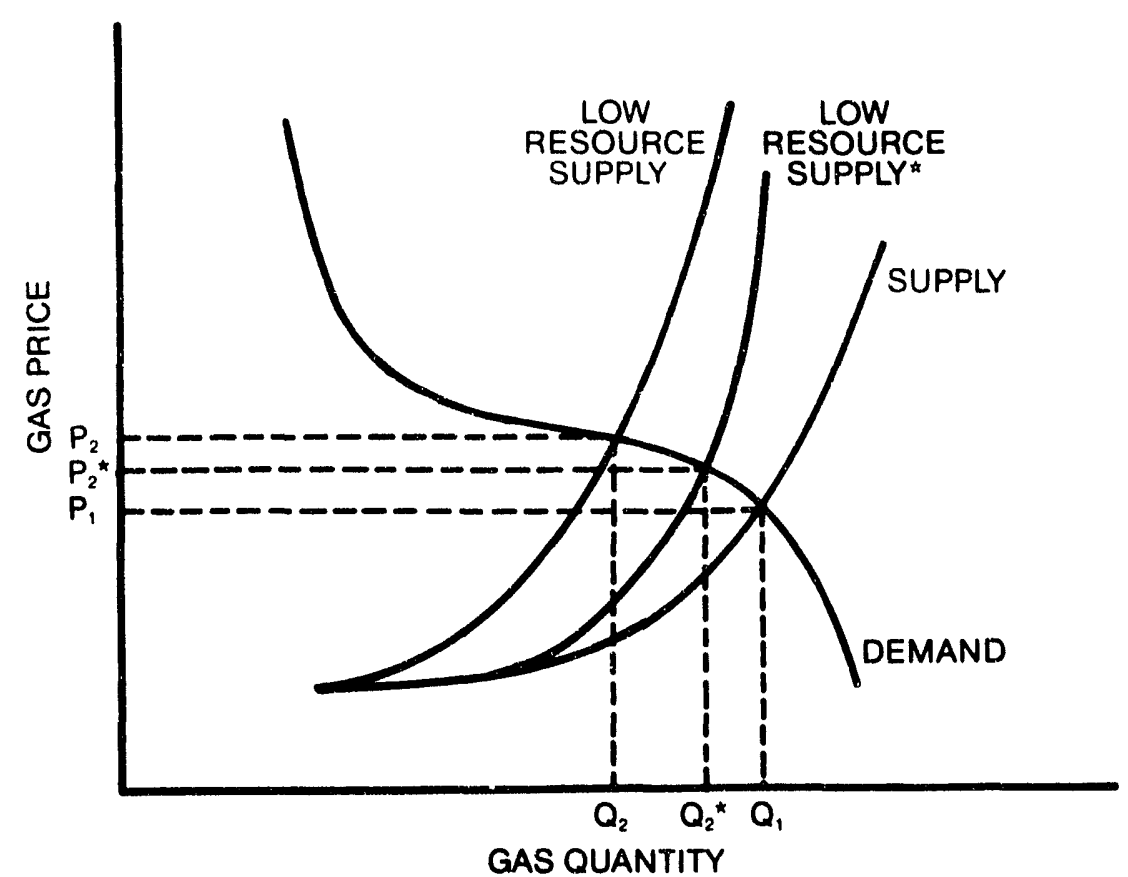

Figure 4.17: Supply-Demand Representation of the Low Resource Scenario

base. These models use a relatively simple representation relating gas resources and supply to price, without explicitly accounting for resources at different depths and field sizes. In this study, the lower supply estimates are applied across the full range of resources in these models. Each cost category is reduced proportionally in accordance with the reduction in total resources provided by EMF. Each point along the low-resource supply curve in Figure 4.17 is some fixed percentage of the point on the reference supply curve at all prices. These inputs are consistent with the view that there exists comparable uncertainty about low-cost as well as high-cost supplies.

An altemative approach to represent the lower supply conditions is adopted by the models with extensive detail on the resource base by cost characteristics-ICF, Lewin, and GRI Hydrocarbon. Here, high-cost gas is reduced proportionally more than low-cost gas, as indicated by the alternative low-resource supply curve (indicated by an asterisk in Figure 4.17). Essentially, this view holds that there exists more uncertainty about the amounts of high-cost gas available in this lowresource world. As can be seen from this figure, the supply curve shifts very little in the vicinity of the market-clearing level for the wellhead price under the latter assumption. As a result, the price and amount sold change less in these models.

The low-resource conditions are implemented differently in the two remaining models. The finding rate for conventional resources in GAMS is lowered so that more drilling (footage) is required to produce each unit of gas. In TERA, $100 \mathrm{Tcf}$ of reserve additions are removed, representing supplemental sources which are unresponsive to price in the model.

\section{Prices}

Scarcer gas resources mean a higher gas price than in the upper oil price case, even though the oil price has not changed. Wellhead prices rise more rapidly in this scenario, with GTM and GAMS reporting 


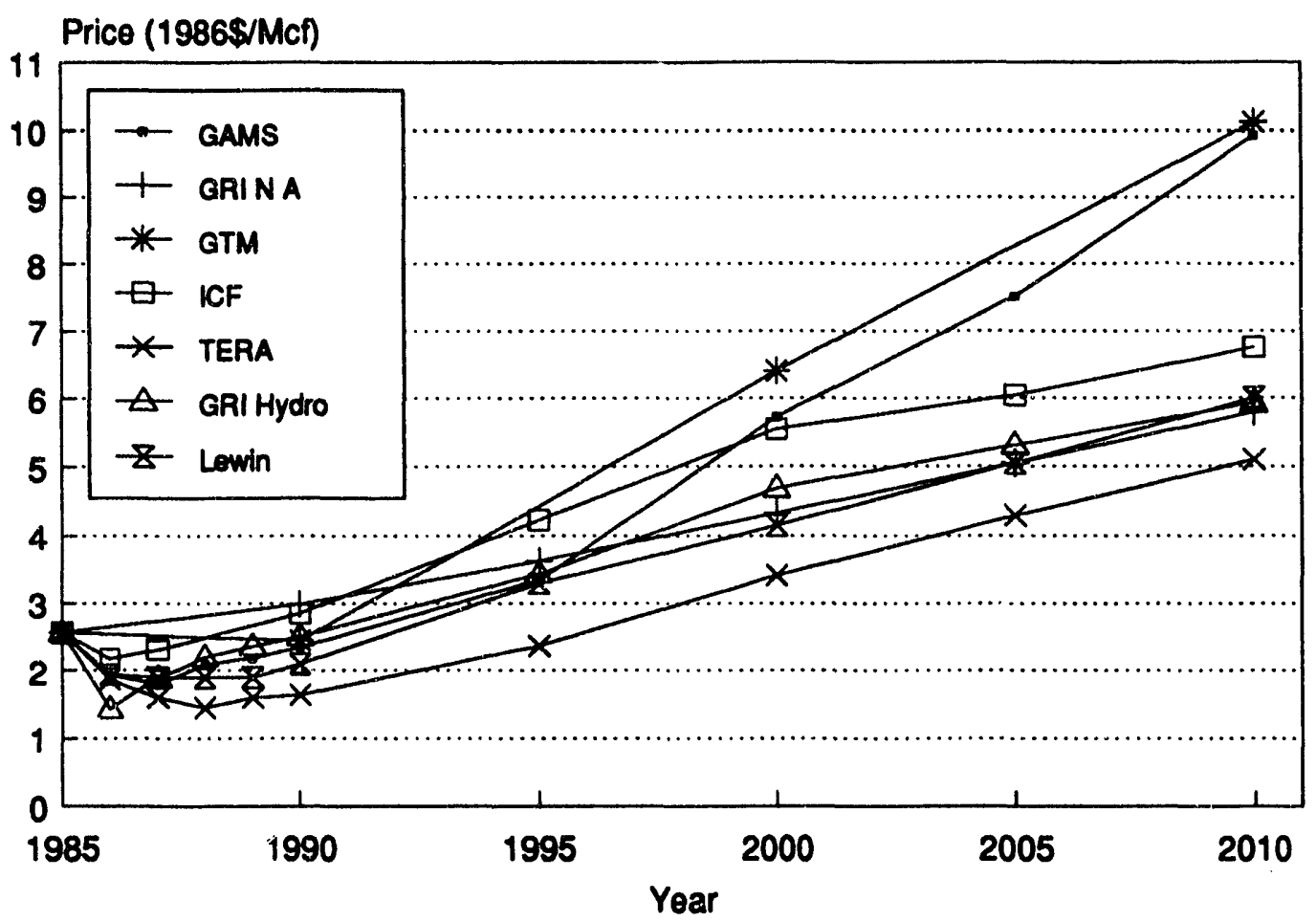

Figure 4.18: Average U.S. Wellhead Price by Model in the Low Resource Scenario

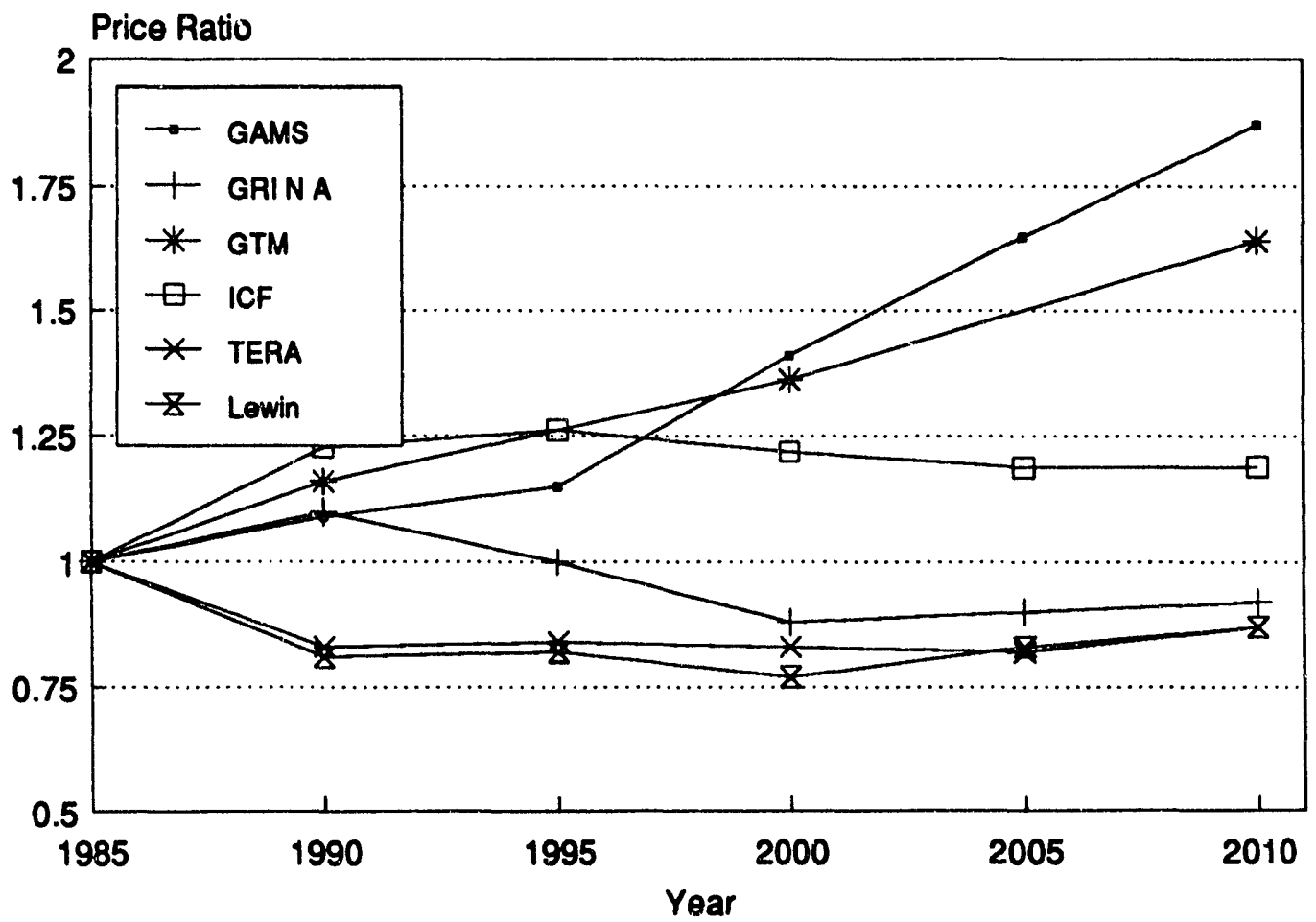

Figure 4.19: Industrial U.S. Gas-Oil Price Ratio by Model in the Low Resource Scenario 
Table 4.8: U.S. Production, Consumption, and Delivered Price Responses to Lower U.S. Resources, 1990-2010 (with respect to the upper oil price case)

\begin{tabular}{|c|c|c|c|c|c|}
\hline & 1990 & 1995 & 2000 & 2005 & 2010 \\
\hline \multicolumn{6}{|l|}{ Average Delivered Price } \\
\hline Upper Oil Price (Mean) & 4.07 & 4.86 & 5.72 & 6.36 & 6.75 \\
\hline \multicolumn{6}{|l|}{ Change $(1986 \$ / \mathrm{Mcf})^{a}$} \\
\hline Maximum & 0.60 & 0.87 & 3.43 & 2.86 & 5.36 \\
\hline Mean & 0.15 & 0.33 & 1.09 & 1.20 & 2.61 \\
\hline Minimum & 0.00 & 0.00 & 0.20 & 0.50 & 1.05 \\
\hline \multicolumn{6}{|l|}{ Marketed Production } \\
\hline Upper Oil Price (Mean) & 16.30 & 16.50 & 17.00 & 16.70 & 16.60 \\
\hline \multicolumn{6}{|l|}{ Change (Tcf) } \\
\hline Maximum & -1.30 & -3.28 & -4.49 & -5.70 & -6.99 \\
\hline Mean & -0.35 & -1.10 & -2.19 & -3.03 & -4.47 \\
\hline Minimum & 0.00 & -0.01 & -0.20 & -0.71 & -1.64 \\
\hline \multicolumn{6}{|l|}{ Total Consumption } \\
\hline Upper Oil Price (Mean) & 17.10 & 17.50 & 18.70 & 18.80 & 19.20 \\
\hline \multicolumn{6}{|l|}{ Change (Tcf) } \\
\hline Maximum & -1.20 & -2.51 & -3.33 & -4.94 & -6.94 \\
\hline Mean & -0.16 & -0.74 & -1.95 & -2.36 & -3.52 \\
\hline Minimum & 0.00 & 0.00 & -0.10 & -0.40 & -1.57 \\
\hline
\end{tabular}

${ }^{a}$ Change in each variable equals the value in the low U.S. resource scenario minus that in upper oil price scenario.

significantly higher wellhead prices by 2010 (Figure 4.18).

In the upper oil price scenario with resource assumptions based upon the PGC most likely case, gas prices in a number of models lie below the Btuequivalent pricc of oil (Figure 4.8). With less abundant U.S. gas supply, an equal number of models report gas prices in 2000 above the residual fuel oil price (on a Btu basis) and below. (Compare price trends with GRI Hydrocarbon in Figure 4.19). In several models scarce and more expensive gas cannot compete in the dual fuel-burning market that can switch easily between residual oil and natural gas. As a result, this market is lost, either partially or totally, as gas prices move closer to oil prices, and sometimes above it.

Once again, a range of impacts for the average delivered gas price for all sectors can be observed in the upper half of Table 4.8. However, all but two of the models show delivered prices to be higher than their upper oil price case levels by about $\$ 1.00$ per Mcf or less in 2000 and by $\$ 1.00$ to $\$ 1.50$ per $\mathrm{Mcf}$ in 2010 . The two exceptionsGAMS and GTM - show substantially stronger increases in delivered prices, partly because they implemented the low resource assumptions by reducing significant amounts of low- to mid-cost gas as well as higher-cost volumes. In order to achieve the fuel switching required to balance quantity de- 
manded with the lower levels of production, a s $s_{\text {. }}$ nificantly larger price increase was needed in this scenario. This issue is discussed more extensively in the next section.

\section{Consumption and Fuel Switching}

Gas consumption falls in the switchable market, where industrial and utility users have dual fuelbuming equipment. Based upon the average result reported in Table 4.8, total consumption is some 2 Tcf lower in 2000 and $3.5 \mathrm{Tcf}$ lower in 2010 than in the upper oil price case, due to the lower U.S. resource base. These reductions are less than those in marketed production because imports replace some of the lost domestic production.

The ICF and TERA results in Table 4.9 follow the pattems established in their fuel-switching results in the lower oil price case (c.g., see Table 4.6). While both GAMS and GTM appear to have quite strong responses by the utility sector in this scenario, some of this can be attributed to the very large price changes required to balance the market under the lower domestic supply conditions.

\section{Production}

Although the impacts of a lower resource base on marketed production (Figure 4.20) cover a wide range of possible outcomes, marketed production is on average $4 \mathrm{Tcf}$ lower by 2010 in this case relative to the upper oil price case. By the end of the period, declines in production are relatively modest: in Lewin, TERA, and ICF because fewer low- and mid-cost resources were removed in these models. Production falls more sharply in GRI North American, GTM, and GAMS because low- as well as high-cost resources were affected in implementing this scenario.

Through the year 2000 , domestic production is affected only minimally in the Lewin, TERA, and GRI Hydrocarbon results. Somewhat larger impacts can be observed for ICF and GAMS, while GTM and GRI North American report the largest declines. By the year 2010, however, GAMS and GRI Hydrocarbon join the latter two models in showing marketed production some 6-7 Tcf lower in the low resource case.

The sharp divergence of the GRI Hydrocarbon production path from the ICF and Lewin results after 2000 partially reflects the price assumptions used by the GRI Hydrocarbon model. In the EMF scenarios, the GRI Hydrocarbon model is not simulated by balancing supply and demand to derive

Table 4.9: Effect of Low U.S. Resources on Total, Industrial, and Electric Utility Consumption by Model, 2000 and 2010 (with respect to the upper oil price case)

\begin{tabular}{lll}
\hline Change in: & 2000 & 2010 \\
\hline Total Consumption (Tcf) & & \\
GAMS & -1.96 & -5.03 \\
ICF & -2.21 & -2.36 \\
TERA & -0.72 & -1.80 \\
GTM & -3.08 & -6.94 \\
& & \\
Industrial Consumption (Tcf) & & \\
GAMS & -1.04 & -1.41 \\
ICF & -0.50 & -1.80 \\
TERA & -0.30 & -0.72 \\
GTM & -0.68 & -1.85 \\
& & \\
Utility Consumption (Tcf) & & \\
GAMS & -0.76 & -3.20 \\
ICF & -1.66 & -0.36 \\
TERA & -0.16 & -0.42 \\
GTM & -0.92 & -2.19 \\
& & \\
Industrial Gas-Oil Price & & \\
Differential (1986 \$/Mcf) & \\
GAMS & & \\
ICF & 1.54 & 5.21 \\
TERA & 0.14 & 0.93 \\
GTM & 0.47 & 1.42 \\
& 3.43 & 5.36 \\
\hline
\end{tabular}

${ }^{a}$ Industrial gas price change; oil price remains unchanged by assumption. Change in the average delivered gas price was used for GTM because industrial gas price was not reported. 


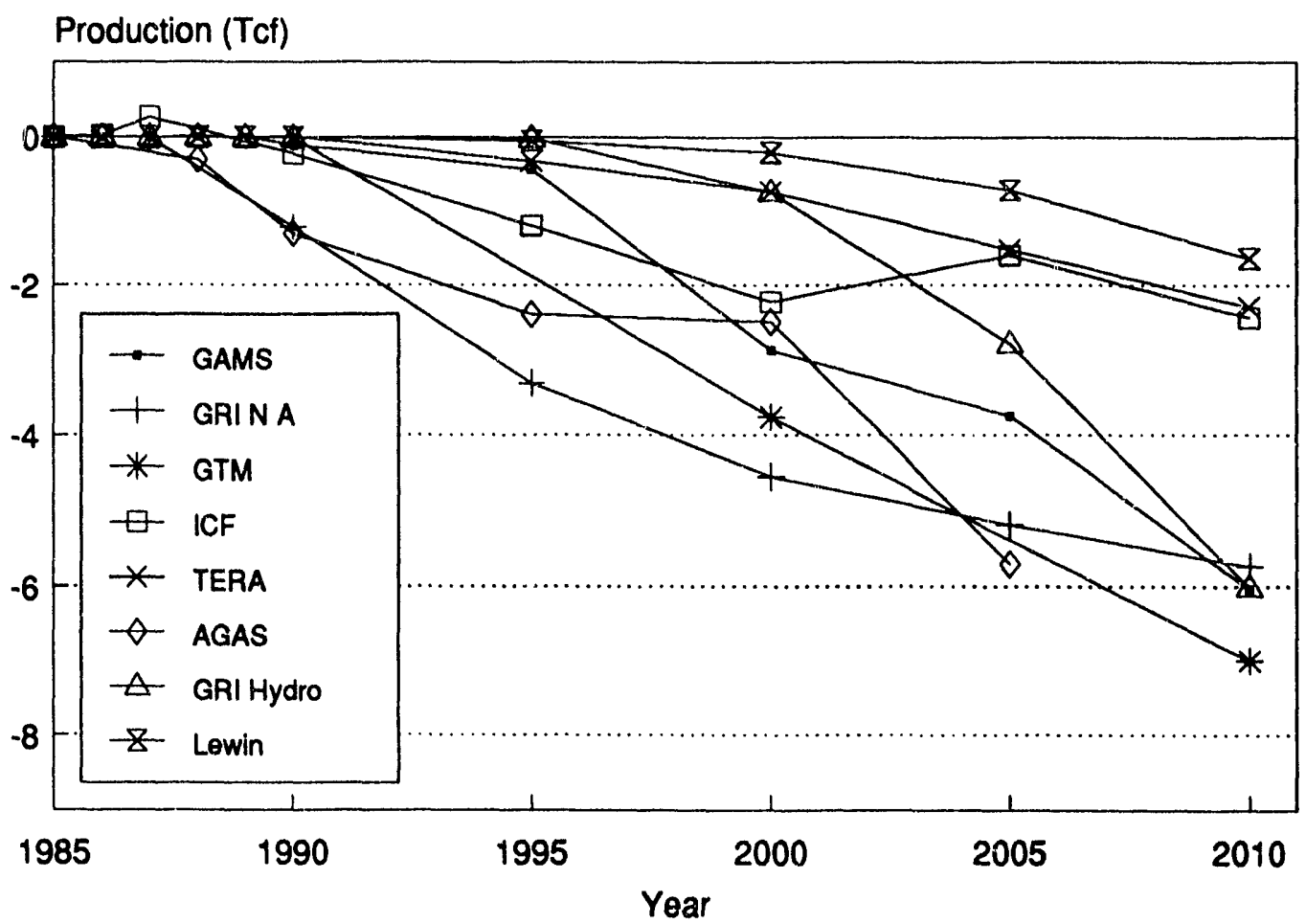

Figure 4.20: Change in U.S. Marketed Production (Dry Gas) by Model in the Low Resource Scenario (relative to the upper oil price case)

a market-clearing price. Instead, it is run as a stand-alone supply model with exogenous wellhead price paths that assume that oil and gas are priced equivalently on a Btu basis at the burnertip. This "netback" price rule prevents gas prices from rising relative to oil prices, in contrast with the other models, which solve for market-clearing prices.

\section{Imports}

Relative to the upper oil price case, gas imports are higher, reaching almost $3 \mathrm{Tcf} / \mathrm{yr}$. The mean growth rate of imports is a relatively high 3.5 percent per year, and imports grow to 18 percent of domestic consumption by the end of the study period. This happens because the resource constraint is imposed on U.S. supply but not on extemal supply, and U.S. wellhead prices are relatively high.

Differences in the level of U.S. imports from all sources are considerably less among models in this scenario (Figure 4.21) than in the two oil price scenarios discussed previously. Imports are virtually unchanged in ICF and Lewin, the two models indicating the highest import levels in the other scenarios. GAMS and TERA, two more models with high import levels, show some LNG being added, but TERA does not show any additional imports until after 2000 (about 0.4 Tcf more of Mexican imports). In contrast, U.S. imports in GRI North American are sharply higher in this scenario, increasing from $0.6 \mathrm{Tcf}$ in the upper oil price case to $2.4 \mathrm{Tcf}$, all but $0.3 \mathrm{Tcf}$ coming from Canada. The more limited U.S. resource base increases the incremental costs of domestic gas relative to Canadian gas, reversing the favorable cost advantage of the former in the two oil price scenarios. These conditions allow Canadian gas, and some LNG $(0.3 \mathrm{Tcf})$, to penetrate the U.S. market successfully.

Interestingly, the average projections for Canadian exports from U.S. and from North American/Canadian models are similar (Figure 4.22). In the U.S. models, Canadian exports are virtually unaffected by the more limited U.S. resource base, whereas exports are stimulated in all Canadian and 


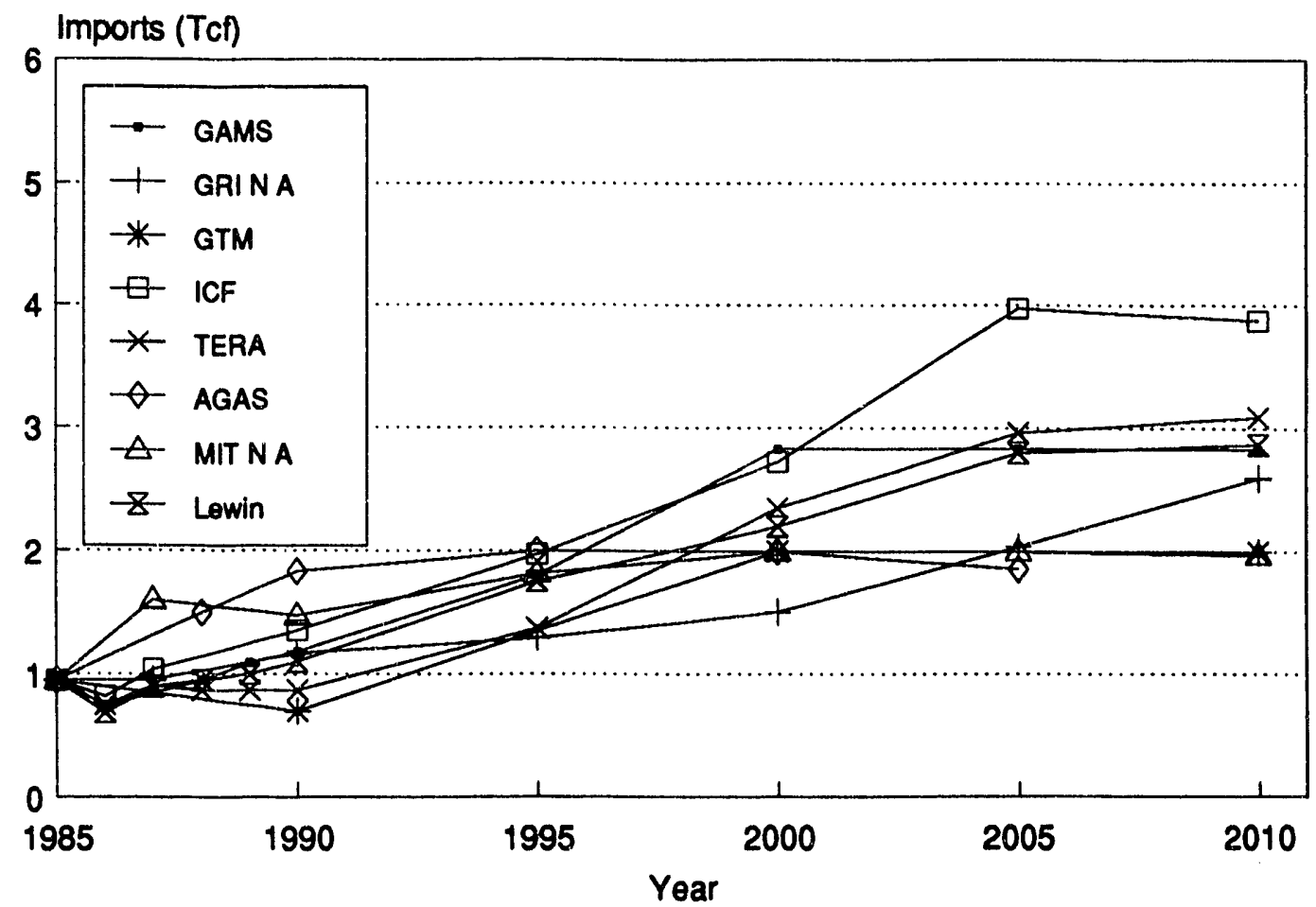

Figure 4.21: Total U.S. Imports by Model in the Low Resource Scenario

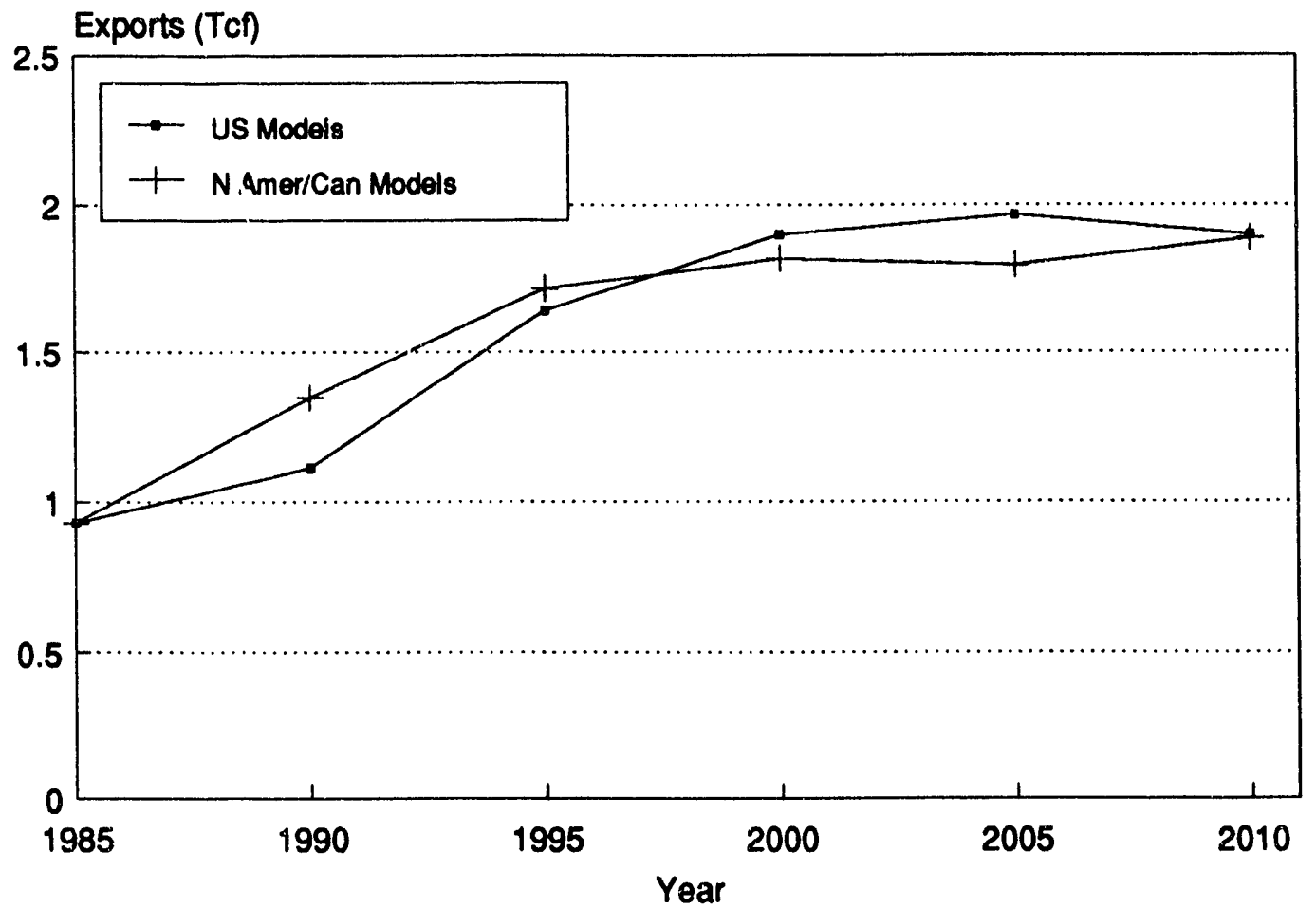

Figure 4.22: Total Canadian Exports in the Low Resource Scenario by U.S. and North American/Canadian Models 


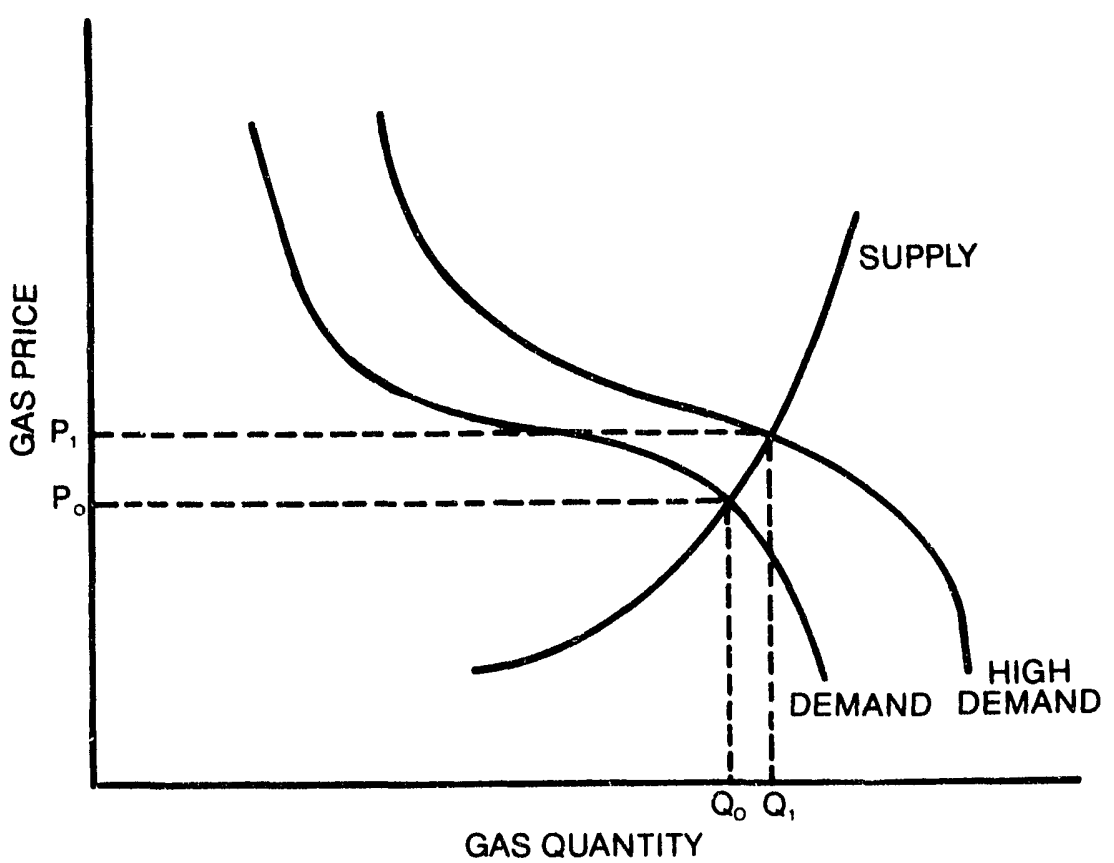

Figure 4.23: Supply-Demand Representation of the High U.S. Demand Scenario

North American models. These trends narrow the gap between the two sets of models. No results are shown in Figure 4.22 for the NEB model, which analyzed the two oil price scenarios only.

\section{High U.S. Demand}

\section{Summary}

The high gas demand scenario is based upon the upper oil price and control natural gas resource assumptions. Comparing this scenario to the upper oil price case suggests the following general conclusions:

- Gas supplies are available to meet a significantly enhanced level of gas demand for electricity generation, although higher gas prices are required to produce these resources. Gas prices rise even though oil prices are unchanged.
- Net gas demand increases by only 1.5 to 2.0 Tcf by 2010 in response to the exogenous increase in potential electric utility demand of $2.8 \mathrm{Tcf}$.

- Higher U.S. domestic production accounts for most of the increased consumption. Imports increase by about $0.2 \mathrm{Tcf}$.

- The impact of an increase in potential demand in the electric utility sector is proportionally greater on delivered gas prices than on total gas consumption and proportionately greater on wellhead prices than on U.S. production. Thus, supply has an inelastic response to gas prices.

- Industrial burnertip natural gas prices and residual fuel oil prices tend to track each other. 
Table 4.10: Key U.S. Results from High Demand Scenario, 1985-2010

\begin{tabular}{|c|c|c|c|c|c|c|}
\hline & 1985 & 1990 & 1995 & 2000 & 2005 & 2010 \\
\hline \multicolumn{7}{|l|}{ Average } \\
\hline \multicolumn{7}{|l|}{ Tcf/Yr: } \\
\hline Marketed Production & 16.38 & 16.73 & 17.31 & 18.12 & 18.13 & 18.76 \\
\hline Total Imports & 0.95 & 1.12 & 1.65 & 1.95 & 2.26 & 2.52 \\
\hline Total Consumption ${ }^{a}$ & 17.28 & 17.66 & 18.69 & 19.84 & 20.12 & 21.21 \\
\hline Import Share (\%) & $5.5 \%$ & $6.4 \%$ & $8.8 \%$ & $9.8 \%$ & $11.2 \%$ & $11.9 \%$ \\
\hline \multicolumn{7}{|l|}{ Price (1986\$/Mcf): } \\
\hline Average Wellhead & 2.57 & 2.34 & 3.26 & 4.28 & 4.95 & 5.77 \\
\hline Average Delivered & 4.84 & 4.14 & 4.99 & 6.09 & 6.84 & 7.57 \\
\hline Crude Oil Parity ${ }^{b}$ & 4.83 & 3.79 & 4.83 & 6.21 & 6.90 & 7.59 \\
\hline \multicolumn{7}{|l|}{ Pct of Crude Oil } \\
\hline Average Wellhead Price & $53.2 \%$ & $61.7 \%$ & $67.5 \%$ & $69.0 \%$ & $71.8 \%$ & $76.1 \%$ \\
\hline Average Delivered Price & $100.3 \%$ & $109.2 \%$ & $103.4 \%$ & $98.2 \%$ & $99.2 \%$ & $99.7 \%$ \\
\hline \multicolumn{7}{|l|}{ Pct of Residual Fuel } \\
\hline \multicolumn{7}{|l|}{ Oil Price: } \\
\hline Industrial Gas Price & $100.0 \%$ & $97.3 \%$ & $93.5 \%$ & $92.8 \%$ & $92.9 \%$ & $96.0 \%$ \\
\hline \multicolumn{7}{|l|}{ Relative Deviation } \\
\hline \multicolumn{7}{|l|}{ From Average ${ }^{c}(\%)$ : } \\
\hline Marketed Production & & $5.1 \%$ & $7.8 \%$ & $9.8 \%$ & $6.5 \%$ & $5.2 \%$ \\
\hline Total Imports & & $30.5 \%$ & $26.1 \%$ & $31.5 \%$ & $43.7 \%$ & $34.8 \%$ \\
\hline Total Consumption & & $4.5 \%$ & $5.6 \%$ & $8.2 \%$ & $5.9 \%$ & $5.1 \%$ \\
\hline Average Wellhead Price & & $15.5 \%$ & $19.0 \%$ & $18.7 \%$ & $16.4 \%$ & $15.9 \%$ \\
\hline Average Delivered Price & & $9.0 \%$ & $13.2 \%$ & $13.7 \%$ & $13.3 \%$ & $13.6 \%$ \\
\hline
\end{tabular}

Averages for seven U.S. models; excludes GRI Hydrocarbon foi which no consumption or imports were reported.

aExcludes changes in inventories and unaccounted for.

${ }^{b}$ Crude oil parity is the crude oil price in $19865 /$ Mcf.

'Measures how much each model result deviates from the avesage on a percentage basis. In actuality, calculated as the standard deviation divided by the mean (in percentage terms). 
Table 4.11: Demand Shifts in the Models to Represent High U.S. Demand Scenarios (Tcf)

2000

2010

$50 \%$ Acid Rain Policy

$+25 \%$ Combined Cycle

(Lewin)

$0.7 \quad 1.4$

Acid Rain Policy

$\left(\right.$ TERA $^{a}$ )

$1.0 \quad 2.3$

Acid Rain Policy

$+50 \%$ Combined Cycle ${ }^{b}$

(GAMS, GRI NA, ICF, AGAS)

$1.4 \quad 2.8$

Acid Rain Policy

$+100 \%$ Combined Cycle

+ Cogeneration

(GTM)

$2.5 \quad 4.0$

Model listed in parenthesis.

${ }^{a}$ Scenario was implemented by reducing coal demand and increasing residual oil price rather than exogenously augmenting gas demand.

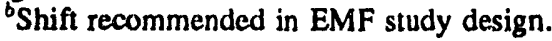

\section{Trends}

On average, both domestic production and consumption rise through 2010 in the high demand scenario. As shown in Table 4.10, higher gas prices are necessary to sustain these higher production levels, but gas still remains competitive with residual fuel oil. Price competition between the two fuels is more intense in this scenario than in the other three scenarios, particularly from 1990 through 2010. Deviations from these averages once again appear most pronounced in the projections for imports and prices.

\section{Representation of the Scenario}

The EMF scenario design sf scified increments in potential gas demand due to the increased pene- tration of cogeneration and combined-cycle technologies and to an acid rain policy, based upon several Gas Research Institute studies. The effect of these assumptions is to shift the demand curve outward (and to the right) at every price level to the curve labeled "high demand" (Figure 4.23). At the old price $P_{1}$, demand exceeds supply, causing prices to rise to $P_{2}$. A new market-clearing equilibrium is restored at $P_{2}$ because the higher gas price encourages more production and reduces gas consumption in other sectors.

Modelers were allowed the flexibility to select which increments to include, so that they would not be adding new demand that was already represented in their base case. Therefore, the implementation of this scenario is not uniform across models, but the size of the demand shifts are effectively similar in all models except GTM and Lewin.

Table 4.11 compares the size of the demard shifts in the various models. GAMS, GRI Norith American, ICF, and AGAS followed the recommendation of the EMF scenario design to include the full effects of the acid rain policy and 50 percent of the combined-vycle gas use. The implicit assumption was that the remaining $\mathbf{5 0}$ percent of combined-cycle gas use was already represented in most models' control case projections. The demand increment in TERA was somewhat smaller because only an acid rain policy was simulated. Due to its structure as an integrated energy model on the demand side, TERA was simulated by reducing coal demand and increasing the residual oil price. Thus, its demand curve may have been shifted by more or less than that reported in Table 4.11 , which shows the acid rain policy's contribution to the increment in potential gas demand as estimated in the GRI studies.

The table emphasizes that the Lewin results represent a substantially smaller demand increment equal to half that for most of the other models. At the other extreme, the GTM simulations added the full amount of the combined-cycle gas use as well as the increment associated with gas-fired cogeneration to the acid rain policy. As a result, industrial 


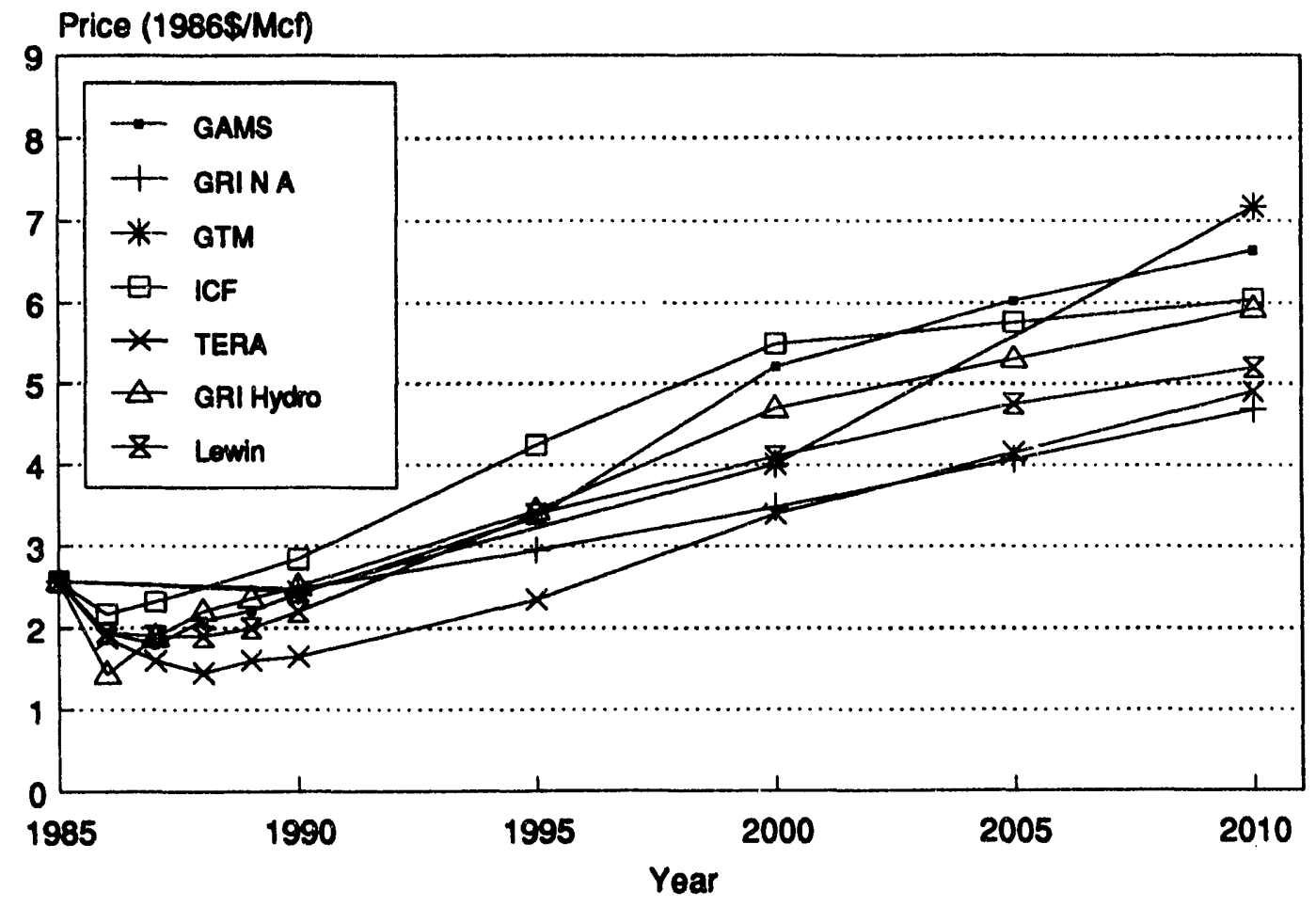

Figure 4.24: Average U.S. Wellhead Price by Model in the High U.S. Demand Scenario

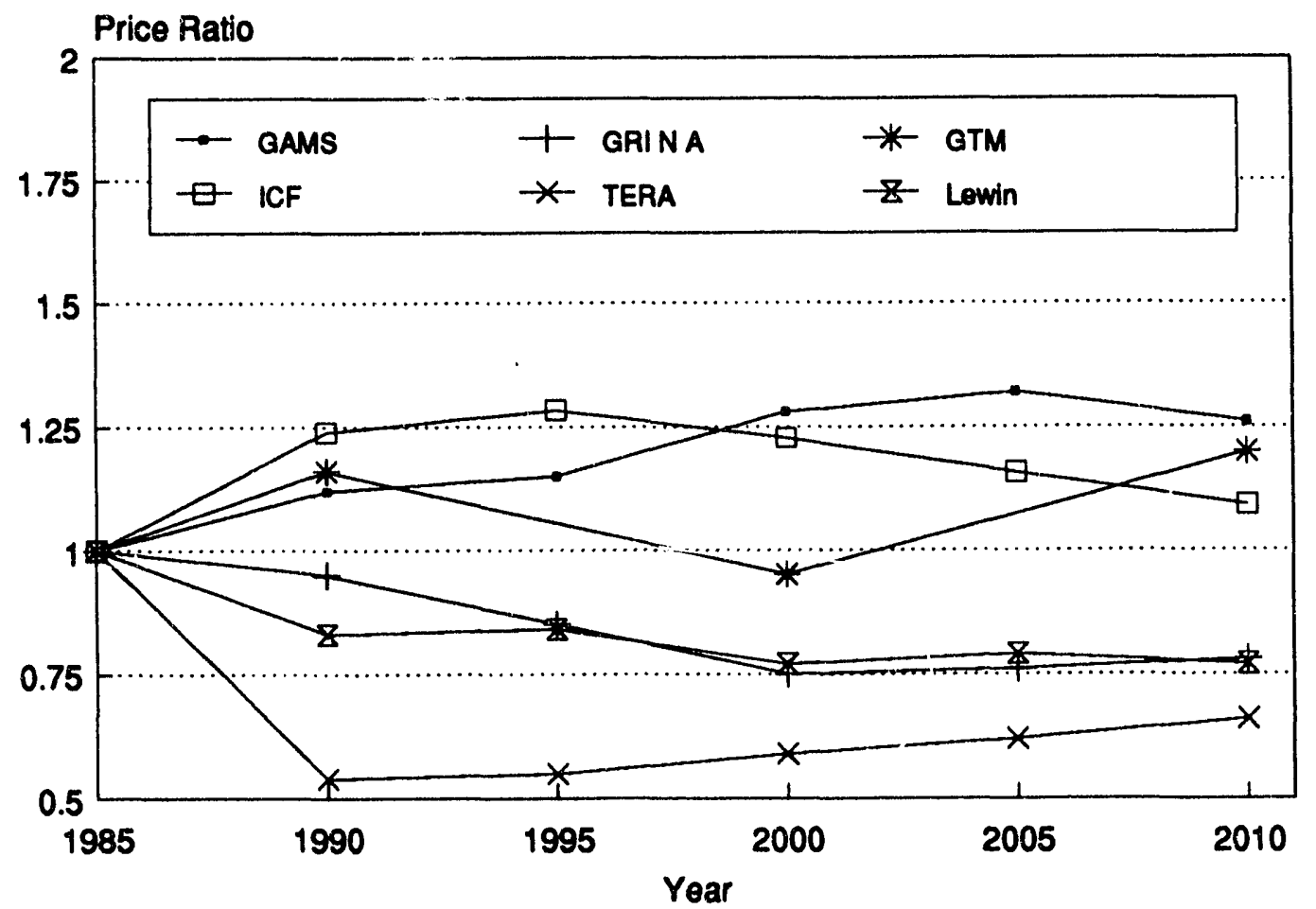

Figure 4.25: Industrial U.S. Gas-Oil Price Ratio by Model in the High U.S. Demand Scenario 


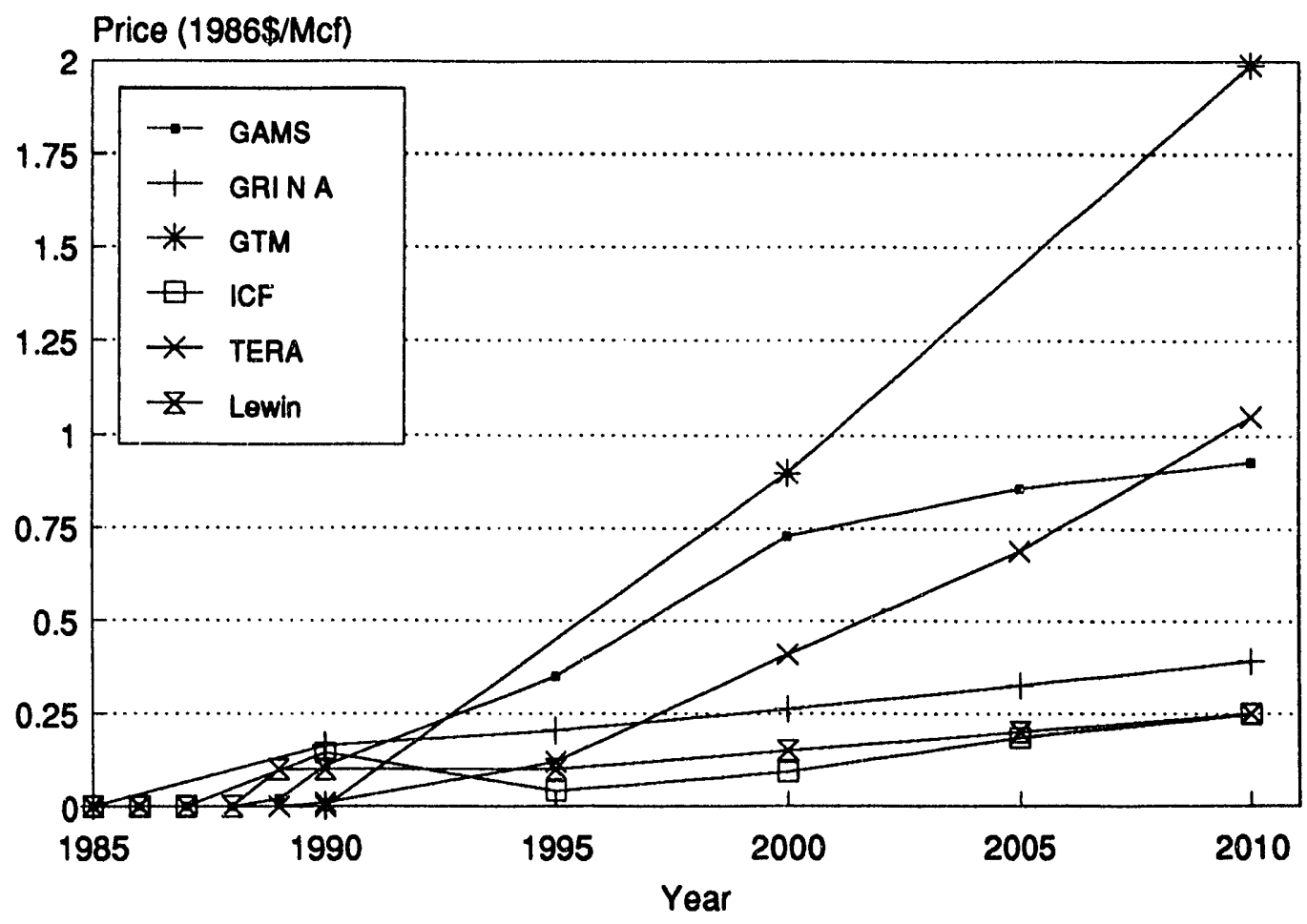

Figure 4.26: Change in the Average U.S. Wellhead Price by Model in the High U.S. Demand Scenario (relative to the upper oil price case)

as well as utility consumption is increased, resulting in a larger demand shift in this model than in other models.

\section{Price}

The results indicate that gas resources could be available to meet a significantly enhanced level of gas demand for electricity generation, but higher prices will be required to produce these resources. Gas prices rise even though oil prices are unchanged.

Wellhead gas prices rise more rapidly in this scenario than in the upper oil price case; more models report wellhead prices above the EMF netback path used by GRI Hydrocarbon in Figure 4.24 than for the upper oil price case. However, gas remains competitive in the dual-fuel market in many models. Figure 4.25 shows as many models with an industrial gas price above the Btu-equivalent resid- ual fuel oil price as those with a gas price below the oil price.

As new demand enters the market, prices at all levels are bid higher by the increased competition among consumers for gas supplies. The average delivered price, as reported for the average model result in the top of Table 4.12, moves abcut $\$ 0.40$ per Mcf higher than in the upper oil price case by 2000 and about $\$ 0.80$ per Mcf higher by 2010 . In responding to the high-demand conditions, the average wellhead price rises proportionately more than marketed production. For example, in the year 2000, domestic production increases by 6 percent relative to the upper oil price scenario in response to a 10 percent increase in the average wellhead price. Thus, while gas production is responsive to price, it is generally inelastic, i.e., it requires a proportionately greater increase in price to increase production by 1 percent.

The impact on the average wellhead price generally rises throughout the period in all models 
Table 4.12: Averge U.S. Delivered Price, Production, and Consumption Responses to Higher U.S. Gas Demand, 1990-2010 (with respect to the upper oil price scenario)

\begin{tabular}{lrrrrr}
\hline & 1990 & 1995 & 2000 & 2005 & 2010 \\
\hline $\begin{array}{l}\text { Average Delivered Price } \\
\text { Upper Oil Price (Mean) }\end{array}$ & 4.07 & 4.86 & 5.72 & 6.36 & 6.75 \\
$\begin{array}{l}\text { Change (1986\$Mcf) } \\
\quad \text { Maximum }\end{array}$ & 0.16 & 0.36 & 0.88 & 0.92 & 2.00 \\
$\quad$ Mean & 0.07 & 0.14 & 0.37 & 0.48 & 0.82 \\
$\quad$ Minimum & -0.02 & 0 & 0 & 0.19 & 0.22 \\
& & & & & \\
Marketed Production & 16.3 & 16.5 & 17.0 & 16.7 & 16.6 \\
Upper Oil Price (Mean) & & & & & \\
Change (Tcf) & 0.77 & 1.04 & 2.69 & 1.49 & 2.61 \\
$\quad$ Maximum & 0.26 & 0.62 & 0.87 & 0.98 & 1.65 \\
$\quad$ Mean & 0 & 0.18 & 0 & 0 & 1.14 \\
Minimum & & & & & \\
& & & & & \\
Total Consumption & 17.1 & 17.5 & 18.7 & 18.8 & 19.2 \\
Upper Oil Price (Mean) & & & & & \\
Change (Tcf) & 0.87 & 1.18 & 3.04 & 1.45 & 2.63 \\
$\quad$ Maximum & 0.25 & 0.67 & 0.97 & 1.08 & 1.85 \\
Mean & 0 & 0.20 & 0.07 & 0.30 & 1.21 \\
$\quad$ Minimum & & & & &
\end{tabular}

${ }^{a}$ Change equals the value in high U.S. demand scenario minus that in upper oil price scenario.

(Figure 4.26). Since transmission and distribution costs do not fluctuate greatly between scenarios, the change in the average wellhead price across models generally reflects that in the average delivered price.

Prices rise modestly relative to the upper oil price scenario-seldom by more than $\$ 0.30$ per Mcf-in four models: ICF, Lewin, AGAS, and GRI North American. Prices change very little in ICF and AGAS because gas prices in the upper oil price case-before the increment in potential demand - are equating with residual oil prices on a Btu basis. The new utility demand is met primarily by rapid fuel switching by boiler users; total consumption and prices change very little in these models. Natural gas is less sensitive to price in the GRI North American model than in ICF or AGAS because the market-clearing gas price lies below the oil-equivalent level in the upper oil price case. Even so, the demand response to price is stronger than in other models, requiring relatively modest gas price increases to restore a supply-demand balance. The Lewin results reflect the smaller shift in demand as well as the fact that gas supplies are more responsive to higher prices than in other models. As a result, gas prices do not need to rise very much to encourage sufficient new supplies to meet the higher potential gas demand for electric generation. 
Prices rise above the upper oil price path more in GAMS and TERA because both supply and demand are less responsive to price than in the other models. In GAMS, electric utility demand is already high (above $5 \mathrm{Tcf}$ in the 2000-2010 period) in the upper oil price (control) case. The introduction of $2.8 \mathrm{Tcf}$ of additional nonswitchable potential gas demand in this sector in the high demand case places considerable upward pressure on gas prices to bring forth the additional supplies that satisfy the higher demand levels. The significantly higher price impact reported by GTM primarily reflects a larger demand shift combined with a relatively weak demand response to pice.

\section{Marketed Production and Consumption}

Both marketed production and total consumption increase steadily from their levels in the upper oil price scenario but by less than the increase in potential demand, as shown by the model averages reported in the lower half of Table 4.12. Consum : $:$ rises by less than the increment in potential ernand because higher prices reduce gas consumption in other sectors as well as in lowervalued utility boiler uses. About 65 to 70 percent of the increase in potential gas demand is eventually realized as gas consumption in any one year. The potential gas demand increase of $1.4 \mathrm{Tcf}$ by 2000 generates about an extra $1.0 \mathrm{Tcf}$ of gas consumption; by 2010, a potential demand stimulus of $2.8 \mathrm{Tcf}$ results in additional gas consumption of about $1.8 \mathrm{Tcf}$.

The additional gas consumption is overwhelmingly met by U.S. gas production rather than gas imports in most of the models. Thus, the analysis can focus on the trends in total consumption by model (Figure 4.27) with similar implications for domestic gas production by model.

Total consumption increases steadily from its upper oil price path in four models-TERA, GRI North American, GAMS, and Lewin. By contrast, the impact on consumption in GTM shows a spike in 2000 before retreating to a more modest increase comparable to the other models by 2010 . The os- cillatory behavior of the gas consumption response reflects GTM's assumptions about the expectations of gas producers and consumers. In the current version, ecisionmakers do not anticipate future market conditions and select their strategies on the basis of current market conditions. The ICF simulation shows little influence of the high demand conditions on total gas consumption through the year 2000 , after which the response grows rapidly to $2.6 \mathrm{Tcf}$ by 2010 .

\section{Imports}

Both the low U.S. resource and high U.S. demand cases increase the demand for imports relative to the upper oil price case level. Imports in the high demand scen:rio, however, do not grow as much as in the low resource scenario, because wellhead gas prices in the North American market do not rise as much. Relative to the upper oil price conditions, U.S. imports from all sources by 2010 average about $0.2 \mathrm{Tcf}$ more under the high demand conditions rather than $0.6 \mathrm{Tcf}$ more under the low resource conditions. The import share of domestic consumption is similar to that in the upper oil price scenario, being in the 10 to 12 percent range in 2000 and beyond.

The range of results for U.S. gas imports from all sources (Figure 4.28) is somewhat less than in the upper oil price case. Once again, imports in the U.S. models often do not change from their relatively high levels in the upper oil price case. At the lower end of the range, imports increase to some degree in AGAS, GRI North American, and GTM, which all model the interactions between U.S. and Canadian markets.

The average projections for Canadian exports in U.S. and North American/Canadian models (Figure 4.29) depart from each other by 2000 , as they do in the upper oil price scenario. Growth in Canadian gas consumption and the cost of transporting gas from remote areas account for the lower levels of gas exports projected by the second group of models. 


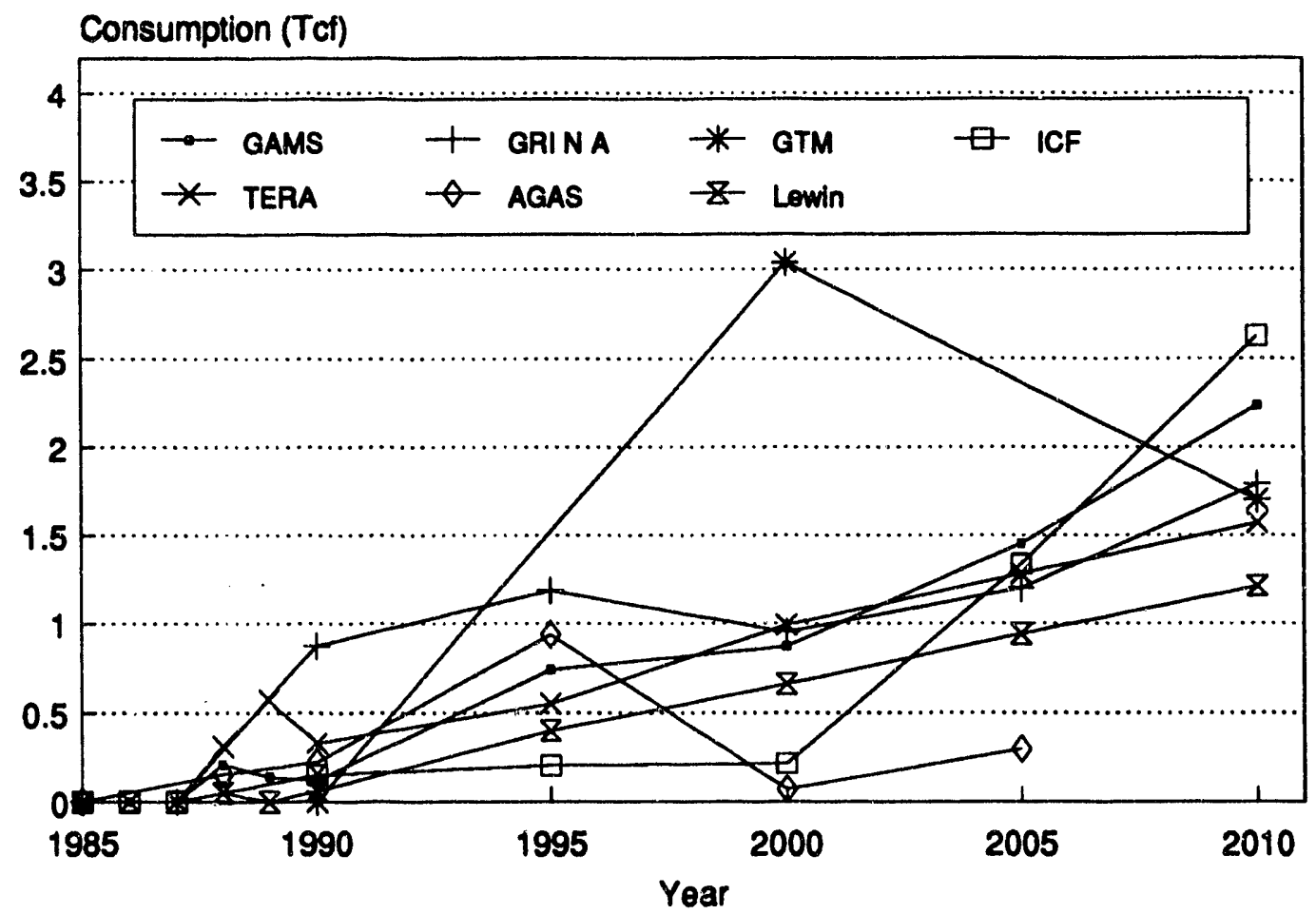

Figure 4.27: Change in the Total U.S. Consumption by Model in the High U.S. Demand Scenario (relative to the upper oil price case)

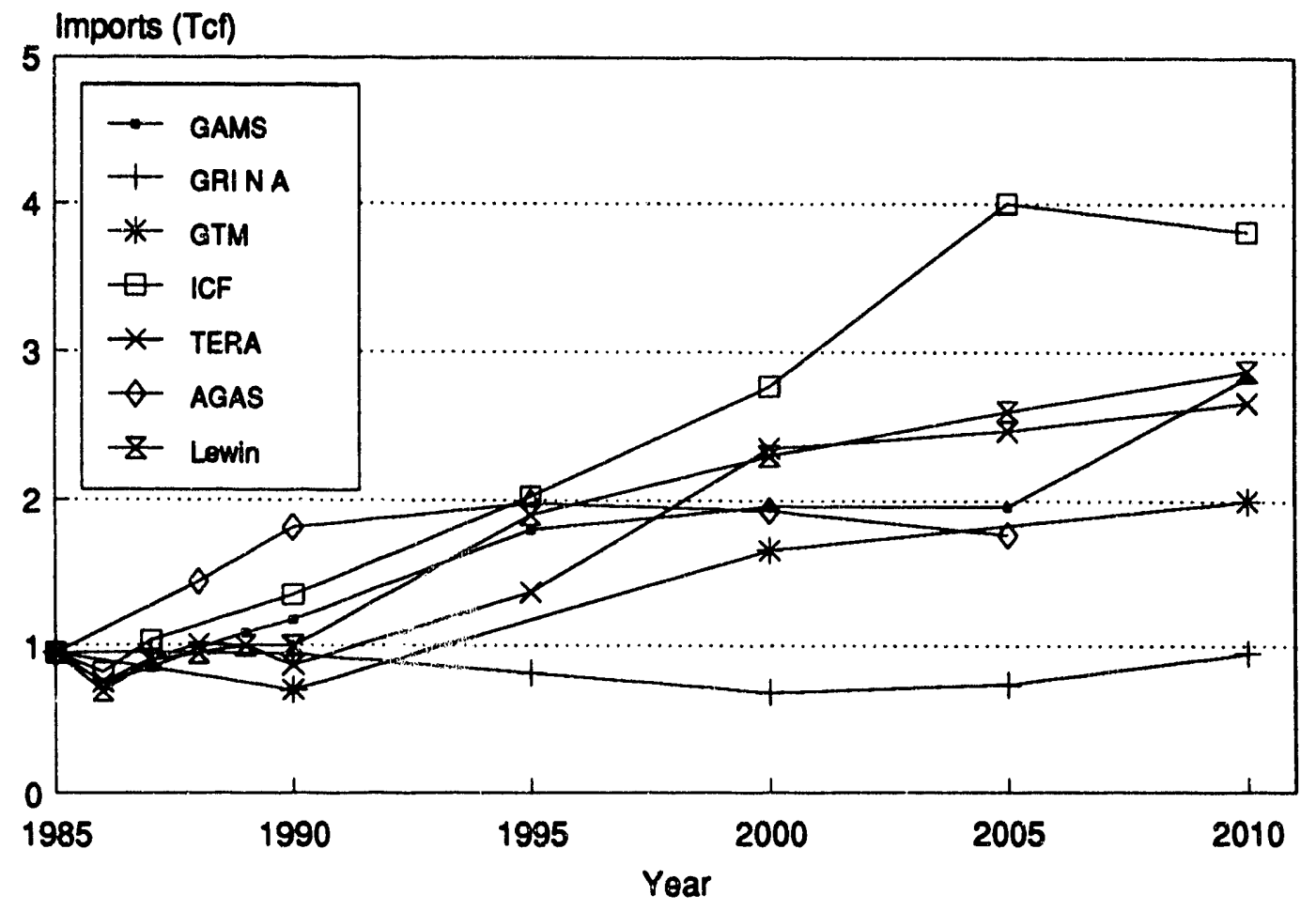

Figure 4.28: Total U.S. Imports by Model in the High U.S. Demand Scenario 


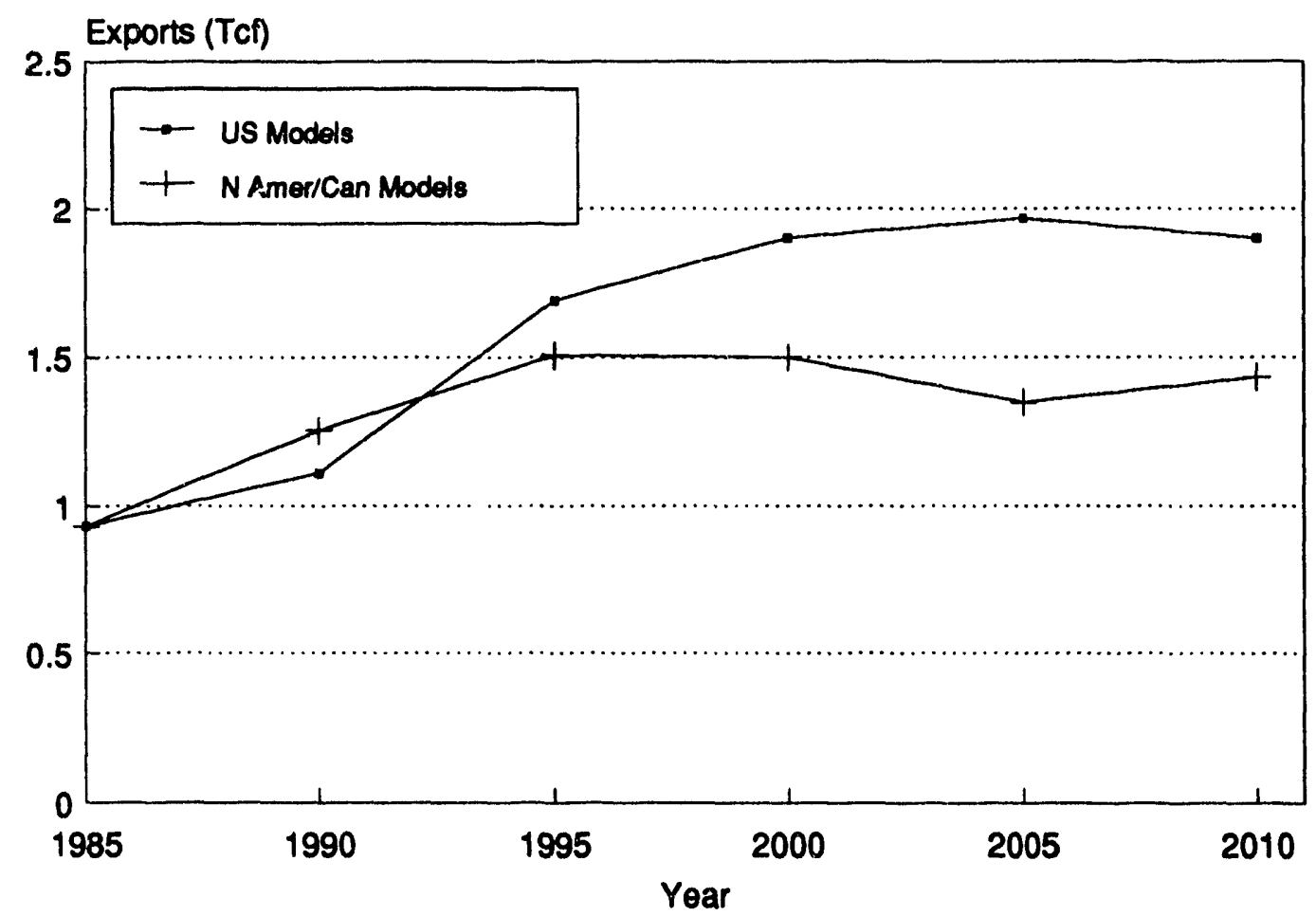

Figure 4.29: Total Canadian Exports in the High U.S. Demand Scenario for U.S. and North American/Canadian Models

\section{Comparison of Industry Survey and Model Results}

The EMF 9 working group also surveyed a group of oil companies and other organizations to determine their natural gas supply and demand outlooks, for comparison to the model results. A similar survey was conducted by the National Petroleum Council (NPC) in 1986. The results from the EMF 9 survey were in close agreement with the NPC survey results.

The survey respondents ${ }^{15}$ have been separated into two groups with the four higher forecasts of production in Group 1 and the five lower forecasts in Group 2. Table 4.13 summarizes the mean results of U.S. dry gas production for the industry survey and the modelers for the upper and lower oil price cases.

\footnotetext{
${ }^{15}$ About 60 questionnaires were sent out, but only 12 were retumed. Three were excluded because no oil price trend was specified.
}

Although the survey responses are limited, for the upper oil price case, the mean of the respondents is closer to the modelers' low resource case than the comparable upper oil price case results. The Group \#1 respondents' means are similar to the modelers', but the Group \#2 respondents' are lower. This implies that the Group \#2 respondents assumed that the natural gas resource/reserve base was lower than that used by the modelers, that the cost of finding and developing the resources was higher, that the rate of developing the resources was slower, or a combination of these factors.

These more pessimistic assumptions are reflected elsewhere in the survey as well. For the lower oil price case, the Group \#2 respondents were again more pessimistic than the modelers, and even Group \#1 respondents showed lower production in 2010 than the modelers. In Table 4.14, the U.S. consumption results for the industry survey were more similar to the EMF 9 models in the low resource than in the upper oil price case. 
Table 4.13: Mean U.S. Dry Gas Production (Tef) In EMF Industry Survey and Model Results

\begin{tabular}{lrrr}
\hline & 1990 & 2000 & 2010 \\
\hline & & & \\
Upper Oil Price Case & & & \\
Group \#1 & & & \\
$\quad$ Mean & 16.2 & 16.2 & 15.8 \\
$\quad$ Range & 1.3 & 0.5 & 0.5 \\
Group \#2 & & & \\
$\quad$ Mean & 16.0 & 13.3 & 12.1 \\
$\quad$ Range & 1.6 & 1.7 & 4.4 \\
All Respondents & & & \\
$\quad$ Mean & 16.1 & 14.7 & 14.0 \\
$\quad$ Range & 1.6 & 1.7 & 4.4 \\
EMF 9 Modelers & & & \\
$\quad$ Upper Price & 16.4 & 16.6 & 16.5 \\
Low Resource & 16.1 & 14.8 & 12.0 \\
High Demand & 16.8 & 18.0 & 18.3 \\
& & & \\
Lower Oil Price Case & & & \\
Group \#1 & 15.6 & 14.7 & 11.6 \\
Group \#2 & 14.8 & 11.0 & 9.0 \\
All Respondents & 15.1 & 12.5 & 10.0 \\
EMF 9 Modelers & 15.6 & 15.0 & 14.0 \\
& & &
\end{tabular}

Table 4.14: Mean U.S. Consumption (Tcf) In EMF Industry Survey and Model Results

\begin{tabular}{llll}
\hline & 1990 & 2000 & 2010 \\
\hline & 17.3 & 17.6 & 18.3 \\
Group \#1 & 17.2 & 15.1 & 14.2 \\
Group \#2 & 17.2 & 16.7 & 16.2 \\
All Respondents & & & \\
& & & \\
Modelers & 17.2 & 18.5 & 18.8 \\
$\quad$ Upper Oil Price & 16.9 & 16.7 & 15.6
\end{tabular}

Table 4.15: Comparison of Mean U.S. Dry Gas Production (Tcf) with National Petroleum Council (NPC) Survey

\begin{tabular}{lcc}
\hline & 1990 & 2000 \\
\hline & & \\
Upper Oil Price Case & & \\
NPC Survey & 16.4 & 14.5 \\
EMF 9 Survey & 16.1 & 14.7 \\
EMF9 Model Results & 16.4 & 16.6 \\
& & \\
Lower Oil Price Case & & \\
NPC Survey & 15.5 & 12.4 \\
EMF 9 Survey & 15.1 & 12.5 \\
EMF9 Model Results & 15.6 & 15.0 \\
& &
\end{tabular}

The National Petroleum Council (NPC) conducted a survey in 1986 using the same price trends as did the EMF 9 survey, except that no post2000 information was requested. There were 28 responses to the NPC survey, which included information on oil and other energy sources as well as natural gas. Table 4.15 compares the results of the NPC survey with the EMF 9 survey and the models. For either price trend, the differences in the 1990 lorecasts by the three groups are small. The lower oil price case results are about $1 \mathrm{Tcf}$ lower than the upper oil price case levels. For either price trend, the results in 2000 for the EMF 9 and NPC surveys are almost identical, but the survey means are 2-2.5 Tcf lower than the model means. The implications of these results are similar to those already discussed - that the survey respondents envision less resources, higher costs of finding and development, or both. 


\section{Chapter 5}

\section{The Structure and Regulation of the Natural Gas Industry}

\section{Introduction}

The natural gas industry is in the midst of a fundamental revision of its traditional market institutions and business practices. Because formal models are not well suited to studying such global changes, a separate subgroup of the EMF 9 working group was formed to focus on issues of regulation and market structure in the gas industry. The purpose of the group was to:

1. Understand how the industry will evolve in a more competitive world, and identify the nolicy issues which will most strongly shape the evolving market.

2. Specify the scenarios under which the industry might not evolve toward a competitive world, i.e., the circumstances in which regulators may have incentives to overtum some pro-competitive policies.

The work started from one fundamental premise: the unbundling of transportation and gas sales, encouraged by partial wellhead decontrol and increasing access to interstate pipeline transportation, is the new reality within which the future evolution of the natural gas industry must be understood. In addition to this overriding point of yiew, several other recurrent themes guided the group's thinking about future market issues:
1. Gas production is essentially a competitive industry; transmission and distribution are less so, although competition between pipelines, between sales and transportation service, between distributors and pipelines, and between gas and other fuels at the bumertip is significant in many regions.

2. Rapid, accurate transmission of price signals throughout the industry leads to a better balance of supply and demand.

3. Regulators will continue to have a major effect on the gas market through their pricing and access policies for transmission and distribution services.

4. With greater pricing flexibility throughout the industry, concems about supply reliability are being joined by concerns about price stability.

5. A streamlined approval process for entry into the interstate transportation market and greater ease of access by pipelines to end-use markets tend to improve the allocation of resources.

6. The distribution of economic benefits and risks is an important element in many of the regulatory issues facing the gas industry, but market forces will ultimately constrain the ability of regulators to allocate economic benefits. 
7. To the extent industry participants anticipate that pro-competitive policies will be reversed, some participants may reduce investments.

\section{Economic Efficiency and Distributional Is- sues}

Any analysis of regulatory policy and market structure in the natural gas industry must be sensitive to the tension between tvo regulatory objectives: economic efficiency, on the one hand, and satisfying public policy concerns regarding the distribution of economic surplus, on the other.

An efficient market is attractive because it maximizes the total economic value created by an industry, generating a larger "pie" (compared to less efficient market structures) to be shared by all participants in the market. Surpluses and shortfalls of production (not deliverability) are avoided by allowing the market price to equilibrate supply and demand. ${ }^{1}$

In the gas market, efficiency has often yielded to distributional concerns. Holding down prices to residential customers has been a frequent motivation for legislators and regulators, sometimes prompting them to adopt inefficient practices. For example, cross-subsidies between customer classes, which distort prices away from marginal costs, have long been commonplace. As another example, the severe curtailments of service that occurred in the 1970s caused many gas-using industries to cut back production and lay off workers. The curtailments were a direct result of well-

\footnotetext{
'In the parlance of economists, efficiency requires that price equal marginal cost for goods and services with no economies of scale or externalities, and that departures from marginal-cost pricing be minimized for goods and services exhibiting increasing returns to scale. Efficient market structure is characterized by free competition in the provision of goods and services lacking economies of scale, and by regulation which minimizes quantity distortions (i.e., departures from the quantities that would be consumed under marginalcost pricing) in the provision of goods and services exhibiting increasing returns to scale. The sort of regulatory pricing just described is referred to as Ramsey pricing. which requires markups over marginal cost to each customer class that are inversely proportional to that class' elasticity of demand.
}

head price controls that held prices below marginal costs, subsidizing consumers at the expense of producers.

Although the industry is currently moving toward a more competitive structure than in the past, the tension between achieving efficiency and protecting at least some classes of consumers remains, and is a recurring theme throughout this chapter.

This potential conflict will be an important consideration underlying the issues that regulators must deal with in the future, as discussed in the following section.

\section{Key Regulatory Policy Issues}

This section explores in greater depth the nature of the ten issues identified in Chapter 3, discussing what pro-competitive policies will look like, whether regulatory policy can be expected to move in the competitive direction, and what effects a pro-competitive policy will have on the gas industry. $^{2}$

\section{Pipeline Issues}

\section{Implementation of Pipeline Open Access}

The general thrust of FERC Order 500 and its precursor, Order 436, is to open the pipeline network to transportation by third parties on a nondiscriminatory basis. The DC Court of Appeals, while affirming the general principles of Order 436, remanded it to the FERC to address the take-or-pay issue (defined below); Order 500 is the FERC's response. There is still some disagreement within the industry, however, as to whether this response is adequate. In addition, a potential weakness of current FERC policy is that the incentives it provides pipelines to offer nondiscriminatory transportation may not be strong enough to persuade all pipelines to open their systems.

Long-term contracts with gas producers typically contain "take-or-pay" (TOP) clauses specify-

\footnotetext{
${ }^{2}$ Discussion papers on these issues will be included in a forthcoming Volume 3.
} 
ing $e x$ ante a minimum quantity that the purchaser must pay for regardless of his need for gas ex post. In the 1980s, an unexpected drop in world oil prices and shrinking gas demand have meant that many gas contracts that appeared sensible when originally signed have become uneconomic in today's gas market. Apportioning the losses from this unexpected decline in the gas market is a slow and disputatious process that continues to hinder the gas industry in its efforts to move toward a more efficient structure.

Some pipelines and producers have already negotiated TOP settlements, while others have been waiting for a FERC or court resolution. Pipelines in the latter category have strong incentives not to become nondiscriminatory transporters; carrying the burden of excess contract supplies, they prefer to sell their contract gas to reduce their take-or-pay liability rather than transport gas for others. FERC policy on TOP settlements is important because it affects the speed with which pipelines and producers resolve TOP issues that are currently preventing some pipelines from becoming nondiscriminatory transporters.

Relative to gas market pattems in 1988, any resolution of take-or-pay problems that passes settlement costs along to end-users could lead to price increases and load loss. Regulatory policy for takeor-pay cost recovery needs to be carefully structured so that market signals and consumption patterns are distorted as little as possible. Regardless of how Order 500 and tiv take-or-pay liability issue is eventually resolved, long-term contracts with some form of minimum purchase obligation are likely to continue to be used in the gas industry because some market participants think they provide benefits such as sccurity of supply, reduced transactions costs, and price stability.

Successful implementation of Order 500 will depend heavily on the FERC's allocating in an acceptable manner the cost of existing take-orpay obligations and establishing a framework for the future within which contracting parties can choose the allocation of risk suited to their circumstances. It will also depend on nondiscriminatory transportation being adopted by most, if not all, pipelines and on the state Public Utility Commissions (PUCs) establishing a set of policies for local distribution companies (LDCs) that are consistent with the open-access principles of Order 500 .

\section{Pipeline Rate Structure}

As gas industry services are gradually unbundled, pipeline rate structures will be crucial in determining whether unbundling and partial deregulation actually produce a more efficient gas market. ${ }^{3}$ In theory, an efficient rate structure will fully unbundle rates and allow market forces to set prices for services that do not have economies of scale. The unbundled services that could be provided include capacity reservations, backhauls and exchanges, standby supply services, and-to the extent the pipeline retains the merchant function-supply security and price stability.

The possible effects of implementing an efficient rate structure include: a decline in average transmission and distribution rates in real terms due to increased competition at the bumertip; a modest increase in gas demand as markets expand; a shift on the part of gas utilities from purchases of pipeline system gas toward a greater reliance on direct purchases; displacement of a portion of the pipeline merchant function by competitive gas marketing companies; and reliance on a gas inventory charge by pipelines that keep at least a portion of their merchant function. Many of these changes had already occurred by 1988 .

In practice, ine move to increase efficiency by unbundling pipeline services at competitive prices is hindered by 50 years of cost-of-service regulation. Assuming that this half-century of legal precedent is not overturned, a partial solution may be to repackage pipeline services in new "bundles" that more accurately fit the current needs of pipeline customers, with pipeline rates held to just covering the cost of service in the aggregate, while allowing rates on some segments in some time pe-

\footnotetext{
${ }^{3}$ FERC Order 436 has already established some new principles for unbundled rates.
} 
riods to go above or below cost-based rates. Rebundling of pipeline services might prove superior from a pure market-based perspective as well: the transaction costs faced by customers who must coordinate unbundled pipeline services themselves could be significant enough to make some bundling of services economically efficient.

\section{Pipeline Service Obligation}

Part of the tradition of public utility regulation in the pipeline industry has been that pipelines, in exchange for monopoly privileges in a particular market, are not allowed to unilaterally reduce the level of service they are committed to provide after being officially certificated. This "obligation to serve" prevents pipelines from opportunistically threatening to cut off service to local distribution companies after the LDCs have made specialized investments to connect to and use the pipeline's services.

While protecting LDCs from potential pipeline market power is a legitimate concern, the service obligation as it has evolved under case law is unresponsive to market signals and to recent changes in the gas industry. In recent years, pipeline market power in most regions of the U.S. has been greatly weakened by interpipeline competitionmore than one pipeline serves most major LDCsand pipelines now transport more gas for others than they take title to and sell themselves. Furthermore, under FERC Order 380, variable costs (such as gas costs) in minimum bills have been struck from contracts between pipelines and distributors, thereby relieving distributors of any obligation to purchase under these contracts. Despite these changes which enhance the ability of LDCs to purchase gas from alternative sources, pipelines' service obligations remain at the "contract demand" (CD) level initially specified in the original certificates issued under section 7(c) of the Natural Gas Act that granted them the right to enter a particular market. The pipeline must maintain the supply to provide this level of " $C D$ " service, regardless of changes in-or expiration of-the gas supply contracts that arrange for the actual production and consumption of gas moved through the pipeline. If an LDC suddenly calls upon its traditional pipeline supplier for gas supplies and the pipeline is unable to meet its CD service level, the LDC can require performance of the pipeline's service obligation. Thus, pipelines have been left with gas supply obligations for which they are not currently being compensated.

As at least a partial step toward providing for adequate future pipeline supplies, FERC Order 500 contains principles for a "gas inventory charge" (GIC) that pipelines can collect from their customers, indicating the FERC believes that in a competitive market there is value in assured supply. Once the GIC is implemented, and the " $\mathrm{CD}$ contracts" problem recedes, a second element of the pipeline service obligation may come to greater attention, i.e., whether pipelines should be given incentives to offer, at some charge, a standby service to transportation customers or whether such a service should remain purely a matter of individual negotiation between the pipeline and the buyer. ${ }^{4}$

\section{Economic Allocation of Pipeline Capacity}

Historically, pipeline regulation has carefully limited the construction of new pipelines, thereby reducing duplicative facilities and bestowing extra value on those pipeline projects that were actually allowed to be built. However, regulators also employed cost-of-service pricing to allocate the excess value of pipelines above their historical costs to local distribution companies and their customers.

As the pipeline system moves toward a regime of nondiscriminatory transportation, traditional capacity allocation practices are challenged by the need for a more flexible and efficient allocation system. Current methods of allocating pipeline transportation capacity-such as first-come firstserved policies-are inefficient: it is highly unlikely that capacity will end up in the hands of

\footnotetext{
${ }^{4}$ Standby service provides gas supply "insurance" for transportation customers who wish to improve the reliability of supplies they purchase on the direct sale market.
} 
those willing to pay most for it. Improving these allocation mechanisms would be a significart step toward a more efficient industry.

It appears possible for a secondary market in pipeline capacity rights to work efficiently in the gas industry; the difficulty lies in determining the initial allocation of firm capacity from which the secondary market will be allowed to start operating. Simply allowing the secondary market to begin operating immediately would in effect allocate all excess pipeline value above historical costs to those currently holding firm capacity rights, primarily local distribution companies. Whether this would be a fair policy is debatable, but LDCs will surely fight vigorously any FERC policies that interfere with their current firm capacity rights.

Regardless of how the initial allocation problem is handled, it is possible to outline some of the features that would characterize a more open market in transportation capacity. Capacity would be offered in both firm and interruptible varieties, and for long- and short-term periods. Customers holding unneeded long-term firm pipeline capacity would be allowed to sublet the space at marketclearing rates (i.e., on the secondary market) which could be above or below cost-based rates.

Tensions between regulatory objectives may affect how a more efficient system of capacity allocation will be implemented. Traditionally, costof-service regulation has been used as the standard for pricing pipeline services, yet the sort of secondary market in capacity rights discussed here uses a market-based standard instead. As mentioned above in the discussion of rate structures for unbundled pipeline services, reconciling the two standards may be a delicate matter. One option may be for regulators to hold pipeline rates to just covering the cost of service in the aggregate, while allowing rates on some segments in some time periods to go above or below cost-based rates.

Beyond the benefits of more efficient allocation of existing capacity, more flexible allocation of capacity could lower total industry costs by reducing the need for new pipeline construction and increasing utilization during off-peak periods. In addition, pipeline capacity expansion would be guided more accurately, through the use of market signals, into the areas where it is most valuable.

\section{New Pipeline Entry}

In tandem with opening up access to pipeline transportation capacity, the FERC has also taken steps to expedite the construction of new pipeline projects by those pipelines that have elected to be nondiscriminatory transporters. However, a number of potential pipeline entrants into the bottlenecked northeastern U.S. are now awaiting regulatory approval. Further steps to speed the approval process for new pipeline projects would decrease the lead time for construction and generally tend to increase competition. These policies should increase total gas consumption.

True free entry for new interstate pipelines is unlikely to occur since it would raise the possibility that duplicative facilities would be built, forfeiting economies of scale and-if cost decreases from increased competition did not outweigh the loss-of-scale economies-increasing the unit cost of the transportation network. A system that combines the use of market signals to indicate where new capacity is needed (as mentioned in the previous section) and a streamlined approval process for new pipelines may be a workable compromise. It is important to note, however, that the FERC's ability to speed up the approval process is inherently limited. New pipelines must obtain environmental approval under the National Environmental Protection Act (NEPA) and face the problem of obtaining the right to use space from the many property owners along a planned pipeline route. These hurdles can create delays regardless of any FERC policy.

\section{Local Distribution Company Issues}

\section{LDC Open Access with Unbundling}

Many of the issues involved in unbundling gas supply from pipeline transportation services are duplicated at the local utility level. Gas utilities are 
increasingly offering open access transportation to large end-users who prefer to purchase their own gas supplies and arrange transportation for them. Such responses by LDCs to increased pressures in their service territories move the competitive market in gas supply all the way downstream to industrial customers, putting increased pressure on the gas supply purchasing practices of gas utilities.

One major effect of LDC open access is that lags between changes in the spot price at the wellhead and at the citygate are reduced, making the market as a whole more responsive to changes in demand or supply.

Another important effect is to move the market aivay from average-cost pricing toward marginalcost pricing at the bumertip, at least for industrial customers. In theory, since most PUCs do not allow utilities to procure separate supplies of gas for industrial and residential customers, any movement toward marginal-cost pricing of industrial gas supplies should also affect residential and commercial prices. In practice, however, while industrial prices have dropped significantly over the last few years, prices to residential and commercial customers have fallen considerably less. Wisat appears to have happened is that the access of many industrial customers to low spot market prices and nondiscriminatory transportation has effectively reduced their gas costs, while the residential/commercial market has remained on more of an average-cost pricing basis.

The Califomia PUC, on the other hand, has been explicit in separating the gas supplies of core (i.e., residential and small commercial) and noncore customers, recognizing that core customers may have different preferences regarding price stability and supply reliability than do larger customers. Under this sort of regime, in which core supplies would for the most part be procured under contracts with more price fixity than spot purchases, the core market will also remain on essentially an average-cost basis.

As the market moves toward greater reliance on marginal-cost pricing, contracts between LDCs and producers increasingly will tie contract prices to the spot price, although contract prices may still not track spot prices exactly. Part of the motivation for such pricing provisions may be to reduce the impact of industrial demand swinging on and off system supply as spot prices fluctuate above and below the utility's average cost of gas. Such fluctuations in industrial demand are undesirable for residential customers because they increase the average cost of gas to the residentials. Residential customers must pay system supply prices when the spot price is lower than system supply costs, but industrial customers can purchase spot gas. However, industrial customers share the benefits of system supplies, since they can buy system gas when the spot price is higher than system supply, thus raising the cost of system supply. Some state PUCs are developing regulations that restrict the ability of industrial customers to swing on and off the system, or are implementing rate structures that explicitly charge such customers for the privilege of doing so. Trying to keep noncore customers from imposing burdens on core customers (or vice versa) could eventually lead more states to follow California's example of separating the gas supplies of core and noncore customers.

The effects of industrials swinging on and off the system will be intensified if PUCs are inflexible and do not allow seasonal prices. If LDC gas prices are not flexible by season, then high load factor customers will prefer to buy their supplies in the spot market during summer periods when prices are lower, and will retum to system supply during the winter if spot prices rise above the price of system supply, producing costs to residential customers similar to those described above.

The issue of industrials movin,- between system supply and direct purchases caises questions about the LDC's service obligation that parallel those about service obligation at the pipeline level. Should LDCs be required to provide standby service, at some charge, to transportation customers? If so, what charge would be appropriate?

Another effect of LDC open access and unbundling is that it increases competition in the wellhead market, and helps to make the well- 
head market more nationally integrated. Suppliers around the country will have greater ability to shift supplies to those areas where gas is most needed; as a result, the effects of sudden regional demand increases or supply outages can be spread over the entire integrated market, possibly necessitating a lower level of aggregate reserves than was needed when the market was more segregated by region. Open access and unbundling also tend to better balance LDC load throughout the year.

\section{LDC Bypass}

When industrial customers are dissatisfied with the cost or reliability of the gas supply and the transportation service provided by their LDC, they may prefer to bypass the utility altogether and connect directly to a pipeline.

The threat of bypass puts pressure on LDCs to offer more competitive rates in order to retain industrial load. Given its economies of scale, the LDC should be alsle to respond to bypass threats with competitive rates that retain the customer and prevent the duplication of distribution facilities. However, ne ability of LDCs to provide competitive $r$ ses may be hampered by PUC policies that atter.spt to subsidize residential rates at the expense of industrial rates. If state PUC policies do not allow LDC rates to respond efficiently to competition from prospective bypasses, it is possible for bypasses to be profitable to individual customers but also economically inefficient, causing duplication of facilities and unnecessary costs.

To the extent that bypass provides greater flexibility and reliability of service than traditional LDC service, perhaps due to less PUC regulation, its introduction will tend to increase gas demand on the part of those customers who can take advantage of bypass opportunities. However, an increase in the gas demand of potential bypassers may be partially offset by reduced demand on the part of other customers whose rates must rise if LDC cost reductions do not cover the lost contribution to fixcd costs from customers who leave the system.
The effect of bypass on total gas demand depends in part on whether the lost contribution to fixer costs is placed in the demand or commodity charges of other users. Increasing the commodity charge might distort prices and could decrease total demand below what it "Nould be if the increased costs were placed in the riemand charge. Marginal consumption decisions would not be changed by placing costs in the LDC's demand charge, although some customers might leave the system altogether because of the increased demand charges.

In addition to its possible effects on the total quantity of gas sold, bypass also tends to increase the aggregate elasticiiy of industrial demand; without the intervention of the PUC in pricing, bypassers can react more quickly and flexibly to changes in the marketplace.

\section{\&. LDC Marketing/Growth Policy}

Closely related to the question of how much competition to allow into the LDC market is the question of whether it is desirable to have restrictions on the ability of LDCs to compete for new sales.

Until very recently, some PUCs discouraged utilities from marketing gas service to new industrial and commercial customers through such s.ueans as:

- Full rate proceedings required to respond to price competition. Until the 1980 s, full proceedings were required in order to adjust rates to meet competition (e.g., from changes in residual oil prices to industrial boilers).

- Restrictions on advertising. A survey of LDCs conducted by the American Gas Association in 1982 found that 78 percent of respondents faced some restrictions on advertising imposed by their state PUCs.

- Hookup moratoria. In the mid-1970s more than half of the nation was subject to PUC-mandated moratoria on new customer hookups. 
Furthermore, until it was rescinded in 1987 the Powerplant and Industrial Fuel Use Act (PIFUA)passed by Congress when interstate gas supplies were scarce due to price controls-explicitly iestricted the use of gas for many "low priority" uses.

Some PUCs are now allowing LDCs greater pricing flexibility to meet competition for industrial load from other fuels. However, limits on advertising by LDCs and taxes on LDC gas sales (though not on transportation) continue to place LDCs at a competitive disadvantage compared to other gas marketers and other energy sources.

Restrictions on marketing may hinder efficient increases in gas use. From the perspective of many state regulators, however, the key issue is whether increased gas sales will benefit residential customers. They clearly will do so in periods of surplus deliverability, because increased demand tends to reduce unit transportation and distribution costs and unit take-or-pay costs, with little wellhead price impact. The net impact on residential customers when deliverability is tight is moie difficult to analyze, since increased nonresidential demand will then put upward pressure on wellhead prices, partially counterbalancing the positive effects of spreading fixed costs over more units sold. For any given service territory, however, any increase in demand is likely to be only a very small part of the whole wellhead market, and will probably have a negligible effect on wellhead prices. Thus, even from the perspective of maximizing the benefits to residential customers alone, restrictions on gas marketing are likely to be detrimental.

As competition from unregulated marketers of gas and other fuels increases, deregulation of industrial gas sales (though not necessarily of transportation service) may be necessary to allow LDCs to compete effectively. Separating the marketing division from the rest of the LDC, or at least providing guidelines for the relationship between the two, might be needed to ensure fair competition.

\section{PUC Oversight of LDC Contracts}

As is illustrated in some of the issues above, it is easier to bring competition to bear on industrial gas prices than on residential prices. Industrial customers have more alternative sources of energy, and often consume enough gas to justify becoming sophisticated players in the gas market.

PUCs across the country are experimenting with new regulations designed to induce LDCs to reduce residential customers' gas costs; PUCs are concerned in particular with the mix of long-term contracts and spot market purchases that comprise a utility's system supply. A few states have tried regulations which share gas cost decreases between ratepayers and stockholders; these have given utilities increased incentives to purchase efficiently with minimal regulatory oversight. Much more common, however, are "least-cost purchasing" requirements, which direct LDCs to purchase the cheapest gas supplies available consistent with maintaining reliable service.

Enforcement of least-cost purchasing requirements has generally been of two types: (1) The PUC closely scrutinizes the LDC's gas supply plans before they are implemented, requires any changes it sees as necessary, and then "blesses" the plans, declaring them to be prudent given all the available information, or (2) The PUC may audit the LDC's gas supply plans after they have been implemented, and disallow the recovery of any gas costs it deems imprudent.

The first approach requires substantial PUC involvement in LDC contracting decisions, increases informational lags in the gas system, and places the risk of cost increases on consumers. Even if a PUC adopts this approach and prices later get too far out of line, it is still possible that the PUC may decide it was misled by the utility and disallow the recovery of costs which are unacceptably high.

The second approach allows the utility flexibility to make its own decisions, but exposes it to the risk that it will be "second-guessed" in hindsight. If an LDC believes that regulator, will engage in opportunistic disallowance of coists ex post (i.e., 
disallowances not based solely on the information available to the LDC at the time it entered its gas contracts), it will design a gas acquisition strategy to avoid retroactive disallowance rather than to minimize purchased gas costs. Regulatory policy that induces such a strategy tends to increase the expected consumer cost of gas, and unfortunately no PUC can credibly commit itself to eschew opportunistic hindsight review. (The implications of the inability of present regulators to bind future commissions are explored further in a later section.)

How the pipeline service obligation is resolved may also have important implications for LDC supply purchasing. At present, LDCs backed up by continuing pipeline $\mathrm{CD}$ obligations can buy cheap spot gas with very little risk, since they can always retum to pipeline system supply when spot prices tum upward. If pipeline obligations were no longer available free of charge but instead priced out through a gas inventory charge, LDC spot purchases decisions would become more risky, almost inevitably increasing the chance of opportunistic hindsight reviews.

\section{Canadian-U.S. Gas Trade Issues}

\section{Regulations Affecting Canadian Exports}

Since 1985, Canada has been moving toward a market-oriented regime for natural gas. In September 1987, the National Energy Board (NEB) abandoned reserve/production $(R / P)$ ratio requirements for exports; instead the Board adopted a new "Market-Based Procedure" for determining whether to license an export application. The Board will use two mechanisms to ensure that natural gas to be licensed for export is "surplus to Canadian needs": (1) public hearings to consider applications for export licenses, and (2) ongoing monitoring of developments in the natural gas market that may merit concern. ${ }^{5}$

\footnotetext{
${ }^{5}$ The Energy Regulatory Administration (ERA) authorizes gas imports and exports to and from the United States.
}

The public hearings will allow for the denial of export licenses: (1) if there are unresolved, valid complaints from Canadian customers that they are unable to obtain gas on terms and conditions similar to those under which it is to be exported, (2) if the exports are considered likely to cause difficulty to Canadians in meeting their energy needs at "fair market prices", or (3) if the exports are viewed as being contrary to the national public interest.

Canadian/American nondiscriminatory trade policies and regulatory practices in gas sales and transportation are also important to creating a more competitive gas market. Even if trade and regulatory practices within each country are nondiscriminatory, competition might still be distorted on account of particular regulatory arrangements that affect gas supply differently on each side of the international border. It may not be possible or desirable to make both countries' regulations identical; however, a more integrated market will more clearly expose the impacts of altemative regulatory practices on competition.

The Canadian-U.S. Free Trade Agreement has been signed and ratified. This agreement commits Canadian and U.S. governments not to restrict energy imports or exports or to impose minimum export price requirements, except as allowed in the Agreement.

\section{Gas Industry Evolution in a More Competitive World}

This section draws upon the discussions of individual issues from a preceding section to produce two alternative views of the future natural gas market. The first is a hypothetical benchmark case representing a very pro-competitive regulatory environment; the second is a more moderate but still competitive case that reflects several possible noncompetitive regulatory policies. These cases provide a framework for the next major section that examines future scenarios in which the gas market may fail to move even to the moderately competitive case described below. 
The Benchmark Case: criaracteristics of a Hypothetical Pro-Competitive Regulatory Environment

Even in the most competitive possible future for the gas industry, regulation will continue to play an important role due to elements of market power in the interstate pipeline industry, and natural monopolies in the provision of some local distribution services. The focus here is on defining the characteristics of the most competitive possible future for the industry in the context of wellhead decontrol and open access to transportation.

In this situation, gas demand would be stimulated, competitive pressures would lower transmission and distribution margins, and crosssubsidization would be reduced. As a result, producers would have correct incentives to explore for reserves. Greater competition would lead to extensive use of short-term contracts or contracts with flexible price terms, although some players would prefer contracts with a degree of price fixity as a means of sharing risks. Contracts for firm gas supply would probably continue to contain minimum purchase obligations, reflecting the costs to suppliers of reserving supplies for particular customers. Time lags to reach equilibrium would be reduced, and periods of surilus (or inadequate) deliverability would be of shorter duration. In a nationally integrated market, production is less likely to be "shut-in", and aggregate reserve to production ratios could decrease.

Existence of a competitive gas industry certainly requires the continued unbundling of services, with pipelines and LDCs acting as nondiscriminatory transporters. Pipeline obligations would be priced by type of service under a market system, e.g. through a demand charge, backup charge, reservation fee, etc. A secondary market in pipeline capacity rights would be developed. Other policies conducive to a competitive market include a streamlined regulatory process for approving the entry of new pipeline projects; a "level playing field" in the area of gas marketing, including the same tax policies for all marketers, be they in- dependent marketers, pipeline affiliates, or LDC affiliates; and reduced restrictions on bypass of LDCs. PUCs would give LDCs a share of any cost savings they bring about through astute gas purchasing, thus giving them additional incentives to purchase efficiently. In addition, a truly competitive gas market would provide adequate mechanisms for sharing risks, such as enforceable long-term contracts and a gas futures market. A competitive market place would also require Canadian/American nondiscriminatory trade policies and regulatory practices in gas sales and transportation.

\section{The Moderately Competitive Case: What Limits to Competition Can Be Expected?}

Movement to a competitive gas market is hindered by three primary factors: (1) regulators' responses to the political demands of residential and other "high-priority" customers, (2) market power on the part of local distribution companies and some pipelines, and (3) incomplete markets for risk-bearing.

For example, two types of policies likely to be affected by public policy concerns other than efficiency are bypass regulations and oversigit of LDC contracts. As discussed previously, bypass by a given end-user may harm remaining customers as rates rise to cover lost contributions to fixed costs. Thus, regulators may face considerable pressure to prevent bypass. (To date, only Indiana has a law prohibiting bypass. However, strong sentiment against bypass has been expressed recently in the U.S. Congress in the form of three bills-two in the House and one in the Senatewhich would prevent the FERC from overruling state PUC attempts to block bypasses.)

PUCs may also face political pressure if wellhead gas prices tum sharply upward. Consumer groups may press regulators to protect consumers by disallowing full recovery of gas costs, thus imposing additional costs and risks on stockholders.

Natural monopolies in portions of the LDC and pipeline segments of the industry make a 
truly "competitive" industry impossible, but the use of pricing to minimize quantity distortions (i.e., departures from the quantities that would be consumed under marginal-cost pricing) can bring about efficiency in a second-best sense. Regulators, however, are generally unenthusiastic about such pricing because it requires markups over marginal cost to each customer class that are inversely proportional to that class's elasticity of demand: residential customers must pay higher markups than industrials. Regulatory politics thus make it likely that some inefficiency will always characterize local distribution company rates.

Within the emerging competitive market structure, most pipelines and LDCs will find it to their advantage to offer transportation services. However, some LDCs and pipelines, in some regions of the country, may choose to reduce the competitiveness of the industry by refusing to offer transportation service at nondiscriminatory rates. This could be addressed through legislation if Congress and the respective state legisiatures implemented mandatory carriage bills.

Price volatility will also create problems for the gas industry to the extent markets for risk are not fully developed. Long-term contracts consistent with the new regulatory regime have not yet fully evolved, a gas futures market does not yet exist, and vertical integration is regarded with suspicion by regulators. Even if a futures market does develop, it will be unlikely to extend far enough into the future to allow for the complete hedging of all relevant gas industry risks. The effect of allocating risks among market participants is an important topic deserving more analysis.

\section{Scenarios in Which the Industry May Not Evolve Into a Competitive World}

The previous section described how the natural gas industry is likely to look as it becornes an increasingly competitive industry. There is no guarantee, however, that the gas market will continue to evolve in the competitive direction it is currently taking. Under some scenarios, regulators may face strong political pressure to change course, overtum (or simply nut adopt) some pro-competitive policies.

Three main sources of political pressure may be anticipated: (1) if gas prices are below parity with oil product prices, regulators may attempt to increase revenues from dual-fuel customers in order to subsidize high priority customers, (2) rapidly rising gas prices may lead regulators to control prices to high priority customers, or (3) rapidly rising prices for pipeline transportation may lead regulators to subsidize the use of firm capacity by high-priority customers. Other pressures may emerge in particular situations. The pressures that may be faced by regulators in alternative scenarios are explored more fully below.

\section{Political Pressures for Inefficient Regula- tory Policies}

\section{Upper Oil Price Case}

In the results for the upper oil price case, all models show the wellhead gas price clearing at or below the netback price of oil (i.e., the burnertip price of oil minus transportation costs). This observation has implications for the political incentives that might be faced by state regulators in this scenario. Industrial customers who have the capacity to use either gas or oil are saving money by using gas. Regulators may question why industrial customers should receive all the benefits from gas' low price relative to oil. They may once again raise industrial prices closer to the oil-parity price and use the proceeds to hold down prices to residential customers, as was done under the incremental pricing provisions of Title 2 of the Natural Gas Policy Act. Most industrial gas customers have other options, however, such as buying their own gas and transporting it through the utility, or bypassing the utility altogether. Thus, cross-subsidization will only be possible to the extent industrial users' options are restricted. Regulators and legislators can act to reduce the options of industrial customers 
by: (1) limiting (or taxing) access to transportation through gas utility systems, and (2) restricting bypass. In fact, the first restriction will have limited impact on industrial customers who are close enough to pipelines to make bypass an economical option.

Thus, in the upper oil price case, policymakers may have strong incentives to impose restrictive measures on a competitive gas market. For individual state PUCs, such anticompetitive policies carry their own risk: they could drive some industrial customers to other states with more competitive policies.

The above observations call into question whether regulators will allow bumertip oil and gas prices to remain decoupled in the future. If prices are coupled by regulatory fiat, the total demand that occurs in the future will be less than projected by the models, as highly elastic industrial customers face higher prices than expected and inelastic residential customers face lower prices than expected.

As gas prices rise, PUC policies goveming gas contracting practices could be reversed: even if the PUC grants prior approval to a utility's gas supply plans, it may later choose to disallow the recovery of some gas costs.

\section{Lower Oil Price Case}

The lower oil price case contrasts sharply with the upper oil price case in that many of the models show wellhead gas prices clearing above parity with oil product prices. Regulators thus have little ability to reallocate benefits in this case.

If lower oil prices result in significant loss of industrial gas demand, the delivered cost to residential customers will rise as the contribution made to the fixed distribution costs by the industrial sector is reduced. This may generate policies directed at ensuring adequate supplies to the residential customers at "fair" prices, such as increased cresssubsidization of residential customers by remaining nonswitchable (in the shor term) industrial and powerplant customers or recontrol of wellhead prices. LDC marketing effo.ts would be discour- aged and their gas purchase contracts would receive greater review with an increased possibility of cost increases being disallowed.

The implementation of such policies would introduce distortions in the market which would also affect the Canadian market. This would likely result in the introduction of compensating regulation in Canada, further interfering with market forces, and introducing additional market distortions. Interested parties might also intervene with complaints at National Energy Board hearings on gas export applications, under the complaints provision of the Board's "Market-Based Procedure", if thev thought the terms and conditions of the proposed :xport more favorable than those available to Canadian customers.

\section{Low Resources Case}

This case resembles in some respects the "supplyconstrained" environment of the 1970s. In this scenario, gas prices rise rapidly and regulators may act to ensure that resider.ial customers receive the supplies they "need" at "fair" prices. In essence, such a strategy implies price controls for residential customers and cross-subsidization by industrials. It is conceivable that a move toward wellhead price recontrol would arise. Even without recontrol, there are ways for regulators to soften competitive pressures in the low resources case. Regardless of the means employed, this appears to be the case that would create the greatest pressure for reregulation of the gas industry.

Many of the pro-competitive policies discussed earlier in the chapter would be vulnerable to revocation in this case. PUCs would certainly discourage LDC marketing efforts. As gas costs increased, PUCs might increase their use of retroactive review of gas contracts, disallowing certain cost recoveries by LDCs that had not locked into long-term contracts at lower prices. Even openaccess transportation could be threatened if regulators feel that by reducing industrial gas demand through regulatory measures, LDCs could increase 
their monopsony power in the gas market to the benefit of residential and commercial customers.

Congress and the FERC might also be expected to respond to concems about high prices and possible shortages. They would be less inclined to allocate gas supply on the basis of customers' willingness to pay, and might return to a system with fixed priorities for given classes of customers. The pipeline service obligation would be enforced with renewed vigor, with little attention paid to pricing out supply guarantees efficiently. Whether pipeline open access would be revoked could tum on the political ability of pipelines to protest the imposition of a binding service obligation without corresponding purchase obligations on the part of LDCs. Development of new pipeline projects would be carefully scrutinized.

Overall, the low resource case would put considerable pressure on the gas industry to move back to a more heavily regulated world.

\section{High Demand Case}

The pressures impinging on regulators in the high demand case arise principally from increased competition for pipeline capacity and rising prices.

With additional gas demand, regional pipeline bottlenecks will become increasingly tight. Price increases on these segments would provide a signal that new capacity is needed, and applications for new pipeline projects would be made to the FERC. However, most new pipelines will be more expensive than existing, largely depreciated pipeline systems. The prospect of siginiicant increases in pipeline costs might lead the FERC to abandon an economic system of capacity allocation for one with fixed priorities for particular customer classes. By restricting the access of low-priority customers to the transportation network, pipeline demand would be reduced, and pipcline prices would be held down for those customers allowed access; such a policy would create cross-subsidies similar to those generated by wellhead price controls and would attempt to allocate available supplies to high-priority users.
At the state level, gas price increases might trigger close retroactive scrutiny of LDC supply contracting practices, even on supplies regulators had previously thought to be prudent.

\section{Volatility}

Although it was not considered as a separate scenario, a "Volatile Oil Price Case" may be at least as likely as either the upper or lower oil price trends. In this case, regulators will be inclined to "protect" core customers from swings in the market, attempting to stabilize the market through closer regulation. PUCs may intervene in LDC contracting practices, perhaps encouraging LDCs to rely on long-term contracts with stable prices-and thus potentially setting the stage for a repeat of the gas market dynamics of the mid-1980s, when a sudden shift in market conditions rendered many highpriced contracts unmarketable. A less interventionist regulatory response to volatility might be concerted support for the development of a gas futures market, which would allow for efficient hedging of gas price risks by LDCs themselves.

\section{Can the Competitive Genie Be Put Back in the Bottle?}

If the gas market continues in a more competitive direction for the next few years, the new competitive market structure may become entrenched, with a large number of stakeholders having vested interests in maintaining the new structure. If this happens, it will be much more difficult for regulators to depart from the pro-competitive path at this point than earlier in the process.

\section{Effects of Policy Reversals on the Gas Mar- ket as a Whole}

To the extent industry players anticipate that procompetitive policies will be reversed, some may reduce investments in gas-using capital equipment, in computerized systems to cut costs in gas trading and transportation, in new pipeline capacity, and in new gas wells. 
Can regulators credibly commit themselves to a more competitive gas market? Their instruments for so doing appear rather limited. Any regulation or legislation can always be overturned, and as discussed above, policymakers may face strong political pressures to roll back pro-competitive policies in some scenarios. In general, it appears that the only way for regulators to commit credibly to a policy is for the policy to clearly be in their own interest (i.e., the interests of their most highly valued clientele), under all foreseeable future circumstances. If this were the case, firms could confidently make investments for the future. However, very few policies are likely to pass such a test.

More specifically, some likely results of turning back from the path of increasing efficiency by overtuming (or failing to adopt) particular policies are presented below:

1. If regulators were to inhibit attempts to create better markets for allocating risk among industry participants, e.g., by failing to allow pipelines to levy a gas inventory charge in return for holding supplies in reserve or by limiting the ability of LDCs to use a gas futures market, the form of contractual relationship preferred by many buyers and sellers would be frustrated, leading to less efficient pattems of consumption and supply development than would otherwise result.

2. Methods of pipeline capacity allocation based upon noneconomic criteria (c.g., first-come, first-served approaches) would tend to restrict the access of high-valued users to gas pipelines. To the extent that aggregate demand for gas in the field is reduced, these policies will reduce the incentives for producers relative to methods based upon economic criteria. In addition, expansion of the pipeline network to meet these high-valued uses would be hindered.

3. The failure of LDCs to unbundle gas supplies and transportation would tend to increase costs to industrials, and decrease costs to residentials, compared to the policy of unbundling and open access to LDC transportation. Depending on relative elasticities, demand could increase or decrease compared to the competitive case with unbundling; a decrease in total demand is more likely, since industrial users generally have much more elastic demand than do residential customers.

4. If LDCs believe that regulators will engage in opportunistic disallowance of costs ex post (i.e., disallowances not based solely on the information available to the LDC at the time it entered its gas contracts), they will design gas acquisition strategies to avoid retroactive disallowance rather than to minimize expected costs. Such strategies would increase expected consumer costs and reduce demand.

5. If Canadian rules were to restrict exports below competitive levels, the effective supply curve for all gas (including imports) in the United States would be shifted inwards, increasing costs and decreasing sales. ${ }^{6}$ If these same policies made gas more available to Canadian users, the corresponding effect in Canada would be to temporarily shift the domestic supply curve outward, reducing prices and increasing sales. While Canadian producers would be earning more on each unit sold to the United States, they would earn less on each unit sold within Canada. Drilling incentives could be reduced by such policies under certain conditions.

\section{Implications of Regulatory Issues for Future Modeling Efforts}

Most of the models in the EMF 9 study are designed to portray a generally competitive gas market; a few models include detailed information on such items as pipeline tariffs and FERC regulations. Competitive assumptions are generally rea-

\footnotetext{
${ }^{6}$ The effects of this policy are similar to those for a lower U.S. resource base, as represented in Figure 4.17 of Chapter 4.
} 
sonable for the wellhead supply market, but are less so for transmission and distribution (T\&D) rates, which will remain regulated. In fact, the way in which T\&D rates are regulated may well change under various scenarios.

Most modelers have assumed that T\&D rates will remain essentially constant in real terms from 1988 through 2010 . In reality, real T\&D charges on a per-unit basis will probably fall in all scenarios. ${ }^{7}$ In addition, the relative allocation of distribution costs between industrial and residential customurs will change as the market becomes increasingly competitive: less of the fixed costs will be allocated to industrials, which should increase aggregate demand.

In the upper oil price case, on the other hand, regulators may have strong incentives to raise the distribution charges to industrial customers, bringing oil and gas prices at the bumertip closer to parity. In this case, aggregate demand would be less than forecast by the models, since industrial costs would be higher and residential costs lower than assumed.

\section{Conclusions}

Public utility regulation will remain a key factor for local distribution companies (and some pipelines) due to their natural monopoly characteristics; LDCs may be further constrained in the move toward competition by the political concerns of state regulators.

Under certain EMF 9 scenarios, regulators at both the state and federal level may face substantial political pressure to overturn (or fail to adopt) some of the pro-competitive policies currently being applied or formulated in the gas industry. If regulators cannot credibly commit to competitive policies, industry investment will be suboptimal as will total gas production and consumption. The low resources case seems to hold greatest potential for a reversion to the heavily-regulated, supplyconstrained environment of the 1970s.

\footnotetext{
${ }^{7}$ Sec the discussion of T\&D margins in Chapter 3.
}

The assumption of constant real transmission and distribution rates, made in most of the models participating in this study, probably leads to underestimates of total demand, since real T\&D rates may decrease in the future. More detailed modeling of T\&D rates would be an important step in improving the ability of models to analyze the gas industry. 


\section{Chapter 6}

\section{Key Results from Special Studies of Natural Gas Supply}

During the study, several critical natural gas supply issues were identified that were not directly amenable to analysis by modeling. These issues include: (1) the new Departments of Interior and Energy estimates of the U.S. gas resource base, (2) Alaskan and Mackenzie Delta/Beaufort Sea gas potential, (3) alternative estimates of the Canadian resource base, (4) reserve growth through infill drilling as a potential additional source of reserves, and (5) the impact of environmental regulations on natural gas supplies. By drawing upon the research of some working group members and other analysts, these issues were probed to determine their likely impact. Where appropriate, important differences in perspectives are also discussed.

\section{New Departments of Interior and Energy Assessments of the Natural Gas Resource Base of the United States}

The U.S. Geological Survey (USGS) and the Minerals Management Service (MMS) are nearing completion of a 2-year effort to assess the undiscovered oil and gas resources of the United States. Preliminary estimates have been released and a working paper describing the details of the methodology and their assumptions will be reviewed extensively before the study is considered final. In addition, in May 1988, the Department of En- ergy (DOE) completed a new assessment of the U.S. natural gas resource base. ${ }^{1}$ This assessment made extensive use of existing resource estimates by the Potential Gas Committee (PGC), USGS, and MMS. ${ }^{2}$ Included were preliminary 1988 estimates made by USGS and MMS.

Resource assessments typically proceed from consideration of reasonably well known quantities (proved reserves) to consideration of increasingly less well known quantities (undiscovered resources). Other than proved reserves, all volumes of future natural gas supply are estimates based on information derived from past and current experience in gas production and reservoir development. Even proved reserves are an estimate subject to periodic revision. Natural gas reservoirs termed unconventional are usually reviewed separately, including gas in low-permeability reservoirs, gas in shale formations such as the Devonian of the East-

\footnotetext{
${ }^{1}$ Fisher, W.L., Finley, R.J., Seni, S.J., Ruppel, S.C., White, W.G., Ayers, W.B., Jr., Dutton, S.P., Kuuskraa, V.A., Mcfall, K.S., Godec, M., and Jennings, T.V., An Assessment of the Natural Gas Resource Base of the United States, The University of Texas at Austin, Bureau of Economic Geology; ICF-Lewin Energy Division, ICF, Inc.; and Argonne National Laboratory; prepared for the Office of Policy, Planning, and Analysis, U.S. Department of Energy, under contract no. 80622401,77 p., plus appendices (bound separately), 126 p., May 1988.

${ }^{2}$ U.S. Department of Interior, U.S. Geological Survey and Minerals Management Service, National Assessment of Undiscovered Conventional Oil and Gas Resources, USGS-MMS Working Paper, Open-File Report 88-373, May 1988.
} 
em United States, and coalbed methane resources. Alaskan gas reserves represent a special case, because they are significant and proven, but currently lack a transportation system from the North Slope to the lower-48 states.

The 1988 USGS estimate of undiscovered recoverable gas is 34 percent lower than its 1981 estimate (Table 6.1). There are several reasons for this decrease.

- New discoveries since 1979 (the vintage of the data used in the 1981 report) have moved some of the resources from the undiscovered column into the inferred and proved reserves categories.

- Drilling since 1979 has produced new geologic information that has reduced the estimated undiscovered resource in some basins.

- DOI used a different methodology from the 1981 effort. They used a play analysis methodology, as opposed to a volumetric approach. The play analysis forced the analysts to locate the gas in fields of specific sizes and to verify that undrilled areas exist into which these fields could fit. This reduced the amount of estimated undiscovered gas in some basins.

- A more explicit economic truncation is used in the current report. This is most likely to have the greatest effect offshore where relatively large fields may become uneconomic. This effect was seen when the Minerals Management Service updated the offshore oil and gas estimates in $1985^{3}$

- Tight gas formations were explicitly excluded from the 1988 gas estimate.

The assessment of natural gas resources conducted for the U.S. Department of Energy analyzed the major components of the natural gas supply

\footnotetext{
${ }^{3}$ Larry W. Cooke, Estimates of Undiscovered, Economically Recoverable Oil and Gas Resources for the Outer Conti. nental Shelf as of July 1984, United States Department of the Interior, Minerals Management Service MMS 85-0012, 1985.
}

based on existing resource estimates derived using established methodologies. In addition to traditionally defined elements of the natural gas resource base, a new component-reserve growth in heterogeneous reservoirs-is quantified in this study. The DOE assessment is based on technically recoverable natural gas volumes reviewed by a national review panel of 17 leading geologists, engineers, and economic analysts from government, industry, universities, and research and consulting organizations. This panel also made judgments about the amounts of economically recoverable resource.

A summary of the results of this assessment (Table 6.2) shows that the technically recoverable reserve and resource base of 1,059 trillion cubic feet (Tcf) of natural gas exists in the lower 48 states. Of this resource base, $800 \mathrm{Tcf}$ exists or is estimated to exist in conventional reservoirs. More than half of the lower-48 states resource, or $583 \mathrm{Tcf}$ of gas, is judged economically recoverable (including finding costs) at less than $\$ 3 / \mathrm{Mcf}$ (all prices are wellhead prices in 1987 dollars). An additional 174 Tcf of gas is judged economically recoverable at $\$ 3$ to $\$ 5 / \mathrm{Mcf}$. The panel adopted a conservative view of technical recoverability and the total U.S. resource accessible at different price ranges. This was particularly true for unconventional resources, which were assumed to be recovered using only current technology.

The EMF resource cases, however, are based on the 1986 estimates of the Potential Gas Committee, modified to add an estimate of decp water (greater than 1,000 meters) resource. The control resource case used PGC's "most likely" estimates, while the low resource case was based on PGC's "minimum" estimates, using a rule-of-thumb algorithm to approximate the probabilistic methodology that would be required to correctly add the regional estimates. Table 6.1 shows the DOE (1988), the PGC and Department of Interior (1981 and 1988) estimates of recoverable gas resource, along with the numbers that are used for the EMF scenarios. Note that the PGC and EMF numbers for undiscovered resource include only the possible and speculative resource categories in order to correspond to DOI's 
Table 6.2: Total U.S. Gas Reserves and Resources Assessed in the U.S. Department of Energy Study

\begin{tabular}{|c|c|c|c|}
\hline & \multirow{2}{*}{$\begin{array}{l}\text { Technically } \\
\text { Recoverable } \\
\text { Gas }(\mathrm{Tcf})^{b}\end{array}$} & \multicolumn{2}{|c|}{$\begin{array}{c}\text { Recoverable Gas } \\
\text { By Price }^{a}\end{array}$} \\
\hline & & $<\$ 3 / \mathrm{Mcf}$ & $\$ 3-5 / \mathrm{Mcf}$ \\
\hline \multicolumn{4}{|l|}{ Lower-48 (Conventional) } \\
\hline \multicolumn{4}{|l|}{ Proved Reserves, $12 / 31 / 86$, } \\
\hline \multicolumn{4}{|l|}{ Inferred Reserves/Probable } \\
\hline Resources, 12/31/86, Onshore & 85 & 85 & - \\
\hline \multicolumn{4}{|l|}{ Inferred Reserves, 12/31/86, } \\
\hline Offshore & 23 & 23 & - \\
\hline \multicolumn{4}{|l|}{ Extended Reserve Growth in } \\
\hline Nonassociated Fields, Onshore & 119 & 56 & 18 \\
\hline \multicolumn{4}{|l|}{ Gas Resources Associated with } \\
\hline Oil Reserve Growth ${ }^{c}$ & 61 & 30 & 11 \\
\hline Undiscovered Onshore Resources & 219 & 88 & 59 \\
\hline Undiscovered Offshore Resources $^{d}$ & 134 & 54 & 28 \\
\hline $\begin{array}{l}\text { Subtotal } \\
\text { Lower-48 (Unconventional) }\end{array}$ & 800 & 495 & 116 \\
\hline Gas in Low-Permeability Reservoirs & 180 & 70 & 49 \\
\hline Coalbed Methane & 48 & 8 & 4 \\
\hline Shale Gas & 31 & 10 & 5 \\
\hline \multicolumn{4}{|l|}{ Alaska } \\
\hline Alaska Reserves & 33 & $7^{e}$ & 0 \\
\hline \multicolumn{4}{|l|}{ Alaska Inferred Reserves } \\
\hline (Cook Inlet Area) & 3 & 3 & 0 \\
\hline \multicolumn{4}{|l|}{ Alaska Undiscovered Onshore } \\
\hline and Offshore & 93 & $2^{e}$ & $2^{e}$ \\
\hline TOTAL & $\overline{1,188}$ & 595 & 176 \\
\hline
\end{tabular}

Source: Fisher et. al., op. cit.

${ }^{a}$ Volumes of gas (Tcf) judged recoverable with existing technology by the DOE Review Panel at wellhead prices shown (1987\$).

${ }^{b}$ Volumes of gas judged recoverable with existing technology.

cJudged at oil prices of less than $\$ 24 / \mathrm{bbl}$ and $\$ 24-40 / \mathrm{bbl}$.

${ }^{d}$ Outer Continental Shelf.

${ }^{e}$ Component in Southern Alaska. 
undiscovered resource. The probable category is defined the same as DOI's inferred reserves, i.e., reserves expected to be added in known fields, and is added at the bottom of the table along with gas from unconventional resources and infill drilling to arrive at total recoverable gas for the lower- 48 .

The preliminary USGS estimate falls about 60 Tcf below the EMF low resource scenario for the lower-48 gas resource base. The DOE assessment shows that the EMF estimate of 774 Tcf of natural gas resources included in the control resource base is reasonable and very close to the comparable DOE assessment estimate of $787 \mathrm{Tcf}$ of technically recoverable natural gas resources available in the lower-48 states. ${ }^{4}$ Thus, the EMF cases provide a useful sensitivity analysis for those who want to analyze the impacts of variations in the resource base.

\section{Gas Resources of Alaska and the MacKenzie Delta/Beaufort Sea Area of Canada}

Substantial gas resources exist on the North Slope of Alaska and in the Mackenzie Delta/Beaufort Sea area of northern Canada. Estimated recoverable reserves in Alaska's Prudhoe Bay are approximately 28 Tcf. Nearby areas of the North Slope contain substantial additional resources. Some estimates indicate potential resources on the North Slope to be about 50 Tcf. Esso Resources Canada Ltd. estimates discovered recoverable gas reserves in the Beaufort area to be $11.1 \mathrm{Tcf}$, while the Canadian Department of Energy, Mincs and Minerals estimates total potential resources in the Mackenzie Delta/Beaufort Sea area to be as great as $76 \mathrm{Tcf}$.

It has generally been assumed that, because of their remoteness and difficult operating conditions, these extensive gas resources could be produced and delivered to major North American gas mar-

\footnotetext{
${ }^{4} T$ This number does not include proved reserves or unconventional gas economic above $\$ 5.00$ per Mcf. The additior of these categories would bring the DOE total to the 1,059 Tef shown in Table 6.1.
}

kets only at high gas prices. At the outset of its work, the EMF study team, considering historically available cost estimates for this gas, chose to exclude North Slope gas from explicit consideration in determining the U.S. resource base for model runs.

Significant uncertainty remains regarding the cost and availability of Alaskan and Mackenzie Delta-Beaufort Sea gas for shipment to the major North American gas markets. Major capital investments in transportation systems would be required. A recent estimate ${ }^{5}$ indicates that significant volumes of this gas could become available by the year 2000 at future U.S. lower-48 gas prices projected by the EMF models.

\section{Natural Gas Supplies of Canada}

Canadian gas supplies are now and will continue to be an important component of the U.S. gas market. Uncertainties about the size, productivity, and economics of the Canadian resource base result in considerable differences about the level of Canadian exports to the U.S. The estimates of the westem Canadian resource base reviewed by the group ranged from 200 to $300 \mathrm{Tcf}$. Up to 50 percent difference is due to differing estimates about formation and reserve growth in existing (known) fields. In addition, up to $25 \mathrm{Tcf}$ of tight gas resources are estimated to be developable at $\$ 7.00 / \mathrm{Mcf}$. How-

\footnotetext{
${ }^{5}$ On June 6, 1988, Northwest Alaskan Pipeline Company and Foothills Pipe Lines (Yukong) Ltd., sponsors of the Alaska Natural Gas Transportation System (ANGTS), announced a reestimate of the cost of transporting Prudhoe Bay gas to U.S. lower-48 markets. As a result of a 45 percent reduction in capital costs (to $\$ 14.6$ billion in 1988 U.S. dollars) and some other changes, the average levelized transportation cost over the first 10 years of operation has been reduced to $\$ 3.05 / \mathrm{MMBtu}$ in 1988 U.S. dollars. Esso Resources Canada Ltd. has recently made available an economic assessment of a "Mackenzic Valley" pipeline to deliver Mackenzie Delta-Beaufort Sea gas to the northem border of the United States via a route through the Northwest Territories and Alberta. The economics for this pipeline, with an annual capacity of $0.44 \mathrm{Tcf}$ and flow starting in 1997 , indicate a pipeline tariff of $\$ 1.40 / \mathrm{MMBtu}$ or less in 1987 U.S. dollars. Capital investment is projected to be $\$ 3.3$ billion in 1987 U.S. dollars.
} 
Table 6.3: Canadian Conventional Resource Estimates (Tcf)

\begin{tabular}{crrr}
\hline & NEB & WGML & ICF-Lewin \\
\hline Technically Recoverable & & & \\
(less) Cumulative Production to Date & 54 & 293 & $244-260$ \\
$=$ Remaining Resource & 151 & 54 & 54 \\
at \$2.00 per Mcf & 86 & 239 & $190-206$ \\
at \$3.00 per Mcf & 111 & n.e. & n.e. \\
at \$5.00 per Mcf & 136 & n.e. & n.e. \\
& & & n.e. \\
(less) Proved Reserves & 74 & 74 & 74 \\
(less) Reserve Growth & n.e. & n.e. & 46 \\
$=$ Undiscovered Resource & 77 & 165 & $70-86$ \\
at \$2.00 per Mcf & 12 & n.e. & n.e. \\
at \$3.00 per Mcf & 37 & n.e. & n.e. \\
at \$5.00 per Mcf & 62 & n.e. & n.e.
\end{tabular}

n.e. - not estimated.

ever, significant technological improvements will be required to produce these latter resources.

\section{Conventional Resource}

The National Energy Board (NEB), Western Gas Marketing, Ltd. (WGML), and ICF-Lewin prepared estimates of the resource available from conventional formations in the Western Sedimentary Basin. Overall, the NEB estimates of the resource base, at 205 Tcf, are lower than those of ICFLewin, at 244 to $260 \mathrm{Tcf}$, and those of Westem Gas Marketing, at $293 \mathrm{Tcf}$, as shown in Table 6.3.

The principal difference between the NEB and ICF-Lewin estimates of conventional gas from the Western Sedimentary Basin is the 46 Tcf potential for reserve growth through extension and more intensive development of known ficlds. The Canadian Geological Survey (CGS) is updating its estimate of the Canadian natural gas resource. The preliminary indication, based on work to date in oil, is that CGS may increase the size of the resource from their previous estimates. In addition, Western Gas Marketing, Ltd. has submitted an esti- mate of $293 \mathrm{Tcf}$ for the Westem Sedimentary Basin total resource, with a remaining undiscovered potential of $165 \mathrm{Tcf}$.

\section{Tight Gas Resource}

Canadian Hunter and ICF-Lewin provided estimates of the tight gas resource for a defined portion of the Deep Basin where Canadian Hunter holds significant leases. As shown in Table 6.4, the two resource estimates are compatible and indicate that a portion of the tight resource is economically competitive with conventional gas.

Amoco Canada stated that technology has not yet been demonstrated for producing the tight gas resource. This situation results from undesirable fracture height growth in the portion of the Deep Basin being developed by Amoco.

\section{Production and Constraints}

The EMF 9 working group reached a consensus that Canadian export capacity would be limited to $2 \mathrm{Tcf} / \mathrm{yr}$ in the time period 1988-2010. Within this 
Table 6.4: Canadian Tight Gas Resource Estimates

\begin{tabular}{lrr}
\hline & $\begin{array}{c}\text { Wellhead } \\
(\$ / \text { Mcf) }\end{array}$ & $\begin{array}{r}\text { Resource } \\
\text { (Tcf) }\end{array}$ \\
\hline ICF-Lewin & $\$ 2.50$ & 4 \\
& $\$ 3.50$ & 11 \\
& $\$ 7.00$ & 25 \\
& $\$ 3.00$ & 6 \\
Canadian Hunter & $\$ 5.00$ & 18 \\
& $\$ 7.00$ & 24 \\
& & \\
& & \\
constraint, however, Canadian gas would need to \\
compete economically with U.S. and other sources \\
of imported gas.
\end{tabular}

\section{Summary of Key Resources Studies}

\section{National Energy Board of Canada}

The National Energy Board (NEB) staff study of Canadian export potential concentrated on conventionally producible natural gas. Although the potential for supplies from low permeability reservoirs was recognized, NEB did not feel that sufficient information was currently available to estimate with confidence either the size of the resource base or the future levels of production.

The NEB estimates for the Western Canada Sedimentary Basin are summarized in Table 6.5. The resource assumptions are founded on the average expectation estimate of $88 \mathrm{Tcf}$ of undiscovered recoverable natural gas potential, made in 1983 by the Geological Survey of Canada. After allowance for subsequent discoveries, the undiscovered resource currently becomes 83 Tcf. Combining this with $54 \mathrm{Tcf}$ of cumulative production and $68 \mathrm{Tcf}$ of remaining established reserves yields a total resource base for the Basin of 205 Tcf. NEB notes that this resource base estimate is between a high probability estimate of $170 \mathrm{Tcf}$ and a speculative
Table 6.5: National Energy Board Estimates of Conventional Resources of the Western Canada Sedimentary Basin (Tcf)

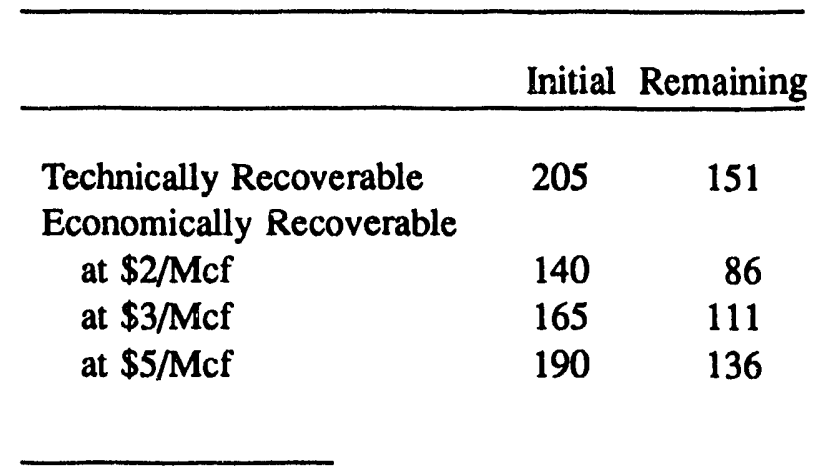

Resources based on the average expectation estimate of the Geological Survey of Canada, 1983.

estimate of 290 Tcf, as calculated from Geological Survey data.

NEB noted that the average size of pools booked between 1976 and 1986 was less than 2 Bcf/pool. NEB considers that many of these small pools have limited scope for reserve appreciation. Hence, NEB thinks that reserve growth may not be a significant component of future gas supplies from small pools.

NEB estimated the economically recoverable resource by using a supply function which related discovered resource to marginal supply costs. The principal determinant of future gas costs was the rate of new reserve additions per unit of new drilling.

The NEB also provided estimates of reserve potential for the Beaufort Sea-Mackenzie Delta region, the Arctic Islands, and the eastern Canada offshore regions, also based on the 1983 estimates of the Geological Survey of Canada. These total $263 \mathrm{Tcf}$ at average expectation, including 35 Tcf discovered to date. Some production from the Beaufort-Mackenzie and eastem offshore regions is assumed by the NEB in arriving at its estimate of export potential. 


\section{ICF-Lewin Energy}

The ICF-Lewin Energy natural gas resource study concentrates on the conventional and tight gas resources of the Westem Sedimentary Basins of Canada. This study estimates that the total economically recoverable natural gas resource base is from 244 to $260 \mathrm{Tcf}$, as shown in Table 6.6. The estimate for undiscovered economically recoverable conventional natural gas resource is 70 to 86 Tcf. This estimate was developed using two approaches - a field/pool size distribution analysis for the gas plays of Alberta and a finding-rate analysis, again for Alberta. The minimum economic field size was set at $1 \mathrm{Bcf}$. The results from Alberta were then extrapolated to the total for the Westem Sedimentary Basin, assuming that Alberta accounts for 75 percent of undiscovered conventional resources in the basins. The ICF-Lewin Energy estimate for additional reserve growth in existing fields of 46 Tcf was based on work by Alberta's Energy Resources Conservation Board as well as an independent appraisal using the data base on discovered gas fields and pools of Alberta. Gas production to date and remaining proved reserves are from official Canadian sources. The estimates for tight gas of $25 \mathrm{Tcf}$ were prepared for the Deep Basin area of Alberta and relied considerably on work by Canadian Hunter and Amoco Canada.

ICF-Lewin's economic analysis of tight gas is based on simulation of prospect performance using realistic cost and financial parameters. The ICF-Lewin Energy study made no estimates for the frontier areas of the Mackenzie Delta, the Arctic Islands, or the Scotian Shelf.

\section{Canadian Hunter}

The Canadian Hunter study addresses the tight gas resources of the Deep Basin in Alberta and, specifically, the Elmworth/Wapiti study area within which the company has obtained comprehensive technical data on tight sand resources.

Canadian Hunter estimates $12 \mathrm{Tcf}$ as the recoverable resource in the conventional reservoir sands of this area of the basin (sands with in-
Table 6.6: ICF-Lewin Energy's Estimate of Canada's Conventional and Tight Gas Resources of the Western Canada Sedimentary Basin (Tcf), 1986

Total

Alberta Westem

\begin{tabular}{|c|c|c|}
\hline Conventional Gas Resources & & \\
\hline Produced to date & 43 & 54 \\
\hline Remaining $R t$ serves & 64 & 74 \\
\hline Reserve Growth & 39 & 46 \\
\hline $\begin{array}{l}\text { Undiscovered Recoverables } \\
\text { (Greater than } 1 \mathrm{Bcf} / \mathrm{Pool} \text { ) }\end{array}$ & $54-66$ & $70-86$ \\
\hline Total & $\overline{200-212}$ & $244-260$ \\
\hline $\begin{array}{l}\text { Tight Gas Resources } \\
\text { (Greater than } 1 \mathrm{Bcf} / \text { Well) }\end{array}$ & 25 & 25 \\
\hline at $\$ 2.50$ & 4 & 4 \\
\hline at $\$ 3.50$ & 11 & 11 \\
\hline at $\$ 7.00$ & 25 & 25 \\
\hline
\end{tabular}

situ permeabilities greater than 0.05 millidarcies (md), $1.0 \mathrm{md}$ at the surface). The company also estimates that an additional $24 \mathrm{Tcf}$ of tight gas is recoverable from formations with in-situ permeabilities between $0.006 \mathrm{md}$ and $0.05 \mathrm{md}$. Cana-

Table 6.7: Canadian Hunter Estimates of Canadian Tight Gas Resources at Different Prices

Wellhead

Gas Price

Resource (1987\$/Mcf) (Tcf)

$\$ 2.00$

$\$ 3.00$

$\$ 4.00$

12

$\$ 5.00$

18

$\$ 6.00$

22

$\$ 7.00$ 
dian Hunter's tight gas resource is primarily in the shallower Fahler (A-D) and Cadotte formations of Deep Basin.

The price-supply curve for Canadian tight gas in the study area is provided in Table 6.7, in 1987 U.S. dollars per Mcf. Using the upper oil price track provided by EMF, Canadian Hunter estimates that $0.4 \mathrm{Tcf}$ of tight gas could be produced by 1995 , 0.9 Tcf by 2000 , and 1 Tcf by 2010 , assuming a reserves-to-production (R/P) ratio of 15 .

\section{TransCanada Pipeline/Western Gas Marketing}

In 1987, Western Gas Marketing Ltd. undertook a study of the ultimate gas reserves of the Westem Canada Sedimentary Basin. The results indicate that significant remaining reserves could be developed in this area. The technically recoverable reserves, or ultimate reserves, are estimated to be $293 \mathrm{Tcf}$ with a remaining undiscovered potential of $167 \mathrm{Tcf}$.

The WGML study divided the Westem Canada Sedimentary Basin (WCSB) into 12 study areas. Ultimate natural gas reserves were estimated for each area utilizing a statistical method which related cumulative drilling effort to cumulative reserve additions. The results for each area were tabulated to arrive at an aggregate estimate for the basin, as indicated in Table 6.8 .

A supplemental study was done to estimate the economically recoverable reserves in Alberta. This was achieved by relating plant-gate price and finding rate to gas well costs in Alberta. The results indicate that the plant-gate price would have to be $\$ 3.00 / \mathrm{Mcf}$ to economically develop the estimated $236 \mathrm{Tcf}$ of ultimate gas reserves in Alberta.

\section{Amoco}

Amoco Canada's position on tight gas reservoirs in the Deep Basin area of Alberta and British Columbia is:

"Amoco is of the opinion that there is yet no proven technology to economically produce the low permeability reservoirs in which the unconventional gas resources of the area occur. It be- lieves that pilot projects are necessary to demonstrate commercial viability."

A rore detailed technical paper, presented by J. Sherrod Moore and David J. Hassan of Amoco Canada at the 11th World Petroleum Congress (1983), addresses the deeper very tight Nikanassin formation of the Deep Basin in the Grande Prairie Block area. It concluded that large (greater than 500-foot wing-length) fractures are essential for producing the tight sands in this area. The authors conclude that such fractures cannot be achieved in this formation without the occurrence of undesirable fracture height growth.

\section{Reserve Growth and Infill Drilling in Gas Reservoirs}

The response of domestic oil production to price decontrol and to the price structure that prevailed in the period 1979 to 1985 was substantial. For many, this response of reserve replacement from a mature resource base was indeed unexpected. Disaggregation of oil reserve addition figures ${ }^{6}$ has shown that by far the greatest category of recent additions, more than 80 percent in fact, was through reserve growth rather than now field discoveries, even after appreciation. Abundant case studies are being developed that show that reservoirs are more complex and heterogeneous than previously thought. Thus, poorly drained or entirely uncontacted reservoir compan uments are left as targets for infill drilling and recomplction of wells in all but the simplest reservoirs with the most efficient drive mechanisms. This is not surprising in view of the average 38 percent primary and secondary recovery across Texas oil reservoirs. Despite the greater mobility of gas in the reservoir, the same concepts of reservoir heterogeneity are believed to apply to gas.

For the purpose of the Energy Modeling Forum (EMF) analysis, an estimate of gas reserve growth

\footnotetext{
${ }^{6}$ Fisher, W.L., "Can the U.S. Oil and Gas Resource Base Support Sustained Production?" Science, Vol. 236, pp. 16311636, 1987.
} 
Table 6.8: Western Gas Marketing Resource Estimates (Tcf) for Western Canada Sedimentary Basin

\begin{tabular}{lcccr} 
& Alberta & $\begin{array}{c}\text { Nortixeast } \\
\text { British } \\
\text { Columbia }\end{array}$ & $\begin{array}{c}\text { Westem } \\
\text { Saskatchewan }\end{array}$ & $\begin{array}{r}\text { Total } \\
\text { WCSB }\end{array}$ \\
\hline Produced to Date & 46 & 6 & 2 & 54 \\
Remaining Established & 61 & 8 & 2 & 72 \\
Remaining Undiscovered Potential & 129 & 35 & 4 & 167 \\
Ultimate Resources & 236 & 49 & 8 & 293
\end{tabular}

potential was developed as part of the resource base assumptions for the models. The appropriateness of this input is largely based on evidence from studies that exist within state commission hearing files or are part of research in progress. This research, supported by the Gas Research Institute and by the U.S. Department of Energy under different projects, is aimed at providing a sound fundamental basis for gas reserve growth.

For example, Texas Districts 2, 3, and 4 along the Gulf Coast and the South Louisiana Onshors contribute 21 percent of domestic production and coniain reservoirs which are highly complex and probably have gas within numerous undrained compartments. Furthermore, many reservoirs have been bypassed in these types of fields. Whether bypassed gas is included as undiscovered resource in known fields needs to be clarified; most often, undiscovered gas resources in known fields are conceived of as deeper pool prospects with less emphasis on those reservoirs already drilled into.

Recoveries from individual conventional gas reservoirs have been quoted in the range of 50 to 80 percent. Reservoir type, drive mechanism, and wellhead pressure relative to line pressure are factors most frequently cited as affecting gas recovery efficiency. Geological reservoir complexity is acknowledged, but little basis exists for desc:ibing, much less quantifying, its impacts. The initial consensus of a number of gas analysts is that the direction will be positive, based on the most recent experience in oil. Based upon previous studies of oil reservoirs, but accounting for the greater mo. bility of gas, the EMF 9 group considered the gas reserve growth potential to be about 20 percent of estimated ultinat recovery, based on triditional methods of reservoir ievelopment. As an exanple, application of 20 percent growth to a reservoir with $100 \mathrm{Bcf}$ of original gas in place (OGIP) and an estimated ultimate recovery of 65 percent would mean the recovery of an additional $13 \mathrm{Bcf}$ of gas or 13 percent of CGIF. The degree of gas reserve growth potential is expected to vary according to the type of reservoir.

\section{Other Reserve Growth Estimates}

Reserve growth of gas fields has historically been calculated from annual tables of ultimate recovery by year of discovery published by the American Petroleum Institute and the American Gas Association. This data series ended in 1979 and captures historical and traditional sources of reserve growth, such as extensions and new pools. However, through 1977, the vast majority of major nonassociated gas reservoirs were still at one well drilled per 640 acres spacing and some even at one well drilled per 1,280 acres. As a result, these data do not reflect the potential recovery from reservoirs drilled at closer spacing. To affect the tables 
published in 1979, such infill drilling would have occurred by at least 1977 and probably even earlier.

In a new reserve growth assessment done for the U.S. Department of Energy, some 10,000 fields distributed across the U.S. in 334 groups of geologically related reservoirs, termed plays, were evaluated for increased recovery on the basis of their geologic complexity. Onshore nonassociated gas reservoirs appraised from the data base represent 90 percent of lower- 48 onshore nonassociated gas reserves. A geologic assessment of the reserve growth capacity of these reservoirs was made on a play-by-play dnalysis. The result is a rese ve growth potential of 119 Tcf when extrapolated across the full lower- 48 onshore nonassociated gas reserve base, including probable resolives.

Because few major gas reservoirs are developed at spacings below 640 acres per well and eve fewer below 320 acres per well, it is likely that there is minimal overlap with probable resources/iaferied reserves. Inferred reserves are derived from historical reserve appreciation factors in the inethodology of the USGS and the MMS. Probabie resources defined by the PGC are primarily deeper prol ant extension development done in he histo ical contex $i$ of field development. Since almost all of this historical sevelupment was done at the well spacing cited above, projections of future development based on these data do not include infill drilling.

\section{Gas Reserve Growth in the EMF 9 Study Design}

The incremental gas resource available from extended reserve growth as entered into the EMF scenario design amounts to $27 \mathrm{Tcf}$ at $\$ 2.50 / \mathrm{Mcf}$ and $50 \mathrm{Tcf}$ at $\$ 5.00 / \mathrm{Mcf}$ for the reference case, and $24 \mathrm{Tcf}$ at $\$ 2.50 / \mathrm{Mcf}$ and $44 \mathrm{Tcf}$ at $\$ 5.00 \mathrm{Mcf}$ for the low resource case. These volumes assume primarily currently available technology and represent a conservative approach to reserve growth potential. Advances in gas extraction technology are expected to increase the availability of both infill and unconventional resources. For gas reserve growth, research on the improved extraction of bypassed and infill gas resources, as well as the advanced prediction of deeper pool resources, is now under way.

Estimates of gas volumes from infill drilling is less sensitive to price than is gas from unconventional resources. This is because gas reserve growth involves more current and foreseeable technologies, but unconventional gas will require more advanced recovery technologies.

\section{Environmental Regulations}

The Environmental Protection Agency (EPA) recently reviewed the need for increased levels of environmental regulations for domestic U.S. oil and gas drilling and production. Several studies have shown that the impacts of full RCRA Subtitle $C^{7}$ hazardous waste regulations would have severely reduced production and reserves. Therefore, the EPA concluded in their report that full compliance with potential Subtitle $C$ regulations was unnecessary and impractical at this time. They made final recommendations to Congress that will focus on augmenting existing state programs, with no Subtitle $\mathrm{C}$ regulations.

None of the models used in the EMF study incorporate environmental regulations of this type. Yet EPA will continue to consider additional environmental regulations and requirements that could be costly to the industry. This section reviews the potential cost impacts of such regulations, as estimated in recent analyses.

While most potential environmental regulations primarily affect oil and water production and mud disposal, the capital consequences of potential regulations may induce budgetary constraints and

\footnotetext{
${ }^{7}$ Under Subtitle C hazardous waste regulations of the Resource Conservation and Recovery Act (RCRA), hazardous drilling wastes would be disposed of in special facilities and hazardous water would be injected into Class I injection wells. Subtitle C-1 assumes that produced water in secondary recovery operations is exempt from regulation.
} 
hamper gas-directed exploration and development activities. The focus that follows is therefore on the potential initial and annual cost impacts for both onshore and offshore areas. Potential benefits of regulation are not addressed, since no studies have analyzed potential benefits.

For onshore production operations, the EPA studied three major scenarios. A baseline scenario represented current waste management practices. Second, intermediate and Subtitle C-1 cases represented somewhat stricter controls. And finally, a Subtitle C case represented full RCRA compliance. For each case, two scenarios were run, assuming that either 10 percent or 70 percent of wastes were classified as hazardous. The EPA reported an annual cost of compliance that ranges from $\$ 49$ million to $\$ 12$ billion, depending on the severity of regulations. Under the most stringent scenario (Subtitle C, 70 percent), projected U.S. oil production in 2000 falls by 19 percent and oil prices rise $\$ 1.08 /$ barrel (bbl).

Data Resources Inc. (DRI) performed a study for the Department of Energy (DOE) using the EPA scenarios and costs. The resulting impacts are sim:ilar-a range from negligible to severe, depending on the scenario. The maximum impacts are that, relative to the baseline case, U.S. oil production falls 16 percent (770/MBD) and gas production declines 4 percent (.55 Tcf) for the 19952000 period if full Subtitle $C$ controls are implemented. U.S. oil imports increase by $770 \mathrm{MBD}$ in 1995.

ICF-Lewin Energy also studied potential regulation using the EPA scenarios. Their results are consistent with the EPA and DRI conclusions. The impact of the intermediate case is small, but Subtitle $C$ regulations severely reduced current reserves and production. This study also quantified the impacts on enhanced oil recovery (EOR) production. The range of EOR reserve losses ranged from 55 million barrels oil-equivalent (MMBO) in the intermediate 10 percent case to 5.1 billion barrels oil-equivalent (BBO) in the Subtitle C 70 percent case. Production losses for this range are 0-290 $\mathrm{MBO} / \mathrm{D}$ in 2000.
ICF-Lewin also performed a study on the impact of increased environmental regulations on the undiscovered resource base. The conclusions are that full Subtitle $\mathrm{C}$ regulations have the same impact on undiscovered U.S. crude oil reserves as a $\$ 15 / \mathrm{bbl}$ decrease in oil price. As a result, up to 4.2 BBO of undiscovered reserves would become uneconomical at $\$ 25 / \mathrm{bbl}$ oil prices.

Potential increased offshore costs as a result of compliance with the proposed New Source Performance Standard (NSPS) regulations on the reinjection of produced water were calculated by the EPA, then critiqued by three groups: the API, Walk Haydel and Associates, and Lewin and Associates. The EPA calculated that the impact of compliance with NSPS shallow water regulations would be $\$ 587$ million (1983). However, all other parties generally reported higher cost impacts than did the EPA. Lewin and Associates estimated the maximum potential capital impact for offshore operations to be $\$ 1.4$ billion through the year 2001 , with annual costs of $\$ 275$ million in 2001 . In addition, lost revenues from early platform abandonments and uneconomical fields could be up to $\$ 34.2$ billion. Finally, the lost reserves due to early abandonments could be $60 \mathrm{MMBO}$ and $80 \mathrm{Bcf}$, and could be up to $1.2 \mathrm{BBO}$ and $1.7 \mathrm{Tcf}$ due to uneconomical fields.

All of the above studies in general assume that current drilling and production practices continue. Practically speaking, drilling and production technology changes will occur in response to any new regulations. This should serve to lower costs and mitigate the impacts of increased environmental regulations. 


\section{Appendix to Chapter 6}

\section{Key Results by Resource Category in the DOE Study ${ }^{8}$}

\section{Proved Reserves}

All lower-48 onshore and offshore gas reserves of 159 Tcf (dry gas basis) are judged economically recoverable at less than $\$ 3 / \mathrm{Mcf}$. This is the most certain element of the resource base because proved reserves are those estimated quantities that analysis of geologic and engineering data demonstrates with reasonable certainty to be recoverable in future years from known reservoirs under existing economic and operating conditions.

\section{Inferred Reserves/Probable Resources On- shore}

The DOE review panel estimates that $85 \mathrm{Tcf}$ of inferred reserves/probable resources occur onshore in the lower-48 states. All gas in this category is judged economically recoverable at less than $\$ 3 / \mathrm{Mcf}$. This gas is from the expected expansion of known fields through developinent drilling of field extensions and pools at other, generally greater depths. This is more uncertain than proved reserves because producing wells have not been drilled; however, it is known that these reservoirs exist.

\section{Inferred Reserves/Probable Resources Off- shore}

A total of $23 \mathrm{Tcf}$ of inferred reserves/probable resources exists offshore in the lower-48 states, and 100 percent is judged economically recoverable at less than $\$ 3 / \mathrm{Mcf}$.

\footnotetext{
${ }^{8}$ This supplementary information is adapted from the report by Fisher et al, op.cit., prepared for the U.S. Department of Energy.
}

Extended Reserve Growth in Nonassociated Gas Fields Onshore

This category of the natural gas resource base represents gas distributed in known fields recoverable through intensive development of heterogeneous reservoirs. This gas is uncontacted in existing reservoirs at current field spacings and completion intervals. Definition of this resource category is a major contribution of the DOE study. More than 300 plays, or groups of geologically related reservoirs, including some 10,000 fields, were evaluated nationally, and a natural gas resource of $105 \mathrm{Tcf}$ in existing fields was defined. This resource can be accessed through infill drilling in new wells and recompletion of bypassed zones in existing wells. An additional $14 \mathrm{Tcf}$ of resources can come from extended reserve growth of new pools and extension drilling used to develop onshore inferred reserves/probable resources. Because the gas occurs in existing reservoirs, it would tend to be relatively inexpensive. The total volume of resource defined as having extended reserve growth potential is 119 Tcf. Of that, $56 \mathrm{Tcf}$ is judged recoverable at less than $\$ 3 / \mathrm{Mcf}$ and $18 \mathrm{Tcf}$ is judged recoverable at $\$ 3$ to $\$ 5 / \mathrm{Mcf}$. A volume of $50 \mathrm{Tcf}$ of gas resource accessible by infill drilling was included in the EMF base case scenario design at prices of up to $\$ 5 / \mathrm{Mcf}$.

\section{Gas Resources Associated with Oil Reserve Growth}

Detailed data on 450 large reservoirs in Texas and an in-depth study of part of the Permian Basin in West Texas were used to extrapolate to the national level (lower-48 states light oil resource base) the increased amounts of associated gas potentially recoverable through oil reserve growth. Oil reserve growth, the improved recovery of mobile oil from known reservoirs, is currently the largest contributor to oil reserve additions. The national resource evaluated by the review panel in this category is $61 \mathrm{Tcf}$, of which $30 \mathrm{Tcf}$ is judged recoverable at less than $\$ 24 / \mathrm{bbl}$ and $11 \mathrm{Tcf}$ is judged recoverable at $\$ 24$ to $\$ 40 / \mathrm{bbl}$. 


\section{Undiscovered Recoverable Resources On- shore, Lower-48 States}

Estimates in this category by the USGS and the PGC vary. The PGC estimates of undiscovered resources include gas from low-permeability formations, whereas the USGS estimates do not. The difference between the two approaches must be accounted for to make comparable evaluations within this assessment. Therefore, a weighted-average 26-percent low-permeability resource in the PGC estimate of possible and speculative resources was excluded. Further, estimates of undiscovered gas resources in the Anadarko Basin in both estimates ( 25 Tcf by the USGS and 112 Tcf by the PGC) were replaced on a consensus basis by a 1988 estimate of 46 Tcf made by Energy and Environmental Analysis, Inc. for the Gas Research Institute. Excluding estimates of gas in low-permeability formation and the Anadarko Basin, total national estimates by the USGS and the PGC are comparable. The resulting estimate considered by the review panel is an undiscovered lower- 48 onshore resource of $219 \mathrm{Tcf}$. Of this resource, $88 \mathrm{Tcf}$ is judged recoverable at less than $\$ 3 / \mathrm{Mcf}$ and $59 \mathrm{Tcf}$ is judged recoverable at $\$ 3$ to $\$ 5 / \mathrm{Mcf}$. The economic estimates include finding costs but do not necessarily consider the availability of pipelines or markets or the timing of production.

\section{Undiscovered Resources Offshore}

The review panel used the MMS estimate of 128 Tcf for federal offshore lower-48 undiscovered gas resources rather than an average of the MMS and PGC estimates. This was done in view of the data base used by the MMS and modeling conducted by them, and because their estimatcs included deepwater resources in the Gulf of Mexico, and the PGC estimates did not. The Review Panel added $6 \mathrm{Tcf}$ for undiscovered state offshore resources to the MMS federal offshore estimate for an undiscovered offshore resource total of $134 \mathrm{Tcf}$. The review panel judged that $54 \mathrm{Tcf}$ is recoverable at less than $\$ 3 / \mathrm{Mcf}$ and $28 \mathrm{Tcf}$ is recoverable at $\$ 3$ to $\$ 5 / \mathrm{Mcf}$.

\section{Gas in Low-Permeability Formations}

Large estimated volumes of in-place gas exist in low-permeability formations, but only smaller amounts are considered recoverable using current technology. The review panel excluded lowpermeability formations of the Northern Great Plains from consideration in this assessment to maintain a conservative approach to economically recoverable gas. Of a technically recoverable resource base of $180 \mathrm{Tcf}$, the review panel judged $70 \mathrm{Tcf}$ recoverable at less than $\$ 3 / \mathrm{Mcf}$ and $49 \mathrm{Tcf}$ recoverable at $\$ 3$ to $\$ 5 / \mathrm{Mcf}$. Volumes of gas in low-permeability formations assume current technology, but with advanced technology larger volumes can be recovered.

\section{Coalbed Methane}

Of $215 \mathrm{Tcf}$ of original gas in place appraised by ICF-Lewin Energy, 90 Tcf is considered technically recoverable. Of this technically recoverable volume, $48 \mathrm{Tcf}$ is accessible in areas of currently producing basins where production has not yet been developed. The review panel considered this volume of gas as the basis for its assessment. Of the $48 \mathrm{Tcf}, 8 \mathrm{Tcf}$ is judged recoverable at less than $\$ 3 / \mathrm{Mcf}$ and $4 \mathrm{Tcf}$ is judged recoverable at $\$ 3$ to $\$ 5 / \mathrm{Mcf}$.

\section{Shale Gas}

Of 800 to 1,900 Tcf of original gas in place, ICFLewin Energy appraised a resource of $84 \mathrm{Tcf}$. Of the appraised resource, $31 \mathrm{Tcf}$ is recoverable using current technology. The review panel judged that $10 \mathrm{Tcf}$ of the $31 \mathrm{Tcf}$ resource is recoverable at less than $\$ 3 / \mathrm{Mcf}$ and $3 \mathrm{Tcf}$ is recoverable at $\$ 3$ and \$5/Mcf.

\section{Alaskan Natural Gas}

Alaskan gas reserves are an exception to the definition of proved reserves in that they are largely not recoverable at current (1987) economics because of the lack of transporiation to market. Thus, only 7 
Tcf of southem Alaska reserves is economic at less than \$3/Mcf. Similarly, the estimated undiscovered Alaskan resources of $93 \mathrm{Tcf}$, if found, would be producible only in southern Alaska.

\section{Other Resources}

Gas, both natural and synthetic, is available from a variety of other sources that are not considered volumetrically in this analysis. These include gas in water-driven, depleted reservoirs and gas in mature, saturated, geopressured geothermal waters, each available through coproduction of water and gas. Also not included is an increment of natural gas potentially available through reserve growth of natural gas fields yet to be discovered. Finally, this analysis does not consider gas hydrates nor synthetically produced gas from coal and other sources.

Estimations of natural gas in different categories of the resource base, as well as volumes estimated as recoverable at different price levels, have varying levels of uncertainty associated with them. It must be emphasized that all elements of the natural gas resource base, except proved reserves, must be converted to reserves before they can be produced and become part of the supply stream. The volume of the resource base that ultimately becomes supply depends on volume of drilling, which is in turn sensitive to price, technology, and technology development. The estimates that have been incorporated into the EMF 9 study are summarized in Table 6.2 in the chapter's text. 


\section{Chapter 7}

\section{Suggestions for Future Research}

During the study, several natural gas industry issues were defined that the group felt required additional research. For example, the effects of recent regulatory changes in the gas industry are still unfolding and their impacts on the market are only beginning to be felt and analyzed. Lack of analysis of these key issues is reflected in many natural gas models, which do not explicitly incorporate many important regulatory policies. Given the extent of the recent federal and state regulatory changes and the importance of their rulemakings, not incorporating their effects on the industry's operation limits the type of analyses that can be undertaken. In addition, by not explicitly incorporating the regulatory environment, major changes in the direction of the gas industry cannot be adequately analyzed.

Some models used in this study have addressed several of the issues outlined below. However, the group believes that the general analyses of the industry can be improved by addressing these issues qualitatively and quantitatively. Finally, depending upon the objectives of the analyst, not all of these issues need to be addressed.

The following topics werc identified by the working group as requiring additional research. The discussion of each topic is brief, and the order does not reflect the relative importance attached by the group to the particular issue.

1. Modeling of Regulation-As noted above, few attempts have been made to quantitatively analyze and model the effects of regulatory decisionmaking at the state and federal levels on the gas industry. Many of the models assume a workably compctitive market struc- ture and will be most appropriate for analyses if the current trend toward a more competitive gas market continues. Nevertheless, many of the equations used to analyze the industry are based on data from a more regulated time period and could be statistically biased. More significantly, changes in existing regulations cannot be adequately analyzed to determine the effects on the development of the market. It is the working group's opinion that significantly more resources nced to be devoted to improve the methods to understand and analyze the impacts of regulatory policy.

2. Rates-Most of the models utilized exogenous and often fixed transmission and distribution rates. As the industry competes with alternative fuels in the future, transmission and distribution margins could come under increasing pressure. The working group identified this area as being an extremely critical one for additional research. Transmission and distribution rates should be analyzed carefully in future studies, and for some applications they should be incorporated endogenously within the models.

3. Regional Wellhead Gas Price DifferentialsWellhead gas prices vary by region due to the characteristics of the end-use markets in which the gas is consumed, the alternative fuel that gas competes against, and transmission and distribution margins. Some of the models contain only an average wellhead gas price for the U.S. To properly determine the incentives to explore, develop, produce, 
and deliver gas and to understand gas pricing throughout the U.S., analytical tools must be developed that better account for the differences that exist in regional wellhead gas prices. The framework used by some of the EMF 9 models (Group A in Table 4.1 of Chapter 4) represents one possible approach for studying regional wellhead price competition.

4. Interaction of Canadian and U.S. Gas Markets-Many analyses treat the United States and Canadian gas markets as separate entities. In studies of the U.S. markets, Canadian gas imports and prices are often set exogenously. This assumption may have been reasonable when each country's gas market was more tightly regulated, as in the late 1970s and early 1980s. To better understand the reactions of Canadian and U.S. gas producers and consumers in a market-oriented trading environment, models which integrate U.S. and Canadian markets are needed to analyze wellhead gas price developments in the United States and Canada. Examples of such models in this study include GRI North American, GTM, and AGAS.

5. Price Volatility-Price volatility has increased in the natural gas market from the wellhead to the burnertip over the last few years. Historically, gas prices have not been used as a short-term, market-clearing mechanism, in contrast to most commodity markets. As a result, price distortions caused long-term imbalances between the gas supply and demand because natural gas prices followed long-term cycles. Since 1983, gas prices have become an increasingly important factor in the industry and have displayed considerable monthto-month changes. At this time, the effect of price volatility on natural gas demand, supply availability, investment, and strategy decisions is poorly understood. Further research should be undertaken to more clearly understand the effects of price volatility.
6. Seasonality-As the gas market has become more competitive and open, gas prices and demand have displayed greater seasonal variation. Seasonality should be studied to understand fully short-term supply, demand, pricing, and pipeline allocation issues. All of the models that participated in EMF 9 were annual and unable to directly analyze this issue.

7. Shapes of the Gas Demand and Supply Curves-As shown in Figure 3.1 of Chapter 3, the gas demand curve is inelastic at the ends with an elastic section in the middle. The exact shape of the curve, however, is uncertain.

Uncertainty also exists about the shape of the gas supply curve-does it have the traditional constant upward slope or does it also have inelastic portions at the top and bottom with an elastic section in the middle? The latter curve reflects a situation where significant price increases are required to produce the initial and last amounts of gas; but within a middle range, large supply changes could occur for small price changes-the elastic portion. The uncertain shapes of the supply and demand curves could yield either extremely volatilf; gas pricing due to rapid supply and demand shifts or a gas market which could be in balance at a variety of different gas price, supply, and demand levels.

Significant differences exist among the modelers and other analysts in the working group on the exact shapes of the industry's supply and demand curves. A better understanding of the economic, technical, and geologic factors that influence the shapes of these curves is required.

8. Potential Fuel Switching-A major factor that will influence the amount of gas used in the next few years is the potential level of switching to other fuels by gas users. Fuel switching can be characterized by the rate at which it can occur: 
- Very short-term switching (within a few months) of gas to an alternative fuel in dual-fired boilers. Much of this switching could be to residual fuel oil.

* intermediate-term switching (within a year) through retrofits to make gas boilers that can only burn gas, dual fired with other fuels.

- Longer-term switching (within several years) of gas equipment to totally or partially use non-gas fuels.

Several estimates exist which indicate that a significant potential loss of gas load could occur if gas became uncompetitive with selected oil products. In addition, the amount of switching will be instrumental in determining how bumertip and netback wellhead gas prices develop in the future. Unfortunately, little agreement exists about the exact size and rate at which this switching can and will occur. Additional research into the different types of fuel switching is required to better understand the dynamics of gas use in the United States. This analysis will be more useful if done at a very disaggregated level (boiler-by-boiler when possible).

The extent of fuel switching from gas to residual fuel oil also depends upon:

- the effect of oil-refining capacity constraints on residual fuel oil prices;

- the resulting feedback effects of higher oil prices on North American gas markets;

- the national security implications of increased oil imports; and

- the effects of air quality and other environmental considerations on gas and oil use.

9. Conservation-In general, it was not possible to explicitly identify or quantify the factors influencing conservation using the gas industry models. Given that real gas prices are expected to rise in the future and that new, more efficient advanced gas technologies are being developed, better modeling of conservation is an important factor in understanding future levels of gas demand.

10. Effect of Electric Utility Deregulation on Natural Gas Usage-PURPA and recent FERC proposals are starting to deregulate the production and transmission of electricity. In addition, the problems many utilities are having in passing through the costs of existing and new large-scale generating plants-coal or nuclear-are causing them to look into the development of gas-fired generationcombined-cycle gas turbine units, select use, and cogeneration. This study analyzed the effect of additional gas usage by electric utilities to determine the effects on gas pricing, production, and feedback effects on gas demand in other sectors. Substantially more needs to be done to determine the level, location, and type of gas-fired electrical generation (peak vs. base) that might be developed in the future.

11. Impact on Natural Gas Usage of Advanced Alternative Fuel Technologies-Several nongas advanced technologies-such as clean coal or fluidized bed technologies-are under development that could significantly affect the use of natural gas, especially in the industrial and electric utility sectors. This study did not analyze the effects that competitively priced advanced technologies could have on gas usage. For example, competitive clean coal technologies could significantly replace gas use in the industrial and utility boiler markets or a front-end coal gasifier could be installed on combined-cycle gas turbine plants. The working group felt that the potential effects of these advanced technologies on gas usage should be analyzed further.

12. Potential for Natural Gas as a Transportation Fuel-Natural gas can be used as a transporta- 
tion fuel directly as compressed natural gas (CNG) or when converted to methanol. More research needs to be done to define the potential market that natural gas could meet as a transportation fuel along with requirements and costs of developing the infrastructure to deliver it.

13. Supplemental Gas Supplies-If domestic conventional gas production is not available, additional gas supplies, such as liquefied natural gas, could be imported by pipelines, coal could be gasified, or unconventional supplies could be developed. Additional research is required to define more preciscly the potential volume, cost, and location of these resources.

14. U.S. and Canadian Resource Bases-As indicated in comparing the two U.S. gas resource base cases used in the study, their levels and geologic distributions will be critically important in determining the amount and price of gas available for production and trade. Currently, several distinct estimates exist about the size and distribution of the U.S. and Canadian natural gas resource bases-both conventional and unconventional. Confirmation of reserve growth through infill drilling is needed to establish these resources as a separate component not currently included by existing estimation techniques. Moreover, the distribution of the resource base-dcep vs. shallow, onshore vs. offshore-is also critical in determining the likely cost to explore and develop fields. For example, if the U.S. resource growth in existing fields estimate identified in the DOE "Gas Initiative" study is correct, there will be less need to develop new pipelines from untapped supply areas. Since so much uncertainty exists about the resource base, and given its importance in determining the potential gas market that can be served, additional research to better understand the size and distribution and the cost to develop and produce the U.S. and Canadian resource bases should be undertaken.
15. Advanced Gas Drilling and Production Techniques-One conclusion of the study is that wellhead gas prices will be rising in the future as the resource base matures, requiring additional costs to find and produce the smaller marginal gas deposits. Advances in gas exploration and production technology, however, could reduce drilling costs, making both conventional and unconventional resources more economic to find. Additional research on the effects of technology on gas production costs is needed for understanding future market dynamics.

16. Effect of Environmental Regulations on Gas/Oil Drilling and Production-As indicated in one of the special topic papers, the declaration of exploration and production wastes as hazardous by the EPA could have greatly increased the cost of exploring for and producing natural gas and oil. Higher costs due to the proposed regulations could reduce drilling, reserve additions, and production at a given wellhead price. None of the models could adequately analyze this policy or other changes in environmental regulations affecting oil and gas drilling. Further work needs to be done to more accurately assess the impact of potential changes in environmental regulations.

17. Pipeline and Storage Capacities and CostsIn general, the models either assumed that adequate gas pipeline and storage capacities exist and are in the right location when they are needed or that the capacities are fixed. Given the changes that will be occurring in gas supply areas in the future and duc to potential capacity constraints in existing systems, the cost to develop and operate new pipelines will be an important factor in explaining the development of the U.S. gas industry. Analyses need to be undertaken to determine how pipeline and storage factors will influence the gas industry. 


\section{Appendix}

\section{A Glossary of Economic and Industry Terms}

Allocation of Risk The distribution of the economic risks of investment between producers, pipelines, distributors, and consumers.

Associated Dissolved Gas Natural gas which occurs in crude oil reservoirs either as free gas (associated) or as gas in solution with crude oil (dissolved).

Barrel A volumetric unit of measure for crude oil and petroleum products equivalent to 42 U.S. gallons. This measure is used in most statistical reports. A barrel of crude oil equals approximately 5.8 million Btus.

Bef One billion cubic feet of natural gas at 60F and atmospheric pressure at sea level.

British Thermal Unit (Btu) The quantity of heat required to raise the temperature of one pound of water by one degree Fahrenheit at or near $39.2 \mathrm{~F}$.

Burnertip The point of end-use consumption of a particular fuel, most often natural gas or residual fuel oil.

Bypass The ability of industrial customers to obtain gas directly from a pipeline and thereby circumvent local distribution companies.

Clean Coal Technologies Processes for making coal environmentally sound for power-generation purposes.

Cogeneration The simultaneous production of electricity and steam from a powerplant. Electricity is most often sold for utility purposes, while steam is diverted to industrial uses.

Combined-Cycle Gas Turbine A turbine that uses the waste heat from an initial-stage turbine as fuel for a second-stage turbine. Higher heating efficiency relative to a single-cycle gas turbine is the result.

Commercial Consumption Gas used by nonmanufacturing organizations, such as hotels, restaurants, retail stores, laundries, and other service enterprises; gas used in agriculture, forestry, and fisheries; and gas used by local, state, and federal agencies engages in nonmanufacturing activities. 
Commodity Charge That portion of a natural gas rate based upon the volume actually purchased.

Contract Carriage A situation when a pipeline carries gas supplies for selected customers or shippers on a contract basis rather than its own gas supplies for resale.

Contract Demand The amount of gas a seller agrees to deliver on a daily basis for a specific price in accordance with a service agreement. The buyer need not take this maximum quantity on any given day.

Cost of Service A rate-making concept used for the design and development of rate schedules to ensure that the filed rate schedules recover only the cost of providing the gas or electric service at issue. This concept attempts to correlate the utility's cost and revenues with the service provided to each of the various customer classes.

Cost of Service Pricing A tariff that specifies that a natural gas company (seller) shall be reimbursed for his cost of service, including a specified rate of retum on the rate base, as distinguished from the tariff which specifies sales volume.

Cross-Subsidization The practice of charging rates higher than actual costs to industrial and utility customers and passing on lower rates to residential and commercial customers.

Decoupling The dissolution of specified pricing relationships (e.g., parity among bumertip gas and a refined oil product price). Decoupling of gas and oil prices refers to gas and residual fuel oil no longer being priced at parity on a Btu basis.

Deep Gas Gas that lies in formations that are deeper than 15,000 feet.

Deepwater Gulf of Mexico areas with water depths greater than 1000 meters.

Demand Charge That portion of the charge for service which reflects a customer's contract requirements or special facilities.

Distribution Margin The excess of a local distribution company's gas revenue over its total gas purchase costs divided by throughput. On a system basis, end-user gas cost minus citygate gas cost.

Distribution Rates The rates charged by local distribution companies for gas supplies delivered and sold to end-users.

Economic Efficiency An economic condition in which resources are allocated to move "as far as possible in the satisfaction of wants within resource and technological constraints" (New Palgrave, ed. by J. Eatwell, M. Milgate, P. Newman; New York: Stockton, 1987, Vol 2, p. 107.)

Economies of Scale An economic condition in which average costs decrease (economies) or increase (diseconomies) as output expands, holding input proportions constant.

Electric Utility Consumption Gas used as fuel in electric utility plants.

Endogenous Originating from internal sources (i.e., calculated internally).

Energy Modeling Forum An intemational activity headquartered at Stanford, devoted to improving the application of analytical techniques to energy policy and planning. 
Estimated Ultimate Recovery (EUR) The ultimate reserves that a well or field will recover from production initiation to depletion.

Ex Ante "Before the fact".

Ex Post "After the fact".

Exogenous Originating from extemal sources. An external assumption for a computer model.

Federal Energy Regulatory Commission (FERC) The federal agency with jurisdiction over natural gas pricing, wholesale clectric rates, hydroelectric licensing, oil pipeline rates, and gas pipeline certification.

Federal Power Commission (FPC) The regulatory body authorized by the Natural Gas Act of 1938 to regulate gas sales rates in interstate commerce. The FPC was the predecessor to the FERC.

Field A group of one or more wells producing from the same geologic formation.

Firm Capacity Pipeline service offered to customers (regardless of class of service) under schedules or contracts which anticipate no interruptions. The period of service may be for only a specified part of the year as in off-peak service. Certain firm service contracts may contain clauses which permit unexpected interruption in case the supply of residential customers is threatened during an emergency.

Frontier Frontier areas are new, large, relatively remote, and unexplored areas that are expected to be productive. Examples are the Beaufort Sea and offshore Atlantic areas of Canada.

Fuel Switching The ability of a boiler to bum alternate fuels, such as gas or residual fuel oil. Switching occurs when one fuel is substituted for another on the basis of price and can be categorized by the rate at which it occurs:

- Very short-term switching of gas to an alternate fuel in dual-fired boilers. Much of this switching would be to residual fuel oil.

- Intermediate-term switching through retrofits to make gas boilers which can only burn gas, dual fired with other fuels.

- Longer-term switching of gas equipment to totally or partially use nongas fuels.

Gas Bubble The persistent excess of natural gas deliverability above market demand. Deliverability, or the maximum rate at which a well or field can produce, is the important factor, not actual production.

Gas Inventory Charge An inventory holding charge paid by a pipeline to compensate producers for holding reserves that are dedicated to the pipeline.

Gas-to-Gas Competition The competition between different gas suppliers competing for markets. Primarily a function of decreasing demand, the presence of multiple pipelines serving particular markets, and excess deliverability.

Independent Power Producers Electricity producers that are not part of a regional utility, but operate in an entrepreneurial fashion, often with cogeneration facilities. 
Industrial Consumption Natural gas used by manufacturing and mining establishments for heat, power, and chemical feedstock.

Infill Drilling Reducing the effective spacing in already developed fields by drilling between existing wells. This is a means of recovering incremental reserves or accelerating reserve recovery.

Interruptible Capacity A pipeline service in which transportation capacity is assured only if there is excess capacity after all firm commitments are satisfied.

Interstate Transmission of gas across state lines.

Intrastate Transmission of gas cntirely within a state's boundaries.

Liquefied Natural Gas (LNG) Natural gas which has been liquefied by reducing its temperature to minus 260 degrees Fahrenheit at atmospheric pressure.

Load The amount of electric power or gas delivered or requir zd at any point on a system. Load originates primarily at the energy-consuming equipment of the customers.

Load Factor The ratio of average load to peak load for a specified period, usually expressed as a percentage.

Local Distribution Company (LDC) A company that obtains the major portion of its gas revenues from the operation of a retail gas distribution system and that operates no transmission system other than incidental connections within its own system or to the system of another company.

Marginal-Cost Pricing Pricing of a commodity (gas) based on the cost of producing and transporting the most expensive unit actually sold.

Market Power When any buyer or seller, or group of buyers or sellers, exerts a disproportionate share of influence or control in a market.

Mef One thousand cubic fect of natural gas at $60 \mathrm{~F}$ and atmospheric pressure at sea level. Roughly equivalent to a million Btus.

Merchant Service The service of pipelines whereby gas is bought by a pipeline from a producer, then resold by the pipeline to a distribution company or end-user. Actual transfer of title from producer to pipeline to LDC occurs. (Also referred to as "sales service".)

Millidarcy (md) One one-thousandth of a darcy. A darcy is the empirical measure of the permeability of a formation in which a one centipoise viscosity fluid will move at a velocity of one centimeter per second under a pressure drop of one atmosphere per centimeter.

Minerals Management Service (MMS) A department in the U.S. Department of Interior that is charged with overseeing leasing operations and reserve analysis in offshore U.S. areas.

Minimum Bill A charge that requires the purchaser to pay the full commodity charge for a specified percentage of contracted quantitics whether or not the specified amount of gas is actually taken.

Monopsony A market situation with only one buyer. 
Natural Gas Act of 1938 This act gave the Federal Power Commission (FPC) power to issue certificates of public convenience and necessity, and to regulate gas sales rates in interstate commerce. The FPC was the predecessor to the FERC.

Natural Gas Policy Act of 1978 (NGPA 1978) This act set a series of maximum prices for various categories of natural gas, eliminated the dual market system of gas by bringing intrastate gas under FERC jurisdiction, provided for the phased decontrol of some gas supplies, and set up an incremental pricing mechanism that would tie certain industrial gas prices to oil prices.

Netback Pricing A calculation that involves starting at a competitive fuel burnertip price and calculating backwands through the system, incorporating distribution and transmission charges, to arrive at the resultant wellhead gas pric?

Nonassociated Gas Natural gas that is unassociated with conventional oil-exists in the reservoir as a dry gas phase. Liquids may condense and be a separate phase at the wellhead, but they contain much lighter hydrocartons than conventional oil.

Or-Peak The period during a day, week, month, or year when the load being delivered by a gas system is not at or near the maximum volume that system could deliver in the corresponding period of time.

Open Access Nondiscriminatory transportation of gas on a first-come, first-served basis. First initiated by FERC Order 436 in October 1985.

Order 380 (August 1984) This act issued by FERC removed the variable-cost portion of the minimum commodity charge of gas pipeline sales tariffs. As a result, LDCs are free to choose among pipeline suppliers without incurring charges for gas that the LDCs do not take.

Order 436 (October 1986) The act issued by FERC that initiated nondiscriminatory, open-access transportation of gas. Order 436 was designed to allow consumers to have greater access to competitively priced gas supplies, and to allow producers and all consumers of gas the same access to pipeline transportation services that were previously available only to large customers.

Order 500 (August 1987) The act issued by FERC that reaffirmed the open-access transportation provisions of Order 436 and provided for take-or-pay recovery mechanisms for pipelines. The order was in response to the D.C. Circuit Court of Appeals overtuming Order 436.

Penny-Switch The characteristics of switchable markets that allow for switching between alternative fuels over price differentials as low as one cent.

Permeability The state of having pores or openings that permits liquids or gases to flow through.

Phillips Petroleum vs. Wisconsin A landmark decision in 1954 in which the FERC was given regulatory authority over wellhead prices of gas destined for interstate commerce.

Pipeline Service Obligation The contractual obligation of pipelines to hold supplies sufficient to meet the contractual demands of customers.

Play A term for a geologic prospect that has not been drilled yet. Usually refers to an exploration target. 
Possible Reserves Resources that are a less-assured supply source because they are postulated to exist outside of known fields, but are associated with a productive formation in a productive province.

Potential Gas Committee The PGC consists of volunteer members from the natural gas industry, govemment agencies, and academic institutions who provide estimates, based upon expert knowledge, of the potential supply of natural gas which, in conjunction with estimates of proved reserves of natural gas, make possible an appraisal of long-range gas supply.

Powerplant and Industrial Fuel Use Act (PIFUA or FUA) A part of the National Energy Plan of 1978 that (a) prohibited the use of oil and gas as a primary fuel in any newly-constructed utility power generation facility or in new industrial boilers with a fuel heat input rate of over 100 million Btu per hour, and (b) limited the use of natural gas in existing powerplants to the proportion of total fuel used during 1974-1976, and (c) prohibited fuel switching from oil to gas.

Proboble Resources Inferred resources ass sciated with known fields that are the most assured of potential supplies.

Proved Reserves The currently estimated quantities of gas which analysis of geologic and engineering data demonstrate with reasonable certainty to be recoverable in the future from known oil and gas reservoirs under existing economic and operating conditions and technology.

Public Utility Commission (PUC) A state regulatory body that governs intrastate gas movements and local distribution company operations within a particular state.

Public Utility Regulatory Policy Act (PURPA) A part of the National Energy Plan of 1978 that (a) sought to foster conservation, more efficient energy utilization, and more equitable electric utility rates by requiring state commissions to consider and to adopt, if appropriate, 11 federal standards, and (b) increased FERC authority over certain electricity issues.

Ramsey Pricing Regulatory pricing that attempts to minimize losses in economic efficiency in goods and services that have increasing retums to scale. Prices are generally set lower for customers whose demand is more responsive to price.

Regasification The transformation of Liquefied Natural Gas (LNG) from the liquid state necessary for trans-oceanic shipping to the gaseous state required for pipeline transportation.

Reserve Appreciation Factor A factor that describes how much greater are actual reserves relative to initial reserve estimates, when new geologic, reservoir, or production data causes reserve revisions on an existing well or field to be increased.

Reserve Growth Estimate A revision in a reserve estimate for a single entity that changes with time due to additional geologic, reservoir, or production data.

Residential Consumption Gas used in private dwellings, including apartments, for heating, air conditioning, cooking, water heating, and other household uses.

Residual Fuel Oil Fuel that remains after the removal of valuable distillates (gasoline) from petroleum. Different classes of residual fuel oil are based on differing physical properties and are used in different applications. Generally, the higher the sulfur content of residual fuel, the lower the price it commands on a Btu basis. 
Resource Base The amount of natural gas that is yet to be recovered. In order for reserves to be included in the "resource base", they must be recoverable using current or foreseeable future technology.

Sales Margin Pipeline gas sales revenues less purchased-gas costs divided by sales volumes.

Section 311 Transportation Under Section 311 of the NGPA, FERC has authority to authorize any interstate pipeline to transport gas on behalf of intrastate pipelines or local distribution companies (LDCs). Also, intrastate pipelines may transport gas for interstate pipelines or for LDCs served by an interstate pipeline. FERC Order 436 specifically states that Section 311 arrangements under no circumstances will extend beyond October 1987 for pipelines that do not become Order 436 transporters.

Select Use An environmental quality control method in which natural gas is bumed alone, or as part of a mixture of fuels, to achieve compliance with air quality requirements.

Shut-in Production Wells or fields that are capable of producing but are temporarily closed off for a number of reasons, such as curtailments or mechanical difficulties.

Special Marketing Programs (SMPs) Pipeline programs which provided discounted gas to certain users, i.e., industrial customers who used the gas to displace alternate fuels, to prevent a plant closing, or to reopen a closed plant. These marketing arrangements were effectively nullified in MI Maryland People's Counsel v. FERC D (D.C. Cir. 1985).

Speculative Reserves Resources expected to be found in formations or provinces that have not yet been proven to be productive.

Spot Market The market for gas supplies in which gas is sold to the highest bidder without any long-term commitment to sell or buy gas.

Supply Curve An economic representation that depicts the amount of production that can be brought forth at different prices in a given time period.

Surplus Determination Formula A procedure that is used to determine whether proposed gas for export in Canada is in excess of domestic needs and can be exported to the United States.

Synthetic Natural Gas (SNG) A manufactured product chemically similar in most respects to natural gas, which results from the conversion or reforming of petroleum hydrocarbons or from coal gasification and which may easily be substituted for or interchanged with pipeline-quality natural gas.

Take-or-Pay Amount of gas required to be purchased and paid for, even if not taken. Some quantities are based on minimum daily quantities, annual quantities, or minimum contract quantities. Takeor-pay quantities may change over time under initial provisions of the contract or may be changed in an amendment to the contract.

Tef One trillion cubic feet of natural gas at $60 \mathrm{~F}$ and atmospheric pressure at sea level. Roughly equivalent to 1 quadrillion Btus (quad) or 0.5 million barrels per day of oil.

Tight Gas Gas that lies in formations with very few pores or openings permitting the flowthrough of gas and liquids. (Permeabilities are generally below .01 millidarcy.) 
Transportation Rates The tariff rates charged by pipelines for point-to-point delivery of gas not owned by the pipeline.

Transportation Service The service of pipelines when they act solely as a transporter of gas, moving gas from receipt to delivery point without taking title.

Unbundle The separation of pipeline services into discrete components, e.g., transportation, storage, firm service, etc. With unbundling, separate fees are charged for each service.

Unconventional Reserves found in coal seams, Devonian shales, or extremely low-permeability formations that often require stimulation or secondary recovery mechanisms.

United States Geological Survey (USGS) A department in the U.S. Department of Interior with responsibilities for geologic analysis, research, and reserve estimates pertaining to U.S. domestic areas.

Vintage Originally, a term used for a pricing scheme in which gas priced at different levels on the basis of age (date of its initial production ). More recently, the term refers to a pricing scheme in which prices are based on categories that are only loosely related to age or date of initial production.

Wellhead Price The price received by the oil or gas producer for sales in the field (at the wellhead), including charges for natural gas plant liquids subsequently removed from the gas, gathering and compression charges, and state production, severance, and/or similar charges.

Workably Competitive A market that has sufficient numbers of buyers and sellers, with no one firm or group of firms exercising any significant control over the market, such that interfirm rivalry will eliminate most distortions to marginal-cost pricing. 
DATE

FILMED

$2 / 12 / 93$ 
